\title{
RESÚMENES DEL XLVIII CONGRESO CHILENO DE PEDIATRÍA \\ 27 AL 29 DE NOVIEMBRE 2008 VIÑA DEL MAR - CHILE
}


EMBARAZO MOLAR EN ADOLESCENTES, A PROPÓSITO DE UN CASO CLÍNICO

Bertrán $F^{1}{ }^{1}$, Navarro $R^{1}$, Rodríguez $M C^{2}$, Bertrán $F M^{3}$

${ }^{1}$ Hospital de Huépil, VIII Región, ${ }^{2}$ Interna Medicina Universidad San Sebastián, ${ }^{3}$ Alumna Medicina Universidad Austral de Chile.

Introducción: La enfermedad trofoblástica gestacional comprende un espectro de alteraciones que se clasifican en Mola hidatidiforme, Mola invasora, Coriocarcinoma y Tumor sitio implantación del trofoblasto. La mola se origina en el desarrollo del trofoblasto de un huevo anormalmente fertilizado, y puede se parcial o completa. Se presenta con mayor frecuencia en edades extremas. Objetivo: Describir la presentación clínica de un embarazo molar en una adolescente. Caso clínico: KDRS, 15 años, consulta en urgencia del Hospital de Huépil el 28 septiembre. Antecedente de dos consultas previas en policlínico po trastorno digestivo funcional. Refiere cuadro de dolor abdominal y vómitos. Menarquia 12 años. Ritmo 30/6, cantidad normal. Fecha última regla el 18 de Agosto, usuaria de preservativos. Presenta meno metrorragia de 26 días. A examen Presión arterial 115/60, temperatura 36,7 , pulso 150 x'. Destaca un abdomen de configuración normal, blando, depresible, sensible en hipogastrio donde se palpa aumento de volumen, compatible con útero, de $13 \mathrm{~cm}$, duro sensible. Se realiza ecotomografía que muestra imagen de Mola y luego inicia sangrado con eliminación de vesículas. Edad gestacional 6 semanas por FUR Se traslada a Hospital Base de Los Angeles, donde se confirma Embarazo Molar y Aborto en evolución y se hospitaliza. Hematocrito 33,9\% Hemoglobina 11,7 BHCG $>15.000 \mathrm{mUl} / \mathrm{mL}$. Se realiza legrado instrumental y se transfunden $2 \mathrm{Ui}$ GR. Evoluciona favorablemente. Biopsia informa fragmento irregular de tejido placentario y coágulos, con vellosidades de tamaño variable, en conjunto de 11,5 $\times 10 \times 6 \mathrm{~cm}$. Enfermedad gestacional del trofoblasto, de tipo mola completa. Conclusiones: La mola hidatidiforme es una patología que debe estar en la mente del clínico, a pesar de no ser tan frecuente, por el riesgo de transformarse en un coriocarcinoma, y porque, detectado a tiempo, es curable y tiene buena evolución.

\section{EMBARAZO EN LA ADOLESCENCIA: PREVALENCIA DE VIVENCIA CERCANA EN LOS ADOLESCENTES EN LA FAMILIA, EN SUS
PARES O PROPIA Y SUS OPINIONES RESPECTO DEL POR QUÉ SE PRODUCEN*}

Zepeda $\boldsymbol{A}^{1}$, Luengo $\mathrm{X}^{2}$, Tijero $\mathrm{M}^{3}$, Millán $\mathrm{T}^{4}$.

Instituto Chileno de Medicina Reproductiva (ICMER).

El embarazo en la adolescencia sigue siendo un tema del mayor interés que justifica los esfuerzos por prevenirlo. Las explicaciones del porqué las tasas de fecundidad adolescente se mantienen elevadas aún no encuentran una respuesta satisfactoria. Por ello que, como parte de un estudio destinado a conocer la perspectiva de adolescentes escolares sobre los servicios públicos de salud sexual y reproductiva, se estimó la prevalencia de una experiencia cercana de embarazo en la adolescencia: en la familia, entre sus pares y el propio. Interesó también conocer las razones que dan los adolescentes del porqué se producen estos embarazos. El estudio fue realizado el 2007, en población escolar de tres comunas urbanas de Santiago con altos índices de vulnerabilidad y fecundidad adolescente. Personas y Método: Se aplicó un cuestionario autoaplicado, voluntario, anónimo y confidencial, previa firma de consentimiento informado de los padres y de los alumnos/as, validado con prueba piloto. La muestra fue de 368 estudiantes ( 183 de $8^{\circ}$ básico y 185 de $2^{\circ}$ y $4^{\circ}$ medio), representativa de 5616 alumnos/as de colegios municipalizados de "El Bosque", "La Pintana" y "Cerro Navia". Las preguntas analizadas en este trabajo fueron de respuesta cerrada para la prevalencia y, semi-cerrada y múltiple en el caso de las opiniones respecto de las razones de por qué se produce el embarazo. Resultados: El 83,4\% de los adolescentes declaró haber conocido el caso de un embarazo en la adolescencia en su entorno cercano, lo que aumentó con la edad: $77 \%$ en 8ํㅜㅅㅗico, $89,3 \%$ en $2^{\circ}$ Medio y $99 \%$ en $4^{\circ}$ Medio. Lo más frecuente fue entre los amigos $(73,6 \%)$ y más de un tercio en la familia $(35,7 \%)$. La experiencia propia fue reportada en un $8,7 \%$, siendo un $4,2 \%$ en $8^{\circ}$ Básico, $9,6 \%$ en 20 Medio y $24,8 \%$ en 4 Medio. En este último nivel la prevalencia alcanza al $31,5 \%$ de las mujeres. Las razones más frecuentes de por qué se embarazan los adolescentes, fueron: "no creen que les va a pasar a ellos (65,3\% hombres, $72,2 \%$ mujeres)", "les da vergüenza pedir anticonceptivos" ( $61 \%$ para ambos sexos) y "no saben cómo prevenir el embarazo o usan mal los anticonceptivos" ( $51,1 \%$ hombres, $48,7 \%$ mujeres). Conclusiones: Se destaca que prácticamente todos estos escolares de $4^{\circ}$ Medio han conocido un embarazo adolescente en su entorno cercano. Uno de cada cuatro de ellos refiere el antecedente de un embarazo propio, lo que en caso de las mujeres alcanza a una de cada tres. En cuanto al porqué se embarazan los adolescentes, la percepción de invulnerabilidad sigue siendo la primera razón que ellos reconocen como causa del embarazo en sus pares, así como también es importante la vergüenza que genera la consulta por anticoncepción o que reconocen que no saben cómo prevenirlo. Resulta importante no olvidar estos elementos entregados directamente por adolescentes, en el diseño de las actividades de prevención. (*Proyecto A55078, financiado por la Organización Mundial de la Salud). CARACTERIZACIÓN DE PACIENTES CON TRASTORNOS ANSIOSOS
INGRESADOS AL SERVICIO DE PSIQUIATRÍA INFANTIL DURANTE INGRESADOS
EL AÑO 2006

Valdivia PM, Martínez CC, Aliaga JM, Venthur Uslar C.

Servicio de Psiquiatría Infanto-Juvenil Hospital Regional de Concepción.

Introducción: Los trastornos ansiosos en adolescentes son un problema de salud relevante, con implicancias tanto inmediatas como en el desarrollo posterior de los jóvenes. Las tasas de prevalencia global extranjeras giran alrededor del 8 a $10 \%$, lo que lo ubica entre los trastornos frecuentes en la infancia y adolescencia. Objetivos: Carcterizar a la población según variables sociodemográficas, clínicas y de gestión. Metodología: Se analizaron las fichas de 182 pacientes que ingresaron el año 2006 al Servicio de Psiquiatría Infanto Juvenil de Hospital Regional de Concepción. Se estudio la prevalencia de trastornos ansiosos dentro del grupo etáreo adolescente, junto a variables sociodemográficas, lugar de derivación, comorbilidad psiquiatrica, tratamiento, controles psiquiátricos y psicológicos. Resultados: De la población estudiada, un $13,7 \%$ corresponde a patología ansiosa, con un promedio de edad de 13,36 años. Un tercio de los casos presenta comorbilidad psiquiatrica, destacando entre ellos trastornos del desarrollo de la personalidad. El 64\% se encontraba con tratamiento psicológico, y un $40 \%$ con psicoterapia y fármacos. El $44 \%$ fue derivado de APS. En promedio, fueron controlados 4 veces por psiquiatra y 2 por psicólogos. Conclusión: La prevalencia encontrada en esta unidad es más alta que lo descrito en la literatura, por lo que es una patología relevante al momento de elaborar políticas de salud, enfocadas a este grupo etáreo, principalmente en atención primaria en salud. Los datos encontrados en esta casuística son concordantes con aquellos encontrados en la literatura internacional. Sin embargo, en Chile existen escasas publicaciones de estudios y casuísticas acerca de FOD, por lo que es necesario hacer énfasis en su análisis en distintos centros. La evaluación de las características de los pacientes con FOD permitiría clarificar la utilidad de los test diagnósticos a utilizar, de acuerdo a las etiologías y sospechas diagnósticas.
CRECIMIENTO POSNATAL Y ANTICIPACIÓN DE LA MENARQUIA EN ADOLECENTES CHILENAS

Urquidi $\boldsymbol{C}^{1}$, Bustos $\mathrm{P}^{2}$, Amiigo $\mathrm{H}^{2}$.

${ }^{1}$ Programa de Doctorado en Salud Pública Universidad de Chile. ${ }^{2}$ Departamento de Nutrición Universidad de Chile.

Un adelantamiento de la menarquia, ocurrido desde los años 60 , podría estar explicado por eventos iniciales de la vida; a su vez, este adelantamiento podría constituir un importante indicador de enfermedades metabólicas y neoplásicas. El propósito del estudio fue comparar las curvas y velocidad de crecimiento en los dos primeros años de vida en adolescentes con menarquia anticipada versus normal y evaluar la asociación entre el crecimiento y menarquia. Metodología: Diseño de estudio de casos y controles anidado a estudio de cohorte. Para evaluar el crecimiento en la pubertad y menarquia se efectuó un tamizaje de 8.659 niñas de la región de La Araucanía. De esta cohorte se pesquisó aquellas que alcanzaron su menarquia antes de los 12 años a las que se consideró como casos $(n=48)$ y controles, aquellas con menarquia mayor a 12 años $(n=$ 111). Posteriormente, se procedió a la reconstrucción del crecimiento postnatal hasta los dos primeros años de vida a través del carné de salud infantil. Para el modelamiento y comparación de las curvas de crecimiento se utilizó el método estadístico de estimación de ecuaciones generalizadas (GEE). Resultados: La velocidad de ganancia de peso ajustado por peso al nacer, talla y etnia fue de 1,05 $\pm 0,06 \mathrm{~kg} / \mathrm{mes}$ en el primer año de vida para los casos y de $0,55 \pm 0,07 \mathrm{~kg} / \mathrm{mes}$ para los controles, la diferencia del comportamiento de estas curvas fueron significativas desde los 6 meses hasta los 12 meses $(p=0,004)$. Se asoció la mayor ganancia de peso en el primer año con menarquia anticipada (OR 2,1, IC95\%: $1,1,3,9)$. La velocidad de ganancia de talla ajustada por las mismas variables fue de $2,3 \pm 0,7 \mathrm{~cm} / \mathrm{mes}$ en el primer año de vida para los casos y de $2,6 \pm 0,2 \mathrm{~cm} /$ mes para los controles, el comportamiento de estas curvas no fueron estadísticamente diferentes $(p=0,420)$, tampoco hubo diferencia en el crecimiento postnatal según IMC ni asociación de la ganancia de talla con menarquia anticipada (OR 1,1, IC95\%: 0,9, 1,3). Conclusiones: Una mayor ganancia de peso en el primer año de vida podría predecir la anticipación de la menarquia en estas adolescentes, siendo que las características de crecimiento antes de los seis meses y después del año no tienen mayor efecto. Financiado por Proyecto Fondecyt 1060884 
TRASTORNOS DE LA CONDUCTA ALIMENTARIA: ADHESIÓN AL TRATAMIENTO NUTRICIONAL Y EVOLUCIÓN A MEDIANO PLAZO

Marín BV, Berthet C, Dunner P, Quiroga F, Martini AM, Sommer K, Rojas GP

Unidad de Adolescencia (UAIA), Clínica Alemana.

Los trastornos de la conducta alimentaria (TCA) son una de las patologías psiquiátricas que potencialmente generan mayor riesgo vital. Estudios muestran una pronunciada resistencia al tratamiento y un alto porcentaje de abandono. Objetivo: Evaluar adhesión al tratamiento nutricional y evolución antropométrica a un año plazo, en pacientes con TCA que ingresan para tratamiento multidisciplinario, en un centro privado de salud. Pacientes y Métodos: Se estudiaron retrospectivamente, pacientes mayores de 10 años, que consultaron en Nutrición, UAIA, entre los años 2003 y 2006, en quienes se diagnosticó un TCA según criterios DSM IV y asistieron a intervenciones nutricionales, psicoterapéuticas y/o psiquiátricas. Se evaluó adhesión al manejo nutricional a un año plazo, severidad de la patología al ingreso y características antropométricas al ingreso, mes 3, 6 y 12 de tratamiento. Resultados: Ingresaron al estudio 42 pacientes, 20 cumplían criterios diagnósticos de anorexia nerviosa (AN), 8 bulimia (BN) y 14 TCA no especificados (TCA NE). Sólo 3 eran de varones; edad $16,7 \pm 2,8$ años, sin diferencias significativas según diagnóstico. Dada la gravedad del cuadro físico y/o psiquiátrico, inicialmente, 3 (AN) debieron hospitalizarse en clínicas privadas de salud, 14 requirieron hospitalización domiciliaria (AN 10 vs $1 \mathrm{BN}$ y 3 con TCA NE; $\chi^{2}<\mathrm{p}: 0,00$ ) y 25 se manejaron ambulatoriamente. Las pacientes que requirieron hospitalización en clínicas o en su domicilio presentaban significativamente menor edad $(15,7 \pm 2$ años $v s 17,3 \pm 3,1$ años; $p$ 0,05 ), mayor compromiso nutricional (mediana $z I M C ; p<0,005$ ) y mayor porcentaje de bradicardia (12 de 17 vs 6 de 25; $p<0,05)$ Adhesión: $18(43 \%)$ copletaron 1 año de tratamiento nutricional y salud mental enUAIA; 7 (13\%) fueron derivadas a otro centro de salud y $17(40 \%)$ abandonaron tratamiento. $E$ grupo con mejor adherencia al tratamiento fue el de AN (50\%). De las 14 pacientes desnutridas (10 AN y 4 TCA NE) al ingreso, que completaron 1 año de manejo multidiciplinario, 13 se encontraban eutróficas y sólo una se mantenía desnutrida. Conclusiones: Los pacientes con TCA que se controlan en la UAIA presentan un porcentaje de adhesión al manejo nutricional similar al publicado en estudios internacionales. Un alto porcentaje de los pacientes que ingresan y adhieren a él, mejoran su estado nutricional. Estudios a más largo plazo son necesarios.
CONSULTAS PSIQUIÁTRICAS DE MENORES DE 20 AÑOS EN EL SERVICIO DE URGENCIA DEL HOSPITAL DE LAJA

Rudolph QC, Cáceres VF, Gálvez ChA, Balcázar VF.

Hospital de Laja (Servicio de Salud Bío-Bío).

La atención de urgencia y la hospitalización psiquiátrica en los adolescentes ya no es una excepción y se ha incrementado en los últimos años. Dentro de las causas que motivan la consulta destacan los síntomas afectivos y la conducta suicida Objetivos: Conocer la incidencia de consultas psiquiátricas de los menores de 20 años en el Servicio de Urgencia del Hospital de Laja durante el segundo semestre del año 2007 y determinar el perfil epidemiológico de los consultantes. Material y Métodos: Se realizó un estudio descriptivo de corte transversal donde se revisaron los formularios de atención de urgencia del período comprendido entre julio y diciembre del año 2007. Se analizaron las siguientes variables: sexo, edad, diagnóstico e indicación de hospitalización o traslado a centro de referencia. Resultados: De un total de 19.188 consultas en el servicio de urgencia, $1,83 \%$ fueron consultas psiquiátricas $(n=352)$ y de éstas un $12,8 \%$ $(n=45)$ correspondió a menores de 20 años, con un promedio de edad \pm 17 . Existe un predominio del sexo femenino; $73 \%$ sobre el sexo masculino $26,6 \%$, con una relación de 3:1. Los diagnósticos fueron: Estado ansioso $37,7 \%(n=17)$ Intoxicación medicamentosa e ideación suicida $28,8 \%(n=13)$, Crisis de angustia $15,5 \%(n=7)$ y Crisis conversiva $4,4 \%(n=2)$. Las mujeres consultan más por Estados Ansiosos. en cambio, los hombres consultan en su mayoría por Intoxicación medicamentosa. Requirieron hospitalización un 17,7\% $(n=8)$ con diagnóstico de Intoxicación medicamentosa e intento de suicidio y traslado a centro de referencia un $11,1 \%(n=5)$. Destaca también que un $4,4 \%(n=2)$ de las mujeres cursaba con embarazo al momento de la consulta y existió un caso de intoxicación grupal. Conclusiones: La mayor incidencia de consulta psiquiátrica en menores de 20 años se concentra en mujeres cuyo diagnóstico es Estado ansioso. En cuanto a las hospitalizaciones la mayoría fue por Intoxicación Medicamentosa e intento de suicidio. Discusión: Nos queda la tarea como Hospital de baja complejidad el iniciar una intervención en los pacientes que ya tienen alguna patología psiquiátrica a través del Equipo de Salud Mental, as como también estrategias de prevención en los niños y adolescentes a nivel de colegios y liceos de la comuna.

\section{ESCUELA PARA PADRES DE ADOLESCENTES DE 10-14 AÑOS: ADAPTACIÓN DE VIDEOS CHILENOS}

Nagel $L^{1}$, Salas $O^{1}$, Zubarew $T$, Correa $L^{1}$, Pérez $A^{2}$.

${ }^{1}$ Médico pediatra; ${ }^{2}$ Médico Programa de formación de especialistas en $P e$ diatría. Departamento de Pediatría Occidente Universidad de Chile - Pontificia Universidad Católica - Clínica Alemana de Santiago.

Resumen: En un contexto de múltiples programas de prevención de conductas de riesgo en jóvenes, en particular las relacionadas con consumo de sustancias, así como prácticas sexuales no protegidas, es importante utilizar programas de efectividad probada. En este trabajo se muestra una adaptación chilena de una intervención basada en evidencia, del programa "Familias Fuertes", desarrollado por la Organización Panamericana de la Salud, Washington D.C. y adaptado de Programa "Strengthening Families" (lowa State University), el cual tuvo los mejores coeficientes de costo/efectividad, para diferenciar lo que funciona de lo que no. Objetivo: Mostrar la adaptación de este programa,en Chile, con la finalidad de desarrollar una escuela para padres de adolescentes que ayude a éstos a aprender aptitudes de crianza adecuados. Metodología: A través de OPS se formaron agentes multiplicadores en A. Latina. Así -en Chile- docentes capacitados de la PUC replicaron el programa a docentes de U. Finis Terrae y de U. de Chile con material latino. Existen varias modalidades de aplicación: capacitación de capacitadores, de familias y de padres. En este trabajo se mostrará la adaptación de esta intervención para padres de adolescentes de 10 a 14 años. Está dirigida a desarrollar una dinámica basada en el diálogo, para enseñarles maneras efectivas de disciplinar y guiar a sus hijos. Se realizaron 20 videos -elementos importantes de apoyo a las intervenciones- realizados y adaptados a la realidad chilena por las autoras y que representan la interacción entre padres y jóvenes -reales, no actores- en un contexto familiar para ilustrar los temas, los que se van analizando con los padres o tutores. Estos, al ver reflejada su realidad cotidiana de conflictos padre-hijo, internalizan lo que tienen que cambiar, (primero se muestran videos con interacción negativa y luego de una discusión se muestran los videos con interacción positiva). El programa se validó con grupos de padres invitados a la capacitación cuando asisten a la consulta de control sano del adolescente, y que manifiestan interés por venir a los talleres con 10-12 padres, cada taller, realizándose 4. La base del programa: lecturas cortas, videos, discusiones, rol playing, etc, reforzando conceptos de amor y límites, y habilidades parentales. Se interviene en factores de riesgo parentales (estilo parental inadecuado (autoritario/permisivo), castigos y normas de disciplina inefectivas, ausencia de reglas y límites, dificultad en la resolución de conflictos), actuando en factores de protección parental. Resultados: En países en que se ha aplicado se ha retardado el inicio de abuso de sustancias, disminuido niveles de agresión y aumento de habilidad de padres y/o cuidadores en poner límites. 

PERFIL DEL ADOLESCENTE CONSULTANTE A PEDIATRAS DE
ADOLESCENTOLOGÍA DE LA UNIDAD DE ADOLESCENCIA DE CLÍNICA ALEMANA DE SANTIAGO

Hernández $\mathrm{O}^{1}$, Jadue $M^{1}$, Kuschel $J^{1}$, Martínez $N^{1}$, Robert $A^{1}$, Samtani $\mathbf{S}^{1}$, Nagel $L^{2}$, Trautmann $S A^{2}$

${ }^{1}$ Estudiante de $2^{\circ}$ año Medicina, Facultad de Medicina Universidad del Desarrollo-Clínica Alemana Santiago. ${ }^{2}$ Pediatra Unidad de adolescentología, Clínica Alemana Santiago. Facultad de Medicina Clínica Alemana-Universidad de Desarrollo.

Introducción y Objetivo: La Unidad de Atención Integral del Adolescente de la Clínica Alemana de Santiago (CAS) se inicia en el año 2000. Mediante este trabajo se busca determinar el perfil del adolescente (entre 10 y 19 años) atendido en el centro desde marzo del 2007 hasta julio del 2008, con el fin de reorienta las políticas e intervenciones de salud para mejorar el servicio. Material y Método: Se analizaron los principales motivos de consulta, características biopsicosociales, problemas de salud más frecuente y factores de riesgo. Se estudió el universo de pacientes consultantes, correspondiente a 296 fichas electrónicas. Se recopiló información para luego ser incorporada en una planilla de variables que fue analizada mediante estadística descriptiva y correlación lineal, utilizando el programa SPSS 15.0. Resultados: La edad promedio es 14,6 años, predominando el sexo masculino $(53,4 \%)$. El $68,9 \%$ de los motivos de consulta corresponden a chequeo por control de salud, mientras que sólo un $31,1 \%$ se debió a morbilidad. Al examen nutricional la mayoría presenta eutrofia $(71,2 \%$ con un IMC normal $(79,4 \%)$. De la población restante se observa una tendencia al sobrepeso y a la obesidad (19,3\%). Es importante mencionar que un $5,1 \%$ de universo mencionó estar involucrado, ya sea como víctima o bien atacante, en alguna situación de matonaje o "bullying". Desde que se comercializó la vacuna del HPV, se le ha indicado a un $42,5 \%$ de las mujeres consultantes. En cuanto a conductas de riesgo; un 5,1\% de la población entre 10 y 14 años consume alcohol, mientras que entre $15-17$ años, lo hace un $18,2 \%$, y entre $18-19$ años, un $50 \%$. Por otra parte, un $14 \%$ consume tabaco, y $1 \%$ drogas. $11,5 \%$ presenta actividad sexual, que tiene un coeficiente de correlación de 0,555 con el uso de anticonceptivos. En cuanto a tabaco y alcohol, la correlación demuestra un coeficiente de 0,628 (señalando proporcionalidad directa). Conclusión: La edad media de consulta (14,6 años) puede explicarse por que el adolescente de mayor edad aún no se siente identificado con la especialidad de pediatría. Se visualiza una diferencia en el género del adolescente consultante, sin embargo, los motivos de consulta suelen repetirse. Los diagnósticos apelan principalmente a un control sano del adolescente, concordando con el objetivo de la unidad; prevención. El perfil permitirá rediseñar las acciones a desarrollar en el Programa de Salud de Adolescentes CAS.

\section{PERFIL CLÍNICO DE ADOLESCENTES EGRESADOS CON DIAGNÓS- TICO DE INTENTO SUICIDA DURANTE EL AÑO 2007 DE UN HOSPITAL TIPO IV}

\section{Bustos RC, Moraga GV, Zagal CD, Monsalve RJ.}

Hospital La Calera.

Introducción y Objetivos: En la actualidad se ha observado un aumento de la mortalidad por suicido en los adolescentes, siendo la tercera causa de mortalidad en dicho grupo. El objetivo del siguiente trabajo es obtener un perfil de adolescente que se ingresa por intento suicida en nuestro hospital. Materiales y Métodos: Se realiza un estudio retrospectivo, descriptivo de las fichas clínicas de los pacientes egresados en el año 2007 con diagnóstico de intento suicida. Resultados: Egresaron en el 2007 veintidós pacientes con diagnóstico de intento suicida que corresponden al $1,2 \%$ del total de egresos (1.836). De estos $72,7 \%$ son mujeres (16) y $27,3 \%$ son hombres (6). El $90,9 \%$ ingreso por intento suicida y el $9,1 \%$ por ideación suicida. El promedio de días hospitalización fue 3,1 en hombres 3,6días y en mujeres 2,9 días. Los diagnósticos más frecuentes fueron depresión $40,9 \%$ (9 pacientes), disfunción familiar $36,4 \%$ (8), VIF 4,5\% (1). E tipo de intento más frecuente fue la ingesta de fármacos $86,4 \%$ (19) siendo los más frecuentemente utilizados fluoxetina y benzodiazepinas con un $27,3 \%$ cada uno. Sólo el $22,7 \%$ (5) fueron evaluados por psiquiatra y psicólogo y el $77,3 \%$ (17) sólo por psicólogo. El destino al alta fue en el 95,5\% de los pacientes (21) su domicilio sólo en 1 caso fue un hogar de menores. Tras el alta el 40,9\% (9) mantiene los controles, $45,6 \%$ (10) no asiste y en el 13,6\% (3) no esta registrado. Destaca que al año siguiente de la hospitalización (2008) 5 mujeres $(22,7 \%$ ) están embarazadas. Al calcular el riesgo relativo de embarazo al año siguiente de la hospitalización considerando el intento suicida como factor, use como grupo control mujeres adolescentes hospitalizadas durante el mismo año por infecciones dento maxilofaciales, nos da 2,18. Conclusiones: Es importante destacar el aumento de las hospitalizaciones en adolescentes por intento suicida. La patología que con más frecuencia se diagnostica en estos pacientes es la depresión, destacando también la alta frecuencia de disfunciones familiares como gatillante. Es más frecuente en el sexo femenino y el método más frecuentemente utilizado es la ingesta de fármacos. Las adolescentes hospitalizadas por intento suicida tienen el doble de riesgo de embarazo al año siguiente de la hospitalización que las adolescentes hospitalizadas por otras patologías, este resultado es muy importante ya que nos permite actuar precozmente en la prevención de embarazo adolescente en nuestra población.
CITOMEGALOVIRUS (CMV): MODALIDADES BRONCOPULMONARES DE PRESENTACIÓN

Maggiolo MJ, Rubilar OL, Kogan AR.

Unidad Broncopulmonar. Hospital Exequiel González Cortés.

Introducción: El CMV es un virus herpes de amplia distribución mundial, sin embargo, sólo ocasionalmente produce enfermedad en inmunocompetentes, es más importante durante el período embrionario y en inmunodeprimidos. Objetivo: Mostrar las diferentes formas clínicas de presentación del CMV, en el aparato respiratorio. Casos clínicos: 1) Lactante de 2 meses de edad, presenta una neumonía de evolución tórpida, shell vial (SV) en secreción bronquial mediante lavado broncoalveolar (LBA) y en orina (+) para CMV, la evolución es favorable, por lo que no recibe tratamiento; 2) Portador de trasplante renal, en tratamiento inmunosupresor. A los 4 años presenta una neumonía multifocal, SV obtenido mediante LBA positivo para CMV, se trata con ganciclovir (GCV) mostrando una excelente respuesta; 3 ) Lactante de 2 meses, evoluciona con un síndrome bronquial obstructivo de evolución tórpida, SV en secreción bronquial mediante LBA y en orina (+) para CMV, se trata con GCV, sin embargo, persiste sintomática, radiografía de tórax muestra un patrón intersticial, TAC de tórax revela vidrio esmerilado, biopsia pulmonar es informada como neumonitis intersticial crónica, se administra prednisona durante 8 semanas, con buena respuesta; 4) Paciente de 6 meses de vida, desnutrido, presenta diarrea prolongada y neumonía refractaria. Antigenemia VIH (+), SV mediante esputo inducido (+), PCR por LBA para pneumocystis jiroveci (+), se usa GCV y cotrimoxazol (EV) con excelente respuesta. Discusión: El CMV se manifiesta de diversas formas dependiendo del huésped. En el período embrionario puede producir un extenso compromiso sistémico, en inmunosuprimidos la manifestación más frecuente es la neumonía grave, en cambio en individuos inmunocompetentes se puede presentar como una neumonía del primer trimestre o como enfermedad pulmonar intersticial crónica.

PRESIÓN INSPIRATORIA MÁXIMA Y VARIABLES ESPIROMÉTRICAS EN PACIENTES NEUROMUSCULARES SUBSIDIARIOS DEL PROGRAMA CHILENO DE VENTILACIÓN NO INVASIVA

Villarroel G, Zenteno D, Vera R, Benz E, Salinas P, Moscoso G, Prado F, Mancilla $P$, Astudillo $P$.

Programa Asistencia Ventilatoria No invasiva (AVNI) MINSAL.

Introducción: En la evaluación y seguimiento de niños con enfermedades neuromusculares (ENM) que emplean soporte ventilatorio son fundamentales las pruebas de función respiratoria. Su deterioro se asocia a mayor morbilidad. Objetivo: Correlacionar la Pimax con CVF, $\mathrm{VEF}_{1}, \mathrm{VEF}_{1} / \mathrm{CVF}$ e identificar riesgo relativo entre Pimax $<60$ y alteración de variables espirométricas en niños con antecedentes de ENM. Pacientes y Métodos: En 26 niños con ENM, se obtuvo Pimax mediante técnica de Black and Hyatt y en un intervalo menor de una semana se realizó espirometría basal según normas ATS. Los valores de referencia utilizados fueron Szeinberg y Knudsson respectivamente. Se correlacionaron los datos utilizando $r$ de Pearson, considerando significativos $p<$ 0,05 . Se analizaron RR entre Pimax $<60$ y variables espirométricas. Resultados: Mediana de edad 13,5 años (8-18), 20/26 hombres. Diagnósticos: enfermedad de Duchenne (13/26), atrofia espinal II (6/26), miopatía congénita (2/26), mielomeningocele (4/26), lesionado medular (1/26). La Pimax promedio fue $51,5 \%$ $\pm 22,2$, CVF $71,35 \% \pm 28,8, V_{E F}, 68,5 \% \pm 27$ y VEF1/CVF $97,1 \% \pm 11$. Se estableció correlación moderadas de Pimax con: CVF $(r=0,635 p=0,01)$ y $\operatorname{VEF}_{1}(r=0,561 \mathrm{p}=0,01)$. No se encontró correlación con VEF $/ C V F$. Existe una relación causal entre Pimax $<60$ y $C V F<80$. (RR $=2,85)$. Conclusiones: Los niños con ENM estudiados presentaron disminución de Pimax y espirometrías restrictivas. La evaluación espirométrica y de la fuerza muscular inspiratoria son complementarias. Pese a tener una correlacion moderada, el umbral del $60 \%$ del Pimax es un factor de riesgo para un patron ventilatorio restrictivo. 


\section{PROTOCOLO DE TOS MECÁNICA ASISTIDA (MI-E) PARA EXACERBACIONES RESPIRATORIAS EN NIÑOS CON VENTILACIÓN MECÁNICA PROLONGADA}

Benz E, Mödinger $\boldsymbol{P}$, Vera R, Kuo $\mathrm{CH}$, Moscoso G, Villarroel G, Salgado R, Barañao $P$, Prado $F$, Salinas $P$.

Programa AVNI- Hospital Fundación Josefina Martínez.

Introducción: Las exacerbaciones respiratorias (ER) reducen la fuerza muscular (Pemax). En pacientes con ventilación mecánica prolongada (VMP) y to débil por enfermedades neuromusculares (ENM) o compromiso secundario de la musculatura respiratoria son causa frecuente de hospitalización por neumonía y/o Atelectasias (ATL). Los dispositivos mecánicos de tos asistida (MI-E) pueden tener un rol complementario a la KTR. Objetivo: Describir un protocolo de MI-E para el manejo de ER en niños con debilidad primaria o secundaria de la musculatura respiratoria en VMP. Material y Método: Pacientes en VMP hospitalizados HJM o en Programa AVNI (marzo 2007-julio 2008); 1)Peak flow tos (PCF) < $270 \mathrm{l} / \mathrm{m}$; 2) Pemax < $60 \mathrm{cmH}_{2} \mathrm{O}$; 3) Neumonías/ATL > 3 en $6 \mathrm{~m}$. Intervención: Ciclos de I y E de $20-40 \mathrm{~cm} \mathrm{H}_{2} \mathrm{O}$. Inhalación 2-3s/ exhalación 3-6s. Se realizan 3-5 ciclos, 3-5 repeticiones. Resultados: AVNI (15), 11 ambulatorios. VMP por TQ (4), todos hospitalizados. 10 hombres; edad mediana 132 meses (rango 10-204). ENM (8), daño pulmonar crónico (4), hipoventilación central/ enfermedad motoneurona (6), dermatomiositis (1). PCF (7 pacientes) mediana $90 \mathrm{l} / \mathrm{m}$ (rango 50-150). $35 \mathrm{ER} / 19$ pacientes (1-4/paciente). No hubo mortalidad y/ o complicaciones, ningún paciente discontinuo tratamiento. Presión l/E mediana 25/30 cm H20. Frecuencia uso: 2-3v/semana (ambulatorios) -2v/d (hospitalizados). Hospitalización y/o traslado a centro > complejidad 5/35 (14\%). Conclusión: El protocolo de MI-E no se asocio a complicaciones, fue bien tolerado y podría ser útil como terapia complementaria en niños con VMP.

\section{PLEURONEUMONÍA EN PEDIATRÍA: EXPERIENCIA EN CLÍNICA} PRIVADA

Landaeta $\boldsymbol{J}^{1}$, Gárate $R^{1}$, Moore $\mathrm{J}^{2}$, Robles $M \mathrm{~J}^{2}$.

'Médico Pediátra, Clínica Privada Hospital del Profesor de Santiago (CHP).

2Interna Escuela de Medicina Universidad Finis Terrae. Campus Clínico CHP.

Introducción: Pleuroneumonía (PN) es una entidad cuyo manejo correcto es siempre un desafío a fin de evitar morbimortalidad y hospitalización prolongada. Nuestro objetivo es describir la experiencia local en esta patología. Material y Métodos: Análisis descriptivo y retrospectivo de 60 pacientes con diagnóstico de Pleuroneumonía hospitalizados entre Enero de 1999 y Diciembre de 2007. Resultados: Sexo masculino 57\%, edad promedio 61 meses (rango: 6 meses14 años). $68 \%$ al menos 1 consulta previa. Fiebre en $97 \%$, Síndrome Bronquial obstructivo (SBO) en $32 \%$ de los casos. PCR promedio: $267 \mathrm{mg} / \mathrm{dL}$. Etiología en 18 pacientes (28\%), 8 Neumococo, 8 Mycoplasma, 3 Virus (1 asociación VirusMycoplasma). Toracocentésis a 16 pacientes (27\%), Antibiótico más usado Cefotaxima en $82 \%$. Procedimientos: Drenaje pleural en $13(22 \%)$, en 3 fue tratamiento único, Aseo quirúrgico por videotoracoscopia (VTC) en 5, aseo por toracotomía 5 casos, Días de estada promedio: 7,7 días, tratamiento médico 6,4 días, tratamiento médico más drenaje 10,7 días, VTC 11,8, y Toracotomía 14,4 días. Complicaciones: 1 Fístula, 5 Neumotórax y 3 Abcesos. Sin mortalidad. Discusión: Predomina en esta serie el derrame pleural no complicado $(78 \%)$ con alto porcentaje de consulta precoz y buena respuesta a tratamiento médico, además de una significativa presencia de SBO lo que no es descrito en otras. Mycoplasma es relevante, lo que obliga a realizar su búsqueda dentro del estudio etiológico de rutina y considerar la terapia con macrólidos en el esquema antibiótico inicial. Conclusiones: El manejo médico de la PN es suficiente en la mayoría de los casos. Se sugiere aplicar protocolos establecidos para la resolución quirúrgica.

\section{INFLUENCIA DE LA LEVODROPROPIZINA EN EL UMBRAL TUSÍGENO EN NIÑOS SANOS}

Poblete $S^{1}$, Leiva $H^{1}$, Poblete $M^{2}$, Schönffeldt $P^{3}$, Zanni $M^{4}$.

${ }^{1}$ Servicio de Pediatría Hospital Regional Rancagua. ${ }^{2}$ Alumna Escuela de Medicina Universidad Católica de la Santísima Concepción. ${ }^{3}$ Laboratorio de Función Pulmonar Instituto Nacional del Tórax. ${ }^{4}$ Becado Anestesia USACH.

Antecedentes: La tos es uno de los síntomas que originan mayor número de consultas en Pediatría recibiendo tratamiento etiológico o mayoritariamente sintomático. No existen estudios nacionales en niños que evalúen la modificación farmacológica del umbral tusígeno a pesar de la amplia variedad de antitusivos disponibles en el mercado. Objetivo: Establecer el umbral tusígeno (UT) y su modificación con el uso de un antitusivo. Método: Se indujo este reflejo mediante la inhalación de Capsaicina, extracto de pimienta picante de la familia de los Vaniloides administrada en forma de nebulizaciones de dosis controlada en 17 niños sanos, de 7 a 14 años. Se midió la concentración de Capsaicina necesaria para inducir tos, basal y post ingesta de un antitusivo sintético, no narcótico: la Levodropropizina, en dosis de $60 \mathrm{mg}(10 \mathrm{ml}) 3$ veces al día. Se consideró como efecto positivo el aumento de al menos dos concentraciones de Capsaicina necesaria para inducir 2 toses consecutivas, en relación a la concentración basal. Los resultados se compararon mediante t-student para muestras pareadas. Resultados: La edad promedio fue de 11 años (7-14). El promedio logarítmico del umbral tusígeno basal fue $1,86 \mathrm{mM}$ (DS 0,75) y aumentó post ingesta de antitusivo $2,51 \mathrm{mM}(\mathrm{DS} 0,48)$ con diferencia estadísticamente significativa $(p<0,001)$. No hubo diferencias por edad o género. En el $76,4 \%$ de los 17 niños que completaron el estudio, aumentó al menos dos concentraciones el UT después de la administración del fármaco. No se presentaron efectos adversos significativos. Conclusión: Capsaicina induce reproduciblemente el reflejo tusígeno en niños sanos y la Levodropropizina es capaz de modificar el UT, aumentándolo, en forma significativa.
DIECIOCHO MESES DE ENTRENAMIENTO MUSCULAR RESPIRATORIO EN PACIENTES CON ENFERMEDAD NEUROMUSCULAR DEL PROGRAMA NACIONAL DE ASISTENCIA VENTILATORIA NO INVASIVA DOMICILIARIA

Vera R, Torres R, Zenteno D, Villarroel G, Moscoso G, Prado F, Mancilla $P$, Astudillo $P$

Programa Nacional de Asistencia Ventilatoria no Invasiva Domiciliaria (AVNI).

Introducción: El entrenamiento muscular respiratorio (EMR) aumenta la fuerza de la musculatura inspiratoria. EI Programa AVNI utiliza un protocolo basado en los principios fisiológicos del entrenamiento con cargas, cuyo objetivo es mejorar la función muscular. Material y Métodos: Se incluyeron 21 pacientes con enfermedades neuromusculares (ENM) sin limitación cognitiva. Luego de medir la Presión Inspiratoria Máxima (Pimáx) según técnica de Black \& Hyatt, se inicia el protocolo de EMR utilizando válvulas umbral con $30 \%$ de Pimáx, realizando series de $3,5,10$ y 15 minutos de manera incremental según tolerancia, descanso inter-series de 2 minutos, 5 días/semana. Se constató Pimáx al inicio y luego trimensual, durante un período de 18 meses. Se determinó significancia estadística trimensual con t-student $(p<0,01)$. Se utilizaron valores de referencia de Contreras. Los resultados se expresaron como porcentaje de límite inferior (Li). Resultados: Promedio de edad 12,6 $\pm 2,7$ años (6-16); 16/21 $(76 \%)$ hombres, $14 / 21(66 \%)$ usuarios de BiPAP nocturno. Diagnósticos: enfermedad de Duchenne $8(38,1 \%)$, atrofia espinal tipo II $4(19 \%)$, miopatía congénita $6(28,5 \%)$ y otros $3(14,3 \%)$. La Pimáx inicial fue $67,3 \pm 21,8 \%$ y a los dieciocho meses $94,3 \pm 23,5 \%$ del Li. El delta promedio de Pimáx fue $27 \%(p<0,005)$. Discusión: El protocolo de EMR empleado mejoró progresiva y significativamente la debilidad de la musculatura inspiratoria de los niños estudiados. Se propone la utilización de este protocolo para niños con ENM. 

CARACTERIZACIÓN DE UN PROTOCOLO DE REHABILITACIÓN
RESPIRATORIA

Zenteno D, Villarroel G, Moscoso G, Salgado R, Modinger $P$, Salinas $P$, Castro $M$, Prado $F$.

Hospital Josefina Martínez de Ferrari.

Introducción: Las enfermedades respiratorias crónicas (ERC) han aumentado significativamente. La rehabilitación respiratoria (RR) podría mantener o mejorar la capacidad física y calidad de vida (CVRS), disminuyendo la morbimortalidad y costos. Objetivo: Caracterización clínica y funcional de niños con ERC ingresados a un protocolo de RR, describiendo su metodología. Pacientes y Métodos: Siete niños, > de 5 años, con limitación en actividades cotidianas, sin compromiso neurocognitivo y estables 1 mes previo al ingreso. Se registran características generales, tipo de dependencia y número de reagudizaciones (RA). Se realizan test de Marcha 6 minutos (TM6), test de carga incremental y presión inspiratoria máxima (Pimax). Se describen los protocolos para entrenar la capacidad física general (treadmill) y la musculatura respiratoria (válvulas IMT) y su seguimiento: TM6, Pimax, número de RA y evaluación de CVRS. Resultados: Mediana de edad 8 años (rango: 5-11); daño pulmonar crónico (5/7); fallo de bomba secundaria (2/7).

\begin{tabular}{lccrrr}
\hline Diagnóstico & $\begin{array}{c}\text { RA } \\
\text { (6 m previos) }\end{array}$ & Dependencia & $\begin{array}{c}\text { TM6 } \\
\text { (\%) }\end{array}$ & $\begin{array}{c}\text { Pimax } \\
\text { (\%) }\end{array}$ & $\begin{array}{c}\text { CVF } \\
\text { (\%) }\end{array}$ \\
\hline FQ & 10 & A, B, C & 96 & 130 & 37 \\
FQ & 2 & - & 104 & NC & NC \\
BO & 2 & A, B, C & 71 & 90 & 51 \\
BO & 2 & A & 73 & NC & NC \\
DCP & 4 & - & 89 & 113 & 80 \\
AE tipo II & 3 & A, C, D & NR & 50 & NC \\
Dermatomiositis & 2 & A, C, D & NR & 98 & 86 \\
\hline
\end{tabular}

Dependencia. A: hospitalizado. B: $\mathrm{O}_{2}$-dependiente. C: VMNI. D: usuario silla de ruedas. NR: no realizada. NC: no colabora

Discusión: La mayoría de los pacientes tiene limitación de la actividad física con importantes dependencias tecnológicas. La evaluación funcional permite un entrenamiento muscular estandarizado, general y/o respiratorio.
EVALUACIÓN DEL PRIMER PROGRAMA DE TRANSICIÓN: FIBROSIS QUÍSTICA COMO MODELO

Fernández $P^{1}$, Navarro $J^{1}$, Jiménez $P^{1}$, Herrera $O^{2}$, Astorga $L^{2}$, Lozano $\mathcal{J}^{\mathcal{B}}$. ${ }^{1}$ Instituto Nacional del Tórax (INT), ${ }^{2}$ Hospital Luis Calvo Mackenna, ${ }^{3}$ Hospital Roberto del Río.

Introducción: El aumento de la población adulta con Fibrosis Quística (FQ) obliga a desarrollar programas de transición, la que se define como "el traslado programado y previsto de adolescentes y jóvenes con enfermedad crónica hacia el sistema de atención adulto". En Chile en el año 2006, se inició el traslado de los pacientes adultos con FQ a un centro de referencia nacional (INT). Para conocer la percepción de los pacientes respecto a este programa de transición y el nivel de satisfacción de los cuidados por el equipo de adultos, se realizó una encuesta que evaluó la preparación del paciente y familia, el proceso de transferencia, la preparación del centro de referencia y la evaluación del programa. Método: Se contactaron los pacientes en forma telefónica por un encuestador externo, formulándose 13 preguntas cuyo enunciado y alternativas fueron siempre leídas en el mismo orden. Los resultados fueron analizados con el programa SPSS. Resultados: De 35 pacientes trasladados al INT, 23 (66\%) contestaron la encuesta (11 mujeres, 12 hombres, edad $x=24,1$ (16-40) años), 11 no fueron contactados y uno rechazó responder. El análisis de fiabilidad de la encuesta fue bueno (Cronbach alfa $=0,89$ ). La decisión y la forma de traslado fueron consideradas satisfactoria por $60 \%$ de los pacientes e insatisfactoria por $40 \%$ de éstos y por $30 \%$ de las familias. La preparación del hospital de adultos y la preparación emocional y técnica de los médicos de adultos fue considerada como buena o muy buena por dos tercios de los pacientes. El grado de satisfacción con la atención actual y con el resultado del proceso de transición, fue de satisfecho o muy satisfecho para el $74 \%$ de los pacientes. Un $61 \%$ considera que el traslado le aumentó su independencia para tomar más decisiones respecto a la enfermedad. Conclusiones: Para la mayoría de los pacientes con FQ el proceso de transición hacia un centro de adultos fue satisfactorio. Como el proceso de transferencia es un evento importante en la vida de los jóvenes con enfermedades crónicas, en el futuro debieran crearse programa de transición estandarizados que incluyan al paciente, su familia y al equipo de salud pediátrico y de adultos.

\section{EFECTO DE UN AÑO DE ENTRENAMIENTO MUSCULAR INSPIRATORIO EN LA PRESIÓN INSPIRATORIA MÁXIMA Y LA CAPACIDAD VITAL FORZADA EN PACIENTES CON ENFERMEDAD NEUROMUSCULAR}

Vera $\boldsymbol{R}$, Torres R, Zenteno D, Villarroel G, Moscoso G, Prado F, Mancilla $P$, Astudillo $P$.

Programa Nacional de Asistencia Ventilatoria no Invasiva Domiciliaria (AVNI).

Introducción: El entrenamiento muscular respiratorio (EMR) aumenta la fuerza muscular inspiratoria, sin embargo, la literatura no describe su efecto en la capacidad vital forzada (CVF). Objetivo: Evaluar el efecto prospectivo de un protocolo EMR en la presión inspiratoria máxima (Pimáx) y CVF. Material y Métodos: Se incluyeron 13 niños, colaboradores, subsidiarios del Programa AVNI. Luego de medir Pimáx con técnica de Black \& Hyatt y CVF según norma ATS, se inició el protocolo de EMR utilizando válvulas umbral, considerando cargas de $30 \%$ de Pimáx, 5 días/semana. Se constató Pimáx inicial y cada 3 meses, durante un año. Se determinó significancia estadística trimensualmente con $t$-student $(p<0,001)$. Se utilizaron valores de referencia de Contreras para Pimáx y Knudsson para la CVF. Los resultados se expresaron como porcentaje del límite inferior y del predicho. Resultados: Promedio de edad 14,8 $\pm 2,3$ años (11-17), 10/13 hombres. Diagnósticos: enfermedad de Duchenne (6/13), atrofia espinal tipo II (3/13), miopatía congénita (3/13) y mielomeníngocele (1/13). A inicio la Pimáx promedio fue $66,6 \pm 22,2 \%$, tercer mes $87 \pm 26 \%$, sexto $89,5 \pm$ $27,6 \%$, noveno $97,2 \pm 33,6 \%$, duodécimo $102,6 \pm 34,5 \%$. La CVF fue de $61,2 \pm$ $26,6 \%$ al inicio y $63,2 \pm 31,7 \%$ a los 12 meses $(p<0,1940)$. Se produjo un incremento significativo de Pimáx al tercer $(p<0,0003)$, sexto $(p<0,0016)$ noveno $(p<0,0031)$ y al duodécimo mes $(p<0,0008)$. Al año de entrenamiento el delta promedio de Pímax fue $36 \%(p<0,0008)$. Discusión: El protocolo de EMR empleado en los pacientes con ENM revirtió y mejoró la debilidad de la musculatura inspiratoria. No se produjo disminución de la CVF $(p<0,1940)$, como es esperable en la evolución natural de las ENM.
VOLUMEN ESPIRATORIO FORZADO DEL PRIMER SEGUNDO Y
ESTADO NUTRICIONAL, DESCRIPCION DE NORMALIDAD ESPIROMÉTRICA EN ADOLESCENTES

Acevedo GL, Alarcón ER, Muñoz LS, Oyarce TF, Riobó BG. Universidad de Santiago de Chile. Universidad Católica del Norte.

La prevalencia de sobrepeso y obesidad en pediatría ha aumentado y, con esto, alteraciones funcionales varias, entre ellas, la pulmonar. En nuestro medio no existe acuerdo acerca de los valores de referencia espirométricos a utilizar en población pediátrica. Se propuso en este trabajo hacer un estudio observacional de corte transversal a un grupo de 142 adolescentes cursando 4to medio en colegios de la Región Metropolitana. Se realizó a cada adolescente una Espirometría forzada para objetivar el volumen espiratorio forzado del primer segundo $\left(V_{E F}\right)$, y se determinó su índice de masa corporal (IMC) mediante toma de peso y talla, con el objetivo de observar si la variable estado nutricional altera el valor de $\mathrm{VEF}_{1}$. Los datos se agruparon por sexo y luego según IMC en 4 subgrupos: bajo peso (BP), normal, sobrepeso y obesidad. Se calculó el percentil 5 (p5), la media y el percentil 95 (p95) de VEF, para cada subgrupo. En mujeres el p5, la media y p95 de VEF1 por subgrupo fueron: $79,75 \%-91,52 \%-104,60 \%$; $79,10 \%-104,17 \%-123,10 \%$; $96,10 \%-111,35 \%-133,45 \%$ y $104,65 \%-113,90 \%-$ $120,42 \%$ respectivamente, mientras que en varones fueron $81,59 \%-95,15 \%$ $115,43 \%$; 80\%-99,74\%-119,30\%; 84,78\%-101,53\%-117,54\% y 95,14\%-108,83\%$123,60 \%$. Se encontraron valores de VEF ${ }_{1}<80 \%$ sólo en BP y Normal. Se concluye que el p5 de VEF, para adolescentes es distinto según el estado nutricional, existiendo incluso $\mathrm{p} 5$ de igual valor a p95 de otro subgrupo del mismo sexo. De lo observado, existe un mayor valor de normalidad de VEF en función del mayor IMC, por lo que, al no considerar la variable peso, existiría actualmente un sesgo al aplicar los valores de corte. 
ASISTENCIA VENTILATORIA NO INVASIVA EN DOMICILIO: IMPACTO DE UN PROGRAMA NACIONAL EN CHILE

Prado $F$, Salinas $P$, Farías $A$, Vera $R$, Astudillo $P$, Mancilla $P$. Programa Nacional de Asistencia Ventilatoria No Invasiva en Niños, Unidad de Salud Respiratoria-MINSAL.

Introducción: La ventilación mecánica prolongada (VMP) puede ser entregada como asistencia ventilatoria no invasiva domiciliaria (AVNI). Objetivo: Describir las características clínicas, acciones y resultados preliminares del Programa Chileno de AVNI. Pacientes y Métodos: Revisión de fichas electrónicas agosto/ 2006 -agosto/2008. Se describen los criterios de selección, categorización por diagnóstico, dependencia y riesgo (CDDR); función pulmonar, hallazgos polisomnográficos (PSG), evaluación de calidad de vida (CVRS), registro de hospitalizaciones y descompensaciones. En un grupo con enfermedades neuromusculares (ENM) se reportan los resultados de un protocolo de entrenamiento respiratorio (IMT). Resultados: 221 niños, 190 activos. Edad promedio 9 $\pm 5,2$ años (5 meses-20 años). $63 \%$ hombres. Dieciocho fallecidos ( $8 \%)$. Trece (6\%) alta. CDDR: autosuficiencia parcial $53 \%$, dependencia parcial $40 \%$, dependencia total $7 \%$. Bajo riesgo $72 \%$, mediano riesgo $26 \%$, alto riesgo $2 \%$. ENM Cifoescoliosis 66\%; Daño pulmonar crónico 19\%; Mielomeningocele operado (MMO) 5\%; Síndrome apnea obstructiva del sueño (SAOS) 4\%; Misceláneas $6 \%$. Prestaciones entregadas: BiPAP/AVNI 76\%; IMT 34\%. Oxígenoterapia 22\% y VMP invasiva $20 \%$. La hospitalizaciones disminuyeron en relación a los 12 meses previos (60 a 21\%, p < 0,00001); hospitalizaciones/paciente/año (1,3 a 0,$3 ; p<0,00001$ ). Se registraron 124 eventos, mediana complejidad $68 \%$, alta $48 \%$, baja 37\%. La Pimax y espirometria en 26 pacientes con ENM fue: Pimax 60,4\%. CVF 46,7\%; VEF 65,7\% y VEF/CVF 95,4\%. Correlación Pimax/CVF

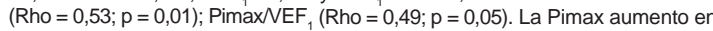
13 pacientes con IMT12m ( $36 \% ; p=0,0008)$; sin modificarse CVF (T0: $61,2 \%$; T12: $63,2 \%)$. Resultados PSG $(n=45)$ : 12 tuvieron PSG normal; ronquido primario (RP) 4; síndrome resistencia aumentado en la vía aérea (UARS) 3; hipopnea obstructiva $(\mathrm{HO})$ 2; hipopnea central $(\mathrm{HC}) 13$ y 9 SAOS. 9/11 mejoraron con Bipap en la misma noche del registro. La CVRS evaluada en 82 niños aumentó a los 12 meses (AUQUEI 23,8 $\pm 5,6$ puntos, IRS $34 \pm 8,2$ puntos; $p$ $0,005)$. Conclusiones: El programa AVNI disminuyó las hospitalizaciones, mejoró la CVRS. En pacientes con ENM mantuvo la función pulmonar y aumentó la fuerza muscular. Es factible implementar un Programa de VMP con criterios estrictos de selección.

CARACTERÍSTICAS PACIENTES PORTADORES DE FIBROSIS QUISTICA CONTROLADOS EN HOSPITAL DR. LUIS CALVO MACKENNA

Astorga $L^{1}$, Herrera $\mathrm{O}^{1}$, Mardones $P^{1}$, Wevar $M E^{1}$, Saldaño $B^{2}$, Hidalgo $G^{3}$. ${ }^{1}$ Médico, ${ }^{2}$ Enfermera, ${ }^{3}$ Kinesiólogo. Unidad de Broncopulmonar Hospital Dr. Luis Calvo Mackenna.

Introducción: La Fibrosis Quística (FQ) es la enfermedad hereditaria letal más frecuente en la raza blanca, de herencia autosómica recesiva, causada por la mutación en el gen que codifica para la proteína reguladora de conductancia transmembrana de la FQ (CFTR), ubicado en el brazo largo del cromosoma 7. Objetivo: Mostrar algunas características de los pacientes afectados por esta enfermedad que se controlan en nuestro hospital. Método: Trabajo retrospectivo realizado mediante revisión de fichas. Veinticinco pacientes portadores de esta patología son controlados en forma mensual, evaluándoseles a cada uno (cultivo secreción bronquial, saturometría, mediciones antropométricas y espirometría basal en aquellos que es factible). Resultados: Trece mujeres y doce varones portadores de FQ acuden a nuestro policlínico, cuyas edades fluctúan entre 2 años 1 mes y 16 años 1 mes ( 6 pacientes (2-6 a), 5 pacientes $(5-10$ a), 10 pacientes (10-15 a), 4 mayores 15 a). La edad de diagnóstico varió entre 3 meses y 9 años. Características nutricionales de los pacientes según $\mathrm{P} / \mathrm{E}$ (desnutridos 3 , normales 12 , sobrepeso 5 y obesos 5 ); según $P / T$ (desnutridos 3 normales11, sobrepeso 4 y obesos 7). Relación T/E (-2DS (2),-1DS (4), normales (13y + 1DS (6)). Según cultivo de secreción bronquial nuestros pacientes presentan las siguientes características: colonizados (5), infecciones frecuentes (12) y negativos (3). De los pacientes colonizados por Pseudomona aeruginosa (1) y Staphylococcus aureus (4). En sólo 20 de nuestros pacientes es posible realizar función pulmonar mensual presentando en diez de estos limitación ventilatorias restrictiva leve (6), moderada (2) y severa (3). Correspondiendo las espirometrías con alteraciones severas y moderadas a pacientes colonizados. Conclusiones: Los pacientes controlados en nuestro policlínico de FQ se caracterizan por: - Ser en un alto porcentaje mayores de seis años (76\%). - De punto de vista nutricional destaca la presencia de peso mayor al normal por P7T y $\mathrm{P} / \mathrm{E}$ (44\% y $40 \%$ respectivamente). - Cinco de los pacientes se encuentran colonizados (20\%), cuatro por $S$. aureus y uno por $P$. aeruginosa. - La mitad de los pacientes que pueden realizar espirometría la presenta alterada (10 pacientes)
GENERADORES DE FLUJO A TRAVÉS DE TRAQUEOSTOMÍA PARA VENTILACIÓN PROLONGADA CRÓNICA

Montes S, Barañao P, Salinas $P$, Méndez M, Prado F, Mancilla $P$, Astudillo $P$. Programa Nacional de Asistencia Ventilatoria No Invasiva en Niños, Unidad de Salud Respiratoria-MINSAL. Hospital Josefina Martínez.

Introducción: La necesidad de ventilación mecánica invasiva prolongada (VMIP) ha aumentado, al igual que la opciones de equipamiento para este objetivo. No existen reportes del uso de generadores de flujo con presión binivelada (BiPAP) a través de traqueostomia (TQT). Objetivos: Reportar la experiencia de VMIP con BiPAP a través de TQT describiendo características clínicas y protocolo de uso. Metodología: Descripción de pacientes manejados en HJM, centros de la red asistencial del MINSAL y domicilio (Programa AVNI). Resultados: 41 pacientes. Mediana de edad 36 meses (rango 10 meses-19,5 años). Tiempo de permanencia 2-84 meses. Prestaciones domiciliarias 26 (63\%), hospitalizados $15(37 \%)$. Causa VMIP: Enfermedad neuromuscular y compromiso primario de la bomba respiratoria $21(51 \%)$, DPC $8(21 \%)$, compromiso de vía aérea 8 $(21 \%)$ y síndrome hipoventilación central $4(10 \%)$. No hubo mortalidad, 7 pacientes tuvieron complicaciones menores. La ventilación fue continua en 21 pacientes (51\%) y con períodos de desconexión 20 pacientes $(49 \%)$. Parámetros ventilatorios: presión positiva inspiratoria 8-18 $\mathrm{cmH}_{2} \mathrm{O}$, presión positiva espitaroria 4-10 $\mathrm{cmH}_{2} \mathrm{O}$ y frecuencia respiratoria $0-25$ por minuto. Conclusión: Los resultados sugieren que la VMIP con BiPAP a través de TQT, es un método que puede ser implementado en forma eficiente y segura. Se requieren estudios comparativos con ventiladores clásicos para definir su rol real.

\section{EXPERIENCIA EN TRAQUEOSTOMÍA EN UN CENTRO DE HOSPI-} TALIZACIÓN PROLONGADA: CARACTERIZACIÓN CLÍNICA

Jakubson L, Montes S, Barañao P, Salinas $P$, Rosales A, Prado $F$ Hospital Josefina Martínez.

Introducción: La traqueostomía (TQT) suele ser indicada por requerimiento de ventilación mecánica prolongada (VMP) y obstrucción crítica de la vía aérea alta (OVAS). Objetivo: Reportar las características clínicas de los pacientes con TQT hospitalizados en el Hospital Josefina Martínez. Métodos: Estudio descriptivo, revisión fichas clínicas. Resultados: 30 pacientes con TQT hospitalizados. Hombres $18(60 \%)$. Edad: 31 meses $(8-186 \mathrm{~m})$. Indicación de la TQT: VMP $20(66 \%)$, OVAS $7(24 \%)$ y ambas $3(10 \%)$. Duración de TQT: 15 meses (1-70 m). Promedio cambio cánulas 27 días $(9-30)$. Modalidad VMP: BiPAP a TQT $14(47 \%)$ y ventilador convencional $9(30 \%)$. Acciones complementarias: válvula de fonación $11(37 \%)$, educación a los cuidadores 30 (100\%); evaluación fibrobroncoscópica 25 (83\%). Complicaciones: colonización de la vía aérea 30 $(100 \%)$, gérmenes habituales: Pseudomonas aeruginosa y Moraxella catharralis. Hubo 13,3 infecciones por cada 100 días de TQT (2,8/paciente). Hubo 7,1 eventos vinculados a la cánula de TQT por cada 100 días de TQT (decanulación 10 obstrucción 20 , queloides 2 , hemorragias 9 y granulomas 5 ). No fue necesario el traslado a centros de $>$ complejidad por complicaciones, 3 pacientes fueron decanulados en forma programada y 5 pacientes fallecieron por causas secundarias a su enfermedad de base. Conclusión: La causa más frecuente de TQT fue la VMP lo que determina su indicación en forma prolongada y como prestación intrahospitalaria. Las complicaciones son bajas y la mortalidad no se vinculó al manejo de la vía aérea. Es deseable la entrega de programas de educación a los cuidadores, y seguimiento protocolizado interdisciplinario. 


\section{ESTUDIO DESCRIPTIVO DE 21 MALFORMACIONES PULMONARES}

Arancibia JC, Velarde J, Reyes $H$, Tobar A, Jaime $C$

Servicio de Pediatría, Hospital Gustavo Fricke, Viña del Mar.

Introducción: Las malformaciones pulmonares constituyen un hallazgo infrecuente, representando el $2 \%$ de las necropsias en neonatos y niños. Objetivo: Presentar la experiencia en nuestro servicio en torno a esta entidad nosológica. Material y Método: Estudio retrospectivo y prospectivo. Revisión fichas clínicas y pacientes con diagnósticos de malformación pulmonar congénita en registros de unidades neonatológicas y quirúrgicas del Hospital Dr. Gustavo Fricke entre enero 1999 y agosto 2008. Resultados: 21 pacientes con las siguientes características: Diagnósticos: Atresia bronquial $\mathrm{LSD}=1$; Secuestro pulmonar 5 ; Enfisema lobar congénito $=2$; Malformación Adenomatosa Quística $=4$; Quiste pulmón izquierdo $=1$; Agenesia LSI y Língula $=1$; Hipoplasia pulmonar $=6$ Neumatocele LSD $=1.10$ eran de sexo masculino. Edad diagnóstico entre 18 semanas EG y 8 años. Sobrevida 14/21 (67\%). Seguimiento varió entre 2 meses y 9 años. Tratamiento quirúrgico en 18 pacientes. Modo de presentación: distress respiratorio en 8 , Bronconeumonía connatal, bronquiolitis, pleuroneumonía hidrotórax, neumonía, dolor torácico en 7 , asintomático en 5 . Una complicación postoperatoria en RN con MAQ: atelectasia masiva y fístula broncopleural. Once pacientes ingresaron a $\mathrm{UCl}, 6$ requirieron VM entre 2 horas y 5 días. Conclusiones: En 10 años, 21 pacientes se han diagnosticado con algún tipo de malformación pulmonar; dos han sido hallazgos ecográficos recientes. La mayoría fue sometido a cirugía con resección completa del lóbulo comprometido, presentando sólo uno complicaciones. Sobrevida: $67 \%$ con seguimiento hasta 9 años poscirugía. Queda por evaluar calidad de vida, función pulmonar y complicaciones a largo plazo, si las hubiera.
AUMENTO DE SOBREVIDA EN EL PROGRAMA NACIONAL DE FIBROSIS QUISTICA

Astudillo $\boldsymbol{P}^{1}$, Mancilla $P^{\dagger}$ y Grupo Colaborativo del Programa Nacional de Fibrosis Quística².

${ }^{1}$ Unidad de Salud Respiratoria, Ministerio de Salud, ${ }^{2}$ Servicios de Salud del País.

Introducción: Desde el año 2003, el Ministerio de Salud de Chile (Minsal) inicia un Programa Nacional de Fibrosis Quística (FQ) carácter integral, uno de cuyos objetivos es aumentar los años de sobrevida de los pacientes. Objetivo: Evaluar si la sobrevida de los pacientes ha mejorado desde el inicio del Programa. Material y Métodos: Se compara la primera base de datos nacional, confiable, sin casos repetidos, que corresponde a junio de $2003(n=221)$ con la base de datos actual, junio $2008(\mathrm{n}=326)$, en cuanto a la proporción de pacientes mayores de 15 y de 18 años. Resultados: En junio de 2003, el 25,8\% (57/221) y en junio de 2008 el $39,3 \%(128 / 326)$ eran $>15$ años (OR = 0,537; IC 95\% 0,362 $0,793 ; p=0,001)$. En junio de 2003, el $25,8 \%(57 / 221)$ y en junio de 2008 el $39,3 \%$ (128/326) eran > 18 años (OR=0,278; IC 95\% 0,149-0,496; $p<0,0001)$. Discusión: Se comprueba que existe un aumento estadísticamente significativo de los pacientes mayores de 15 y sobre todo de 18 años desde la puesta en marcha de Programa Nacional de FQ. Esto no se debe a un aumento del diagnóstico de pacientes mayores, pues el promedio de edad de los pacientes diagnosticados después de 2005 es de 5 años 1 mes. La instalación de Programas Nacionales, de carácter vertical, con conducción centralizada por especialistas con conocimientos del tema y con ejecución descentralizada, pero dotadas además con recursos específicos y con evaluación continua, permite alcanzar estos resultados.

\section{KINESITERAPIA RESPIRATORIA EN EL TRATAMIENTO DE BRONQUIOLITIS AGUDA: EFICACIA E INFLUENCIA EN LOS DÍAS DE HOSPITALIZACIÓN}

Milinarsky A, Arredondo A, Vásquez M, Ciudad D, Bertoglia M, Orellana A. Servicio de Pediatria, Hospital Carlos Van Buren, Valparaíso.

La bronquiolitis aguda constituye una patología frecuente, con una alta incidencia durante en período invernal. El promedio de hospitalización en el Hospital Carlos Van Buren fue de 6,2 días en el 2005, en contraste con los 3,5 días que reporta la literatura internacional. Se aplicó un protocolo de kinesiterapia respiratoria, basado en la mecánica ventilatoria combinado espiraciones lentas prolongadas y tos provocada con el objetivo de evaluar su influencia en la duración del período de hospitalización de los lactantes con bronquiolitis ingresados durante los meses de mayo a octubre de 2006. Un total de 54 pacientes fueron enrolados y aleatorizados en dos grupos: 27 pacientes (grupo control) recibieron tratamiento médico convencional y 27 (grupo caso) recibieron además tratamiento kinésico dos veces al día. Se midieron días de hospitalización y datos de su evolución clínica como: score obstructivo, curva de saturometría de pulso, freciencia cardíaca y temperatura, necesidad de oxígenoterapia y complicaciones. Además de tratamiendo médico indicado: corticoides, broncodilatadores, antibióticos. Un único evaluador enmascarado registró los datos de ambos grupos. Se observó un score obstructivo al ingreso de 4,2 ( $\pm 1,6$ puntos) vs 3,8 ( $\pm 1,9$ puntos) con un promedio de días hospitalización de 5,9 ( $\pm 2,7$ días) vs 4,8 ( \pm 2 días) en el grupo caso y control respectivamente. Concluimos que la kinesiterapia respiratoria asociada al tratamiento médico, no disminuyó los días ni costos de hospitalización. Estos resultados pueden ser atribuidos a un comportamiento atípico de la bronquiolitis durante el invierno del año 2006, mostrando grados de severidad menor a otros años. Futuros estudios son necesarios para poder demostrar resultados más satisfactorios. Financiado por FONIS proyecto SA5120114.

\section{ASOCIACION ENTRE № DE SALAS IRA Y DESCENSO DE LA MORTALIDAD INFANTIL POR NEUMONÍA}

Astudillo $\boldsymbol{P}$, Mancilla $P$, Prieto MJ.

Unidad de Salud Respiratoria, Ministerio de Salud.

Introducción: Durante la década de los 80, la mortalidad por neumonía sufrió en Chile un incremento, al contrario de lo que ocurría en otros países de la región. A contar de 1990, El Programa Nacional de Infecciones Respiratorias Agudas de Chile ha desarrollado la estrategia de instalar progresivamente salas IRA en establecimientos de Atención Primaria de todo el país. Objetivo: EI presente estudio pretende analizar si el aumento de salas IRA está o no relacionado con el descenso de la mortalidad infantil por neumonía (MIN) que se ha observado en el país. Material y Métodos: Se realiza una correlación entre el número de Salas IRA instaladas en Chile entre 1990 y 2007 con la tasa de mortalidad infantil por neumonía en igual período. Los datos fueron aportados por la Unidad de Salud Respiratoria y por el Departamento de Estadísticas e Información de Salud, del Ministerio de Salud (Minsal), respectivamente. Resultados: Se encuentra un muy alto coeficiente de correlación, con una alta significación estadística $(r=-0,925 ; p<0,0001)$ entre el número de salas instaladas a lo largo del período analizado, con el descenso en la tasa de MIN. Conclusiones: Si bien la mortalidad infantil por neumonía es de origen multicausal, el aumento de salas IRA instaladas por el Programa Nacional de IRA, está nítidamente asociado con la reducción de esta tasa. Los Programas nacionales son de diseño y dirección centralizados, pero de ejecución descentralizada, lo que ha permitido lograr resultados, que en este tema son próximos a los de países desarrollados. 
USO CLÍNICO DE LA PRUEBA DE PROVOCACIÓN BRONQUIAL CON METACOLINA Y MEDICION DE TCPO2 EN PRE-ESCOLARES
PARA EL DIAGNÓSTICO Y TRATAMIENTO DEL ASMA BRONQUIAL

Einisman H, Sánchez I, Caussade S.

Pontificia Universidad Católica de Chile.

Introducción: El diagnóstico del asma bronquial es clínico. Las pruebas de función pulmonar ayudan a su confirmación y seguimiento. En escolares y adultos están estandarizadas, no así en niños menores. En pre-escolares se ha utilizado la provocación bronquial con metacolina y medición de presión

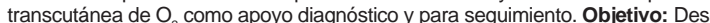
cribir la utilidad clínica de este examen. Métodos: Se estudiaron preescolares con diagnóstico o sospecha de asma referidos a realizarse la prueba, ésta se realizó según el método de Cockroft modificado. Se siguieron telefónicamente para evaluar evolución y tratamiento médico. Resultados: Se enrolaron 31 preescolares (45\% hombres) de 36 a 70 meses $(53+9)$ referidos con diagnóstico (n: 19, 61,3\%) o sospecha de asma (n: 12, 38,7\%). Asmáticos, 4 tuvieron el test normal: 2 con corticoides inhalados (Cl) (a 1 se le suspendió), 2 sin $\mathrm{Cl}$ (a 1 se le reinició porque se había suspendido para realizarse el examen). 15 tuvieron la prueba alterada: $5 \sin$ tratamiento (a 2 se le inició $\mathrm{Cl}$ y a 1 Montelukast (M)), 5 usuarios de $\mathrm{Cl}$ (a 2 se le cambió el tipo y a 1 se le suspendió), 3 con $\mathrm{Cl}$ suspendidos para realizarse el examen (en 2 se reinició), 1 con M y 1 con ambos, sin modificaciones posteriores. Sospecha de asma: 3 estaban con $\mathrm{Cl}$ y 2 con $\mathrm{M}$, todos suspendidos para realizarse el examen. La prueba fue normal en 2 descartándose asma. De los alterados (10), en todos se confirmó asma, salvo 1 en que se mantuvo como sospecha y 1 que no ha ido a control. Del resto, 2 se mantuvieron sin terapia, a 3 se les reinició la terapia previa, a 2 se les inició $\mathrm{Cl}$ y a $1 \mathrm{M}$. No hubo diferencias en esta decisión según el grado de hiperreactividad bronquial en ambos grupos. No se encontró correlación significativa entre e grado de severidad por clínica y alteración de la prueba, sin embargo, existe una tendencia de disminución en la PC20 al aumentar la severidad (GINA): leve 0,84 $\mathrm{mg} / \mathrm{ml}$ y moderado persistente $0,4 \mathrm{mg} / \mathrm{ml}$. Conclusiones: El test confirmó el asma en los niños con diagnóstico clínico y permitió descartarlo en 2 de los niños con sospecha. Se vio que casi la totalidad de las conductas tomadas frente al resultado fueron acordes a éste, pudiéndose concluir que es una herramienta útil y confiable para tomar decisiones terapéuticas.

EVALUACIÓN DE LA FUNCIÓN DE LA GLÁNDULA SUPRARRENAL EN PACIENTES CON CRISIS BRONQUIALES OBSTRUCTIVAS TRATADOS ENTRE 5 A 7 DÍAS CON CORTICOIDES SISTÉMICOS. RESULTADOS PRELIMINARES

Arancibia $\mathbf{H F}^{1-4}$, Holmgren $L^{2-4}$, Vega-Briceño $L E^{2-4}$, Martínez $A A^{3-4}$ ${ }^{1}$ Residente pediatría, ${ }^{2}$ Broncopulmonar infantil, ${ }^{2}$ Endocrinologo pediátrico, ${ }^{4}$ Departamento de Pediatría Pontificia Universidad Católica de Chile.

Los corticoides sistémicos (CS) son ampliamente utilizados en pacientes con crisis bronquiales obstructivas (CBO). La norma chilena recomienda su uso hasta un máximo de 5 días para evitar efectos adversos. En este tipo de no ha sido evaluado si tratamientos por cursos cortos pueden suprimir el eje hipotálamo hipófisis suprarrenal (HHS). La prueba con microdosis de ACTH $(1,0 \mathrm{mcg} / 1,73$ $\mathrm{m}^{2}$ ) provee un índice más sensible de la respuesta suprarrenal que la prueba con dosis estándar de ACTH (250 mcg). Objetivo: Evaluar mediante la prueba de microdosis de ACTH la función del eje HHS en pacientes con CBO tratados entre 5 a 7 días con corticoides sistémicos. Diseño: Estudio observacional, prospectivo en una muestra piloto de niños tratados en el Servicio de Pediatría del Hospital Clínico UC. Materiales y Pacientes: Pacientes con edades > 3 meses y $<13$ años con SBO que recibieron corticoides sistémicos entre 5 a 7 días. Luego de 48 a 72 horas de suspendido la prednisona, se determinó ACTH plasmática, Cortisol plasmático basal y 30 minutos después de la inyección endovenosa de ACTH $\left(1,0 \mathrm{mcg} / 1,73 \mathrm{~m}^{2}\right)$. Se consideró como respuesta anorma un cortisol postestimulo $<20 \mu \mathrm{g} / \mathrm{dL}$. Resultados (mediana y rango): Hasta la fecha se han reclutado 7 pacientes, con una mediana de edad de $4^{4 / 12}$ años (rango: 4 meses - 8 años). Todos usaron prednisona, con una dosis promedio de 1,6 mg/kg/día (rango: 1,2 a $2 \mathrm{mg} / \mathrm{kg} /$ día), equivalente a $197 \mathrm{mg} / \mathrm{m}^{2} /$ día de cortiso (rango: $\left.136-220 \mathrm{mg} / \mathrm{m}^{2} / \mathrm{día}\right), 13$ a 20 veces la dosis fisiológica $\left(\approx 10 \mathrm{mg} / \mathrm{m}^{2} / \mathrm{día}\right.$ ) durante 5 a 7 días, con una mediana 5 días. Entre las 48 a 72 horas, la ACTH promedio fue $15 \mathrm{pg} / \mathrm{ml}$ (rango: 5 a $53 \mathrm{pg} / \mathrm{ml}$ ), con un cortisol basal promedio de $6,5 \mathrm{mcg} / \mathrm{dL}$ (rango: 1 a $9 \mu \mathrm{g} / \mathrm{dL}$ ) y post estímulo de $13,6 \mu \mathrm{g} / \mathrm{dL}$ (rango: 3,7 a $20 \mu \mathrm{g}$ $\mathrm{dL})$. Seis pacientes $(86 \%)$ presentaron una respuesta post-estimulo $<20 \mu \mathrm{g} / \mathrm{dL}$. Conclusiones: Luego de 48 a 72 horas de haber suspendido el uso de CS de curso corto, fue frecuente encontrar una respuesta anormal a la prueba de ACTH microdosis. Esto puede ser reflejo de una insuficiencia suprarrenal. Está pendiente evaluar la importancia clínica y duración de este hallazgo. Proyecto financiado parcialmente por SOCHIPE (NP2008007) y del Centro Investigaciones Médicas PUC (Proyecto Becado PG30/08)
DISPLASIA BRONCOPULMONAR: SEGUIMIENTO DE 2 AÑOS

Navarrete $\boldsymbol{P}$, Zamorano A, Pittaluga E, Navarrete $P$.

Unidad de Respiratorio, Unidad de Neonatología, Servicio de Pediatría, Hospital Dr. Sótero del Río. Universidad Católica de Chile.

Introducción: De todos los recién nacidos prematuros aproximadamente un $25 \%$ desarrollarán displasia broncopulmonar (DBP), requiriendo hospitalización por infección respiratoria aguda dentro de los dos primeros años de vida un gran porcentaje de ellos. Objetivos: Caracterizar los pacientes portadores de DBP en control en el Hospital Dr. Sótero del Río. Métodos: Se revisaron las fichas clínicas de todos los pacientes con diagnóstico de DBP nacidos desde agosto 2004 hasta agosto del 2006 controlados en el policlínico de seguimiento del Hospital Dr. Sótero del Río; se analiza seguimiento hasta los 2 años de vida. Resultados: En el período estudiado se controlaron 42 lactantes ( 23 hombres), cuyas madres en un $39 \%$ eran primigestas, $10 \%$ adolescentes y $21 \%(9)$ no recibieron corticoides prenatales. Con respecto al peso de nacimiento, el $50 \%$ fue menor de 1.000 gramos. $62 \%$ fueron menores de 28 semanas. $83 \%$ (33) pacientes requirieron Ventilación mecánica invasiva (promedio 28,5 días). Siete (17\%) no recibieron surfactante. Doce evolucionaron con bronconeumonía y 4 presentaron estridor. Ocho pacientes requirieron corticoides sistémicos postnatales. La hospitalización promedio fue de 105 días, la edad al alta de 42 semanas de edad gestacional, El peso de alta 3.445 gramos. Treinta y nueve pacientes fueron dados de alta con oxígeno ambulatorio ( 0,24 It.x' promedio), requiriendo 272 días de oxígeno. $73 \%$ se rehospitalizaron al menos 1 vez con un total de 71 hospitalizaciones siendo el $77,5 \%$ por causa respiratoria. Veinticuatro pacientes recibieron corticoide inhalados. Conclusiones: Existe en los pacientes con DBP oxígeno dependiente un alto número de hospitalizaciones por causa respiratoria en los primeros años de vida lo que hace necesario implementar políticas nacionales que protejan a este grupo de alto riesgo.

\section{FIBROSIS QUISTICA. EXPERIENCIA DE 5 AÑOS EN ANTOFAGASTA}

Vega $M^{1}$, Cárdenas $A^{1}$, Cárdenas $D^{2}$, Zlatar $Y^{3}$.

${ }^{1}$ Pediatra, Hospital Regional de Antofagasta. ${ }^{2}$ Interna de Medicina, Facultad de Medicina, Universidad del Desarrollo. ${ }^{3}$ Interna de Medicina, Facultad de Medicina y Odontología Universidad de Antofagasta.

Introducción: La Fibrosis Quística (FQ) es la enfermedad genética más frecuente de la raza blanca. En Chile, se ha estimado una incidencia de 1:8.000 RNV. En Antofagasta se cuenta con un equipo multidisciplinario para la atención integral de estos pacientes.El Objetivo es describir las características clínicas de nuestros pacientes y comparar con la realidad nacional. Material y Métodos: Se analizaron retrospectivamente las fichas clínicas de los pacientes diagnosticados con (FQ) en nuestro Servicio desde el año 2003 hasta el 2007. Resultados: 10 pacientes han sido controlados en nuestro Servicio con una incidencia de 1/10.000. El 80\% (8/10) son varones. El 60\% (6/10) fue diagnosticado en el período neonatal y la edad promedio de diagnóstico fue de $11,8 \mathrm{~m}$. El antecedente más frecuente fue el íleo meconial, seguido del antecedente familiar y la falta de incremento ponderal. El promedio actual de edad es de 5 años y 6 meses, con un rango entre el año y los 10 años 3 meses. El $50 \%$ tiene algún grado de desnutrición. El $90 \%$ presentan insuficiencia pancreática. Dos pacientes se sometieron a reconstitución intestinal por su íleo. El 40\% presenta algún grado de retraso del desarrollo psicomotor. La letalidad es de un $20 \%(2 / 10)$. Cada paciente tiene en el período de estudio, un promedio de 5,3 hospitalizaciones, con un total de día/ camas de 3.318 para la muestra. La letalidad fue del $20 \%$ y el $60 \%$ tiene estudio genético. Discusión: La incidencia observada es menor a la del resto del país lo que se podría explicar porque aún existe un subdiagnóstico o que influiría la presencia de raza indígena en la zona norte. Por género hay predominio de masculino $(80 \%)$ que es mayor al país. Nuestra precocidad en el diagnóstico $(X$ $=11,8 \mathrm{~m}$ ) se explica por la permanente capacitación. Lo anterior hace que la principal sospecha de esta afección fuera por íleo meconial y no por patología respiratoria. El $50 \%$ tiene algún grado de desnutrición y otro 40\% algún grado de retraso el desarrollo, lo que nos obliga a preocuparnos de estos aspectos. Lo anterior está en directa relación con la gran cantidad de hospitalizaciones. La mutación genética en los 6 que fueron estudiados fue la delta F 508, similar al resto del país. 
FIBROSIS QUÍSTICA EN UN LACTANTE

Michea K, Zuloaga N, Peñafiel M.

Hospital Carlos Van Buren. Valparaíso.

Lactante 4 meses 7 días, sexo femenino, antecedentes perinatales (-), antecedentes mórbidos: Reflujo Gastroesofágico, manejado con Fórmila antirreflujo y Prokinéticos. Consulta por cuadro de una semana de evolución de lesiones maculares descamativas generalizadas; Examen físico: paciente hidratado, afebril, lesiones máculo descamativas cafe generalizadas, edema bipalpebral resto sin alteraciones. Evaluación Desnutrición: Riesgo de Desnutrición. Exámenes Unidad de Emergencia: Hto: $24,7 \% \mathrm{Hb}: 8,5 \mathrm{gr} / \mathrm{dL}$ Rcto Bcos: $13.500 \mathrm{pH}: 7,257 \mathrm{HCO}$ : 17,0 BE: -8,4 Na: 140 K: 5,6 Cl: 109 Glic: 114 Creat: 0,14 Urea: 8 NU: 3,7 BdT: 0,60 BbD: 0,48 ALAT: 102 ASAT: 269 Prot Total: $3,5 \mathrm{mg} / \mathrm{dL}$ Albumina: $1,8 \mathrm{mg} / \mathrm{dL}$ Amonio: 0,59 Lactato: 20 TP: 47,8\%. Ingresa con diagnóstico de Desnutrición Calórica Proteíca, ¿Enfermedad Metabólica? Hepatitis ¿TORCH? ¿Hígado graso por desnutrición?. Evoluciona con aumento de deposiciones de consistencia disminuida, se generaliza edema y se traslada a UCIMP. Exámenes de control Aminoacidemia y Aminoaciduria Normal, IgM CMV (-) IgG CMV (+) Toxoplasmosis (-) VIH (-) Sudan III: Grasas neutras +++, Esteatocrito ácido: 60\%, IgE Prot leche de Vaca: 0,98 (Mod), Rx EED: normal. Electrolitos en Sudor: $50 \mathrm{Eq} \mathrm{NaCl} / \mathrm{mmol} / \mathrm{L}$ (Macroduct). Mejora clínica gastrointestinal y disminuye edema en forma significativa. Inicia cuadro de tos seca fracuente y signología obstructiva al examen pulmonar. Aumento importante de la tos, presentando episodio de cianosis al alimentarse, exámenes muestran parámetros sépticos en rango viral, IFI Viral (+) Parainfluenza, Rx Tórax: Infiltrado interticial en ambos ápices y base derecha. Se maneja con $\mathrm{O}_{2}$, salbutamol inh, Corticoides sistémicos e inhalados. Evoluciona con mejoría transitoria, en rx control imagen sugerente de atelectasia basal $\mathrm{D}^{\mathrm{a}}$, presenta aumento de dificultad respiratoria y requerimientos de $\mathrm{O}_{2}$, se agregan al examen crépitos bibasales por lo que se inicia Cefotaxima + Cloxacilina. Cultivo Secreción Bronqueoalveolar (+) Acinetobacter Baumanni. Evoluciona favorablemente con disminución de requerimientos de $\mathrm{O}$ y de dificultad respiratoria. Se solicita $2^{\mathrm{a}}$ muestra Electrolitos en Sudor $100 \mathrm{Eq}$ $\mathrm{NaCl} / \mathrm{mmol} / \mathrm{L}$ (Macroduct) se realiza confirmación diagnóstica con método Gibson-Cooke $1^{\mathrm{a}}$ muestra: 104,3 mEq Cl/L 2 $2^{\mathrm{a}}$ muestra: 103,5 mEq Cl/L. Confirmándose diagnóstico de Fibrosis Quística. Ingresándose a Programa GES y manejándose según guía.

PERFIL DEL PACIENTE ASMÁTICO PEDIÁTRICO RESIDENTE EN SANTIAGO CENTRO

Villanueva ChM', Barrientos $\mathrm{H}^{2}$.

Becada Pediatría HCSBA - Universidad de Chile. Hospital Clínico San Borja Arriarán. ${ }^{2}$ Tutor. Unidad Broncopulmonar HCSBA.

Introducción: El asma como enfermedad inflamatoria crónica de las vías aéreas ha aumentado su prevalencia en la población pediátrica chilena. Presenta características evolutivas de acuerdo a su asociación a atopia y a otros factores donde destaca el estado nutricional. Objetivos: Describir las características clínico-laboratoriales y grado de severidad de un grupo de pacientes asmáticos pediátricos residentes en Santiago Centro. Así como establecer el nivel de asociación, si existe, entre el nivel de gravedad y factores considerados de interés. Métodos: Estudio de tipo descriptivo, observacional y retrospectivo. Se revisaron fichas clínicas de pacientes asmáticos ingresados entre el año 2000-2002 a CDT Broncopulmonar HCSBA a las que se les aplicó una ficha de recolección de datos de interés para el estudio. Se evaluaron datos estadísticos paramétricos y para datos de asociación se utilizó el chi cuadrado de Pearson empleando un error alfa de 0,05. Resultados: 210 pacientes cumplieron con los criterios de inclusión; de los cuales 79,51\% estuvo constituido por pacientes entre los 9 y 12 años, con similar distribución por sexo, procedencia urbana en su mayoría (78\%). Antecedentes de atopia familiar (55,5\%) y personal (33\%). Un $47,62 \%$ tiene antecedentes de tabaquismo intrafamiliar. Inició sintomatología antes de los 2 años: $74 \%$. Síntoma más frecuente: tos (87\%). El $80 \%$ reconoce claramente un factor desencadenante, siendo la etiología viral la más frecuente $(60,4 \%)$ reconocida. Un 50,72\% tiene al menos una hospitalización de causa respiratoria. E Test cutáneo fue positivo en el $43 \%$ y el valor de lgE estuvo elevado en un $68 \%$. El $39,05 \%$ tenía sobrepeso u obesidad, mientras que el $28,57 \%$ era eutrófico. Se encontró Asma intermitente en un $47,6 \%$. Se obtuvo un valor significativo $p$ para valores de $\mathrm{lgE}$ entre el grupo de asmáticos intermitentes y persistentes leves versus los asmáticos persistentes moderados y severos. Así como $p=0,03$ entre los asmáticos intermitentes versus los asmáticos persistentes para el Test Cutáneo. Mostrando mayor severidad en los últimos. No se encontraron otras asociaciones estadísticas significativas para definir severidad. En cuanto al estado nutricional, no se encontraron asociaciones independientes significativas entre el estado nutricional y la severidad de asma. Sin embargo, se encontró diferencia significativa en el IMC > p85 entre asmáticos intermitentes y persistentes leves vs los asmáticos persistentes moderados y severos. Conclusión: El grupo estudiado tiene características predominantemente urbanas, correspondiendo en su mayor parte a Asmáticos intermitentes y persistentes leves. La principal asociación estadística encontrada para definir severidad fue el fenotipo atópico (test cutáneo positivo e lgE elevada). Hallándose además diferencia significativa entre los asmáticos intermitentes y persistentes leves con IMC superior al $p$ > 85 para la edad respecto a los eutróficos. No se encontró ninguna otra asociación estadística significativa. Palabras clave: Asma, atopia.
FIBROSIS QUISTICA: CARACTERÍSTICAS EN PACIENTES PEDIÁTRICOS DE UN HOSPITAL PÚBLICO DE SANTIAGO DE CHILE METROPOLITANO

Pavez D, Osses $P$, Osses A, Parraguez C.

Hospital San Juan de Dios.

La fibrosis quística (FQ) es una enfermedad multisistémica, de trascendencia pública y en cuyo manejo ha habido progresos sustanciales que han ocasionado cambios en su prevalencia y características de los afectados. Propósito: Precisar y analizar las características clínicas y epidemiológicas de los pacientes en control en la Unidad Broncopulmonar Infantil del Hospital San Juan de Dios. Materiales y Métodos: Se revisaron 19 historias clínicas de pacientes diagnosticados con FQ desde abril del año 2000 hasta noviembre del 2007, tabulando y analizando los datos. Resultados: 12 pacientes eran de sexo masculino. El promedio de edad al ingreso de cuidado especializado llegó a 114,7 meses; con una desviación estándar de 64,44 y una mediana de 125; equivalente a 10 años y 5 meses de edad. El niño que ingresó con mayor edad tenía 245 meses (20 años) y el que ingresó más joven, sólo días de vida. El promedio de seguimiento en la Unidad alcanzó a 53,5 meses (desviación estándar: 22,5) y la mediana a 56 meses ( 4 años, 8 meses). Se realizó estudio genético a 18 niños, siendo negativo en 9 de ellos para las 32 mutaciones buscadas, 5 eran heterocigotos y 1 homocigoto para DF508; el resto era heterocigoto para otras mutaciones. Al ingreso las manifestaciones más frecuentes fueron el compromiso respiratorio $(n=14)$, siendo lo más común el SBOR y la neumonía a repetición. Sólo 2 pacientes debutaron con compromiso digestivo y 9 tenían compromiso nutricional al diagnóstico. Durante la evolución, 17 pacientes tuvieron compromiso respiratorio, siendo lo más frecuente las reagudizaciones. Trece tuvieron compromiso digestivo, siendo lo más frecuente la insuficiencia pancreática. Sólo 3 pacientes cursaron con compromiso hepático y ninguno presentó pancreatitis o diabetes mellitus. El estado nutritivo no empeoró a lo largo del seguimiento. Ocho pacientes tuvieron infección por Pseudomona aeruginosa y también 8, por Staphyloccocus aureus. Sólo 9 niños estuvieron alguna vez hospitalizados, con un promedio de 1,7 internaciones y DE de 2,96. Conclusión: La edad de ingreso está muy sobre lo deseado y posible pero, después del ingreso, la evolución es satisfactoria. Se debe mejorar la detección precoz de la FQ.

ALTERACIONES HEMODINAMICAS EN ETAPA INICIAL DEL SINDROME DE DISTRESS RESPIRATORIO AGUDO. ENSEÑANZAS DE UN MODELO EXPERIMENTAL

Cruces P, Díaz F, Donoso A, Carvajal C, Salomon T, Torres MF, Erranz B. Hospital Padre Hurtado.

Introducción: El síndrome de distress respiratorio agudo (SDRA) representa entre el $4-8 \%$ de los pacientes pediátricos ventilados mecánicamente, sin embargo, la mortalidad reportada llega al $30 \%$. Las interacciones cardiopulmonares son importantes en esta patología, ya que nos entregan una ventana fisiológica que puede influir en la terapia inicial y en forma secundaria en el pronóstico. Objetivo: Describir alteraciones hemodinámicas secundarias a la inducción de un SDRA en un modelo experimental. Método: 41 cerdos anestesiados de 4,9 $0,3 \mathrm{~kg}$, traqueostomizados, conectados a ventilación mecanica y monitorizados con cateter PiCCO®. Se indujo SDRA (instilación traqueal de $2 \mathrm{~mL} / \mathrm{kg}$ de Tween 20) y se registraron las variables hemodinámicas habituales y derivadas de la termodilución transpulmonar en condiciones basales y posterior a la inducción del SDRA. Los valores fueron expresados como media \pm DS. Estadígrafos utilizados: Paired t-test. Consideramos significativo un $p<0,01$. Resultados: Tras la inducción del SDRA hubo una reducción significativa de la $\mathrm{Pa} / \mathrm{FIO}_{2}(345 \pm 61$ a $155 \pm 37 \mathrm{mmHg})$, de la compliance estática $\left(1,6 \pm 0,6 \mathrm{a} 0,9 \pm 0,2 \mathrm{~mL} / \mathrm{cmH}_{2} \mathrm{O} / \mathrm{kg}\right)$ y un incremento del shunt intrapulmonar $(15+7$ a $44+11 \%)$. En forma concomitante hubo una disminución significativa de volumen de final del diastole (GEDI) de $257 \pm 39$ a $237 \pm 34 \mathrm{ml} / \mathrm{m}^{2}$ y un aumento del agua pulmonar extravascular (ELWI) de 11,8 $\pm 2,0$ a $14,9 \pm 2,1 \mathrm{ml} / \mathrm{kg}$ y el PVPI de $3,25 \pm 0,55$ a $4,48 \pm 0,68$. No se registraron cambios significativos en la presión venosa central (PVC) ni presión arterial media (PAM). Discusión: La inducción de SDRA genera cambios hemodinámicos graves, sugerentes de hipovolemia aguda secundaria a un aumento en fuga capilar de fluidos hacia el "compartimiento pulmonar". Estas alteraciones no fueron detectadas por los métodos de monitorización habitual. Es fundamental detectar minuciosamente y corregir precozmente las alteraciones del volumen circulante efectivo en individuos que padecen este síndrome, ya que junto con mejorar la hipoxemia con la terapia ventilatoria, es necesario también optimizar la entrega de oxígeno a los tejidos para prevenir el desarrollo de la morbilidad asociada secundaria a disoxia. Estudio financiado por la Sociedad Chilena de Pediatría (Concurso 2007) y proyecto Fondecyt 11075041. 


\section{ENDOCARDITIS BACTERIANA AGUDA (EBA), A PROPÓSITO DE UN CASO}

Arriaza M, Malebrán B, Pulido N.

Servicio de Pediatría, Hospital Dr. Gustavo Fricke de Viña del Mar. Facultad de Medicina, Universidad de Valparaíso.

La EBA es una entidad infrecuente en pediatría. La mayoría de los casos se presenta en pacientes con factores de riesgo, como cardiopatías congénitas. Presentamos un caso de EBA en un adolescente sin antecedente de cardiopatía. Paciente de 14 años, portador de DM1 desde los 6 años. Ingresa por cuadro febril de una semana de evolución asociado a lesiones petequiales palmoplantares y ungueales, nódulos de Osler, artralgias de codo y hombro. Sus exámenes iniciales demuestran PCR elevada, hiperglicemia, sin cetosis y $\mathrm{HbA} 1 \mathrm{C} 14,2 \%$, Ingresa con diagnósticos de DM1 compensada con pobre control metabólico, vasculitis y artralgias en estudio. Se inicia tratamiento con Cloxacilina. Evoluciona con fiebre elevada y continua, aparición de soplo sistólico III/VI, distress respiratorio, insuficiencia cardíaca y artritis séptica. Un ecocardiograma demuestra presencia de vegetación en válvula mitral con insuficiencia mitral sin cardiopatía, estableciéndose el diagnóstico de EBA y se ajusta dosis de antibióticos. Los hemocultivos y cultivos de líquido articular confirman presencia de St. Aureus. No se evidencia foco de entrada. Tras 6 semanas de tratamiento con Cloxacilina cede la fiebre y la vegetación valvular mitral desaparece persistiendo la insuficiencia valvular. La endocarditis infecciosa es una afección microbiana localizada en válvulas cardíacas o endocardio mural y es causada por bacterias, hongos, rickettsias y clamidias. La bacteriana es la forma más reconocida y se clasifica en agudas (EBA) o subagudas (EBSA) dependiendo de la presentación. Las manifestaciones clínicas reflejan la fisiopatología: el proceso infeccioso (fiebre, CEG), el daño valvular (soplo e insuficiencia cardíaca), la respuesta inmunológica (nefritis artritis y artralgias) y embolias infecciosas (petequias) entre otros. La EBA es de inicio súbito con fiebre alta y remitente. Las manifestaciones cutáneas son importantes para la sospecha diagnóstica. En adultos el $50 \%$ de los casos se desarrolla sobre corazón sano y asociada a procesos piógenos en otra localización, a uso de catéteres centrales o tratamientos EV. En la EBA son comunes las manifestaciones embólicas, a SNC y riñones. En niños un $70 \%$ presentan cardiopatías, principalmente cianóticas. Para el diagnóstico es fundamental un alto índice de sospecha, especialmente en pacientes sin factores de riesgo asociados y que cursen con fiebre alta y persistente. Los hemocultivos no siempre demuestran gérmenes. La ecocardiografía doppler color bidimensional, nos permitió confirmar el diagnóstico definitivo y ajustar el esquema antibiótico. La DM fue un factor que complicó el manejo inicial.

COMPARACIÓN ENTRE CINTIGRAMA MIOCÁRDICO Y ECOCARDIOGRAFÍA DOPPLER TISULAR EN ENFERMEDAD DE KAWASAK

Alcántara $\mathbf{A}^{1}$, Jofré $M^{1}$, Salinas $M E^{2}$, Toledo $X^{1}$.

Hospital Militar de Santiago*, ${ }^{2}$ Hospital Juan Noe Arica.

Introducción: Es conocido que la Enfermedad de Kawasaki (EK) tiene riesgo de desarrollar aneurisma coronario. El riesgo de estos pacientes es que desarrollen áreas de hipoperfusión secundaria. La pesquisa de éstas actualmente conlleva a la realización de un Cintigrama miocárdico (SPECT), encareciendo el costo. Se presenta la comparación de evaluación ecocardiografica por doppler tisula con alteración concordante con lo demostrada por cintigrama miocárdico. Métodos: Paciente mujer de 7 años 4 meses con antecedente de EK diagnosticada a los 2 años 8 meses, que recibió gammaglobulina al $3^{\circ}$ día de fiebre. El seguimiento demuestra aneurisma de arteria coronaria derecha (ACD), por lo que se mantiene con aspirina y neosintron. A los 5 años de edad se realiza SPECT de perfusión miocárdico con Tc99m-SESTAMIBI (MIBI) bajo estrés farmacológico con Dipiridamol. La coronariografía de rigor demostró calcificación de aneurisma en ACD. En septiembre de 2008 se realizó control de SPECT con protocolo equivalente, para lo cual, la paciente en laboratorio de Cardiología del Hospital Militar se somete a monitorización ECG y presión arterial (PA) con administración de Dipiridamol y MIBI, posterior a lo cual se realizo seguimiento cintigráfico de perfusión y 2 hrs después de administración de Dipiridamol, Ecocardiografía (ECOCG) convencional a la cual se le aplicó protocolo de doppler tisular y strain 2D. Resultados: Monitoreo ECG y PA con la administración de Dipiridamol no demostró isquemia miocárdica como tampoco síntomas. La captación de radiofármaco en el ventrículo izquierdo fue irregular evidenciando un segmento de hipoperfusión a nivel basal del septum tras la administración de Dipiridamol y con reperfusión significativa en la fase de reposo. La evaluación ECOCG demostró anatomía normal excepto la dilatación $\mathrm{ACD}$, la función sistólica convencional fue normal, presentó patrón de disfunción diastolita del ventrículo derecho. A analizar el Strain 2D se objetiva patrón de disfunción sistólica en segmentos septales y anteriores que concuerdan con el cintigrama de perfusión miocárdica. Conclusiones: En este paciente se encontró buena correlación entre la información entregada por Cintigrama de perfusión miocárdica y EcoCG con evaluación tisular y Strain 2D. Esta correlación puede aportar mayor simplificación en el seguimiento de pacientes con EK al aplicar protocolos de Doppler Tisular.
CIERRE PERCUTÁNEO DE GRANDES DEFECTOS DE COMUNICACIÓN INTERAURICULAR

Aguirre D, Álvarez P, Fernández C, Acevedo V, Palominos G, TM Maravi $R$, EU Maidana $V$.

Servicio de Cardiología y Cardiocirugía. Hospital de Niños Roberto del Río y Cínica Alemana. Santiago, Chile.

El cierre percutáneo de comunicación interauricular (CIA) con dispositivo es actualmente un tratamiento eficaz y seguro. Se considera un defecto grande a aquel cuyo tamaño es mayor de $20 \mathrm{~mm},>15 \mathrm{~mm} / \mathrm{m}^{2}$ o bien $1 \mathrm{~mm} / \mathrm{kg}$ de peso. El objetivo del presente trabajo es presentar nuestra experiencia en el cierre de grandes defectos de CIA. Método: Desde Marzo de 2003 a Septiembre de 2008 fueron sometidos a cierre percutáneo 19 pacientes portadores de CIA grande. E diagnóstico se realizó por clínica y Eco2D. Bajo anestesia general o sedación los pacientes fueron sometidos a ECO transefofágica (TE) o ecocardiografía intracardíaca (ICE) previo al procedimiento, realizándose cateterismo cardíaco derecho e izquierdo. El procedimiento consistió en medición del tamaño máximo del defecto y del septum interauricular desde distintos ángulos. El tamaño del dispositivo de cierre fue 2-4 mm mayor que el defecto. Una vez liberado el dispositivo se reevaluó su correcta posición, presencia de cortocircuito residual y relación con las estructuras vecinas. El seguimiento se realizó con Eco2D a la 24 hrs, 1 semana, 3, 6 y 24 meses y luego cada año. Resultados: 12 mujeres y 7 varones. Edad: 4 a 60 años (mediana: 7 años) con un peso promedio de $29 \pm 20$ $\mathrm{kg}$. Todos los pacientes presentaban sobrecarga moderada de volumen de cavidades derechas. La relación $\mathrm{Qp} / \mathrm{Qs}$ promedio fue de 3:1 (2,5 a 4:1) y la presión media de arteria pulmonar de $17 \mathrm{mmHg}$. El diámetro de defecto promedio fue de $20 \mathrm{~mm}$ con ECO y 20,7 con catéter balón. El tamaño del dispositivo en promedio fue $22 \mathrm{~mm}$ (15-30). Dos pacientes fueron derivados a cirugía por reborde insuficiente. En todos los pacientes el dispositivo fue instalado exitosamente no existiendo cortocircuito residual a la eco TE o ICE. Evaluación Eco 2 D a la 24 hrs mostró dispositivos adecuadamente posicionados, sin cortocircuito residual y ausencia de insuficiencia de las válvulas AV. En ningún caso se demostró erosión. Todos los pacientes fueron dados de alta a las $24 \mathrm{hrs}$ del procedimiento. El tiempo de radioscopia en promedio de 13,4 $\pm 5,4 \mathrm{~min}$ con un tiempo total de procedimiento de 30-120 min. El período de seguimiento de 2 a 66 meses ( $x$ : 35 meses). Conclusión: El cierre percutáneo de CIA grandes puede ser realizado sin complicaciones. En pacientes portadores de grandes defectos el cierre con dispositivo continúa siendo el tratamiento de elección.

\section{CIERRE PERCUTÁNEO DE COMUNICACIÓN INTERAURICULAR SIN UTILIZACIÓN DE CATÉTER BALÓN}

Aguirre D, Álvarez P. Fernández C, Acevedo V, Palominos G, TM Maravi $R$, EU Maidana $V$.

Servicio de Cardiología y Cardiocirugía. Hospital de Niños Roberto del Río y Cínica Alemana. Santiago, Chile

La utilización del catéter balón en la medición del diámetro máximo de defecto de comunicación interauricular (CIA) constituye parte de la técnica del cierre percutáneo. Sin embargo, puede prescindirse del mismo si se realiza una buena evaluación con el ecocardiograma. El objetivo del presente trabajo es presentar nuestra experiencia y eficiencia en el cierre percutáneo de CIA sin la utilización del catéter balón. Método: Desde Marzo de 2007 a Agosto de 2008 fueron sometidos a cierre percutáneo 27 pacientes portadores de CIA. El diagnóstico se realizó por clínica y Eco2D. Bajo anestesia general o sedación los pacientes fueron sometidos a ECO transefofágica (TE) o ecocardiografía intracardíaca (ICE) previo al procedimiento, realizándose cateterismo cardíaco derecho e izquierdo. El procedimiento consistió en medición del tamaño máximo del defecto y del septum interauricular desde distintos ángulos. El tamaño del dispositivo de cierre fue 2-4 mm mayor que el defecto. El dispositivo fue liberado bajo visión ecocardiográfica y radioscopia. Una vez liberado el dispositivo se evaluó su correcta posición, presencia de cortocircuito residual y relación con las estructuras vecinas. El seguimiento se realizó con Eco2D a la 24 hrs, 1 semana, 3,6 y 24 meses y luego cada año. Resultados: 15 mujeres y 12 varones. Edad: 4 a 60 años (mediana: 11 años) con un peso promedio de $36 \pm 20 \mathrm{~kg}$. Todos los pacientes presentaban sobrecarga de volumen de cavidades derechas. La relación $\mathrm{Qp}$ Qs promedio fue de 3:1 (2,5 a 4:1) y la presión media de arteria pulmonar de 17 $\mathrm{mmHg}$. El diámetro de defecto promedio fue de $12 \mathrm{~mm}$. El tamaño del dispositivo en promedio fue $15 \mathrm{~mm}$ (7-30). Se excluyeron dos pacientes que fueron derivados a cirugía por reborde insuficiente. En todos los pacientes el dispositivo fue instalado exitosamente no existiendo cortocircuito residual a la eco TE o ICE. Un paciente recibió dos dispositivos por defecto doble. Evaluación Eco 2D a la 24 hrs mostró dispositivos adecuadamente posicionados, sin cortocircuito residual y ausencia de insuficiencia de las válvulas AV. Todos los pacientes fueron dados de alta a las $24 \mathrm{hrs}$ del procedimiento. El tiempo de radioscopia en promedio de 7,4 \pm 6,5 min con un tiempo total de procedimiento de 30-120 min. El período de seguimiento en promedio fue 9 meses (1-17 meses). Conclusión: El cierre percutáneo de CIA sin la medición con catéter balón puede realizarse en forma segura y eficaz con una buena evaluación ecocardiográfica. 
CIERRE PERCUTÁNEO DE COMUNICACIÓN INTERAURICULAR ASISTIDO CON ECOCARDIOGRAFÍA INTRACARDÍACA

Aguirre D, Álvarez P, Fernández C, Acevedo V, Palominos G, TM Maravi $R$, EU Maidana $V$

Servicio de Cardiología y Cardiocirugía. Hospital de Niños Roberto del Río y Cínica Alemana. Santiago, Chile.

El cierre percutáneo de comunicación interauricular con dispositivo es actualmente un tratamiento eficaz y seguro. La ecocardiografía intracardíaca (ICE) como guía durante estos procedimientos es una alternativa novedosa frente a la ecocardiografía transesofágica. El objetivo del presente trabajo es presentar nuestra experiencia en el cierre de CIA ostium secundum (OS) asistida con ecocardiografía intracardíaca. Método: Desde Abril a Agosto de 2008 se seleccionaron 12 pacientes portadores de CIA OS. El diagnóstico se realizó por clínica y Eco2D. Bajo sedación y anestesia local los pacientes fueron sometidos a ecocardiografía intracardíaca (ICE) previo al cierre del defecto con transductor Acunav $8 \mathrm{Fr}$, además de cateterismo izquierdo y derecho. El acceso vascular venoso fue bilateral en pacientes con peso $<25 \mathrm{~kg}$. El procedimiento consistió en medición del tamaño máximo del defecto en distintas proyecciones. En sólo 2 pacientes se utilizó catéter balón. El tamaño del dispositivo de cierre fue 2-4 mm mayor que el defecto. Una vez liberado el dispositivo se evaluó su correcta posición y presencia de cortocircuito residual. El seguimiento se realizó con Eco2D a la 24 hrs, 1 semana, 3, 6 meses. Resultados: Edad: 5 a 44 años (mediana: 13 años) con un peso promedio de $39,6 \pm 20,2 \mathrm{~kg}$. Todos los pacientes presentaban sobrecarga de volumen de cavidades derechas. El diámetro de defecto promedio fue de 14,8 mm (7-27). Dos pacientes fueron derivados a cirugía por borde septal deficiente. El dispositivo utilizado fue Amplatzer $\AA^{\circledR}$. En todos los pacientes el dispositivo fue instalado exitosamente no existiendo cortocircuito residual al ICE. Evaluación Eco 2D a la 24 hrs mostró dispositivo bien ubicado, sin cortocircuito residual y ausencia de insuficiencia de las válvulas AV. Todos los pacientes fueron dados de alta a las $24 \mathrm{hrs}$ del procedimiento. El tiempo de radioscopia en promedio de $13,3 \pm 6,5 \mathrm{~min}$ ( 9 a $24 \mathrm{~min}$ ) con un tiempo total de procedimiento de 30-60 min. El período de seguimiento de 1 a 4 meses ( $x$ : 2 meses). Conclusión: La ecocardiografía intracardíaca proporciona suficiente información en la evaluación y asistencia en le cierre de percutáneo de CIA con dispositivo.

\section{CIERRE PERCUTÁNEO DE DUCTUS ARTERIOSO CON EL NUEVO DISPOSITIVO AMPLATZER ADO II}

Aguirre D, Álvarez P, Fernández C, Acevedo V, Palominos G, TM Maravi $R$, EU Maidana $V$

Servicio de Cardiología y Cardiocirugía. Hospital de Niños Roberto del Río y Cínica Alemana. Santiago, Chile.

El cierre percutáneo de ductus arterioso persistente (DAP) con dispositivo tipo amplatzer (ADO) en lactantes pequeños puede generar obstrucción a nivel de la aorta descendente. Con el nuevo dispositivo ADO II puede evitarse estos problemas gracias a su diseño que permite mejor adaptación al defecto. El objetivo de presente trabajo es presentar nuestra experiencia inicial en el cierre de de DAP con el nuevo dispositivo amplatzer para cierre de ductus (ADO II). Método: Desde Marzo a Agosto de 2008 se seleccionaron 11 pacientes portadores de DAP derivados para cierre percutáneo. El diagnóstico se realizó por clínica y Eco2D. Bajo sedación y anestesia local los pacientes fueron sometidos a cateterismo izquierdo y derecho. El procedimiento consistió aortografía para la evaluación y medición del tamaño ductal. En 9 pacientes se utilizo la vía retrógrada para el cierre de ductus y en sólo 2 la vía anterógrada. El ductus medido e su extremo pulmonar midió en promedio $2.9 \mathrm{~mm}$. Una vez liberado el dispositivo se realizó angiografía manual a través de introductor para evaluar correcta posición del dispositivo, presencia de cortocircuito residual y relación del dispositivo con la aorta descendente y arteria pulmonar. El seguimiento se realizó con Eco2D en la 1 semana, 1 mes, 3 meses. Resultados: Edad: 5 a 52 meses (mediana: 13 meses) con un peso promedio de $8,7+3,7 \mathrm{~kg}(6-15,2 \mathrm{~kg})$. Todos los pacientes presentaban sobrecarga de volumen de cavidades izquierdas. El Qp: Qs en promedio fue de 2,3:1. El tamaño del ductus medido e su extremo pulmonar en promedio fue 2,8 mm. (2-3,4 mm). El dispositivo utilizado fue el nuevo dispositivo ADO II (Amplatzer®). En todos los pacientes el dispositivo fue instalado exitosamente sin complicaciones. En 9 pacientes se utilizó la vía retrógrada para la implantación del dispositivo. Evaluación Eco 2D a la 24 hrs mostró dispositivo bien ubicado, sin cortocircuito residual, sin obstrucción aórtica, ni en rama pulmonar izquierda. Todos los pacientes fueron dados de alta el mismo día de procedimiento. El tiempo de radioscopia en promedio de $15,4 \pm 6,6 \mathrm{~min}(5,3$ a 27 $\mathrm{min}$ ) con un tiempo total de procedimiento de 30-60 min. El período de seguimiento de 1 a 5 meses (x: 3 meses). Conclusión: El nuevo dispositivo ADO II permite realizar el cierre de ductus en forma segura y eficaz, además que permite mejor adaptación a las estructuras vecinas al ductus.

\section{CIERRE PERCUTÁNEO DE DUCTUS MEDIANOS Y GRANDES}

Cabrera A, Eimbcke F, Miranda P, Pérez D, Reyes C, Romero L, Soler $P$, Cárdenas L.

Hospital Luis Calvo Mackenna, Laboratorio de Hemodinamia. Santiago.

Objetivos: Evaluar la eficacia y seguridad del cierre percutáneo de los ductus arteriosos persistentes (DAP) con distintos dispositivos. Métodos: Análisis retrospectivo de pacientes con DAP medianos y grandes a los que se les realizó cierre percutáneo con distintos dispositivos entre 08/06 y 08/08. Resultados: Se realizó cierre percutáneo de DAP en 26 pacientes, 23 de sexo femenino, cuya mediana de edad fue 53 meses (10-190). La mediana de peso fue $18,5 \mathrm{~kg}(6,4$ $69,1)$. El diámetro ecográfico del ventrículo izquierdo previo al procedimiento muestra valores $Z$ con mediana de $2(0,11-5,04)$ y una relación aurícula izquierda/aorta con mediana de 1,35 (1,04-2,2). La mediana del diámetro mínimo del ductus fue $3,8 \mathrm{~mm}$ (2-9). Los tipos de dispositivos utilizados fueron PFM (PFM) en 7 pacientes, Amplatzer Duct Occluder (ADO) 1 en 11, ADO 2 en 6 y Vascular Plug en 2. La mediana del tiempo de fluoroscopia fue 23,5 minutos $(6,6-36,7)$ y de la dosis utilizada de 116 mGym² $^{2}(66,4$ - 156,4). Según la clasificación de Krichenko el $84,6 \%$ correspondió al tipo A1 (22 pacientes), el 11,5\% al tipo A2 (3 pacientes) y $3,8 \%$ al tipo B1 (1 paciente). La mediana del diámetro menor encontrado en la angiografía fue 3,1 $\mathrm{mm}(2-6)$. Se encontró shunt residual leve en la angiografía en 4 pacientes (15,3\%), en 2 de ellos se utilizó dispositivo PFM y en 2 se utilizó ADO 1, uno $(3,8 \%)$ con dispositivo PFM presentó filtración moderada que requirió reforzar cierre con 2 coils en ese mismo procedimiento y en ningún paciente se encontró shunt severo. No se observó estenosis pulmonar n coartación aórtica en ninguno de ellos en la visión angiográfica. De las complicaciones relacionadas con el procedimiento, sólo en un paciente se produjo migración del dispositivo hacia la arteria pulmonar izquierda. Se rescató el dispositivo (ADO 2) por vía percutánea sin incidentes, siendo dado de alta a las 24 horas para cirugía posterior. No hubo casos de trombosis venosa ni arterial. En el control ecocardiográfico a las 24 horas, se encontró 3 casos $(11,5 \%)$ con filtración residual leve (dispositivos PFM). Los días de hospitalización fueron de 1 día en 25 pacientes $(96,2 \%)$ y 2 días 2 días en 1 paciente $(3,8 \%)$. En el seguimiento alejado, sólo en 2 pacientes se pesquisó filtración residual leve con dispositivo tipo PFM en ambas. No se registran otras complicaciones. Conclusión: El cierre de ductus medianos y grandes con los dispositivos disponibles en el mercado es seguro en el corto y mediano plazo, con baja frecuencia de complicaciones, estadías hospitalarias cortas y escasa incidencia de shunt residual.

SEGUIMIENTO A LARGO PLAZO DE PACIENTES PORTADORES DE TETRALOGÍA DE FALLOT

Castillo NME, Toro RL, Herrera LF, Zelada PP, Alcántara PA, Garay VR, Ferreiro CM, Arretz $C^{\dagger}$, Becker $P^{1}$

Hospital Dr. Sótero del Río, ${ }^{\top}$ Hospital Clínico Pontificia Universidad Católica de Chile.

Introducción: La tetralogía de Fallot (T4F) es la cardiopatía congénita cianótica más frecuente en la edad pediátrica y las lesiones residuales a largo plazo luego de su corrección han sido ampliamente reportadas en la literatura nacional e internacional. Objetivo: seguimiento de pacientes (pac) portadores deT4F: edad de seguimiento, sexo, otras patologías asociadas, tipo de cirugía, reintervenciones, mortalidad, general y quirúrgica, capacidad funcional (CF). Material y Método: Se revisaron retrospectivamente las fichas de los pacientes con T4F del Hospital Dr. Sótero del Río desde 01-1996 a 07-2008, se determina edad, sexo, tiempo de seguimiento, malformaciones asociadas,edad de cirugía, complicaciones y evolución, mortalidad, y reintervenciones. Resultados: 103 pac T4F, 51\% hombres. Ochenta y cinco tuvieron indicación y resolución quirúrgica $(82,5 \%$ ) y 18 no se han operado; 9 quedaron fuera de indicación quirúrgica, de éstos todos son plurimalformados (PMF), 5 mueren antes de operarse, 1 esta esperando cirugía, 1 no se opera x negación materna, 2 trasladados a otro centro. Del total $20(19 \%)$ presentan atresia pulmonar (AP) y $3(2,9 \%)$ agenesia de velos (AV) y 3 canal atrioventricular (CAV). $29 \%$ está asociado a síndrome genético. La edad de seguimiento promedio fue 12 años $4 \mathrm{~m}$ ( $1 \mathrm{~m}-37$ a $10 \mathrm{~m})$. De los 85 operados: 75 son reparadoras ( $88 \%$ ) en su primera cirugía, 8 tienen un shunt previo, y 2 un shunt y conexión VD-AP previa. Parche transanular tiene el $45 \%$. La edad promedio de cirugía fue 9,4 m (1 día-8 años $4 \mathrm{~m}$ ), el 23,5\% eran menores de 1 mes. La mortalidad quirúrgica fue de 7 niños $(8,2 \%), 4$ en el postoperatorio inmediato. De los fallecidos todos eran complejos; 4 T4F c/AP, 1 con AV, 1 con coronaria anómala, 1 con T21. En los últimos 5 años la mortalidad quirúrgica es de $3 \%$. La mortalidad total fue de 21 niños (2\%) 14 no operados. Las complicaciones más frecuentes de cirugía son: CIV residual $4,7 \%$, taquicardia nodal $2,4 \%$. Son reoperados 15 pacientes (17\%); 5 recambio valvular pulmonar (de estos 4 tenían parche transanular y uno homoinjerto), 6 reparadora post SBT, 2 nuevos SBT, 1 marcapaso, 1 estenosis subaórtica. Cinco presentan ERP que requieren balonplastías. En CF I el 100\%. Conclusiones: Del total de nuestros pacientes con T4F la gran mayoría tiene resolución quirúrgica, con buenos resultados a mediano plazo y baja mortalidad general, estando esta asociada a T4F más extremos, o con mala anatomía. La mayoría tienen cirugía reparadora en la $1^{\mathrm{a}}$ etapa $(88 \%)$. 
CALIDAD DE VIDA EN PACIENTES PORTADORES DE CARDIOPATÍA CONGÉNITA

Castillo NME, Toro RL, Zelada PP, Herrera LF, Garay VR, Alcántara PA Ferreiro CM, EU Agusti D.

Hospital Dr. Sótero del Río. SSMSO.

Introducción: Aunque mejorar la calidad de vida de los cardiópatas congénitos ha sido una preocupación y el fin último de la corrección de las cardiopatías congénitas (CC) existen sólo estudios por patología específica en nuestro medio y no hay reportes comparativos con niños sanos. Objetivo: Estudiar la calidad de vida de pacientes portadores de CC objetivando 3 áreas: actividad escolar, actividad cotidianas (generales y física) e interacción familiar; en tres grupos de CC con complejidad diferente, y compararlos con un grupo control de niños sanos. Material y Método: Se escogieron 4 grupos de niños del área sur oriente de Santiago; 3 grupos portadores de CC de diferente complejidad; comunicación interventricular (CIV), T. Fallot (T4F), Ventrículo único (VU) y 1 un grupo sano (S), se sometieron a encuestas de calidad de vida de salud, niños y padres por separado. Al ítem de escolaridad se agrego edad-curso y promedio de notas para mejor objetivarla .En actividad física se realizó Test de esfuerzo (TE). Se analizaron las encuestas y se compararon de acuerdo a las 3 áreas específicas evaluadas. Se aplicó análisis estadístico de $\chi^{2}$. Resultados: Se seleccionan 65 niños de los cuales 12 son CIV con edad promedio de 12,9 a, 18 son T4F, con edad promedio de 11 a, 15 tienen VU con edad promedio de $11,3 \mathrm{a}$, y 20 son sanos con edad de 12 a. Treinta y tres de ellos son hombres (50,7\%). Los pacientes con CIV tuvieron 1 cirugía y se encuentran sin patología residual, los T4F tuvieron 1,3 cirugía/niño y tienen patología residual, los VU tuvieron 3,5 cir/ niño y tienen patología. En escolaridad no existen diferencias significativas en edad/curso, promedio de notas $(5,7)$, repetición $(24,8 \%)$, en percepción de notas y rendimiento escolar los $\mathrm{VU}$ tanto pacientes como padres perciben peor rendimiento que el curso. En relación a actividades físicas de mayor esfuerzo, sin limitación (SL) Sano $73,6 \%$ CIV 83\%, T4F 63\%, VU 20\%, en actividades medianas SL, S 73,6\% CIV 91.65 T4F 66\% VU 40\%, esfuerzo leve S $84,2 \%$ CIV $83 \%$ T4F 72\% VU 73\%. Los padres en general tienen una percepción de mayor limitación. EI TE reveló: S: 11: 75 min CIV: 12: 2 min, T4F: 10 min y VU: 7: 3 min. En percepción de vida familiar: muy buena (MB) S 58\% CIV 50\% T4F33\% VU 53\%. En buena relación con los mamá: S 63\% CIV42\% T4F33\% VU53\%. Angustia materna por la salud del hijo: S $36,6 \%$ CIV $41,6 \%$ T4F $35 \%$, VU $66,6 \%$, y por salud emocional: S $63 \%$, CIV $66,6 \%$ T4F $35 \%$, VU 46,6\%. En reducción de tiempo dedicado al resto de la familia: S $5 \%$. CIV $16,6 \%$, T4F $29 \%$, VU $40 \%$ Conclusiones: En RE no hubo DS en los 4 grupos. En AF no hubo DS entre $S$ y CIV; T4F y VU tienen limitación en AF de acuerdo a complejidad. La vida familiar sólo T4F presenta más dificultades, en preocupación materna por salud sólo VU tiene DS y en tiempo dedicado a hijo es en relación a complejidad. En actividades vida diaria sólo VU se encuentra limitado y en ser diferente al resto de acuerdo a complejidad. Contento con la vida CIV tiene mejor percepción.

USO DE CARDIODESFIBRILADOR IMPLANTABLE EN UNA POBLACIÓN PEDIÁTRICA: EXPERIENCIA CLÍNICA EN 43 PACIENTES CONSECUTIVOS

Quezada K, Acevedo A, Álvarez P, Palominos G

Hospital Roberto del Río.

Introducción: La indicación de cardiodesfibrilador implantable (CDI) para la prevención de muerte súbita (MS) en la población pediátrica es cada vez más frecuente. El objetivo de este trabajo es evaluar la indicación, enfermedad cardíaca subyacente, eficacia y complicaciones tempranas y tardías en pacientes pediátricos en los cuales se instaló un CDI. Material y Método: Entre agosto del 2003 y julio del 2008 se instaló un CDI en 43 pacientes (ptes), 20 mujeres, evaluados en cardiología en el Hospital Roberto del Río. Al momento del implante el promedio de edad fue de 9,5 años, (rango 4 meses a 16 años). Se reviso la ficha clínica y los datos del seguimiento del dispositivo. Resultados: En 12 ptes el CDI se implantó como prevención secundaria de MS y en los restantes como prevención primaria. Las enfermedades subyacentes fueron: Síndrome de QT largo en 21, miocardiopatía hipertrófica en 7, miocardiopatía dilatada en 2, fibrilación ventricular idiopática en 3 , distrofia muscular en 2 , taquicardia ventricular 2 y cardiopatía congénita 3 . La instalación fue transvenosa en 40 ptes y epicardica en 3 ptes. En el seguimiento de 2 a 60 meses 11 ptes han recibido terapia apropiadas del CDI y 3 inapropiadas. Han tenido complicaciones 2 ptes (Disfunción de electrodo). Conclusiones: 1) La terapia con CDI en nuestra experiencia es factible y segura; 2 ) Un tercio de los ptes (32\%) han tenido descargas apropiadas durante el seguimiento, indicando la utilidad del dispositivo en estos ptes.
EXPERIENCIA DE 10 AÑOS EN EL MANEJO DEL SÍNDROME DE LA CIMITARRA

Miranda $J P^{1}$, Fernández $C^{2}$, Aguirre $D^{2,3}$, Álvarez $P^{2,3}$, Palominos $G^{2}$ Hernández $P^{2}$

${ }^{1}$ Becado de Cardiología Infantil, Universidad de Chile, ${ }^{2}$ Servicio de Cardiología y Cirugía Cardiovascular. Hospital de Niños Roberto del Río. ${ }^{3}$ Servicio de Cardiología y Cardiocirugía, Clínica Alemana.

Introducción: El síndrome de la cimitarra es un cuadro clínico poco frecuente caracterizado por la existencia de un drenaje venoso anómalo pulmonar parcial o total de las venas pulmonares derechas hacia la vena cava inferior, se asocia a distintos grados de hipoplasia pulmonar con dextroposición cardíaca y circulación colateral sistémico-pulmonar. Objetivo: Describir las características clínide la cimitarra en el Servicio de Cardiología del Hospital Roberto del Río. Materiales y Métodos: Análisis retrospectivo de fichas clínicas de pacientes entre agosto de 1998 y agosto de 2008. Se determinó la edad al momento del diagnóstico, manifestaciones clínicas, exámenes y método diagnóstico utilizado, indicación y el tipo de cirugía y/o procedimientos intervencionales realizados. Resultados: Se encontraron un total de 8 pacientes ( 5 de sexo femenino). La edad al momento del diagnóstico fue en promedio de 3,8 años (rango: 0,2-12 años). La presentación clínica fue: neumonía o síndrome bronquial obstructivo recurrente en 4 casos, insuficiencia cardíaca en 2 y hemoptisis en otro paciente. En un caso el diagnóstico fue un hallazgo radiológico. A todos se les realizó una radiografía de tórax, la cual demostró una imagen sospechosa en 6 y en 2 pacientes fue normal. El ECG demostró crecimiento de cavidades derechas en 2 pacientes, bloqueo incompleto de rama derecha en 3 y fue normal en 3 casos. El Ecocardiograma doppler color (ECO 2D) mostró dilatación de cavidades derechas en 6 pacientes y apoyó el diagnóstico en 6 casos. Siete pacientes fueron sometidos a un cateterismo cardíaco demostrándose el drenaje anómalo con la imagen característica y además circulación colateral sistémico pulmonar en 3 casos en los que se realizó embolización. En 3 casos se demostró hipertensión pulmonar. En 6 se complementó el estudio con un angioTAC de tórax y en 4 casos un cintigrama ventilación/perfusión. Dentro de los defectos cardíacos asociados se encontró: comunicación interauricular tipo ostium secundum (4 pacientes), ductus arterioso persistente (1 paciente), comunicación interventricular (1 paciente), vena cava superior izquierda persistente con desamarraje de cavas (2 paciente) e interrupción de vena cava inferior (1 paciente). Dentro de las enfermedades o malformaciones extracardíacas encontramos 1 paciente con doble sistema pielocaliciario más una hemivértebra, 1 con fibrosis quística y otro con probable enfermedad de Hirschprung aún no confirmada. Seis pacientes fueron sometidos a cirugía por sobrecarga de volumen significativa. Esta consistió corrección del drenaje anómalo y cierre de CIA en 5 pacientes y en uno cierre de CIA más ligadura de circulación sistémico pulmonar. Un paciente falleció por complicaciones respiratorias en el postoperatorio. El seguimiento promedio fue de 5,9 años (rango: 0,8-9,5 años). La edad promedio actual es de 9,7 años (rango: 1,2-19 años), 6 de ellos se encuentran asintomáticos, en CF I de la NYHA Conclusiones: El Síndrome de la Cimitarra constituye una entidad poco frecuente muy variable en su presentación clínica. El cateterismo cardíaco permite confirmar el diagnóstico, determinar el grado de hipertensión pulmonar y efectuar la embolización de vasos anómalos sistémico-pulmonares. La indicación quirúrgica debe ser ndividualizada e indicada en pacientes sintomáticos con sobrecarga de volumen significativa.

\section{UTILIDAD DEL TEST DE RUFFIER-DICKSON COMO PREDICTOR DE CAPACIDAD AEROBICA EN ADOLESCENTES CON MALA RESPUESTA CARDIOVASCULAR AL EJERCICIO}

Tapia ZJ, Tapia UP, Siegmund SD, Tapia UC, Carrasco DMI, Morales CA, Araneda GM.

Hospital Guillermo Grant Benavente, Facultad de Medicina, Departamento Pediatría Universidad de Concepción.

Introduccón: El sobrepeso, la sarcopenia y el aumento de la resistencia al flujo inspiratorio, en adolescentes con mala tolerancia al ejercicio, son factores que determinan en ellos una mala condición física. El Test de Ruffier-Dickson que se aplica en muchos cursos de enseñanza básica y media del país permite iden tificar aquellos con mala respuesta cardiovascular cuando es $>10$ y a los que requieren revisión médica previo a la práctica deportiva cuando es $>15$. Objetivo: correlacionar en una cohorte de alumnos con mala adaptación cardiovascular al ejercicio, los parámetros clásicos del Test de Esfuerzo Pediátrico con los resultados del Test de Ruffier-Dickson, para determinar el grado de correlación entre ellos. Pacientes y Métodos: 14 niñas (8-17 años) y 12 niños (8-16 años) con antecedentes de dolor precordial, presíncope o malestar durante las clases de educación física, son evaluados con el Test de Ruffier-Dickson antes de realizar un test de esfuerzo máximo en cinta sin fin con protocolo de Bruce. Todos con ecocardiograma normal y sin cardiopatía. Se determina el tiempo de resistencia (Cumming); METS, VO máx; Doble Producto (PAxFc); Reserva cardíaca (\%); CF; Flujo inspiratorio nasal máximo (FINM); IMC; \% grasa; masa magra y masa grasa; cintura y perímetro braquial. Se calcula el coef. de correlación de Pearson entre cada uno de ellos y los valores del Test de RuffierDickson, se presentan aquellos con relación significativa. Resultados: Se encontró buena correlación entre el valor de Ruffier y la Fc basal $(+0,77)$; El valor de Ruffier y el \% de FC máx $(+0,4358)$, entre los Mets alcanzados y el FINM $/ K g$ $(+0,62)$. No se encontró correlación con el VO máx/DP $(-0,05)$; Mets $(-0,001)$; recuperación al $1^{\circ}$ minuto $(-0,028)$; DP $(0,00049)$; IMC $(0,135)$. Conclusión: En esta cohorte con mala adaptación cardiovascular al ejercicio, el Test de RuffierDickson no permite inferir la capacidad aeróbica. 
TUMOR DE MEDIASTINO MEDIO: QUISTE BRONCOGÉNICO EN UN ESCOLAR, HOSPITAL HERNÁN HENRÍQUEZ ARAVENA-TEMUCO

Venegas $\boldsymbol{P}^{1}$, Baquerizo $A^{2}$, Moscoso $\mathbf{G}^{1}$, Martínez $A^{3}$.

${ }^{1}$ Pediatra, ${ }^{2}$ Cirujano Tórax Adulto, ${ }^{3}$ Becado de Pediatría. Hospital Hernán Henríquez Aravena-Temuco.

Introduccion: El quiste broncogénico es una anomalía congénita benigna de sistema embrionario, pulmonares y extra pulmonares y rara vez se diagnostica en edades tempranas. Representan el $18 \%$ de todos los tumores primarios de mediastino y son las lesiones quísticas más frecuente en esta localización. Tienen un revestimiento de epitelio columnar ciliado, presencia de cartílago y relleno de material mucoide. Su presentación clínica puede ser asintomática y los síntomas dependen de su localización o derivan de alguna complicación (hemorragia intraquística, perforación, infección o degeneración metaplásica). Caso clínico: Escolar,varón de 9 años,previamente sano que consulta con pediatra a fines del año 2007 por sensación de ahogo y taquicardia en relación principalmente con el ejercicio de 2 semanas de evolución.Se solicita Rx de Tórax que informa masa paravertebral izquierda pudiendo corresponder a una lesión de mediastino posterior.TAC de tórax:quiste de $4,2 \mathrm{~cm}$ de diámetro en el mediastino medio, paramediano izquierdo posiblemente tipo congénito.Se efectúa toracotomía izquierda en Enero del 2008, encontrándose una masa quística de $5 \times 5 \mathrm{~cm}$ de diámetro,de contenido mucoide sólido blanquecina en el mediastino medio. Informe de biopsia: estructura compatible con quiste bronquial. Comentario: Frente al hallazgo en las imágenes de una masa quística en el mediastino medio, el diagnóstico diferencial se plantea con un quiste del intestino anterior (duplicación esofágica), quiste pericárdico o QB. Conclusión: Los QB son procecsos relativamente poco frecuentes. Son tumores benignos y, aunque a veces constituyen un hallazgo radiológico accidental, pueden originar gran variedad de síntomas y complicaciones. Generalmente, se ubican en la linea media en relación con las estructuras del mediastino,cercano a la tráquea, esófago, bronquios o en medio del parénquima pulmonar. Constituido por epitelio ciliado pseudoestratificado, lo que confirma el diagnóstico histológico. La tos y el dolor toráxico son los síntomas más frecuentes causados por la compresión de estructuras vecinas. $\mathrm{E}$ diagnóstico se sospecha por la radiografía de tórax: imagen bien delimitada homogenea y redondeada en el mediastino. El estudio se completa con TAC o RNM. El diagnóstico diferencial se hace con: quiste hidatídico, neumatocele, quiste de duplicaión esofágica, malformación adenomatosa quística, quiste pericárdico. El tratamiento es la resección quirúrgica por toracotomía o videotoracoscopia.

\section{ENTEROCOLITIS NECROTIZANTE Y CIRUGÍA. EXPERIENCIA DE 30} AÑOS

Valdés OMV, Morán VJ, Venegas CG, Roizen RJ, Cienfuegos G. Unidad Recién Nacido y Cirugía Hospital Luis Calvo Mackenna.

Introducción: La principal emergencia quirúrgica de las UTI Neonatal es la ECN. El $70 \%$ de los casos ocurre en los recién nacidos de pretémino (R.N.P.T.) bajo 36 semanas. Su principal complicación es la necrosis intestinal que obliga a una resección de intestino. Según edad gestacional el compromiso anatómico es diferente lo que conlleva a una evolución y pronóstico también diferente. Objetivos: Comparar RNT con RNPT que presentaron ECN analizando sus antecedentes clínicos, y protocolo operatorio determinando el compromiso anatómico que requirió resección intestinal y establecer su evolución. Material y Método: En un estudio retrospectivo de pacientes hospitalizados desde 1976 al 2008 (agosto), se analizan comparativamente 124 RNPT y 115 RNT: sus antecedentes perinatales, peso de nacimiento, sitio de resección intestinal, evolución, morbimortalidad. Resultados: El promedio de edad gestacional de los RNPT fue de $32,27 \mathrm{sem}$ (DS 2,87) y con un peso promedio de $1639 \mathrm{~g}$ (DS 578). Los RNT tenían 38,53 sem (DS 1,07), con un peso promedio de $2948 \mathrm{~g}$ (DS 578). La ECN se presentó en los RNPT a los 7,85 días de vida versus 6,3 días en los RNT (p:0,27). El antecedente materno más relevante fue la hipertensión materna que se presentó en un $12 \%$ en los RNT, versus $21 \%$ en los RNPT ( $p: 0,073$ ), sin otros antecedentes que fueran estadísticamente significativos. El parto por cesárea fue $56 \%$ en RNT versus $66 \%$ en RNPT. Presentaron APGAR menor de 7 en un $26 \%$ los RNT versus $45 \%$ los RNPT (p: 0,01 ). La mayoría de los RN de los 2 grupos tuvieron alimentación previa a la ECN. De las patologías previas a la ECN el SDR. Se presentó en un $10 \%$ en RNT versus un $36 \%$ en RNPT ( $p<$ $0,001)$. En un $23 \%$ los RNT presentaron cardiopatía congénita cianótica versus $11 \%$ en RNPT (p: 0,03). El antecedente de poliglobulia se presentó en un $20 \%$ en RNT y en un $4 \%$ en RNPT $(p<0,001)$. El tratamiento quirúrgico en los RNT fue en un $64 \%$ versus $77,5 \%$ en RNPT. El colon se comprometió en un $68 \%$ en RNT versus $48 \%$ en RNPT (p: 0,002). El intestino delgado se comprometió en un $33 \%$ en los RNPT versus $14 \%$ en los RNT $(p<0,001)$. La mortalidad de los RNT fue de $26 \%$ versus $31 \%$ en RNPT (p: 0,4 ). En ambos grupos la principal complicación fue la Estenosis postenterocolitis, presentada en 6 RNPT y en 8 RNT y el Sd. de Intestino corto en 7 RNPT (Fallecen 4) y en 3 RNT (fallecen 3). Conclusiones: No hubo antecedentes importantes prenatales, ni una diferencia en la edad de presentación de la ECN para los 2 grupos. Para los RNPT el antecedente de hipoxia tuvo una diferencia significativa, igual que el SDR $(p<0,001)$ con respecto a los RNT. El antecedente de poliglobulia fue relevante para los RNT. El sitio de compromiso intestinal preferencial en los RNT fue el colon y para los RNPT el intestino delgado, lo que explica la mayor presencia de SIC.
CARACTERIZACIÓN DE PACIENTES CON INVAGINACIÓN INTESTINAL: EXPERIENCIA DE UNA DÉCADA EN HOSPITAL CLÍNICO REGIONAL DE CONCEPCIÓN

Monsalve MP, Muñoz MC, Pontoni ZA, Lara DJ, Correa SP. Departamento de Cirugía Infantil, Hospital Clínico Regional de Concepción, Chile.

Introducción: La invaginación intestinal es causa frecuente de obstrucción intestinal en lactantes y niños mayores. Puede ocurrir a cualquier edad, sin embargo, la mayor incidencia se observa en lactantes entre 5 y 9 meses de edad, presentándose más de la mitad de los casos durante el primer año de vida. Material y Método: Estudio descriptivo retrospectivo de datos obtenidos de los registros clínicos de pacientes con diagnóstico de invaginación intestinal atendidos en los últimos diez años en el Hospital Regional de Concepción, analizados con el programa estadístico SPSS. Resultados: Se tabularon datos de 60 pacientes, de los cuales 34 fueron varones. Edad promedio 10,18 meses. El motivo de consulta más frecuente fue el dolor abdominal con un $48,3 \%$ seguido de rectorragia y vómitos, $25 \%$ y $23,3 \%$ respectivamente. En el $90 \%$ de los casos el diagnóstico fue clínico de los cuales el $51,8 \%$ fue complementado con estudio imagenológico. La reducción no quirúrgica se intentó en un $6,7 \%$ de los casos, siendo operados un $98,3 \%$, efectuándose apendicetomía profiláctica en un $93,2 \%$. Se realizó resección intestinal en $11,8 \%$ de los pacientes intervenidos quirúrgicamente. El tipo de invaginación más frecuente fue la lleocecocolica con un $88,4 \%$. El $95 \%$ de las intususcepciones fue de causa idiopática. Conclusiones: La invaginación intestinal continua siendo un cuadro propio del lactante menor siendo su diagnóstico predominantemente clínico. Palabras clave: Invaginación, dolor abdominal, ileocecocolica.

\section{CALIDAD DE VIDA PRE Y POST CIRUGIA EN PACIENTES OPERADOS DE PECTUS EXCAVATUM MEDIANTE TÉCNICA DE NUSS}

Silva $\boldsymbol{P}$, Velarde J, Elton MA

Hospital Gustavo Fricke, Universidad de Valparaíso.

Antecedentes: Pectus Excavatum (PE): deformidad congénita de la pared torácica anterior, afecta esternón y 4 a 5 cartílagos costales inferiores, formando una concavidad en la pared anterior desde la tercera a la octava costilla, asimétrica y de profundidad variable. Su corrección puede ser mediante técnica de Nuss que consiste en la inserción de una barra metálica. Objetivos: Conocer el cambio en la calidad de vida de los pacientes operados mediante técnica de Nuss en nuestro centro. Material y Métodos: Estudio descriptivo, realizado en el servicio de cirugía pediátrica, hospital Gustavo Fricke. Se encuestaron todos los pacientes operados de (PE) mediante técnica de Nuss los años 2004-2008. Se midió calidad de vida pre y post cirugía con el cuestionario de Nuss para pacientes pediátricos. Obteniendo puntajes pre y post cirugía de acuerdo a las respuestas, a las cuales se les asignaba un puntaje de 1 a 4 . Resultados: Se evaluaron 14 pacientes, los resultados son los siguientes: 1) Como te sientes con tu aspecto: pre cirugía $1,9(\mathrm{Ds}+0,66)$ post $3,7(\mathrm{Ds}+0,46) ; 2)$ Como te sientes con el aspecto de tu tórax al mirarte al espejo sin camisa pre: 1,4 (Ds $+0,49)$ post: 3,6 ; 3) Como te sientes por lo que dice la gente de tu tórax al mirarte: pre: 2,1 (Ds + 0,99 ) post: 3,5 (Ds + 1,09); 4) La gente se ríe de ti por el aspecto de tu tórax: pre: 1,2 (Ds + 0,42) post: 3,3 (Ds + 0,91); 5) El aspecto del tórax te lleva a evitar hacer cosas delante de desconocidos? pre $1,6(\mathrm{Ds}+1,08)$ post: $3,2(\mathrm{Ds}+0,89$ ); 6) Ocultas tu tórax pre: $1,8(\mathrm{Ds}+1,18)$ post: $3,6(\mathrm{Ds}+0,49)$; 7) Te has sentido incómodo de cómo la gente mira tu tórax pre: 1,8 (Ds + 0,83) post 3,9 (Ds + 0,26 ); 8 ) Te sientes avergonzado cuando la gente mira tu tórax pre: 2,4 (Ds + 1,08) post: 3,8 (Ds $+0,42)$; 9) Te sientes mal por tu enfermedad: pre 1,4 (Ds + $0,84$ ) post: 3,7 (Ds $+0,46) ; 10$ ) Tienes apuro por terminar las clases de gimnasia pre: 2,0 (Ds $+0,96)$ post: 3,9 (Ds $+0,36) ; 11$ ) Sientes que te cuesta respirar por tu tórax pre: 1,5 (Ds $+0,85)$ post: 3,4 (Ds $+0,85) ; 12$ ) Te cansas rápidamente al hacer ejercicio pre: 3 (Ds + 0,61) post: 3,6 (Ds + 0,49). Todas las preguntas fueron estadísticamente significativas mediante T-Student. Conclusiones: La técnica de Nuss permite cambios significativos en autoestima, capacidad física, interacción social, lo cual justifica el manejo quirúrgico debido al gran impacto biopsicosocial que tiene en los pacientes. 
HAMARTOMA FIBROSO DE LA INFANCIA: REPORTE DE UN CASO

Pontigo $C L^{1}$, Folatre $B R^{2}$, del Pozo $L M^{3}$, Wenger $C R^{4}$, Lagos $S W^{5}$ ${ }^{1}$ Médico Becado Pediatría Hospital Regional Valdivia. ${ }^{2}$ Hemato-Oncóloga Infanti Hospital Regional Valdivia. ${ }^{3}$ Anátomo-Patóloga Hospital Regional Valdivia. ${ }^{4}$ Médico Radiólogo Hospital Regional Valdivia. ${ }^{5}$ Cirujano Infantil Hospital Regional Valdivia.

Introducción: El Hamartoma Fibroso de la Infancia fue descrito por primera vez por Reye en 1954. Es una neoplasia mesenquimal benigna que compromete el tejido subcutáneo o dermis reticular. Es poco frecuente, representando un 0.02 $\%$ de todos los tumores partes blandas, presentándose en un $91 \%$ de los casos en el primer año de vida. Es una lesión casi siempre única, de crecimiento rápido que alcanza entre 1 y 10 centímetros, localizándose preferentemente en axila ,hombro, extremidades superiores, región inguinal y pared torácica. Su tratamiento es la escisión quirúrgica y la recidiva es de un $16 \%$, asociada a escisión parcial del tumor. Reporte de un caso: Lactante de dos meses, de sexo masculino, domiciliado en Valdivia, con aumento de volumen progresivo en zona interescapular, indoloro, sin aumento de temperatura local y adherido a planos profundos, de aproximadamente seis centímetros de diámetro mayor Evaluado en Cirugía Infantil del Hospital Base Valdivia se estudia con TAC de tórax la cual informa masa de aspecto tumoral. Se realiza escisión quirúrgica el 09 de junio de 2008. Biopsia de la lesión concluye Hamartoma Fibroso de la Infancia, con compromiso de sus bordes quirúrgicos. Actualmente en seguimiento en Policlínico de Cirugía Infantil de este centro, sin evidencias clínicas de recidiva. Discusión: El hamartoma fibroso de la infancia es un tumor de partes blandas, clasificado por la Organización Mundial de la Salud como un tumo fibroblástico/miofibroblástico de carácter benigno. Tiene tres características histológicas distintivas: trabéculas de denso tejído fibrocolagenoso, con típicos islotes de células ovales primitivas y células adiposas maduras, con predominio variable de estas estructuras. Tiene buen pronóstico y su tratamiento es la escisión quirúrgica local. Su recurrencia se asocia a escisión incompleta, siendo en estos casos de aproximadamente un $16 \%$, y su tratamiento es la reescisión. En el caso reportado, la biopsia informó escisión parcial de la lesión, con compromiso del borde quirúrgico inferior y dorsal. Dadas las características de este tumor benigno de partes blandas, se decidió mantener una conducta expectante y seguimiento, planteándose una reescisión quirúrgica en caso de recidiva.

\section{INDICADORES DE CALIDAD DE VIDA EN NIÑOS GASTROSTOMIZADOS}

Egaña A, Pittaluga E.

Hospital Sótero del Río, Centro NINEAS.

Introducción: Los pacientes portadores de gastrostomia (GT) presentan numerosas complicaciones y el cuidado que reciben es frecuentemente inadecuado por escasez de insumos adecuados, atención profesional especializada y capacitación de los cuidadores. La atención a través de un protocolo de gastrostomizado (PTG) permite mejorar la calidad de vida de estos niños. Objetivo: Evaluar la eficacia de una intervención dirigida a los niños portadores de GT. Metodología: Se elaboró un PTG que incluye atención por enfermera experta en el cuidado de estomas y en instalación de dispositivos de GT. Se gestionó la compra de insumos adecuados y se capacitó a los padres. Se registró diagnósticos ingreso, causa y fecha de la cirugía, complicaciones, duración y causa de retiro de los dispositivos (DP), facilidad de uso, satisfacción, adherencia a los controles. E análisis se hizo en EPI Info. Resultados: 47 pacientes ingresaron al protocolo entre Noviembre 2006 y Septiembre 2008, edad promedio 7 años. Veinticinco requirieron la instalación de un $2^{\circ}$ DP y 8 un tercero. Nueve pacientes fallecen en el estudio, 2 son dados de alta, 36 permanecen activos (76\%). Los diagnósticos asociados fueron neurológico $93 \%$ Respiratorio $76 \%$; Genético $65 \%$; Digestivo $45 \%$ y cardíaco $21 \% ; 57 \%$ son varones. La edad de la Qx fue 3,2 años, $25 \%$ antes de los 6 meses. Causa de la GT fue trastorno deglución 92\%, atresia esófago $4 \%$, anorexia $2 \%$, DCP severa $2 \%$. $32 \%$ se mantenía en control en cirugía Los DP al ingreso fueron: Sonda 84\% (38): 15 foley látex, 19 foley siliconada y 4 sonda GT; Botón $16 \%$ (7), globo 5 y balón rígido 2 .

Tabla 1. Analisis Comparativo de los indicadores de calidad de vida en niños Gastrostomizados

\begin{tabular}{|c|c|c|c|}
\hline Dispositivo & Previo & $1^{\circ}$ Dispositivo & $2^{\circ}$ Dispositivo \\
\hline $\mathrm{N}^{\circ}$ & 47 & 47 & 25 \\
\hline Filtración & 86 & 36 & 28 \\
\hline Erosión & 75 & 17 & 15 \\
\hline Desplazamiento & 11 & 2,4 & 0 \\
\hline Rotura & 55 & 22 & 10 \\
\hline Expulsión & 60 & 22 & 14 \\
\hline Obstrucción & 42 & 15 & 10 \\
\hline Duración promedio & 4 meses & 6 meses & 6,1 \\
\hline Facilidad de uso & 60 & 92 & 90 \\
\hline Satisfacción usuaria & 17 & 51 & 70 \\
\hline
\end{tabular}

Conclusiones: La aplicación de un PTG disminuye las complicaciones, mejora calidad de vida en niños gastrostomizados y sus cuidadores.
INVAGINACIÓN INTESTINAL: LA IMPORTANCIA DE LA TRIADA CLÁSICA

Muñoz MC, Monsalve MP, Pontoni ZA, Lara DJ, Correa SP.

Departamento de Cirugía Infantil, Hospital Clínico Regional de Concepción, Chile.

Introducción: La invaginación intestinal ocurre generalmente en un lactante eutrofico manifestándose con dolor abdominal, rectorragia y masa abdominal palpable, la triada clásica. Material y Método: Estudio descriptivo retrospectivo de datos obtenidos de los registros clínicos de pacientes con diagnóstico de invaginación intestinal atendidos en los últimos diez años en el Hospital Regional de Concepción, analizados con el programa estadístico SPSS. Resultados: Se diagnosticaron 60 casos en el período en estudio, siendo 34 de ellos varones. La edad promedio fue de 10,18 meses. El motivo de consulta más frecuente fue e dolor abdominal, presentando la triada clásica con rectorragia y masa palpable el $35 \%$ de los casos, y al menos uno de ellos en el $95 \%$. El $51,7 \%$ de los menores presentaron manifestaciones sistémicas asociadas al cuadro digestivo, siendo las más frecuentes el decaimiento y la irritabilidad con un $41,7 \%$ ambos. El diagnóstico se efectuó en base al cuadro clínico en el $90 \%$ de los casos, siendo el diagnóstico principal al ingreso en el $66,8 \%$. Al momento del diagnóstico cerca del 50\% tenía menos de 24 horas de evolución del cuadro, consultando el $81,7 \%$ antes de las 72 horas. Se efectuó un tratamiento quirúrgico en el $98,3 \%$ de los casos, sin complicaciones del cuadro en el $95 \%$ de ellos. No se presentaron complicaciones postoperatorias en el grupo en estudio, con un tiempo de estadía hospitalaria promedio de 5,5 días. Conclusiones: El diagnóstico de la invaginación intestinal continua siendo predominantemente clínico, debiendo tener un alto índice de sospecha en lactantes con presencia de uno o más de los signos clásicos. Palabras clave: Invaginación, dolor abdominal, triada.

PERFIL EPIDEMIOLÓGICO DE PACIENTES PEDIÁTRICOS QUEMADOS EN EL PERÍODO COMPRENDIDO AGOSTO 2004-AGOSTO 2008 EN EL SERVICIO DE CIRUGÍA INFANTIL DEL HOSPITAL CLÍNICO REGIONAL ANTOFAGASTA

Cañón CR, Castillo PH, Almonte ChE, Weibel A.

Facultad de Medicina y Odontología, Universidad de Antofagasta. Antofagasta, Chile. Servicio Cirugía Infantil de Hospital Clínico Regional Antofagasta Dr. Leonardo Guzmán.

Material y Método: Estudio retrospectivo transversal correspondiente a todos los casos de pacientes hospitalizados por quemaduras en el Servicio de Cirugía Infantil del Hospital Clínico Regional Antofagasta, entre Agosto del 2004 y Agosto del 2008, realizándose el análisis en base a números absolutos, porcentajes y promedios. Resultados: En el período estudiado se registraron un total de 194 ingresos al Servicio de Cirugía Infantil del Hospital Clínico Regional Antofagasta, correspondiendo al $33,5 \%$ de los casos a mujeres con un promedio de edad de 5,71 años con SD de 4,07 y el $66,5 \%$ de los casos a varones con edad promedio de 5,06 años y SD de 3,93; con un total de días/cama de 1.173, promedio de días de hospitalización de 6,07 y SD de 5,99; se encontraron 7 agentes causantes de quemaduras en los casos analizados, siendo el principal agua caliente con (151 casos), seguido por electricidad (14), solar (9), fuego (8), productos químicos (6), utensilios domésticos (plancha) y vapor ambos con 3 casos; se encontraron 9 pacientes con más del $20 \%$ de la SCT quemada, correspondiente al $4,63 \%$ del total de casos ocurridos; el tipo de quemadura se caracterizó según aspecto clínico en 5 categorías: tipo A con 17 casos, A-AB 73 casos, AB 43 casos, AB-B 38 casos y $B$ en 23 casos; los principales sitios afectados fueron extremidad superior en 57 casos, seguido de tórax en 45 casos y dorso en 31 casos, desglosándose el resto de los casos en otros sitios anatómicos afectados; del total de casos $32,47 \%$ recibió tratamiento antibiótico ya sea profiláctico o para manejo de infección, se realizó aseo quirúrgico al $50 \%$ de los casos y el $28,35 \%$ de los pacientes requirió injerto, de los cuales $94,54 \%$ fueron del tipo dermoepidérmicos y sólo el 5,45\% piel total; 179 de nuestros pacientes no presentaron complicaciones en su tratamiento, 13 presentaron infección de la zona afectada y sólo hubo pérdida de 2 injertos. Todos los pacientes afectados correspondieron a accidentes en su domicilio, destacándose que todos aquellos, que recibieron o no aseo quirúrgico y no recibieron injerto se les realizó curaciones tullvaselina o moltopren. Conclusiones: Desafortunadamente muchos niños de nuestra región siguen siendo víctimas de accidentes en su domicilio todos los cuales podrían ser evitados bajo la adecuada supervisión de un adulto, sufriendo quemaduras en diversas regiones corporales, las cuales eran afectadas con relativa concordancia al agente causal así como también su profundidad. Continúa siendo la causa más frecuente la quemadura por agua caliente en menores de 2 años, siguiendo en frecuencia la quemadura por electricidad, en prepúberes y adolescentes fueron más frecuentes las solares y por fuego. Se presentó un bajo porcentaje de gran quemados, considerando el período de tiempo analizado. 
TUMORES PANCREÁTICOS (TP) EN NIÑOS Y ADOLESCENTES (TPNA). DESAFÍOS DIAGNÓSTICOS Y TERAPÉUTICOS

Rossi FR, Franco C, Cassorla F, Rossi MR, Herrera JM, Barriga F, Correia G, Iglesias $M$.

Clínica Alemana, Santa María, Indisa y Hospital Clínico San Borja-Arriarán.

Los TPNA son infrecuentes ya que el Memorial Hosp. de Nueva York reportó sólo 17 casos en 35 años. Los tipos histológicos y el comportamiento difieren los TP del adulto. Se describe la presentación, tratamiento y resultados de 10 pacientes tratados entre 1995 y 2007. La edad media fue de 11 años (1 mes a 17 años). El diagnóstico de TU fue incidental en 4 (1 in útero en ecotomografía de control prenatal- $2^{\circ}$ reportado), 2 pacientes (pt) tenían síntomas por producción de polipéptidos (1 gastrinoma y 1 insulinoma), 3 dolor ( 1 hemoperitoneo) y 1 ictericia obstructiva distal. El estudio por imágenes indicó que 6 eran sólidos y 4 quísticos. Se efectuaron 3 pancreatectomías $(\mathrm{P})$ distales con preservación de bazo, 2 abiertas y 1 laparoscópica (sólo 5 en la literatura pediátrica); 4 pancreatoduodenectomías (PD); $1 \mathrm{P}$ segmentaria central que permite conservar tejido pancreático y función endocrina (tercera en la literatura); 1 enucleación con resección de margen pancreático (linfangioma) y 1 resección parcial de urgencia (pt. con hemoperitoneo por TU sólido quístico seudopapapilar). A este pt se le practicó electivamente una $\mathrm{PD}$ con resección y reconstrucción de la vena porta. En todos los pt. se logró la resección completa del TU. No hubo mortalidad pero un pt. desarrollo una fístula biliar transitoria. Patología: 1 pancreatoblastoma, 3 TU sólido quístico seudopapilar, 2 TU neuroendocrinos funcionales, 1 TU neuroectodérmico primitivo (PNET), 1 TU seromucinoso, 1 seudo TU inflamatorio quístico con pancreatitis focal, 1 linfangioma. El pt. con PNET recibió quimioterapia. Todos los pt. están libres de enfermedad y se han desarrollado bien con una media de seguimiento de 60 meses. Un pt. desarrolló esteatorrea que requiere enzimas y otro tuvo episodios transitorios de pancreatitis; ambos problemas se relacionan a estenosis de la anastomosis pancreáticas en conductos muy finos en niños. Ningún pt. ha desarrollado diabetes. Conclusiones: Esta serie de 10 pacientes muestra la variabilidad en la presentación de los TPNA y su diagnóstico diferencial. El pancreatoblastoma es el más comun en niños, mientras que los sólido quísticos seudopapilares y neuroendocrinos son más frecuentes en adolescentes. Los TPNA tienen más tendencia al crecimiento expansivo y menos a metastizar que los TU del adulto y por ende mayor posibilidad de resección curativa. La cirugía debe individualizarse, ser completa y minimizar morbilidad y secuelas metabólicas. El trabajo conjunto de un cirujano de adultos con experiencia en páncreas y del cirujano pediatra nos parece una buena opción para optimizar resultados en esta patología de baja frecuencia.

\section{ABDOMEN AGUDO DE ORIGEN APENDICULAR EN MENORES DE} 3 AÑOS. SERIE CLÍNICA

Morales V, Monge M, Lizama M, Zavala A.

Hospital Clínico Pontificia Universidad Católica de Chile.

Introducción: La apendicitis aguda (AA) es la patología de Urgencia quirúrgica más frecuente en Pediatría, especialmente en la edad escolar. Sin embargo, en lactantes, no es el primer diagnóstico que se sospecha en un paciente que consulta en SU. Dado ciertas condiciones anatómicas y fisiológicas de este último grupo de pacientes, el cuadro clínico de AA, es distinto al clásico descrito, lo que hace retardar el diagnóstico, con el riesgo para el paciente de presentar complicaciones locales y sistémicas. Objetivos: Evaluar características clínicas y de laboratorio de los pacientes menores de 36 meses que consultaron en SU de Hospital Clínico de la Pontificia Universidad Católica y que fueron hospitalizados en el Servicio de Pediatría con diagnóstico definitivo al alta de Abdomen agudo de origen apendicular. Metodología: Fueron incluidos pacientes menores de 36 meses, hospitalizados en el Servicio de Pediatría del Hospital Clínico de la Pontificia Universidad Católica, entre Enero 2004 y Marzo 2008 cuyos diagnósticos de egreso fueron: Apendicitis aguda, Peritonitis aguda, Absceso apendicula y/o Plastrón apendicular. Se revisó la ficha médica, exámenes de laboratorio imágenes y protocolos Operatorios. Resultados: Se incluyó a 7 pacientes, 4 hombres y 3 mujeres. La edad promedio fue de 23,5 meses. Los motivos de consulta más frecuente fueron vómitos $(87,5 \%)$, fiebre $(62,5 \%)$, dolor abdomina $(62,5 \%)$ y diarrea $(43 \%)$. El cuadro clínico tuvo una duración promedio antes de ingreso de 5 días, con un promedio de consulta previo de 1,7 veces. En cuanto a los diagnósticos de ingreso en el $62,5 \%$ de los pacientes fue abdomen agudo de origen apendicular. En todos los pacientes se realizó Ecografía abdominal, siendo en todos ellos compatible con abdomen agudo de origen apendicular y en 6 se realizó exámenes de laboratorio (hemograma, VHS, PCR) destacando los siguientes valores promedio: PCR 10,9, Leucocitos de 22.583, RAN 16.783, VHS 60 y $2 \%$ de baciliformes. La conducta fue quirúrgica en el $100 \%$ de los casos siendo inicialmente médica en 2 pacientes. El tratamiento ATB ev fue en promedio de 3,65 días y total de 8 días. Llama la atención que en los diagnósticos quirúrgicos, el $57 \%$ fueron Abdomen agudo asociado a complicaciones (plastrón apendicular, peritonitis y abscesos). El promedio de hospitalización fue de 7,7 días. Conclusiones: Esta es una serie pequeña, sin embargo, nos parece destacable que la conjunción de síntomas como vómitos, fiebre y dolor abdominal, sumados a PCR elevada, leucocitosis y neutrofilia podrían ser de ayuda en la toma de decisiones, tomando en cuenta que un alto porcentaje de los pacientes terminan siendo operados en etapas tardías, por el bajo índice de sospecha de esta patología en este grupo etario. Es necesario analizar series de mayor número de pacientes, para poder sacar conclusiones de más válidas y así lograr un diagnóstico precoz.
CIRUGÍA DE NORWOOD-SANO, VISIÓN OTORRINOLARINGOLÓGICA

Pardo $\mathrm{JJ}^{2}$, Gutiérrez $C D^{2}$, Aranís $\mathrm{JC}^{4}$, Tapia $T P^{3}$, Beltrán $C^{4}$, de la Paz F', Becker RJ $J^{5}$, Castillo $A^{5}$

${ }^{1}$ Residente Otorrinolaringología. ${ }^{2}$ Interna de Medicina. ${ }^{3}$ Fonoaudióloga del Departamento de Otorrinolaringología. ${ }^{4}$ Otorrinolaringólogo. ${ }^{5}$ Cirujano Cardíaco. Departamento de Otorrinolaringología y Cardiocirugía de la Pontificia Universidad Católica de Chile.

Introducción: La cirugía de Norwood (cNW) es realizada en recién nacidos (RN) con cardiopatía congénita, Síndrome hipoplasia de corazón izquierdo. Su realización causa daño al nervio laríngeo recurrente, describiéndose hasta $9 \%$ de parálisis cordal izquierda (PCVI), $24 \%$ de aspiración y $21 \%$ trastornos de succión, que determinan morbimortalidad post quirúrgica. Nuestro hospital es centro de referencia, y desde el año 2007, realiza evaluación otorrinolaringológica (ORL) postquirúrgica de rutina, mediante nasofibroscopia. Objetivo: Describir morbilidad ORL secundaria a cNW y su evolución. Método: Estudio retrospectivo de RN sometidos a cNW entre Septiembre 2005 y Julio de 2008. Se revisaron antecedentes clínicos relevantes y en septiembre de 2008 se entrevistó telefónicamente a los padres sobre su evolución. Resultados: Se operaron $25 \mathrm{RN}, 18$ de ellos tuvieron evaluación por ORL. De éstos, 16 fueron RN de término y $10(58 \%)$ de sexo masculino. El promedio de edad a la cirugía y los días en ventilación mecánica fueron $8,9+4,9$ y $9,8+6,2$ días respectivamente. En la evaluación por ORL, un $23,1 \%$ se encontraba asintomático, $46,2 \%$ presentó llanto disfónico, y los restantes presentaron estridor, ausencia de llanto o mala succión. Mediante nasofibroscopia, se diagnosticó en 12/18 (68\%) PCVI, en 3/10 trastorno de deglución; sólo 2/18 presentaron examen laríngeo normal. Post evaluación, al 87,5\% se indicó sonda nasogástrica (SNG) y a $11 \%$ se le indicó Omeprazol. Al seguimiento, se contactó a 13 niños, de los cuales 3 han fallecido, ninguno secundario a patología ORL. De los 10 restantes, la edad promedio al seguimiento fue de 19,8 meses; 6 se sometieron a cirugía de Glenn, 3 han presentado neumonía, y 2 trastorno de deglución. El 80\% usó SNG, con un promedio de 36 días, sólo 1 necesito gastrostomía. El $100 \%$ de los padres considera que su tratante tomo en cuenta los trastornos postQx, pero al $30 \%$ le hubiese gustado recibir mayor información. Un $100 \%$ de los padres considera a su hijo "sano" actualmente. Conclusiones: La cirugía NW causa con alta frecuencia PCVI; por esto se requiere una pronta evaluación por $\mathrm{ORL}$ para prevenir complicaciones, las que posiblemente fueron evitadas por indicación precoz de SNG. Es importante evaluar deglución, a fin de evitar el uso de SNG y así trastornos de deglución o succión. Encontramos una alta tasa de recuperación y baja tasa de complicaciones a largo plazo.

\section{EPIDERMOLISIS BULLOSA TIPO I. A PROPÓSITO DE UN CASO DE MANEJO NO TRADICIONAL EN LA PRÁCTICA DIARIA}

Cisterna C, Bajaña G, Alvarado O, Jaime C, Tobar A Hospital. Dr. Gustavo Fricke, Universidad de Valparaíso.

La Epidermolisis Bullosa, corresponde a un grupo de enfermedades transmitidas genéticamente, alteraciónes principalmente en los genes de la citoqueratina basa 5 (gen KRT5), 14 (gen KRT14), en los genes (PLEC1), una proteína que se encuentra en el interior de la capa hemidesmosomal, explicaría la formacion de las ampollas, que le son características de la enfermedad y alteraciones descritas en la laminina 5 (genes LAMA3, LAM63 y LAMC2), la integrina $\alpha 6 \beta 4$ (genes ITGA6 y ITGB4) y el colágeno XVII (COL17A1). Otras mutaciones relacionadas con la forma distrófica, (gen COL7A1), se altera el colágeno VII. Esta información podría ser utilizada en el diagnóstico prenatal y perspectivas de tratamiento futuro. Esta enfermedad es poco frecuente, 1/50.000 nacidos vivos, en nuestro país existen reportados 121 casos manejados por la fundación DEBRA que se dedica al manejo de estos paciente. La característica de la enfermedad es la aparición espontánea o al mínimo traumatismo de ampollas, úlceras, heridas en la piel y en las mucosas. El caso es de una lactante de 2 meses, que presenta lesión ampollosa de 1 mes de evolución en pabellón auricular izquierdo manejado como impetigo con flucloxacilina oral y mupirocina tópica ambulatoria, aparición de lesiones con halo eritematoso y contenido seroso en región cervical posterior y muslo izq con signos de necrosis lo que motiva ingreso hospitalario con diagnóstico de ectima gangrenoso. Es evaluada por dermatólogo, quien sospecha lesión penfigoide, cirujano infantil indica manejo como quemadura. $\mathrm{Pa}$ ciente ingresa en buenas condiciones generales, afebril, examenes de laboratorio normales, se aislo en cultivo de secresión de ampollas stafilococo coagulasa (-) sensible a oxaciclina, se manejo con antibióticos endovenosos, al 5 día no mejoraba y aparecen nuevas lesiones en dorso, muslo derecho, región inguinal, gluteos, se generalizarón, afectando mucosa oral, se replantea el diagnóstico, las lesiones fueron evaluadas en conjunto con fotografías, entre asistentes a congreso nacional de dermatología, se concluyó epidermolisis bullosa, se toman biopsias, las que confirman Epidermolisis Bullosa Tipo I, esto cambió radicalmente la conducta, se agrega analgesia, cuidado de la piel, punción de las ampollas precoz. La paciente fue contactada con Fundación DEBRA, y consultorio APS. Conclusiones: Este caso deja la enseñanza de cómo métodos no tradicionales en la clínica diaria, pudieran cambiar el manejo de un paciente, como lo fue compartir una fotografía. Desafío aparte del diagnóstico fue decidir dar el alta para lo que necesariamente requerimos en este caso de una ONG y la APS. 
ENFERMEDAD DE LYME PRIMARIA, PRESENTACIÓN DE UN CASO CLÍNICO

Fuertes $\boldsymbol{P}$, Jory $M$.

Unidad de Dermatología, Hospital Exequiel González Cortés.

Introducción: La enfermedad de Lyme, es una enfermedad infecciosa multisistémica causada por la espiroqueta Borrelia burgdorferi, que es trasmitida por garrapatas. Su forma primaria se caracteriza por una lesión roja y solevantada en la zona de la picadura, síntomas gripales y artralgias, y posteriormente síntomas cardíacos y neurológicos que pueden conducir incluso a la muerte. El diagnóstico se certifica con IgM para el agente y/o biopsia de la zona afectada, tratándose con amoxicilina, lo que evita la cronicidad, complicaciones y secuelas. Caso clínico: Paciente mujer de 7 años, sin antecedentes de picaduras de insectos, infecciones concomitantes y con un perro sano en casa. Una semana previa a la consulta inicia en forma aparentemente espontánea lesión redondeada de 7 centímetros de diámetro en su rodilla izquierda, con aumento de tamaño centrífugo, sensación febril, artralgias, sin otras manifestaciones sistémicas. Consulta múltiples veces en servicios de urgencia, recibiendo corticoide endovenoso en una oportunidad como tratamiento. Al momento de la consulta dermatológica la lesión es anular, infrarrotuliana izquierda, de un diámetro de $12 \times 7$ centímetros con rodete eritematoso de 1 centímetro, con lesiones ampollares aisladas en esa zona. La piel de la zona es tibia y brillante, presentando dolor articular a flectar la pierna, sin otros síntomas ni signos al examen físico. Se plantea enfermedad de Lyme, solicitándose biopsia de piel, cultivo de lesiones ampollares e IgM para borrelia burgdorferi. Se inicia tratamiento con amoxicilina, con regresión completa de la lesión 10 días después. Posteriormente se conocen resultados de exámenes, con lgM negativa para borrelia y biosia que muestra vasculitis y perivasculitis dérmica de predominio linfocítico, compatible con Enfermedad de Lyme. Conclusión: Pese a ser una enfermedad infrecuente en el hemiferio sur, es importante de conocer, sospechar y derivar en caso necesario dada la importancia de un pronto diagnóstico y tratamiento para evitar la cronicidad y secuelas que esta enfermedad puede provocar. Así mismo, las medidas higiénicas y de control de ectoparásitos y animales domésticos son relevantes para evitar estas infecciones.

\section{PRIMOINFECCIÓN POR VIRUS HERPES SIMPLEX EN LACTANTE DE 5 MESES}

Zegpi TMS, Pinto SC, Viñuela CJ, Sandoval OM.

Departamento de Dermatología, Pontificia Universidad Católica de Chile.

Introducción: Las infecciones por Virus Herpes Simplex (VHS) tipos 1 y 2 son diversas y bastante comunes en niños. El panadizo herpético es considerada una primoinfección que compromete los dedos, adquirida por inoculación directa o por autoinoculación desde mucosas infestadas por VHS. Habitualmente causado por el VHS-1, aunque también puede ser producido por el VHS-2. Caso clínico: Lactante de 5 meses sin antecedentes mórbidos, consulta por cuadro de una semana de evolución caracterizado por una ampolla en el tercio distal de dedo pulgar izquierdo asociado a una lesión similar de 1 día de evolución localizada en el dedo meñique ipsilateral. Al examen físico febril, irritable, ampolla tensa en 1/3 distal dedo pulgar izquierdo, sobre base eritematosa y edema perilesional. Vesículas agrupadas sobre fondo eritematoso en dedo meñique. En base a estos antecedentes se sospecha de un panadizo herpético. Se solicitó PCR que resultó positiva para virus Herpes tipo 1. Se manejó con aseo quirúrgico, curaciones periódicas y Aciclovir oral $400 \mathrm{mg} / 5 \mathrm{ml}$ a dosis de $2 \mathrm{cc} \mathrm{c} / 4 \mathrm{~h}$ por 10 días con excelente respuesta clínica a la semana de evolución y curación total a los 13 días. Discusión: El diagnóstico se realiza en base a los hallazgos clínicos, aunque a veces es necesario el uso de tests de laboratorio confirmatorios. Dentro de estos tests destacan el cultivo viral, la PCR para VHS-1 y VHS-2, el tes de Tzanck, la inmunofluorescencia directa y la detección de antígenos. Actualmente están disponibles tests serológicos tipo-específicos simples basados en las diferencias antigénicas en la glicoproteína G entre VHS-1 y VHS-2, lo que representa una ventaja con respecto a los test serológicos previos que no permitían hacer esta diferencia. La mayoría de las infecciones por VHS no requieren tratamiento específico. Éste se indica para las infecciones con tendencia a la prolongación, altamente sintomáticas, o complicadas. Aciclovir $15 \mathrm{mg} / \mathrm{kg}$ de peso 5 veces al día por 7 días es la dosis más utilizada para la primoinfección por VHS en población pediátrica. Valaciclovir y famciclovir podrían ser de similar efectividad, sin embargo, aún no han sido estudiados en este ámbito y tampoco está aprobado su uso en niños.
CELULITIS: UNA PIODERMITIS FRECUENTE EN PACIENTES PEDIÁTRICOS

Arellano $\mathbf{J}^{1}$, Orellana $Y^{1}$, Muñoz $M^{2}$, Riquelme $M^{3}$.

'Internos de Medicina, Universidad de Santiago de Chile. ${ }^{2} P e d i a t r a$, Servicio de Pediatría Hospital El Pino, San Bernardo. ${ }^{3}$ Médico Dermatólogo.

Introducción: Las piodermias son infecciones bacterianas de la piel y sus estructuras asociadas. Destacan en frecuencias las foliculitis, impétigo, erisipela y celulitis, siendo esta ultima la más importante ya que puede generar en su evolución una fasceitis necrotizante. La celulitis se extiende en la dermis y en parte del tejido subcutáneo. El Stphylococcus Aureus y los estreptococos del grupo A, son por lejos los agentes implicados con mayor frecuencia. (Aunque cualquier otra bacteria podría potencialmente generar una piodermia). Por lo general se asocian a algún trauma pequeño u otra puerta de entrada para la bacteria. Es importante la ubicación ya que podría comprometer órganos y estructuras importantes. Objetivo: Realizar una descripción clínico epidemiológica de los pacientes hospitalizados con el diagnóstico de Celulitis en el Servicio de Pediatría del Hospital El Pino, durante el período comprendido entre Enero 2006-Julio 2008. Materiales y Métodos: Estudio descriptivo restrospectivo. Se revisaron las estadísticas de todos los egresos hospitalarios del Servicio de Pediatría entre Enero 2006-Julio 2008 y se seleccionaron todos los pacientes con diagnóstico de celulitis. Realizamos un análisis descriptivo de las características clínicas de los pacientes seleccionados. Resultados: Se seleccionaron un total de 32 pacientes, $41 \%$ (13) hombres y $59 \%$ (19) mujeres. La edad promedio al momento del ingreso fue: $69,8 \pm 42,3$ meses y el tiempo promedio de hospitalización fue: $3,4 \pm 2,3$. Según localización de la celulitis: $25 \%$ eran periorbitarias, $40 \%$ faciales (no periorbitarias), $22 \%$ en miembros inferiores, $7 \%$ en región inguinal, $3 \%$ cervical y $3 \%$ en miembro superior. Destaca como foco de entrada en un $65 \%$ foco dental, $32 \%$ traumatismos (mordedura de perro, gratage, lesiones punzantes, etc) y $3 \%$ secundario a un adenoflegmón. No se realizo cultivo en ningún paciente. Conclusión: Las piodermias son lesiones frecuentes en todas las edades, especialmente en la edad pediátrica. El tratamiento de la celulitis es de vital importancia ya que su evolución puede ser rápida pudiendo comprometer órganos importantes y generar compromiso vital, por lo que el tratamiento debe instaurarse precozmente. Respecto a la localización, los resultados son concordantes a lo descrito en la literatura siendo la región facial la afectada con mayor frecuencia en pacientes pediátricos. Es posible prescindir de cultivos, sin embargo, se recomiendan en los casos en que el tratamiento falla o la evolución es tórpida.

\section{INCONTINENCIA PIGMENTI: A PROPÓSITO DE UN CASO}

Arellano $\mathbf{J}^{\mathbf{1}}$, Orellana $\mathrm{Y}^{1}$, Hernández $\mathbf{M}^{2}$, Vera $M^{3}$ ${ }^{1}$ Interno de Medicina, Universidad de Santiago de Chile. ${ }^{2}$ Infectologa Pediatra, Hospital el Pino. ${ }^{3}$ Neonatologa, Hospital El Pino.

Caso Clínico: Recién nacido de término de 40 semanas adecuado para la edad gestacional, sexo masculino, nació por parto vaginal, primer hijo de padres sanos sin consaguinidad. Se recibe recién nacido y se objetivan lesiones pápulocostrosas de distribución lineal en las cuatro extremidades, pero más numerosas y confluentes en extremidad inferior izquierda. Se solicita evaluación por Infectología pediátrica, por sospecha de herpes connatal. Por las características clínicas de la lesión se solicita además evaluación por dermatología y exámenes de screening infeccioso: cultivo de piel, cultivo para hongos, serología para rubeola, toxoplasma, chagas, citomegalovirus y virus herpes, todos los cuales resultaron negativos. A los dos meses de edad algunas de las lesiones habían adoptado un aspecto hipopigmentado y atenuado. Se decide completar estudio con biopsia, en la cual se objetiva a nivel de epidermis queratinocitos disqueratócicos, en dermis papilar se observan melanófagos, histiocitos y focos de infiltrado linfocitario, hallazgos concordantes con Incontinencia Pigmenti en estadio pigmentoso post inflamatorio. Discusión: La incontinencia pigmenti, llamada también síndrome de Bloch-Sulzberger, es un desorden raro, de herencia dominante ligada al X. Se presenta casi exclusivamente en mujeres, puesto que casi todos los varones mueren en la etapa perinatal a menos que su cariotipo sea 47XXY. Los hallazgos dermatológicos son los primeros en presentarse y se dividen en 4 estadios: vesicular o inflamatorio, verrucoso, pigmentario y atrófico. Los hallazgos histopatológicos difieren en cada uno de ellos. En el manejo de las lesiones de piel se consideran sólo medidas generales puesto que van a la resolución espontánea. En el estadio vesicular, se puede usar soluciones astringentes a modo de compresas, opinamos que el empleo de antibióticos podría considerarse en esta etapa si las medidas higiénicas no fueron adecuadas al momento del ingreso. Lo más importante es el seguimiento multidisciplinario y el consejo genético. 
DERMATOSIS EN PACIENTES HOSPITALIZADOS EN EL SERVICIO DE PEDIATRÍA, HOSPITAL CLÍNICO UNIVERSIDAD DE CHILE

Arellano $\mathbf{J}^{\mathbf{1}}$, Orellana $Y^{\prime}$, Saavedra $T^{2}$, Ramírez $\boldsymbol{\beta}^{\beta}$.

${ }^{1}$ Internos de Medicina, Universidad de Santiago de Chile. ${ }^{2}$ Dermatóloga, Servicio de Dermatología Hospital Clínico Universidad de Chile. ${ }^{3}$ Becado de Dermatología, Hospital Clínico Universidad de Chile.

Introducción: Las patologías cutáneas son una causa importante de interconsultas, ya que la afectación puede ser primaria de la piel o secundaria a algún compromiso sistémico o de órganos internos. Por lo general las dermatosis se clasifican en 3 grandes grupos Inflamatorias, Infecciosas y Tumorales; siendo las más frecuentes en edades pediátricas las infecciosas, patologías que todo pediatra esta capacitado para manejar; no obstante en patologías de otras etiologías la necesidad de evaluación dermatológica especializada seria importante para lograr un manejo integral de los pacientes hospitalizados. Objetivos: Descripción clínico-epidemiológica de los pacientes hospitalizados en el servicio de Pediatría del Hospital Clínico Universidad de Chile (HCUCH) a los cuales se les solicitó una evaluación especializada por Dermatología. Materiales y Métodos: Se realizo un estudio de tipo descriptivo y retrospectivo; para lo cual se reviso el libro de registro de las interconsultas realizadas por dermatología entre el período de Abril/2007-Mayo/2008. Se incluyó en el estudio todos los pacientes que requirieron evaluación dermatológica estando hospitalizados en el Servicio de Pediatría del HCUCH y se realizó un análisis clínico epidemiológico. Resultados: De un total de 541 interconsultas, $20(3,6 \%)$ fueron realizadas en e servicio de Pediatría durante el período estudiado. Nueve (45\%) correspondieron a pacientes de sexo masculino y $11(55 \%)$ a sexo femenino. La edad promedio de los pacientes interconsultados fue $6,8+4,2$ años. Se clasificaron las patologías en grupos: $50 \%$ (10) correspondió a patologías inflamatorias, todas fueron dermatitis (2 vasculares, 6 medicamentosas y 2 alérgicas); $25 \%$ (5) Infecciosas (todos etiología viral); $20 \%$ (4) Otras (Miliaria rubra, dermatosis artefacta y exantemas no virales) y $5 \%$ (1) Tumoral secundario a linfoma cutáneo. Conclusión: Las dermatosis que requirieron ser interconsultadas fueron inflamatorias en su mayoría, esto podría deberse a dos factores: 1) las patologías inflamatorias se presentan con clínica evidente y fácilmente pesquisable por el medico no especialista; 2) el segundo grupo de patologías que según la literatura podría se igualmente frecuente serian las infecciosas, sin embargo, es importante destaca que el pediatra esta capacitado para diagnosticar y tratar la gran mayoría de estas dermatosis, por su frecuencia en la edad pediátrica, requiriendo ser sólo las presentan características clínicas diferentes de lo habitual.

\section{TRASTORNOS MENSTRUALES EN ADOLESCENTES CON DIABETES MELLITUS TIPO 1 (DM1) EN TRATAMIENTO INTENSIFICADO (TI)} SE RELACIONAN A DOSIS DE INSULINA Y CONTROL METABÓLICO

Gaete $X^{\prime}$, López $P^{2,5}$, Vivanco $\boldsymbol{M}^{\prime}$, Eyzaguirre $F^{2}$, Unanue $N^{2}$, Rhumie $K^{3}$, Iñiguez $G^{2}$, Pérez $F^{4}$, Cassorla F', Codner $E^{2}$.

${ }^{1}$ Hospital Roberto del Río. ${ }^{2}$ IDIMI, Facultad de Medicina, Universidad de Chile ${ }^{3}$ Hospital Sótero del Río. ${ }^{4}$ INTA, Universidad de Chile. ${ }^{5}$ Hospital San Borja Arriarán.

Objetivo: Evaluar si las pacientes DM1 con TI tienen trastornos menstruales en un estudio prospectivo controlado y determinar su relación con control metabólico y dosis de insulina. Diseño: Estudio prospectivo con grupo control. Método: Se reclutaron 57 adolescentes DM1 postmenárquicas, usando $\geq 3$ dosis diarias de insulina y 56 adolescentes sanas reclutadas en colegios (C). Ambos grupos fueron pareados por edad ginecológica, e índice de masa corporal (IMC). Se realizó registro prospectivo de menstruaciones por 6 meses consecutivos. Se evaluó promedio $(\mathrm{Pr})$ y variabilidad de los ciclos mediante el coeficiente variación (CV) de la duración de los ciclos, prevalencia de amenorrea (> 90 d), oligomenorrea $(>45 \mathrm{~d})$ y polimenorrea $(<25 \mathrm{~d})$. Se determinó por regresión lineal el efecto del IMC, HbA1c, dosis y $\mathrm{N}$ de inyecciones diarias de insulina sobre Pr y CV del ciclo. Resultados: Las niñas DM1 presentaron mayor $\mathrm{Pr}$ $\mathrm{CV}$, y frecuencia de oligomenorrea y amenorrea (Tabla). La HbA1c $(B=5,3 ; p<$ $0,001)$ fue el único factor determinante sobre $\mathrm{Pr}$, y la dosis diaria de insulina $(B=$ 12,$5 ; p=0,04$ ) fue el único factor determinante sobre el CV.

\begin{tabular}{lrr}
\hline & \multicolumn{1}{c}{ DM1 } & \multicolumn{1}{c}{$\mathbf{C}$} \\
& \multicolumn{1}{c}{$(\mathbf{N}=\mathbf{5 7})$} & \multicolumn{1}{c}{$\mathbf{( N = 5 6 )}$} \\
\hline Edad (años) & $15,3 \pm 1,8$ & $14,7 \pm 1,5$ \\
BMI SDS & $0,6 \pm 0,6$ & $0,7 \pm 0,8$ \\
Duración ciclos (días) & $48,4 \pm 38,6$ & $32,0 \pm 7,0^{*}$ \\
CV (\%) & $30,2 \pm 19,2$ & $23,7 \pm 18,4^{\star}$ \\
Oligomenorrea (\%) & 59,6 & $19,6^{*}$ \\
Amenorrea (\%) & 12,1 & $1,7^{*}$ \\
\hline $\mathrm{p}^{*}<0,05$ & &
\end{tabular}

Conclusión: Las adolescentes con DM1, con tratamiento intensificado, presentan más alteraciones del ciclo menstrual que las niñas C. Las alteraciones del ciclo se asocian con el uso de mayores dosis de insulina y a un deficiente control metabólico.

\section{CARACTERIZACIÓN DE LA TELARQUIA PRECOZ. EVOLUCIÓN Y TEMPORALIDAD}

Vivanco $\boldsymbol{M}^{\boldsymbol{1}}$, Pezo $\boldsymbol{C}^{2}$, Gaete $X^{1}$.

${ }^{1}$ Unidad de Endocrinología Hospital Roberto del Río. ${ }^{2}$ Interno Medicina, Universidad de Chile.

Introducción: La telarquia precoz es un motivo de consulta frecuente en endocrinología infantil y algunas de ellas son seguidas por largos períodos de tiempo. Existen pocos trabajos sobre la evolución natural de dicha condición y no existe ninguno reciente en nuestro país. Objetivo: Caracterizar la evolución natural de las pacientes en control por telarquia prematura. Método: Se revisaron retrospectivamente las fichas de las pacientes controladas en el policlínico de endocrinología del Hospital Roberto del Río con el diagnóstico de telarquia precoz entre los años 2005-2008. Se evalúo el porcentaje que evoluciona hacia la resolución espontánea, hacia pubertad normal o hacia pubertad precoz y además se describe la temporalidad de dichos eventos. Los resultados se expresan en porcentaje y se realiza estudio estadístico de $\chi^{2}$ con corrección de yates considerando una significancia con un $p<0,05$. Resultados: Entre los años estudiados consultaron 120 pacientes con el diagnóstico de telarquia precoz, $5 \%$ (6) abandonaron controles. De las 114 pacientes seguidas, $45,8 \%$ (55) correspondieron a telarquias que se inician en el período neonatal (TN). La edad de inicio del resto de las pacientes fue de $54 \pm 29,9$ meses (4-95). (TP). De las TN $96 \%$ (53) se resolvieron espontáneamente, siendo la edad de resolución los $34 \pm 23$ meses (7-114). Del grupo de TP 6,7\% (4) evolucionaron a pubertad precoz, $54 \%$ (32) resolvió su telarquia y $38 \%$ (23) no desapareció y evolucionaron hacia pubertad normal (12), adelantada (2) o aún no han iniciado pubertad (9). Al comparar los estudios imagenológicos (edad ósea y ecografía ginecológica) realizados al comienzo del seguimiento de las pacientes que presentaron pubertad precoz con los de las que no la desarrollaron, no hubo diferencias estadísticamente significativas entre ambos grupos. Conclusión: Un porcentaje importante de las telarquias se resuelven espontáneamente. Las TN en su mayoría se resuelven, siendo la edad de resolución en promedio mayor de 24 meses. Si bien los cambios en la ecografía ginecológica y la edad ósea son importantes para orientar en el diagnóstico de pubertad precoz no servirían para predecir qué niña con telarquia desarrollará a futuro una pubertad precoz, lo que sugiere que estas pacientes deben continuar en control estricto por especialista.

DIFICULTADES EN EL DIAGNÓSTICO DE INSULINORESISTENCIA EN NIÑOS: LA IMPORTANCIA
LA MEDICIÓN DE INSULINA

Molina $\mathbf{M}^{1}$, Eugenin $D^{2}$, Bancalari $R^{2}$, Vergara $M^{2}$, Bobadilla $E^{2}$, García $H^{1}$. Departamento de Pediatría Pontificia Universidad Católica de Chile y Clínica Santa María-Universidad de los Andes ${ }^{2}$.

Introducción: Obesidad y Resistencia Insulínica (Rl) constituyen una epidemia mundial. La medición de Insulina y Glicemia en ayunas constituye uno de los mejores métodos disponibles clínicamente. Para ello es fundamental que el método de medición de Insulinemia sea confiable y reproducible. Objetivo: Comparar y correlacionar 2 de los métodos más utilizados en medición de insulina. Material y Métodos: Se analizó el plasma obtenido, con consentimiento informado, de 130 escolares sanos de 9 a 14 años de edad, cuyo estado nutritivo se clasificó como Obeso, Sobrepeso o Normal en $40 \%$, 33\% y 24\%. En ellos se midió en forma paralela Insulina por Radioinmunoanalisis (RIA) monoclonal con mínima lectura cruzada $(0,2 \%)$ con Proinsulina (LINCO) y quimioluminiscencia (QM) (IMMULITE 2000) de uso habitual en nuestro laboratorio, que posee muy buena sensibilidad, y $8 \%$ reacción cruzada con Proinsulina. Además se midió Glicemia y se calculó HOMA en cada caso. Resultados: Ambas series tienen una distribución normal. Los resultados de QM y RIA fueron 10,3 + 4,7 y 22,1 + $8,8 \mathrm{uUi} / \mathrm{ml}$ respectivamente. Utilizando $2 \mathrm{DS}$ como criterio de normalidad, QM excluye 12 y RIA 9 casos, de los cuales 6 casos son comunes a ambos métodos.La correlación entre ambos métodos se muestra en gráfico. Glicemia 90,4 $\pm 5,7$ mg\% y el HOMA $1,98 \pm 1,16$ vs $4,5 \pm 1,85$ en QM y RIA respectivamente. Conclusiones: Ambos métodos se correlacionan adecuadamente pero con valores significativamente menores de QM vs RIA. Nuestros datos demuestran que antes de establecer puntos de corte como diagnóstico de RI, debe considerarse el método utilizado así como los valores propios de cada población. 
CROMOSOMAS EN ANILLOS: UNA CAUSA DE TALLA BAJA

Molina $\mathbf{M}^{1}$, Martínez $A^{1}$, García $H^{1}$, Valdebenito $C^{1}$, Aracena $M^{1}$, Repetto $G^{2}$, Bassaure $J^{3}$

Departamento de Pediatría Pontificia Universidad Católica de Chile', Universidad del Desarrollo-Clínica Alemana², Hospital Alberto Hurtado ${ }^{3}$.

El Síndrome del cromosoma en Anillo (SdCA) tiene una gran variabilidad fenotípica, dependiendo del cromosoma y banda afectada, pero la talla baja es común. Dependiendo de las bandas comprometidas, el uso de hormona de crecimiento podría ser cuestionable. Objetivo: Presentar dos pacientes con talla baja cuyo cariograma mostraba un cromosoma en anillo. Caso 1: Consultó a la edad de 9 años 11 meses por talla baja, $129 \mathrm{~cm}(-1,4 \mathrm{DE})$ y pubarquia prematura. PesoRN 2.520 gr (-1,6 DE) y L-RN 44 cm (-2,2 DE); relación Edad ósea (EO)/Edad cronológica $(E C)=1,35$; microcefalia, asimetría facial, clinodactilia y sindactilia cutánea entre el 2 y 3 ortejo. Se descartaron causas de hiperandrogenismo e inició uso de $\mathrm{GH}(0,15 \mathrm{U} / \mathrm{Kg} / \mathrm{d})$ y letrozol $(5 \mathrm{mg} /$ día) por un año y luego LHRHa. Su último control fue a la edad de 12 años 8 meses con una talla de $145,4 \mathrm{~cm}$, 1,07 DE (delta talla $+0,33 \mathrm{DE}$ ), la relación $E O / E C=1$. Caso 2: Consultó a la edad de 11 meses por talla baja, Peso-RN $3.665 \mathrm{gr}(0,2 \mathrm{DE})$ y L-RN $51 \mathrm{~cm}(0,38$ $\mathrm{DE})$, pérdida de velocidad de crecimiento desde los 3 meses de vida, relación $\mathrm{EO} / \mathrm{EC}=0,7$; dismorfias faciales, retraso desarrollo psicomotor. Se descartaron causas de malabsorción. La prueba de glucagón mostró un peak de $\mathrm{GH}$ de $>40$ $\mathrm{ng} / \mathrm{mL}$ con IGF-1 $90 \mathrm{ng} / \mathrm{ml}$, sugerente resistencia a GH. Su último control fue a la edad de 4 años 4 meses con una talla $88 \mathrm{~cm}$ en $-3,7 \mathrm{DE}$ (delta talla $+0,3 \mathrm{DE}$ ) El caso 1 presentaba un cromosoma en anillo $13(r(13)(p 11 ; q 34))$, los pacientes reportados presentan retardo mental en grado variable, microcefalia, dismorfias, talla baja. El caso 2 presentaba un cromosoma en anillo $18(r(18)$ (p11.1q21), un reporte describe deficiencia de $\mathrm{GH}$ e hipotiroidismo en un paciente con cromosoma en anillo 18. Comentarios: En pacientes con talla baja y dismorfias se debe descartar anormalidades cromosómicas. La existencia de un cromosoma en anillo puede tener implicancias en su tratamiento, eficacia y seguridad.
EVALUACIÓN DE UN PROGRAMA INTEGRAL DE TRATAMIENTO DE LA OBESIDAD EN NIÑOS ESCOLARES Y ADOLESCENTES EN SANTIAGO DE CHILE (1999-2006)

Flores CJC, Eyzaguirre CF, García FG, Vega NV, Cosentino AM, Silva AR, Román RR, Cavada CG, García BH.

Pontificia Universidad Católica de Chile.

Introducción: La obesidad y sobrepeso constituyen actualmente una epidemia mundial. En Chile entre 1986 y 1998, la prevalencia de malnutrición por exceso según criterio CDC-2000, aumentó desde $12,6 \%$ a $49,1 \%$ en varones de 6 a 11 años, y desde $14,9 \%$ a $40,2 \%$ en mujeres de 6 a 9 años respectivamente. Los riesgos de niños obesos para desarrollar resistencia insulínica, hiperlipidemia, y HTA están claramente establecidos, y la mayoría permanece con obesidad en la etapa adulta. No existe consenso acerca del mejor tratamiento, aunque la evidencia indica que programas multidisciplinarios parecen ser los más beneficiosos. Objetivo: Evaluación del programa integral de obesidad para niños y adolescentes de la Clínica Santa María. Pacientes y Métodos: Estudio prospectivo, en el cual se evaluaron 324 niños ( 155 hombres, 169 mujeres) entre 5,4 y 18 años, que ingresaron al programa entre 1999 y 2006. La intervención consistió en un trabajo multidisciplinario que combinaba dieta, actividad física y apoyo psicológico. Se tabularon las siguientes variables iniciales: edad, peso, talla, IMC, desviación estándar del IMC (zIMC), diagnóstico nutricional, HTA, síndrome metabólico (SM), porcentaje de grasa, circunferencia de cintura, insulina/glicemia de ayuno, y perfil lipídico. Al finalizar el programa se midió peso, talla, IMC y zIMC. Se realizó un análisis comparativo del cambio del zIMC, asociándolo con las otras variables para evaluar predictores de la respuesta. Resultados: Inicialmente, un $17,8 \%$ de los pacientes cumplía con los criterios definidos para SM, y un $4.9 \%$ presentaba HTA. Durante el programa, se observó una baja de peso que fue estadísticamente significativa, con una diferencia entre el zIMC inicial y final, de $-0,28$ (IC 95\%: $-0,31$ a $-0,25, p<0,001$ ), sin diferencia entre ambos sexos. Un $60 \%$ de los pacientes logra bajar más del $5 \%$ de su peso inicial. Las únicas variables que fueron predictoras del cambio de zIMC, fueron el tiempo de permanencia en el programa, a favor de la baja de peso, y la circunferencia de cintura inicial, que se asoció a una falta de respuesta. Se pudo estimar además, que durante el tiempo de intervención, los pacientes logran disminuir el zIMC en 0,05 puntos por mes (IC 95\%: $-0,07$ a $-0,025, p<0,001$ ). Conclusiones: En niños y adolescentes, ingresar a un programa multidisciplinario de obesidad logra una baja de peso sostenida, que es directamente proporcional al tiempo de permanencia en control, lo cual aconseja intervenciones prolongadas.

\section{CÁNCER DE TIROIDES EN LA INFANCIA. DIAGNÓSTICO, MANEJO Y SEGUIMIENTO}

Peñaloza PG, Gleisner EA, Torres BC, Asenjo MS, Rojas CS, Cordero P. Hospital Guillermo Grant Benavente (HGGB), Universidad de Concepción.

Introducción: El cáncer tiroídeo es una neoplasia rara en la infancia. Su debut es más agresivo que en el adulto, sin embargo, su evolución es más favorable. Objetivo: Caracterizar los casos de cáncer tiroídeo diagnosticados en nuestro centro. Material y Método: Se realizó un estudio descriptivo que analizó todos los casos de cáncer tiroídeo diagnosticados en el policlínico de endocrinología infantil del HGGB entre enero de 2005 y septiembre de 2008, determinándose su presentación, diagnóstico, histología y terapia. Resultados: En el período estudiado se evaluaron 11 casos de nódulos tiroídeos. De ellos 5 resultaron malignos. La edad al diagnóstico (promedio \pm DS) fue 12,4 \pm 2 años. Cuatro pacientes son de sexo femenino. Ningún menor tenía antecedentes de patología tiroidea o neoplásica previa. Todos debutaron con aumento de volumen cervical anterior no doloroso. El tiempo de evolución previo a la primera consulta fue en promedio 9,2 meses. En $3 / 5$ se encontró nódulo único. El tamaño promedio fue $24 \pm 11$ $\mathrm{mm}, 3 / 5$ de consistencia dura, y con adenopatías sospechosas $3 / 5$. La ultrasonografia describió nódulo único en $3 / 5$, tamaño promedio $26,2 \pm 14,5 \mathrm{~mm}$. Ecogenicidad disminuida en $2 / 5$, contenido heterogéneo en $3 / 5$, contorno bien definido en $3 / 5$. Microcalcificaciones en $2 / 5$ y aumento de la vascularización al Doppler en $4 / 5$. Adenopatías en $4 / 5$. El cintigrama tiroídeo mostró nódulo frío en $3 / 5$, caliente en $1 / 5$ y mixto en $1 / 5$. Función tiroidea normal en todos los menores. La conducta fue tiroidectomía total más vaciamiento cervical en todos los casos. No hubo complicaciones posquirúrgicas. La biopsia mostró cáncer papilar en $4 / 5$ ( $2 / 5$ difuso y $2 / 5$ variedad folicular) y cáncer tipo folicular $1 / 5$. Compromiso de bordes y metástasis a distancia en 2/5. Los 3 casos localizados recibieron terapia ablativa con radioyodo $100 \mathrm{mCi}$, con buena respuesta. Evolución posterior asintomática. Los 2 casos metastáticos permanecen asintomáticos, con indicación de radioyodo $150 \mathrm{mCi}$. Conclusión: El cáncer de tiroides es una patología rara pero agresiva en la infancia y su pronóstico depende de un diagnóstico y manejo precoz. 


\section{RELACIÓN CINTURA/TALLA COMO PREDICTOR DE RIESGO CARDIOMETABÓLICO EN NIÑOS}

Bancalari $\boldsymbol{R}^{1}$, Díaz $C^{2}$, Barja $S^{2}$, Acevedo $M^{2}$, Aglony $M^{2}$, Zamorano $J^{1}$, Garbin $F^{1}$, Cerda V', Cavada $G^{1}$, Valenzuela $M^{1}$, Fernández $M^{1}$, Muñoz $P$, Arnaiz $P^{2}$, García $H^{2}$

${ }^{1}$ Departamento Pediatría Universidad de los Andes. ${ }^{2}$ Departamento Pediatría Pontificia Universidad Católica de Chile.

Introducción: Tanto la Obesidad como la grasa visceral en niños se asocia con riesgo cardiometabólico en la vida adulta. La presencia de síndrome metabólico (SM) se considera un predictor objetivo de este riesgo en todas las edades. Estudios realizados en niños sugieren que la relación cintura/talla $(C / T)$ sería un mejor predictor de SM que el índice de masa corporal (IMC). Objetivo: Comparar la capacidad del IMC vs la relación C/T para identificar niños chilenos con riesgo cardiometabólico, expresado como SM. Sujetos y Método: Estudio transversal de 618 escolares, de 10,6 +2,2 años, (51,6\% mujeres), 179 eutróficos, 177 sobrepeso y 252 obesos, de estrato socioeconómico medio bajo, pertenecientes al área urbana de Santiago. En ellos se midió peso, talla, perímetro de cintura, perfil lipídico, glicemia, presión arterial sistólica y diastólica. Se determinó valor $z$ de IMC ( $\mathrm{z} I \mathrm{MC}$ ), relación $\mathrm{C} / \mathrm{T}$ y la presencia SM con $\geq 3$ criterios de Cook (Cintura $\geq$ p90; Hipertensión arterial $\geq$ p90; Trigliceridos $\geq 110$ $\mathrm{mg} / \mathrm{dl}$; Col HDL $\leq 40 \mathrm{mg} / \mathrm{dl} ; \mathrm{y}$ Glicemia $\geq 100 \mathrm{mg} / \mathrm{dl}$ ). El SM fue modelado en función de la relación $\mathrm{C} / \mathrm{T}$ y el z IMC mediante modelos de regresión logística, la capacidad de discriminación de los mismos fue evaluado a través de la curva ROC. Para la sensibilidad y especificidad del modelo se utilizó el índice de YOUDEN. Resultados: La prevalencia de SM fue 15,37\%, considerando que la población de obesos en esta muestra esta sobrerepreresentada. El promedio z IMC: fue $+1,22 \pm 0,90$ y la relación C/T: 0,52 $\pm 0,07$.

\begin{tabular}{lccccc}
\hline & $\begin{array}{c}\text { Punto de } \\
\text { corte SM }\end{array}$ & $\begin{array}{c}\text { Sensibi- } \\
\text { lidad (\%) }\end{array}$ & $\begin{array}{c}\text { Especifi- } \\
\text { cidad (\%) }\end{array}$ & $\begin{array}{c}\text { Correctamente } \\
\text { clasificado (\%) }\end{array}$ & LR + \\
\hline Z IMC & 1,72 & 79 & 72 & 73 & 2,76 \\
Relación C/T & 0,56 & 71 & 72 & 72 & 2,54
\end{tabular}

Conclusión: 1) En nuestra muestra de niños urbanos la relación $\mathrm{C} / \mathrm{T}$ y $\mathrm{z} \mathrm{IMC}$ predicen adecuadamente y sin diferencias el riesgo cardiometabólico expresado como SM; 2) Considerando que la medición de cintura es sencilla y reproducible; el cálculo de la relación $\mathrm{C} / \mathrm{T}$ en cualquier escenario ambulatorio, hace de esta una buena herramienta para definir en forma individual el riesgo cardiometabólico en niños.

\section{LA ESTATURA ACTUAL DE NIÑOS CHILENOS DE ESTRATO ECONÓMICO MEDIO-BAJO SE DETERIORA CON RESPECTO A LOS NORTEAMERICANOS A PARTIR DE LOS 11 AÑOS ESPECIALMENTE EN EL SEXO FEMENINO}

Bancalari $\boldsymbol{R}^{1}$, Díaz $C^{2}$, Zamorano $J^{1}$, Cerda $V^{1}$, Garbin $F^{1}$, Fernández $M^{1}$, Valenzuela $T^{1}$, Cavada $G^{1}$, Muñoz $P^{1}$, García $H^{2}$

${ }^{1}$ Departamento de Pediatría Universidad de los Andes. ${ }^{2}$ Departamento de Endocrinología Infantil, Pontificia Universidad Católica de Chile.

Introducción: Se estima que los niños chilenos han aumentado su estatura con respecto a generaciones anteriores pero no existen estudios actuales que lo demuestren. Objetivo: Comparar la estatura de niños chilenos de 6 a 14 años pertenecientes a clase media baja $(\mathrm{CH})$ con la referencia norteamericana (NA) del año 2000 (CDC). Material y Métodos: Estudio transversal de una muestra representativa de 3.010 escolares de clase media baja de Santiago, Chile. Se ellos realizó evaluación antropométrica en 3 oportunidades consecutivas, expresando el resultado como promedio de ellas. Para la determinación de talla se utilizó un estadiómetro fijo de pared. Resultados: De 3.010 niños evaluados la diferencia global de estatura de los alumnos chilenos $(\mathrm{CH})$ y la referencia fue de $-0,06 \pm 0,963(p<0,05)$. Al analizarlos por edad y sexo se observa que los $\mathrm{CH}$ son más altos que los NA a los 6 años: + 0,134 Z $\pm 1,084 \quad(p<0,05)$. Entre 7 a 10 años los niños y niñas $\mathrm{CH}$ son comparables con los NA: $+0,042 \mathrm{Z}$ y $+0,0018$ $Z$ (p: ns). Desde los 11 años los niños $(\mathrm{CH})$ son estadísticamente más bajos que los (NA): $-0,10 Z \pm 1,009,-0,299 Z \pm 0,994$ y $-0,419 Z \pm 0,954(p<0,05)$ situación especialmente marcada en el sexo femenino (figura).

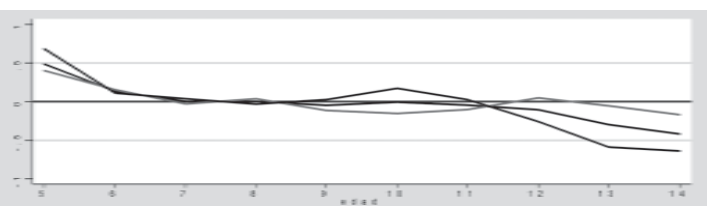

Conclusiones: 1) Los niños $\mathrm{CH}$ de clase media baja son comparables a sus pares NA hasta los 10 años de edad; 2) Desde los 11 años la talla de los $\mathrm{CH}$ comienza a deteriorarse vs los NA, siendo más marcado en mujeres (línea inferior); 3) Esta situación podría deberse a causas genéticas o nutricionales responsables de un estirón puberal más pobre en nuestros adolescentes, observado especialmente en mujeres.
ESTUDIO DE NIVELES DE TSH Y T4 LIBRE EN NIÑOS OBESOS

Sánchez BT, Godoy SJ, García BH, Barja YS

Departamento de Pediatría. Facultad de Medicina. Pontificia Universidad Católica de Chile.

Introducción: Se solicitan estudios de hormonas tiroideas a un alto porcentaje de niños obesos, pero no se conoce en nuestro país la prevalencia de hipotiroidismo en ellos, cuestionándose la justificación de solicitarlas de rutina. Objetivo: Describir en niños obesos chilenos la prevalencia de valores anormales de TSH y T4 libre (T4L), sus niveles y asociación a sexo, edad, desarrollo puberal, grado de obesidad global y abdominal. Método: Estudio transversal, con revisión de fichas clínicas de los niños obesos que consultaron por primera vez a nutrióloga infantil en nuestra institución, entre Enero 2007 y Julio 2008. Se consignó edad, sexo, Tanner, peso, talla, perímetro cintura (PC). Se calculó índice de masa corporal (IMC), z-score IMC e índice peso-talla (IPT). Se registraron valores de TSH y T4L. Resultados: Se obtuvo información de 124 niños, $56 \%$ mujeres, $11,02 \pm 2,8$ años de edad, $43 \%$ prepúberes, zIMC $=1,94 \pm 0,44$ $\mathrm{zTE}=0,18 \pm 0,9, \mathrm{IPT}=146,8 \pm 17,7 \%$ y PC $=83,1 \pm 11 \mathrm{~cm}(133,6 \pm 43 \%$ del pc50). El 14\% presentó obesidad leve (P/T: 120-129), $20 \%$ moderada (P/T: 130 $139 \%), 29 \%$ severa ( $P / T: 140-149 \%$ ) y $37 \%$ mórbida $(P / T \geq 150)$. Hubo más niñas púberes: 75 vs $34 \%\left(\chi^{2} p<0,001\right)$, sin diferencia por sexo en las otras variables. El nivel de TSH fue de 2,6 +1,7 $\mu \mathrm{Ul} / \mathrm{ml}$ y el de T4L $1,26 \pm 0,17 \mathrm{ng} / \mathrm{dl}$. El $4.1 \%$ de los pacientes presentó TSH sobre rango normal $(>5.5$ en prepúberes $\mathrm{y}>4.8 \mu \mathrm{UI} / \mathrm{ml}$ en púberes) y ninguno tuvo T4L disminuido $(<0,8 \mathrm{ng} / \mathrm{dl})$, sin diferencia por sexo, desarrollo puberal, PC ni grado de obesidad. En mujeres se encontró una correlación inversa entre T4L y edad $(R:-0,26, p=0,04)$ y entre TSH y edad ( $R:-0,29, p=0,016)$, al igual que una correlación directa entre TSH y zIMC (R: $0,32, p<0,01)$. Se analizó el cuartil superior para TSH $(>3,40 \mu \mathrm{UI} /$ $\mathrm{ml}$ ), sin encontrarse diferencias en edad, sexo, zIMC, zTE ni PC. Conclusiones: En esta muestra de niños obesos se encontró una baja prevalencia de niveles elevados de TSH. Ésto sugiere la presencia de hipotiroidismo subclínico e implica completar su estudio. En mujeres tanto T4L como TSH disminuyen con la edad y esta última se asocia en forma directa al grado de obesidad. Los niños del cuartil más alto de TSH no presentaron características clínicas que los diferencien de los demás.

\section{ENFERMEDAD DE BASEDOW GRAVES DE PRESENTACIÓN ATíPICA}

Sánchez $A^{1}$, Montoya $M^{1}$, Martínez $G^{1}$, Escobar $P^{2}$, Maturana $M^{3}$, Barría $R^{4}$ ${ }^{1}$ Becadas Servicio de Pediatría Universidad de Concepción. ${ }^{2}$ Unidad de Genética. ${ }^{3}$ Infectólogo Servicio de Pediatría. ${ }^{4}$ Inmuno-reumatólogo Servicio de Pediatría. Hospital Guillermo Grant Benavente, Concepción.

La Enfermedad de Basedow Graves (BG) se caracteriza por bocio, hipertiroidismo y ocasionalmente oftalmopatía. Su prevalencia se estima en 0,1 a 3 casos por 100.000 sujetos. La mayoría de los casos son diagnosticados durante la pubertad, pero se ha descrito que los escolares presentan la enfermedad de forma más severa, caracterizada por una mayor frecuencia de pérdida de peso, diarrea, bocio y taquicardia. Se presenta el caso de una escolar de 9 años, con antecedente de Púrpura de Schonlein Henoch 5 años atrás, Trastorno de déficit Atencional Hiperactivo,y Neuropatía periférica. Ingresa por hematuria macroscópica en el contexto de Faringitis aguda, se pesquisa proteinuria masiva y Pielonefritis aguda. Evoluciona en menos de 24 horas con insuficiencia cardíaca aguda, hipertensión arterial y edema agudo pulmonar. Ecocardiograma evidenció prolapso de la válvula mitral. Presenta ASO elevado pero con descenso breve de complemento que descarta Glomerulonefritis aguda postestreptocócica. Hormonas tiroideas al ingreso normales. Persiste taquicárdica e hipertensa. Nuevo ecocardiograma muestra prolapso valvular mitro tricuspídeo. Se pesquisa bocio difuso sin exoftalmo. Anticuerpos antitiroglobulina y antiperoxidasa elevados, TRAB positivo. Cintigrafía tiroidea muestra bocio difuso leve hipertiroídeo. Evolución y exámenes de laboratorio compatibles con BG por lo que se solicita nuevamente hormonas tiroideas que resultan elevadas, se inicia tratamiento con Propiltiouracilo y Propanolol con respuesta parcial. Presenta diarrea recurrente con estudio de deposiciones negativo. Por hematuria recurrente se sospecha nefropatía por IgA. Ante múltiples patologías autoinmunes se decide buscar diagnóstico integrador descartándose Neoplasia endocrina múltiple y Síndrome Pluriglandular. Se deriva a Hospital Clínico de la Pontificia Universidad Católica para biopsia renal, la cual muestra glomerulopatía con proliferación mesangial leve y membrana basal glomerular delgada sin depósito de complejos inmunes, lo que explicaría la hematuria recurrente. Tras ablación con yodo se logra finalmente el eutiroidismo. La Enfermedad de Basedow Graves puede presentarse atípicamente, de forma insidiosa y asociada a prolapso de la válvula mitral. En esta paciente, por presentar a lo largo de su vida múltiples patologías de orden inmunológico, se pensó en un trastorno endocrino sistémico, finalmente, se concluye que es una forma de presentación atípica, y muy florida, de Enfermedad de Basedow Graves. 

COMA HIPEROSMOLAR: DEBUT DE D. MELLITUS EN ADOLESCENTE
RURAL CON OBESIDAD MORBIDA

Villanueva J, Oyarzo A, González M.

Hospital Base de Puerto Montt.

El aumento de la obesidad en pediatría adelanta patologías del adulto como Dislipidemia y Diabetes tipo 2. Una variante infrecuente en el debut de la diabetes se expone en el siguiente caso. Adolescente 14 años, obeso, sin diabetes familiar con 1 mes de polidipsia y baja de peso de aproximadamente $20 \mathrm{~kg}$. Tras extracción de molar inicia dolor abdominal y vómitos frecuentes agregándose a tercer día compromiso de conciencia siendo llevado al Hospital de Quellón, donde se intuba e hidrata con suero fisiológico y trasladado a Castro y luego a UCIP Hospital de Puerto Montt (13/7/08). Destacando al examen obesidad mórbida, acentuada Acantosis nigricans, y signos de shock. Exámenes: Uremia: 118, pH 7,0. Bicarbonato: 6,3, Leucocitos: 14.200 , Glicemia: 1.041 mg/dl. Creatinina: $3,69 \mathrm{mg} / \mathrm{dl}$, Sodio 173, Potasio 1,98. Diagnóstico de ingreso: Cetoacidosis Diabética grave, coma hiperosmolar y Shock. Evoluciona con falla multiorgánica manejado con ventilación mecánica, drogas vasoactivas, infusión contínua de insulina corrección de hipocalemia e hipernatremia, hemodiálisis por 6 días y Clindamicina 10 días por sepsis oral. Responde con bajos requerimientos de insulina para estabilización metabólica usando esquema intensificado de insulina. Alta al mes asintomático, HGT normales. Insulina 0,2 Ul/kg/día. Exámenes HbA1c 13\%, péptido C $1,91 \mathrm{mg} / \mathrm{ml}$ e ICA (-). Control 27/08: asintomatico, IMC 26,03, disminución de Acantosis y del panículo adiposo. HGT normales, se disminuye insulina $0,1 \mathrm{U} / \mathrm{kg} /$ día. Por evolución clínica sumado a resultados de estudio de laboratorio se plantea Diabetes Mellitus tipo 2, que debutó con un coma hiperosmolar y falla multisistémica debido a consulta tardía.

\section{HEPATITIS AUTOIMMUNE EN EL LACTANTE}

Zuloaga N, Fierro L, Michea $K$

Hospital Carlos Van Buren, Universidad de Valparaíso.

Lactante 11 meses 17 días, sexo masculino, antecedentes perinatales (-), antecedentes mórbidos (-), consulta a Unidad de Emergencia Infantil (UEI) por cuadro de una semana de evolución, caracterizado por diarrea, vómitos alimentarios y fiebre; últimos tres días se agrega ictericia progresiva de piel y escleras. Examen físico: paciente hidratado, afebril, ictericia generalizada, hemodinámicamente estable, Glasgow 15; abdomen blando, depresible, indoloro, sin hepatomegalia. Exámenes UEI: TP: 47,2\%, INR: 1,8, GOT: 4.837, GPT: 4.394 Bilirrubina total $(\mathrm{Bt}): 11.57$, Bilirrubina directa $(\mathrm{Bd})$ : 9,34 , Hematocrito $(\mathrm{Hto})$ : $32,2 \%, \mathrm{Hb}: 11,4$, plaquetas: 176.000 . Ingresa con diagnóstico de Sd. Ictérico en estudio, Obs. Hepatitis aguda viral. Se maneja en UCIMP, dado bajo TP, con vitamina $\mathrm{K}$ im. Evoluciona estable, coluria (-), acolia (-), encefalopatía (-), flapping $(-)$, sin signos de hemorragia activa por lo que se traslada a sala. Dado TP en rango $41 \%$, se continua tratamiento con vitamina $\mathrm{K}$ im por tres días. Exámenes de control al tercer día de evolución: TP: 41,9\%, GOT: 4.032, GPT: 2.696, Bt: 18,4, Bd: 14,5, GGTP: 88 . Se maneja con ácido ursodeoxicólico y lactulosa para hepatoprotección. Evoluciona estable, sin signos de insuficiencia hepática aguda, con ictericia en regresión. Dado ictercia de predominio directo, se realiza ecografia abdominal, informe: normal.Se solicita serología VHA, B, C, VIH, VEB, CMV, resultados (-), screening metabólico en orina y sangre (-). Exámenes 5 día: TP: $43,2 \%$, GOT: 3.020 , GPT: 2.690 , Bt: $21,28, \mathrm{Bd}: 16,51$. Se sospecha de Hepatitis autoinmune, se solicita recuento de Inmunoglobulinas, Anticuerpo antimúsculo liso (ASMA), anticuerpo antinuclear (ANA) y anticuerpo anti-LKM-1. Resultados: Hipergammaglubulinemia, predominio lg $(2.024 \mathrm{mg} / \mathrm{dl})$, ASMA (+). Al 8 día TP: $56,8 \%$, GOT: 1.968, GPT: 1.836, Bt: 18,4, Bd: 14,28. Se solicita biopsia hepática percutánea, informe: tejido hepático desorganizado, trabéculas ensanchadas y congestivas, hepatocitos balonados con multinucleación, obliterando espacio sinusoidal, proliferación fibroblástica que tiende a conectar espacios porta vecinos, infiltrado linfocitario que penetra al lobulillo causando necrosis en sacabocado focal; compatible con Estadio Ishak 3. Se diagnostica Hepatitis autoinmnune tipo I. Evoluciona con mejoría de función hepática, regresión considerable de ictericia. Al alta, día 16: TP: 80,1\%, GOT: 737, GPT: 668, Bt: 13,65, Bd: 10,66 . En control con gastroenterología, se maneja con Prednisona $1 \mathrm{mg} / \mathrm{kg} /$ día, exámenes de control al mes de tratamiento: TP: 106,7\%, GOT: 62 , GPT: 71 , Bt: 4,32, Bd: 3,53, IgG: 1537. En tratamiento actual con ácido ursodeoxicólico, Prednisona (1 mg/kg/día) y Azatioprina $(0,5 \mathrm{mg} / \mathrm{kg} / \mathrm{día})$. Se manejará con dosis decrecientes de corticoides más Azatioprina, con reevaluación de biopsia hepática en 2 años para evaluar estadio de parénquima hepático.

\section{INSUFICIENCIA INTESTINAL EN EL SERVICIO DE PEDIATRIA DEL HOSPITAL DR. GUSTAVO FRICKE. EXPERIENCIA DE 15 AÑOS DE UN EQUIPO MULTIDISCIPLINARIO.}

Schoen K, Chiang M, Reyes H, Reyes J, Ruiz R, Mena J, Torres MT, Cisternas $C$, González $P$, Jofré $P$, González I.

Servicios de Pediatría y Cirugía Infantil Hospital Dr. Gustavo Fricke. Universidad de Valparaíso.

Introducción: La insuficiencia intestinal (II) se define como la reducción critica de la masa intestinal funcional bajo el mínimo necesario para una adecuada digestión y absorción de los nutrientes y fluidos necesarios para satisfacer lo que el organismo requiere para crecer y mantenerse. Existen pocos datos sobre la prevalencia o el impacto económico y humano en la población pediátrica. En general, la experiencia al respecto en nuestro medio se reporta como casos aislados. Objetivo: Describir las causas, evolución, manejo y sobrevida de un grupo de pacientes con insuficiencia intestinal, abordado por un equipo multidisciplinario. Método: Estudio retrospectivo-descriptivo de las historias clínicas de niños portadores de II en un período de 15 años. Resultados: Entre Agosto de 1993 y Agosto de 2008 se identificaron 14 niños entre 4 meses y 14 años de edad actual. Causa de II: 3 Malformaciones intestinales tipo apple-peel, 2 Gastrosquisis, 2 Pseudoobstrucciones intestinales crónicas, 2 Enterocolitis necrotizante neonatal, 1 Gastrosquisis + malformación tipo apple-peel, 1 Enteropatía de tufting, 1 Enterocolitis necrotizante post Cirugía Cardiovascular Compleja, 1 Atresia duodenal con vólvulo intestinal, 1 Enfermedad de Hirschsprung extensa. El tiempo de hospitalización promedio fue 277 días ( 66 a 700). Tiempo de uso NPT promedio 228 días (desde 52a 650). El 50\% logra la adaptación intestinal. Actualmente hay 4 pacientes dependientes de NPT, uno de ellos domiciliaria. Las complicaciones más frecuentes fueron: sepsis por catéter (en 92\%), colestasia asociada a NPT (en $42 \%$ ) y Sd Vena Cava Superior (en 14\%) Sobrevida global $78,6 \%$. Ocho de 11 conservan inadecuado estado nutricional, 2 talla baja. Remanente Intestinal más corto con sobrevida: $18 \mathrm{~cm}$. Conclusión La insuficiencia intestinal significa un gran impacto en la vida del paciente y su familia con largas hospitalizaciones y múltiples complicaciones. El trabajo con un equipo multidisciplinario es esencial para una evolución favorable. Los datos aquí presentados se correlacionan con la literatura.

\section{ENTEROPATÍA EN PENACHO COMO CAUSA DE SÍNDROME DE MALABSORCIÓN CONGÉNITO: REPORTE DE UN CASO}

Martínez LF, Durán HC', Cisterna SC, González I, Jofré P, Tobar A. Servicio de Pediatría, Hospital Gustavo Fricke. Departamento de Pediatría, Facultad de Medicina, Universidad de Valparaíso. 'Internos Pediatría.

La Enteropatía en Penacho (EP) es una enteropatía congénita que se presenta como una diarrea intratable de inicio precoz y que puede causar insuficiencia intestinal. Es una entidad de etiología desconocida que se piensa está relacionada al desarrollo y/o diferenciación anormal de enterocitos. Se presenta el caso de una paciente de 2 años meses de edad, recién nacida de término de padres no consanguíneos, pequeña para la edad gestacional, sin otros antecedentes. Hospitalizada desde los 2 meses de vida por cuadro de diarrea intratable con deposiciones esteatorreicas abundantes asociada a desnutrición crónica descompensada, la cual no tuvo respuesta a tratamiento con sobrealimentación por vía oral. A examen físico se apreció lactante muy enflaquecida, de 2.600 gramos de peso. Fue derivada a nuestro hospital, donde se realizó estudio de malabsorción que incluyó elastasa fecal, electrolitos en sudor, serologías para HIV y CMV, así como ecografía abdominal, siendo todas normales. Ante estos resultados se decide realizar endoscopia digestiva alta para tomar biopsia duodenal, en la que se informa Enteropatía en Penacho o Tufting. Por falta de incremento ponderal se inicia nutrición parenteral total (NPT) a los 70 días de vida, la cual mantiene hasta la fecha, presentando múltiples episodios de infección de catéter venoso que han obligado a su retiro, a la vez que agota las posibilidades de acceso para NPT. Este caso muestra la forma de presentación habitual de la EP, en la que sólo resta la NPT para alimentar al paciente, salvo que se realice trasplante intestinal.Hecho que se esta gestionando a nivel ministerial. Palabras clave: Enteropatía en Penacho, Malabsorción, Nutrición Parenteral Total. 
¿SE PUEDE MEJORAR LA FUNCIÓN INTESTINAL EN PACIENTES CON MIELOMENINGOCELE? EVALUACIÓN
AÑOS DE TRABAJO MULTIDISCIPLINARIO

Ríos MG, Palma N, KNG Pavez F, EU Miranda M, EU Navarrete M, NTC Serrano $E$, Vergara $M$, Salgado I, Retamal G.

Hospital Exequiel González Cortés.

Introducción: El mielomeningocele (MMC) es la malformación congénita más grave compatible con la vida. Se caracteriza por el compromiso multisis-témico (MS): neurológico, nefrourológico, traumatológico, endocrinológico y digestivo. Este último se manifiesta por dificultad para defecar, siendo fre-cuente la incontinencia fecal, condición socialmente incapacitante. Objetivo: Evaluar las características defecatorias de los pacientes con MMC controlados en policlínico MS a su ingreso y post tratamiento. Pacientes y Método: Niños portadores de MMC ingresados a poli MS entre Agosto 2006 y Abril 2008. El nivel del MMC: Toráxico: 3; Toracolumbar: 8, Lumbar: 20; Sacro: 2 y No registrado 7; 29 con válvula derivativa por hidrocefalia; 17 caminan, 18 no y 5 son lactantes. Se evaluó la respuesta al tratamiento en los que tenían más de 1 control hasta Septiembre 2008. Se consideró las características de la deposición, método de evacuación intestinal y requerimiento de medicamentos. La constipación se definió según los criterios de Roma III. El tratamiento consistió en régimen con residuo, medicamento Polietilenglicol 3.350, ejercicios abdominales y en los mayores de 4 años sin retardo mental, que se podían sentar, educación en hábito de evacuación. Resultados: Han ingresado 40 niños, 17 varones, edad de ingreso entre 54 días y 17 años (x: 8,2 a y m: 11 a 3 m). 13/40 (32,5\%) habían tenido 10 + controles en gastroenterología. 25/37 (67,5\%) usan medicamentos por constipación.

\begin{tabular}{|c|c|c|c|c|c|c|}
\hline \multirow[b]{2}{*}{ Ingreso } & \multicolumn{2}{|c|}{ Constipación } & \multicolumn{2}{|c|}{$\begin{array}{l}\text { Estimulación } \\
\text { Perianal }\end{array}$} & \multicolumn{2}{|c|}{$\begin{array}{c}\text { Evacuación Baño } \\
\text { en }>4 \mathrm{a}\end{array}$} \\
\hline & $30 / 40$ & $(75 \%)$ & $23 / 40$ & $(57,5 \%)$ & $3 / 29$ & $(10,3 \%)$ \\
\hline Control & $4 / 34$ & $(11,76 \%)$ & $2 / 34$ & $(5,8 \%)$ & $15^{*} / 29$ & $(51,7 \%)$ \\
\hline
\end{tabular}

3 aun con pañal. De los niños que dejan el pañal 5 no caminan.

Conclusiones: La constipación es un problema frecuente al igual que la incontinencia. El manejo MS de la constipación mejora su evolución ( $88 \%$ ) y permite llegar a controlar la evacuación intestinal en un porcentaje consideración (41\%). La imposibilidad de caminar, no implica que no puedan lograr defecar en baño. Para la recuperación de la incontinencia fecal de otros pacientes se requeriría apoyo con Biofeedback.

\section{PREVALENCIA DE ENFERMEdAd CELÍACA EN PACIENTES} PEDIÁTRICOS PORTADORES DE DIABETES MELLITUS TIPO 1

Alegría QS, Martín PR, García BR, Jara GA.

Hospital de Niños Roberto del Río, Hospital Clínico Universidad de Chile.

Introducción: La diabetes mellitus tipo 1 (DM1) se puede asociar a otras enfermedades autoinmunes. La prevalencia de enfermedad celíaca (EC) en este grupo de pacientes en los últimos años es de un 1-8\% en población pediátrica (10 veces mayor que en la población general). Se ha observado un aumento en su detección, ya que se dispone de marcadores serológicos más sensibles. Nuestro objetivo fue evaluar la prevalencia de EC en nuestros pacientes portadores de DM1. Pacientes y Métodos: Durante el año 2008 se solicitaron a 29 pacientes con DM1 anticuerpos antiendomisio (EMA), antitransglutaminasa (tTG) inmunoglobulina A ( $\operatorname{lgA}$ ). En aquellos en que resultaron positivos los anticuerpos se realizó biopsia intestinal confirmatoria (evaluada según clasificación de Marsh) Se evaluaron edad al diagnóstico de ambas enfermedades, síntomas de presentación de la EC, características nutricionales con índice de masa corporal (IMC), talla y sus desviaciones standard. Además se evaluó comorbilidad autoinmune tiroidea con anticuerpos antitiroglobulina y antimicrosomal. Resultados: De los 29 pacientes, 25 se realizaron EMA y tTG, siendo 14 de sexo masculino (56\%), con promedio de edad de 6,9 $\pm 3,7$ años (9 meses-11,6 años). El IMC promedio fue de $16,8 \pm 1,6 \mathrm{~kg} / \mathrm{m}^{2} \mathrm{y}$ la talla $122,3 \pm 23,9 \mathrm{~cm}$. Los pacientes con anticuerpos positivos fueron $6 / 25(24 \%)$ todos con IgA normal. De estos, 2 tuvieron biopsia normal y 4 alterada ( 2 con atrofia severa, 1 subtotal y 1 parcial). En estos 6 pacientes la edad al diagnóstico fue de $6,4 \pm 3,5$ y $6,8 \pm 3,8$ años para DM1 y EC respectivamente. En 4 pacientes se realizó el diagnóstico de EC en forma concomitante, en 1 fue 6 meses previo, y en el otro 3 años después del diagnóstico de DM1. La sintomatología previa al diagnóstico de EC fueron principalmente dolor y distensión abdominal, diarrea crónica y constipación. Un paciente no presentó síntomas. Se solicitó anticuerpos antitiroglobulina y antimicrosomal a 27 de los 29 pacientes, resultando positivo en 2, ninguno de estos con EC. Discusión: En esta serie la prevalencia de EC en pacientes portadores de DM1 fue más alta a lo descrito en la literatura, probablemente debido al bajo número de pacientes estudiados. A pesar de esto, queda nuevamente demostrada la importante comorbilidad autoinmune (EC y patología tiroidea) que existe en pacientes portadores de DM1. El diagnóstico de EC puede ayudar a mejorar el control metabólico, además de prevenir las complicaciones futuras propias de la enfermedad.

SEDACIÓN, SEGURIDAD Y UTILIDAD DE LA ENDOSCOPIA DIGESTIVA ALTA EN PEDIATRÍA

Riera CF, González FCG, Vaca ZC, Marchant P, Glenz C, Larraín BF, Harris PR.

Departamento de Pediatría, Unidad de Gastroenterología y Nutrición, Facultad de Medicina, Pontificia Universidad Católica de Chile.

Introducción: El estudio endoscópico alto es un procedimiento diagnóstico y terapéutico considerado de rutina en la práctica gastroenterológica, pero su utilización en pediatría se encuentra limitada a pocos centros, dada la necesidad de sedación y monitoreo adecuados. Objetivos: Evaluar prospectivamente las técnicas de sedación, indicación de la endoscopia, satisfacción y percepción de la calidad del examen. Materiales y Métodos: Se enrolaron 190 niños referidos a endoscopia, se obtuvieron datos biodemográficos, tipo de sedación y resultados de la endoscopia. Resultados: La edad promedio de los niños fue de 8,5 $\pm 4,2$ años $(x+1 D S)$. La mayoría fue referido por pediatra $(60 \%)$ y la principal indicación del estudio fue el dolor abdominal recurrente con sospecha de organicidad $(29,8 \%)$. Los pacientes fueron clasificados de acuerdo a la clasificación ASA ( $93 \%$ se catalogó como ASA I y II). Las drogas mayormente utilizadas fueron Midazolam y Meperidina. En la mayoría se requirió de 2 ó más drogas para lograr una sedación óptima. La calidad del procedimiento fue considerada satisfactoria en más del $90 \%$ de los casos. Un $75 \%$ presentaron amnesia completa y un $43 \%$ alguna molestia durante la recuperación. Dentro de los hallazgos macroscópicos destacaron signos de esofagitis en el $26 \%$, mientras el $60 \%$ de los exámenes fueron normales. Al analizar los pacientes en menores o mayores de $14 \mathrm{~kg}$ sólo se encontró diferencia significativa en edad, ASA, indicación de endoscopia y evaluación de la sedación por enfermera. Conclusión: Los procedimientos endoscópicos pueden realizarse de manera segura de forma ambulatoria mediante una sedación moderada. Sin embargo, una adecuada monitorización y conocimiento de técnicas de reanimación son básicos al momento de realizar dichos procedimientos.

PREVALENCIA DE ENFERMEDAD POR HÍGADO GRASO NO ALCOHÓLICO (EHGNA) EN NIÑOS CON OBESIDAD

Lizama DC, Jara GA.

Universidad de Chile. Facultad de Medicina. Departamento de Pediatría y Cirugía Infantil.

Introducción: La EHGNA constituye una de las consecuencias de la obesidad se asocia a insulinorresistencia y puede evolucionar a cirrosis. El diagnóstico de certeza es a través de biopsia, pero por su invasividad, sólo se realiza en circunstancias excepcionales. Habitualmente el diagnóstico es presuntivo con alteración de la ecografía abdominal y de las transaminasas. Objetivo: Conocer la prevalencia de EHGNA en un grupo de niños obesos Metodología: Estudio descriptivo y retrospectivo, donde se revisaron las fichas de una consulta endocrinológica pediátrica. Se incluyó niños entre 6 y 18 años con diagnóstico de obesidad y sin patología hepática concomitante. Se recopiló datos del examen físico y de laboratorio sugerentes de resistencia a la insulina y disfunción hepática. Se diagnosticó EHGNA cuando la ecografía abdominal indicadora del diagnóstico y la relación GPT/GOT era mayor a 2 . Sólo se incluyeron pacientes obesos que no tenían sintomatología ni signología clínica de otras enfermedades hepáticas. Resultados: De 1.233 fichas, un 15,4\% eran obesos. Se realizó un estudio piloto con 100 pacientes obesos, sin embargo, menos del $50 \%$ de los pacientes tenía ecografía, por lo tanto, el diagnóstico se hizo sólo con la alteración de las transaminasas ya definida. Se analizaron 107 pacientes con una prevalencia de EHGNA de 1,8\% (IC 95\% 0,2\%-6,5\%). Un 47,7\% presentó insulinorresistencia y $43,7 \%$ hipertrigliceridemia. Según la ecografía (50 pacientes), un $26 \%$ presentó hígado graso (tabla):

Con hígado graso $\quad$ Sin hígado graso

GPT normal

GPT anormal

Total

4
9

13

31
37

Conclusiones: La frecuencia de EHGNA es distinta según la definición que usemos. La sospecha de esta enfermedad debe estar siempre presente en niños obesos y la aproximación al diagnóstico debe ser con imágenes y laboratorio. 


\section{ESOFAGITIS EOSINOFÍLICA EN NIÑOS: CARACTERÍSTICAS CLÍNICAS} $Y$ ENDOSCÓPICAS

González FCG, Jaime F, Torres J, Molina UR, Harris PR. Departamento de Pediatría, Unidad de Gastroenterología y Nutrición, Facultad de Medicina, Pontificia Universidad Católica de Chile.

Introducción: La esofagitis eosinofílica (EE) es una enfermedad de causa desconocida, cuyas principales manifestaciones incluyen el reflujo y disfagia, lo que tradicionalmente no responden al tratamiento antiácido, afecta de preferencia a hombres jóvenes con una fuerte historia personal o familiar de atopía, asma y alergias. Objetivo: Presentar una serie de tres niños con EE, sus características clínicas, endoscópicas e histológicas, tratamientos recibidos y respuesta a los mismos. Pacientes y Métodos: Revisión retrospectiva de fichas clínicas de 3 niños con el diagnóstico de EE. Resultados: 3 pacientes de sexo masculino, todos con síntomas de disfagia, dos de ellos con dolor torácico secundario espasmos esofágicos, con anormalidades endoscópicas, que incluyeron desde leucoplaquias hasta la presencia de una estenosis esofágica significativa, que requirió de dilatación endoscópica. Se observó que todos los pacientes presentaron alteraciones en los estudios de inmunidad (test cutáneo o niveles de lgE). Los pacientes recibieron tratamiento en base a medidas dietéticas, antiácidos inhibidores de leucotrienos, con buena respuesta clínica, endoscópica e histológica. Conclusión: EE es una patología que debiese sospecharse en aquellos niños con síntomas de reflujo o disfagia con antecedentes personales o familiares de alergia y asma. En esta serie clínica de tres pacientes se exponen las características clínicas y complicaciones derivadas de esta patología. Es necesario continuar investigando en el tema para ofrecer a los pacientes mayores y mejores alternativas terapéuticas.
ADHERENCIA, MANEJO E IMPACTO DE LA DIETA SIN GLUTEN EN PADRES Y NIÑOS CON ENFERMEDAD CELÍACA EN EL HLCM

Bravo F, Muñoz MP, Castillo R.

Hospital Luis Calvo Mackenna.

Antecedentes: El tratamiento de la enfermedad celíaca se basa en la dieta libre de gluten en forma estricta y de por vida. Objetivos: Describir la adherencia a la dieta, su manejo e impacto en la vida diaria de padres y niños con enfermedad celíaca en control en el HLCM. Método: Se aplicó cuestionario de 28 preguntas a los padres de pacientes celíacos menores de 12 años y a niños y padres de niños celíacos mayores de 12 años. Resultados: Se encuestó a 20 celíacos > de 12 años y 40 padres de enfermos celíacos. Edad media 10,5 años, edad del diagnóstico 1,8 años, $62,5 \%$ mujeres. Adherencia: $42,5 \%$, 35\% según padres en celíacos > de 12 años vs $15 \%$ descrita por niños > 12 años. Impacto en la vida diaria: $80 \%$ refiere no sentirse distinto a otro niños, $70 \%$ encuentra la dieta difícil de seguir, $55 \%$ le molesta tener que seguirla principalmente porque no saben bien que comer $(42,8 \%)$, siendo la principal dificultad para los padres la razón económica $(51,5 \%)$. Un $70 \%$ de los padres sienten que sus hijos no sufren discriminación social, pero un $65 \%$ de los niños lo ha sentido alguna vez, no sintiendo que afecte sus relaciones de amistad (60\%). Un 55\% cree que influye en la vida familiar a través de: problemas por limitación de alimentos (55\%), preparación de comida especial $(50 \%)$, salir a comer fuera de casa $(75 \%)$, salir de viaje $(35 \%)$. Manejo de la dieta: los padres y niños tienen claro los alimentos prohibidos, existiendo limitación en encontrar alimentos (75\%) y en su costo $(97,5 \%)$. Un $50 \%$ de los padres le ha dado alguna vez alimentos prohibidos a sus hijos, siendo el lugar de transgresión principalmente el hogar (47\%). La información de la dieta la obtienen principalmente del doctor del hospital (85\%), existiendo un $32,5 \%$ de adherencia a fundaciones celíacas. Un $55 \%$ y $40 \%$ refieren que existiendo más productos en el supermercado y rotulación de alimentos sin gluten respectivamente, les mejoraría la calidad de vida. Conclusiones: Existe una adherencia a la dieta sin gluten más baja a la descrita en la literatura, pero un porcentaje importante de los niños la cumple la mayor parte del tiempo. Existe un impacto de la dieta del punto de vista emocional, social y familiar de los niños. La mayoría de los pacientes y padres tienen claro los alimentos prohibidos, pero existen ciertas limitantes como disponibilidad de alimentos y precio que hacen la dieta difícil de seguir.
EVOLUCIÓN DE CONSTIPACIÓN CRÓNICA EN 200 PACIENTES CHILENOS: UN ESTUDIO PRONÓSTICO. PROMANO FASE II

Jaime F, González CG, Saavedra S, Gana JC, Larraín F, Cofré C, Harris PR.

Departamento de Pediatría, Unidad de Gastroenterología y Nutrición, Facultad de Medicina, Pontificia Universidad Católica de Chile.

Introducción: La constipación crónica es causa frecuente de consulta pediátrica. Sin embargo, es poco lo que se conoce de su pronóstico. Objetivos: Conocer e pronóstico a mediano plazo y comparar éste según las características clínicas de los pacientes. Materiales y Métodos: Prospectivamente, se reclutó pacientes pediátricos a quienes se les realizó manometría rectoanal (MRA) en nuestro laboratorio entre 2004 y 2006. Se contactaron telefónicamente 8 meses después, para conocer su evolución y tratamientos recibidos. Resultados: Se evaluaron 200 pacientes ( $51,5 \%$ mujeres) con seguimiento del $88 \%$ de ellos; edad promedio: $3,6+3,6$ años ( 1 mes a 15 años). Acorde a las tablas de crecimiento NCHS basados en peso, talla, edad e índice de masa corporal, la evaluación nutriciona reveló que el $4 \%$ de los pacientes presentaron bajo peso, $79,5 \%$ eutróficos, $20 \%$ tuvieron sobrepeso, y $5,5 \%$ eran obesos. El período de latencia entre el inicio de síntomas y la MRA fue $11,4 \pm 17,9$ meses (hombres: $41 \pm 42,1$; mujeres: $24,6 \pm$ $30,8 ; p=0,002)$. El $70 \%$ de los pacientes tuvieron MRA normal y en $4,1 \%$ fue sugerente de alteración de la inervación intrínseca. Ocho meses después, el $77,8 \%$ normalizó la consistencia de las deposiciones $(p<0,001), 59,1 \%$ mejoró la frecuencia de las mismas, y $50,7 \%$ del total las normalizaron $(p<0,001)$ Posterior a la MRA, a 9 pacientes se les solicitó biopsia rectal (en 4 de ellos resultó alterada), requiriendo sólo 3 de ellos tratamiento quirúrgico. En el 89,5\% de los pacientes, la MRA fue el último examen solicitado. No se observaron diferencias en la evolución clínica de los pacientes a partir de la conclusión de la MRA. Aquellos niños con encopresis tuvieron menor probabilidad de mejoría ( $R R=0,77 ;$ IC95\% 0,60-0,98); la presencia de rectorragia y dolor abdominal no influyeron sobre el pronóstico, así como tampoco la frecuencia inicial de deposiciones. Durante el transcurso del seguimiento, se observó aumento significativo en el número de medicamentos utilizados para el manejo de la constipación. Conclusiones: La constipación crónica se inicia a edades tempranas, presentando las niñas un menor tiempo de latencia desde el inicio de la constipación hasta la realización de MRA. A 8 meses de seguimiento, gran parte de los pacientes con constipación crónica que requirieron MRA dentro del estudio, mejoraron sus síntomas, sin embargo, también se observó un aumento el número de medicamentos consumidos. Aquellos niños con encopresis tuvieron peor evolución.

\section{SANGRAMIENTO DIGESTIVO OCULTO: UTILIDAD DE LA ENTEROCLISIS CON TAC}

Arancibia ME, Alliende F, Saítua F, Schiappacasse G, Roa I. Departamentos Pediatría, Cirugía Infantil, Radiología y Anatomía Patológica Clínica Alemana de Santiago.

Introducción: Se define sangramiento digestivo oculto a la presencia de sangramiento fecal y/o anemia ferropriva, sin evidencia visible de pérdidas de sangre ya sea por el paciente o el médico. En la mayoría de los casos la etiología se resuelve realizando estudio con endoscopia alta, colonoscopia y evaluación radiológica del intestino delgado, si este estudio es negativo se denomina sangramiento oscuro. La enteroclisis por TAC en la infancia es un método de excepción, principalmente indicada en enfermedad inflamatoria intestinal. Se presenta el caso de un lactante con sangramiento digestivo oculto donde la enteroclisis por TAC orientó al diagnóstico etiológico. Caso clínico: Lactante de 1 año 8 meses, con antecedente de anemia ferropénica y hemorragia oculta positiva en reiteradas muestras desde los 6 meses de vida, refractaria a tratamiento con suplemento de fierro oral. Destaca además mal incremento ponderal y diarrea intermitente. Se realizaron test cutaneos (prick y parches) de alimentos los que fueron compatibles con alergia a proteína leche de vaca y otros alimentos, a realizar dieta de restricción no se evidencia mejoría de la anemia. A los 20 meses presenta mejoría de ascenso ponderal (P/E -1ds, T/E med). Hto $20 \% \mathrm{Hb}$ $7,5 \mathrm{grs}$. Endoscopia alta y colonoscopia larga normal y biopsias compatibles con colitis alérgica, Tránsito intestinal normal. Cintigrama Tc99 fue negativo. La enteroclisis por TAC realizada bajo sedación usando como contraste agua administrada por sonda naso enteral demostró imagen polipoidea ubicada en yeyuno distal. Se realizó extirpación quirúrgica laparoscópica con resección de pólipo único hamartomatoso. Evoluciona con mejoría de la anemia y negativización de hemorragia oculta. Conclusión: 1) La enteroclisis por TAC debe ser considerada como una valiosa herramienta en el estudio etiológico del sangramiento digestivo oculto en la infancia; 2) A diferencia de la cápsula endoscópica y la enteroscopia, la enteroclisis por TAC puede realizarse desde la época de lactante; 3) La enteroclisis por TAC evalua con precisión la pared intestinal y zonas extraintestinales, reconociendose especial utilidad en la enfermedad inflamatoria intestinal. 


\section{PANCREATITIS AGUDA EN PEDIATRÍA}

Avila BML, Alarcón OC, Tajmuch VV.

Unidad de Paciente Crítico, Servicio de Pediatría, Hospital Clínico Félix Bulnes.

Introducción: La Pancreatitis Aguda (PA) es una enfermedad inflamatoria que en niños suele ser autolimitada y de buen pronóstico. Objetivo: Describir características clínicas, evolución y tratamiento de los casos de PA del Servicio de Pediatría del Hospital Félix Bulnes. Método: Estudio retrospectivo de revisión de fichas de pacientes que egresaron con diagnóstico de PA del Servicio de Pediatría del Hospital Félix Bulnes desde febrero 2001 hasta agosto 2008. Se definió como PA la existencia de historia clínica compatible asociada a niveles de amilasa y/o lipasa sérica mayores a 3 veces el valor normal. Resultados: Del total de 11 pacientes hubo 15 episodios de PA, ya que 2 pacientes tuvieron 2 recurrencias. El 55\% fue sexo femenino. La mediana de edad fue 8 años (5-14 años). En 3 casos se encontró asociación a colelitiasis, 2 a trauma abdominal y en 6 no hubo asociación evidente con etiologías habituales. Los síntomas más frecuentes al ingreso fueron: dolor abdominal (14), vómitos (12) y rechazo alimentario (2). La mediana de los valores máximos de amilasa sérica fue 621 IU/I (64-3.575 IU/I); y de la lipasa sérica fue 859 IU/I (100-7840 IU/I). En los 15 episodios se efectuó, al menos un estudio de imagen. En las Ecografías abdominales (14) se vio: páncreas aumentado de tamaño o edematoso (7), pseudoquiste (2), colección líquida (2) y litiasis vesicular (4). Se hizo TAC abdominal a 12 casos, resultando normal 3 y el resto con: páncreas aumentado de tamaño o edematoso (6), pseudoquiste (3), colección líquida (1), colelitiasis (1), necrosis pancreática (1) y atrofia pancreática (1). En los pacientes con recurrencias se hizo estudio complementario con electrolitos en sudor, ERCP y colangioresonancia. Requirieron alimentación parenteral 5. Se indicó antibiótico a 2 casos, por infección del pseudoquiste en uno y eventual colangitis en otro. En 4 casos se usó analgésico narcótico y en 8 AINE. Se hicieron 2 colecistectomías diferidas. Del total de episodios, 1 paciente cursó con shock y falla multiorgánica y 3 presentaron complicaciones locales (colecciones, pseudoquistes y necrosis) El tiempo promedio de hospitalización fue 22 días. Ningún paciente falleció. Discusión: La PA en niños, a diferencia del adulto, tiene diversas causas y en un alto porcentaje no logra identificarse ninguna. La PA infantil es un cuadro cuya incidencia va en aumento, lo que hace necesario reconocer precozmente esta entidad para instaurar un adecuado manejo y buscar probables complicaciones.

\section{SÍNDROME DE DOWN E IMPORTANCIA DE LA EDAD MATERNA COMO FACTOR DE RIESGO: EXPERIENCIA EN EL HOSPITAL SAN JUAN DE DIOS ENTRE LOS AÑOS 2005 Y 2006}

Román G, Salas C, Torres L, Tellerías L, Sanz P. Servicio de Pediatría Hospital San Juan de Dios.

El Síndrome de Down es la alteración cromosómica más frecuente en la especie humana y constituye la principal causa de deficiencia mental de origen genético durante la infancia. Se estima una incidencia de 1 × 600 nacidos vivos, incrementándose a medida que aumenta la edad materna, especialmente a parti de los 35 años. El objetivo de este trabajo es evaluar la edad materna como factor de riesgo en el Síndrome de Down. Pacientes y Métodos: análisis prospectivo del registro de malformaciones congénitas mayores detectadas por el equipo de diagnóstico prenatal y notificadas por el servicio de obstetriciaginecología y neonatología durante el 1 de enero del año 2005 y 31 de diciembre del año 2006 en el Hospital San Juan de Dios. Resultados: De un total de 7.977 partos ocurridos y 8091 recién nacidos vivos durante el período antes señalado se produjeron 178 notificaciones de malformaciones congénitas mayores, de las cuales 18 correspondieron a Síndrome de Down, con incidencia de 1 × 400 nacidos vivos. Características RN: Predominio sexo masculino (56\%), sexo femenino $44 \%$, edad gestacional promedio 37 semanas, peso medio al nacimiento: 2.746 grs. En relación con la edad materna, se estimó un promedio de 35,8 años, en un rango de edad entre 15 y 47 años, siendo en su mayoría mayores de $35(77 \%)$. Comentarios: De acuerdo con los datos obtenidos la incidencia de síndrome de Down es levemente mayor a la observada en la literatura; sin embargo, hay que considerar que la gran mayoría de las madres se encontraban por sobre los 35 años, edad en la cual incidencia es mayor $(1 \times 300)$. La edad promedio de madres con hijos con esta patología se corresponden con los datos obtenidos en estudios realizados en nuestro país. El impacto de la edad materna en la génesis del síndrome de Down se reconoce hace varios años, sin embargo, hasta hoy no se ha podido determinar con certeza los mecanismos subyacentes a este hecho.

\section{SÍNDROME DE CORNELIA DE LANGE}

Cárdenas $A A^{1}$, Kiger $M L^{1}$, Contreras $A K^{2}$

${ }^{1}$ Pediatras. Servicio de Pediatría. Hospital Regional de Antofagasta. ${ }^{2}$ Interna Carrera de Medicina. Facultad de Medicina y Odontología Universidad de Antofagasta. Hospital Regional de Antofagasta.

Introducción: Síndrome Cornelia de Lange (CdLS) es un desorden malformativo múltiple, caracterizado por rasgos faciales característicos, retraso del crecimiento y desarrollo psicomotor, y una variedad de otras anormalidades que afectan en diferentes grados a tejidos y órganos. Esto debido a una marcada heterogeneidad de fenotipos. Se hereda en forma autosómica dominante. Las mutaciones responsables se producen en el gen NIPBL localizado en el cromosoma en $5 p-13,2$. La esperanza de vida es normal de no presentarse Malformaciones congénitas mayores como cardiopatías congénitas complejas, gastrointestinales o apnea por aspiración. El diagnóstico se hace mediante la clínica. Generalmente el Cariograma es normal. Incidencia 1/10.000-50.000 NV. No se ha descrito diferencia de razas, ni de género. Caso clínico: Madre primigesta de 19 años con Embarazo controlado: 3 ecografías Pequeño para edad gestacional (PEG). Cursa con Retardo del crecimiento intrauterino + Síndrome Hipertensivo del Embarazo + podálico y se decide interrumpir por cesárea. Recién nacido pretérmino de 36 semanas PEG severo. Nace en regulares condiciones generales. Apgar 6-9. Peso: 2.020 grs. Talla $41 \mathrm{~cm}$. Aspiración de secreciones: meconio escaso. Requirió estimulación y oxígeno a flujo libre. Examen Físico: hipertonicidad, Hirsutismo. Piel marmorata. Microbraquiocefalia, Puente nasal bajo, Leve hipertelorismo, Paladar ojival, filtrum largo, sinofris, micrognatia, pliegue simiano bilateral, micromelia. Sindactilia parcial ortejos $2^{\circ}-3$ 을 ambos pies. Fontanela anterior continúa con posterior. Cardíaco: soplo holosistólico II/ VI. Visceromegalia (-). Hipoplasia genital, testículos no descendidos. Es dado de alta en buenas condiciones. A los 3 meses de edad es ingresado por Diarrea aguda. Durante su hospitalización llama la atención su microcefalia, falla en incremento ponderal y un llanto como gruñido bajo y débil. Cariograma sin alteraciones cromosómicas evidentes. Estudio TORCH negativo. Por lo anterior se plantea el Sd. Cornelia de Lange. Evaluación Pondoestatural es concordante con el síndrome. Comentario: El CdLS es una genopatía muy poco frecuente, que para su pesquisa se requiere de una alta sospecha clínica, no existiendo un examen confirmatorio accesible. Su diagnóstico precoz permite incorporarlos oportunamente a un programa de estimulación psicomotora y alimentación adecuada que le permitirá un mejor crecimiento y desarrollo psicomotor.

\section{TRISOMÍA 22 PARCIAL, PRESENTACIÓN DE TRES CASOS}

\section{Selman E, Vega ML, Sepúlveda M.}

Unidad de Genética, Hospital Guillermo Grant Benavente. Departamento de Pediatría, Universidad de Concepción. Laboratorio de Citogenética, Sanatorio Alemán.

Introducción: La Trisomía 22 parcial es un trastorno cromosómico que se origina generalmente como producto de una translocación recíproca balanceada en uno de los padres. El fenotipo es variable y las características están dadas por el tamaño y origen del cromosoma derivativo extra. Casos Clínicos: Caso 1. Primera hija de padres jóvenes, no consanguíneos. RNT (PEG) $38 \mathrm{sem}$. Destaca hipotonía, orejas de implantación baja, foseta y papiloma preauricular izq., hipertelorismo, ojos oblicuos hacia abajo,coloboma ojo izq. cejas altas, nariz de base ancha y aplanada, filtrum largo, labios finos, micrognasia, cuello corto con piel redundante, ductus arterioso persistente y riñón multicistico izq. Cariotipo: 47,XX,+mar, FISH: ish 22q11.2 (triple1 $\times 3$ ) Cariotipo madre: 46,XX,t $(5 ; 22)$ (q35;q11.2). Diagnóstico: Trisomía 22 parcial por translocación $(5 ; 22)$, de origen materno. Actualmente tiene 9 meses y presenta RDSM. Casos 2 y 3. Corresponden a dos medios hermanos maternos, derivados por MCM. Ambos RN de 37 semanas y con RCIU. El primero de sexo masculino, presenta microcefalia, dismorfias faciales (ojos oblícuos, foseta preauricular, secuencia de Pierre Robin) piel redundante en cuello, cardiopatía congénita compleja y ano imperforado. Fallece al mes de vida. El segundo hermano, de sexo femenino, con características fenotípicas similares, pero con menor expresividad y no presenta ano imperforado. El estudio citogenético en ambos mostró un marcador extra, similar a un cromosoma 22 deletado. El estudio de la madre reveló una translocación recíproca balanceada entre un cromosoma 11 y un 22 , lo que confirma en ambos, la presencia de un derivativo 22 extra, producto de una translocación balanceada 11;22, de origen materno. Comentario: Aparentemente, no existen otros casos en la literatura de trisomía 22 parcial que deriven de una translocación recíproca $5 ; 22$. La mayoría de los casos publicados se originan a partir de una translocación $11 ; 22$, que corresponde a la translocación recíproca más frecuente en la especie humana. En las madres portadoras de la translocación, se favorecería la no disyunción en la M1, debido a una recombinación aberrante, dada por segmentos cromosómicos cortos. A pesar de que muchos de los casos presentan similares puntos de quiebre, se encuentra una gran variabilidad en su expresión fenotípica. 
PLAN PILOTO DE PESQUISA NEONATAL AMPLIADA EN CHILE. RESULTADOS PRELIMINARES

Valiente A, Cabello JF, Raimann E, Betta K, Cornejo V.

Laboratorio de Genética y Enfermedades Metabólicas, INTA, Universidad de Chile.

Introducción: En Chile desde 1992 funciona el Programa Nacional de Pesquisa Neonatal para Fenilquetonuria (PKU) e Hipotiroidismo Congénito (HC), lo que ha permitido prevenir retardo mental en 900 recién nacidos $(R N)$. En países desarrollados existen los Programas de Pesquisa Neonatal Ampliado (PNA), incorporando un mayor número de enfermedades metabólicas, por espectrometrí de masa en tandem (MS/MS). El Laboratorio de Genética y Enfermedades Metabólicas del INTA, cuenta con esta tecnología, y hoy se puede pesquisar 32 patologías. Objetivo: Evaluar 8 meses de funcionamiento del programa piloto de PNA aplicado en RN del sector privado de Santiago. Metodología: Muestras de sangre en tarjeta de papel filtro de RN con 40 a $72 \mathrm{hrs}$. de vida. Se ocuparon discos de $3 \mathrm{~mm}$ de diámetro los que fueron analizadas en uniplicado. Se estudiaron 32 patologías: aminoacidopatías, acidurias orgánicas y defectos de oxidación de ácidos grasos (MS/MS); Hiperplasia Adrenal Congénita y Fibrosis Quística (Inmunofluorescencia); HC (inmunoradiometría); Déficit de Biotinidasa (Colorimetría) y Galactosemia Clásica (Fluorescencia). Resultados: Se analizó un total de 1.262 muestras de sangre, con edad $X$ de toma de muestra de 2,3 días de edad. El análisis de la muestra se obtuvo en $X$ de 3,2 días. La edad $X$ de $\mathrm{RN}$ al momento de tener el resultado fue a los 4,4 días de edad. Hubo 18 muestras consideradas anormales por estar sobre el punto de corte de normalidad. En 2 casos se confirmó un HC. Se estableció un 1,3\% de falsos positivos. Conclusiones: Se concluye que el funcionamiento del PNA se desarrolló adecuadamente tanto en la fase pre analítica (tiempo de toma de muestra), fase analítica (recepción y análisis de muestras) y fase post analítica (entrega de resultados, confirmación diagnóstica y tasa de falsos positivos) ya que todos los tiempos están dentro de rangos aceptados para un PNA. Es importante enfatizar que al aumentar el número de patologías a pesquisar, se incrementa el beneficio de prevenir el retardo mental y otras condiciones neurológicas a un mayor número de personas. Los resultados obtenidos podrían ser extrapolable a un Programa Nacional del Ministerio de Salud permitiendo mejor equidad en nuestra población de RN.
EVIDENCIA GENÉTICA EN TRASTORNO ESPECÍFICO DE LENGUAJE EN UNA POBLACIÓN ENDOGÁMICA CHILENA: ISLA ROBINSON CRUSOE

Villanueva $\boldsymbol{P}$, de Barbieri Z, Fernández MA, García M, Palomino HM, Palomino $\mathrm{H}$.

Facultad de Medicina y Facultad de Odontología. Universidad de Chile.

Introducción: El trastorno específico de lenguaje (TEL) es una de las patologías por déficit del lenguaje más frecuente en niños. Afecta el desarrollo del lenguaje en sus primeras etapas y es independiente de la educación e inteligencia. Estudios genéticos de agregación familiar y estudios de mellizos, sugieren que el TEL tiene un importante componente genético subyacente. Se ha observado mayor frecuencia en parientes en primer grado de afectados que en controles y mayor concordancia en mellizos monocigóticos que en dicigóticos. La población isleña está parcialmente aislada y su origen, eminentemente caucásico, se inicia a fines del siglo XIX. Su población actual es de 633 habitantes. Objetivos: Determinar consanguinidad de la población, prevalencia de niños con TEL y agregación familiar de esta patología en la isla Robinson Crusoe. Material y Método: Se analizaron todos los matrimonios registrados en el período 1881-2000. Se calculó: índice de consanguinidad, promedio de coeficiente de endogamia de la población y porcentaje de los diferentes tipos de matrimonios consanguíneos. Para diagnosticar TEL y establecer su prevalencia, se utilizó metodología fonoaudiológica estandarizada para esta patología. Para determinar la agregación familiar de trastorno de lenguaje se evaluaron los parientes biológicos en primer grado de los niños con TEL y de los niños con desarrollo normal de lenguaje (control). Resultados: El índice de consanguinidad para el período 1881-2000 fue $13,55 \%$, el promedio de coeficiente de endogamia fue $42,22 \times 10-4$, siendo la unión entre primos segundos el más frecuente en esta población. La frecuencia de TEL en los niños originarios es $35 \%$, significativamente mayor a lo observado en otras poblaciones, tanto chilenas (4\%), como extranjeras (entre 2 y $8 \%$ ) y a la frecuencia en niños no isleños que habitan la isla temporalmente $(3,8 \%)$. A evaluar las familias isleñas, se reporta trastorno de lenguaje en $44.76 \%$ de los parientes de niños con TEL, así como en $18,52 \%$ de los parientes de niños control. Conclusión: La alta frecuencia de trastorno de lenguaje en las familias de probando afectados de TEL, comparadas con las familias control de la isla Robinson Crusoe, asociado al alto grado de consanguinidad y alta prevalencia de TEL existente en su población, sustenta la presencia de mecanismos de trasmisión genética, basados en un efecto fundador relacionado con esta patología. Financiado por proyectos: UCHILE DID TNAC 01-02/01, UCHILE DI MULT 05/ 05-2.

\section{PROGRAMA SEGUIMIENTO SCREENING NEONATAL DE FENILCETONURIA EN CHILE}

Castro G, Cabello JF, Peredo P, Fernández E, de la Parra A, Valiente A Raimann E, Cornejo V.

Laboratorio de Genética y Enfermedades Metabólicas. INTA, Universidad de Chile.

Introducción: Desde el año 1992, el Programa Nacional de Búsqueda Masiva de Fenilquetonuria (PKU) e Hipotiroidismo congénito ha diagnosticado 145 caso PKU. Metodología: El seguimiento considera evaluaciones médicas, nutricionales, neurológicas, psicométricas y bioquímicas. El tratamiento consiste en restringir ingesta de Fenilalanina (FA) y proporcionar una fórmula sin FA Resultados: La edad promedio de diagnóstico fue a los 17,9 (DS: 10,1) días de vida, descartándose déficit de BH4. La FA de diagnóstico promedio de 19,9 mg/ $\mathrm{dL}$, tirosina dg 1,2 mg/dL. La edad actual fluctúa entre 1 mes y 18 años. La dieta proporciona en promedio $1,9 \mathrm{~g} / \mathrm{Kg} /$ día de proteínas, de los cuales la formula aporta un $70 \%$. El aporte diario de Kcal es de $1488 \mathrm{Kcal}$. La ingesta de FA es de $20 \mathrm{mg} / \mathrm{kg}$ peso/día en el grupo PKU. El $81 \%$ de nuestros pacientes mantiene buen control metabólico. Los niños menores de 14 años mantienen niveles de FA en $5,3 \mathrm{mg} / \mathrm{dl}$. Los > de 14 años en $8.5 \mathrm{mg} / \mathrm{dl}$. El estado nutricional en un $13 \%$ de los niños esta en rango de obesidad, $10 \%$ sobrepeso, $73 \%$ eutróficos y $4 \%$ bajo peso. Conclusión: Se destaca la importancia del diagnóstico neonatal y del seguimiento multidisciplinario, que permite a niños PKU un crecimiento y desarrollo normal.

\section{TERAPIA DE SUSTITUCIÓN ENZIMATICA EN LA ENFERMEDAD DE} GAUCHER. EXPERIENCIA EN CONCEPCIÓN

Escobar $\boldsymbol{P}$, Vega L, Selman E.

Unidad de Genética Servicio de Pediatría Hospital Guillermo Grant Benavente. Concepción.

La Enfermedad de Gaucher (EG) es una enfermedad hereditaria, autosómica recesiva, por deficiencia lisosomal de la glucocerebrosidasa. Se caracteriza por hepatoesplenomegalia, anemia, trombocitopenia, lesiones óseas y compromiso del sistema nervioso central, con distintos grados de severidad. La terapia de sustitución enzimática mejora la sintomatología y calidad de vida, pero no atraviesa barrera hematoencefalica. Se presentan dos pacientes con terapia enzimática en Concepción, VIII región. Caso Clínico: 1) Niño de 6 a 4 m, con diagnóstico de Enfermedad de Gaucher desde el 1 a $5 \mathrm{~m}$ de edad, que comienza con terapia de sustitucion enzimatica en mayo 2004. Desde la sexta dosis se nota disminución de la irritabilidad, morbilidad respiratoria y hepatoesplenomegalia. Actualmente DSM normal con alteracion del equilibrio y apraxia oculomotora horizontal, por compromiso SNC; 2) Mujer de 32 años con anemia severa y crisis de dolor óseo, Se dg. Enfermedad de Gaucher en el curso de segundo embarazo en año 2007. Con terapia enzimática desde enero 2008, corrige anemia, desaparecen crisis óseas y mejora calidad de vida. Comentario: Desde 1990 se esta utilizando la terapia enzimática con excelentes resultados. Mejora la visceromegalia crisis óseas y pancitopenia. El compromiso de SNC, es inevitable, pero disminuye al retirar el sustrato del torrente sanguineo. Se administra dos veces al mes en forma ambulatoria. Es de alto costo. 


\section{ANÁLISIS DE LAS EDADES DE MADRES DE RECIÉN NACIDOS PORTADORES DE MALFORMACIONES CONGÉNITAS MAYORES}

Arriagada SC, Torres L, Román G, Tellerías L.

Servicio de Pediatría Hospital San Juan de Dios.

Introducción: En la literatura se describe que el riesgo de tener un hijo malformado es mayor en mujeres mayores de 35 años, así como en el otro extremo, en madre adolescente. Objetivo: Conocer la distribución al nacimiento de malformaciones congénitas en madres de edades comprendidas entre los 11 y 19 años y sobre los 35 años de edad. Material y Método: Se recurrió a los sistemas de archivo de malformaciones congénitas de los servicios de Neonatología y Obstetricia del Hospital San Juan de Dios entre el 1 de Enero de 2005 y el 31 de diciembre de 2006. Resultados: De un total de 7.977 partos se notificaron 179 malformaciones congénitas; de ellas, 40 (22,3\%) correspondieron a hijos de madres entre los 11 y 19 años de edad y 43 (24\%) a hijos de madre de 35 años y más. En el rango de edad comprendido entre los 20 y 34 años se encontraron 95 notificaciones que corresponden al $53 \%$. La edad materna promedio en el grupo de las adolescentes fue de 17,6 años (rango 11-19) y en el grupo de 35 años y más fue de 38.1 (rango 35-47). Conclusiones: Según nuestra muestra, el porcentaje de malformaciones congénitas en hijos de madres de edades extremas es similar, lo que puede sentar un precedente para futuros estudios en nuestra área.
HIPOTIROIDISMO CONGÉNITO EN PACIENTES CON SÍNDROME DE DOWN NACIDOS DURANTE LOS AÑOS 2005 - 2006 - 2007 Y 2008 EN HOSPITAL SAN JUAN DE DIOS

Salas C, Román G, Torres L, Tellerías L, Pérez V, Duffeau V, Bruggendieck JB. Servicio de Pediatría Hospital San Juan de Dios.

Introducción: El hipotiroidismo corresponde a la alteración endocrina más común en los pacientes portadores de Síndrome de Down. Se describe que alrededor de $1 \%$ presentan Hipotiroidismo congénito $(\mathrm{HC})$ y de ellos sólo el $30 \%$ se espera que sea transitorio. El 13-54\% según diferentes series presentan disfunción tiroidea, en su gran mayoría de tipo hipotiroidismo adquirido desde la niñez a la adultez, aumentando el porcentaje a medida que aumenta la edad de los pacientes. En Chile por norma ministerial se toma en forma preventiva TSH y PKU a todos los recién nacidos (RN) para detección y tratamiento precoz de HC. Objetivo: Determinar la presentación de $\mathrm{HC}$ en pacientes $\mathrm{RN}$ portadores de Síndrome de Down. Determinar los niveles de TSH neonatal en pacientes portadores de SD. Material y Método: Estudio descriptivo. Se revisan los registros de la maternidad para identificar los pacientes portadores de SD nacidos los años 2005, 2006, 2007 y 2008 en el Hospital San Juan de Dios y se evalúan los niveles de TSH neonatal, según Programa de Screening Neonatal del Minsal. Resultados: Del total de pacientes con Síndrome de Down se encuentra un $1,5 \%$ de asociación con hipotiroidismo congénito. Conclusiones: Se puede establecer que existe una importante asociación de Síndrome de Down con hipotiroidismo congénito en pacientes nacidos en Hospital San Juan de Dios, mayor a la que existe en la población normal. Es importante resaltar la prevención que significan estos hallazgos por Programa de Screening neonatal dado que en pacientes portadores de SD el diagnóstico de $\mathrm{HC}$ es extremadamente difícil por la superposición de sintomatología propia del síndrome.

\section{SÍNDROME DE DOWN, RIESGO SEGÚN EDAD MATERNA. SITUACIÓN} ACTUAL

Novoa PJM' ${ }^{1}$, Sakovets $I^{1}$, Novoa $B C^{2}$, Carcamo $R J^{1}$, Valenzuela $H P^{1}$ Insunza $F A^{\prime}$

${ }^{1}$ UGC Mujer y RN, Hospital Padre Hurtado. ${ }^{2}$ Alumno Medicina Universidad de Chile.

La trisomía 21 o Síndrome de Down (Tr21) es una condición genética descrita en el siglo XIX y confirmada su asociación de riesgo según edad materna a mediados del siglo XX. La incidencia clásicamente descrita es de 1:800 a 1:650 nacidos vivos. En nuestro hospital se observa una incidencia mayor a lo descrito lo que motiva este estudio. Objetivo: Evaluar en hospital publico de Región Metropolitana en período cercano a 10 años la incidencia global de síndrome de Down. Actualizar las curvas clásicas de riesgo por edad y sugerir rangos acotados según riesgo. Material y Método: Se evalúa información clínica registrada en forma prospectiva en base de datos de todos los nacidos vivos en el período Noviembre 1998 a Agosto 2008, se estudian neonatos con y sin trisomía 21 y se determina curva de incidencia por grupo de edad materna. Resultados: Población en evaluación 62.626 nacidos vivos de los cuales 132 presentan Tr21 riesgo global 1: 474 con incidencia de 2,11 por mil nacidos vivos. Los riesgos por de edad materna agrupados de la forma clásicamente descrita en la literatura se expresan en tabla 1. Dado la marcada variación de riesgo sobre los 35 años se expresan estos en rangos

más acotados de edad materna. La información de riesgo por nuevos grupos de edad de este estudio se entrega en la tabla 2. Para nuestra población el grupo de menor riesgo es 25 a 29 años y el la es 25 a 29 años y el la
tabla 3 se expresa los tabla 3 se expresa los
riesgos relativos de Tr21 considerando este grupo de edad como RR Conclusión: Este estudio revela una incidencia glorevela una incidencia global de Tr21 en 2,11 por lente a $1 / 474$ nacidos vivos. Por grupos de edad materna el riesgo relativo materna el riesgo relativo cativa a partir de los 35 años. Se entrega esta información para conocer los riesgos de presentar Tr21 a diferentes edades Tr21 a diferentes edades maternas y se expresa en grupos más acotados de edad por las grandes variaciones de incidencia según la edad de planificar embarazo.

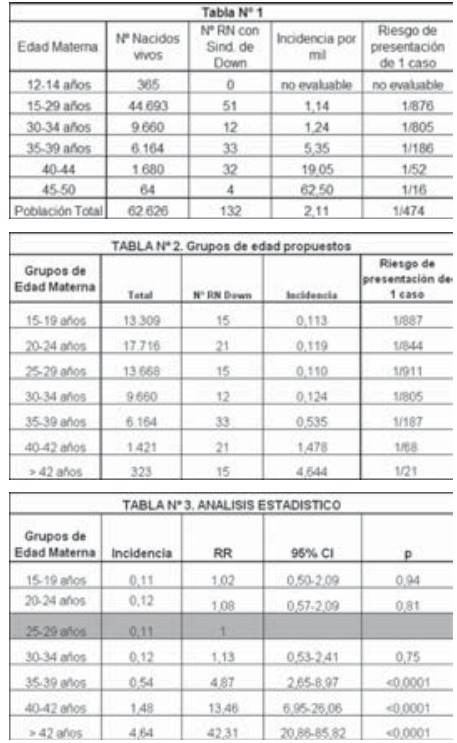




\section{ENFOQUE MULTIDISCIPLINARIO EN EL DIAGNÓSTICO DIFERENCIAL} DE DISPLASIA ESQUELÉTICA CONGÉNITAS LETALES

Moreno $\mathbf{S R}^{1,2,3}$, Arriagada $R S^{2}$, Pérez $\mathrm{ML}^{4,5}$, Veloso $P L^{5}$, Ojeda $B M E^{2}$, Garrido IC $C^{4}$, Pierola $T A^{4}$

${ }^{1}$ ICBM-Facultad Medicina, Universidad de Chile, ${ }^{2}$ Hospital Regional Rancagua, ${ }^{3}$ SSM Sur, ${ }^{4}$ Imagenología, Hospital Clínico Universidad de Chile, ${ }^{5} \mathrm{Hospita}$ Roberto del Río.

Las displasias esqueléticas congénitas letales (DECL) son un grupo poco frecuente de malformaciones osteocondrodisplasias, de incidencia menor a 1:25.000 RNV, en que el diagnóstico prenatal frecuentemente no siempre se logra en un feto con RCIU y "huesos largos cortos". Se presentan varios casos que ejemplifican su estudio, y que en algunos casos, complementamos con estudio imagenológico avanzado de resonancia magnética (RM) y TAC con reconstrucción esquelética, y anatomía patológica. La displasia tanatofórica tipo I, es la forma más frecuente de DECL, antiguamente confundida con la acondroplasia, de la cual debe ser diferenciada. Presentamos el estudio con radiografía, RM y TAC, y anatomía patológica osteocondral. La osteogénesis imperfecta congénita tipo II, se incluye entre las DECL. Su sospecha prenatal es por fracturas óseas múltiples. Diferenciamos casos del tipo A y B. Presentamos el estudio con radiografía, RM y TAC. El síndrome costillas cortas-polidactilia, evidente en una radiografía convencional, difiere en el modo de herencia, siendo el único de los casos estudiados de herencia autosómica recesiva. El diagnóstico se confirma al nacer con el examen clínico y radiológico de todo el recién nacido, la autopsia convencional tiene poco rendimiento diagnóstico en este tipo de malformaciones. La RM permite una autopsia no invasiva y la reconstrucción esquelética del TAC, permite identifica mejor el componente osteocartilaginoso comprometido en cada uno de ellos, y que puede ser de mayor utilidad en otras DECL, con mayor compromiso condral, que no hemos estudiado aún. Se refuerza el concepto de estudio multidiciplinario en el diagnótico del malformado para lograr un asesoramiento adecuado a la familia.
PREVALENCIA SÍNDROME DOWN EN REGIÓN DE O'HIGGINS. PERÍODO 2001 AL 2005

Moreno $\mathbf{S R}^{1,2}$, Ojeda $B M E^{1}$.

${ }^{1}$ Hospital Regional Rancagua, SS O'Higgins y ${ }^{2}$ SSM Sur y ICBM-Facultad Medicina, Universidad de Chile.

La Región de O'Higgins tiene en el Hospital Regional Rancagua (HRR) la prevalencia más alta de síndrome Down (SD), del país. Sin embargo, no se tienen estudios en la Región, que permitan saber si es un fenómeno regional o sólo una acumulación en el hospital de derivación. Se presenta un relevamiento de todos los casos de SD, nacidos en la región durante el período 2000 al 2005. Se describe la prevalencia y algunas de sus características epidemiológicas en el contexto regional. Se informaron 134 posibles casos de SD, en dos casos $(1,49 \%)$ se descarto el diagnóstico por el especialista. Sólo 9 de los 132 casos de SD confirmados $(6,8 \%)$, nacen en Clínicas particulares y son el $10 \%$ de los nacidos en Rancagua. La prevalencia por ocurrencia en la región durante el período en estudio es 18,9 en tasas por 10.000 NV, siendo en HRR de 28, en SS O'Higgins de 21,97 y en privados 6,5 . Los hospitales y postas con menos de $400 \mathrm{NV}$ no tuvieron casos de SD. Los hospitales públicos, tuvieron tasas superiores a las esperadas, salvo en Santa Cruz y San Vicente de Tagua Tagua, con tasas inferiores a las esperadas, con 10,6 y 7,5, respectivamente. La proporción por provincias de la región, en cuanto a población y a casos SD son proporcionales, as son, en Cachapoal $69,54 \%$ y $78,41 \%$, en Colchagua $25,18 \%$ y $4,77 \%$, y en Cardenal Caro $5,27 \%$ y $6,81 \%$, respectivamente. La edad promedio materna, es de 32,13 años, rango entre 15 a 45 años. El $48,6 \%$ de las madres tiene menos de 35 años. La frecuencia de los genes del sistema $A B O$ es: alelo $A=0,2202$, alelo $\mathrm{B}=0,0981$ y alelo $\mathrm{O}=0,6815$ y del sistema Rhesus, el alelo negativo es 0,2995 . Los casos son de sexo masculino el $54,55 \%$. El origen mapuche, está en el 1,6\% de los apellidos maternos y en el 2,1\% de paternos. En 66 de los 132 casos diagnosticados, o sea $50 \%$ están en control por la especialidad. De estos $27,27 \%$ tienen familiares de síndrome Down, al menos uno de los afectados tenía una trisomía 21 libre. Demostramos que la alta prevalencia de SD, es un fenómeno regional, que por sus características epidemiológicas peculiares, debería ser explicada por particularidades genético poblacionales o ambientales.
PREVALENCIA Y CARACTERÍSTICAS DEL SÍNDROME DOWN EN UN SERVICIO SALUD DE LA REGIÓN METROPOLITANA

\section{Moreno SR.}

Hospital Exequiel González Cortés y Barros Luco, SSM Sur.

Chile presenta alta prevalencia de síndrome Down, según lo comunicado por hospitales o clínicas en forma individual. La Unidad de Genética Hospital Exequie González Cortes, es referencia de los pacientes del Servicio Salud Metropolitano Sur (SSM Sur), y efectúa interconsultas a hospitalizados en Hospital Barros Luco, logrando en forma indirecta un registro de los síndrome Down (SD) de SSM Sur, de modo que, se obtiene por primera vez la prevalencia de SD de un área importante de la Región Metropolitana. Se presenta la prevalencia y características de los pacientes con SD, nacidos vivos (NV) en el SSM Sur entre e 2006 al primer semestre 2008. En el período estudiado nacen 30518 NV de los cuales 70 tienen SD, siendo una prevalencia de 22,9 en 10.000 , y riesgo de 1:436 NV en el SSM Sur. La prevalencia por 10.000 NV, por hospitales en el período estudiado, fue Barros Luco 34,31, El Pino 23,97, San Luis de Buin 18,98, Parroquial de San Bernardo 6,94 y Clínica San Bernardo 0,00. Las madres tienen una edad promedio de 30,9 años con rango entre 14 y 44 años. Existe antecedente familia de SD en el $21,4 \%$ de los casos. Presentan cardiopatía congénita el $72,8 \%$, de estas las tres más frecuentes son CIA $52,9 \%$, CIV $19,6 \%$ y Canal AV $7,8 \%$ Malformaciones digestivas tienen atresia duodenal $4,3 \%$, atresia esofágica 2,8\% y ano imperforado 2,8\%. Evolucionan con epilepsia 2,8\% y colelitiasis $2,8 \%$. Ninguno presenta hipotiroidismo congénito. Fallecen en período neonatal el $5,7 \%$. Destaca la alta prevalencia de SD para hospitales públicos, hay una asociación entre mayor número de NV y mayor prevalencia. Llama la atención el bajo promedio de edad materna, habiendo alto porcentaje de casos familiares. Existe una baja frecuencia de malformaciones congénitas que permitan una sospecha prenatal. A pesar de la alta frecuencia de malformaciones cardíacas, la mayoría no requiere operación y hay un bajo porcentaje de Canal AV. Los casos con SD del SSM Sur, presentan características epidemiológicas y de morbilidad que difieren con la literatura internacional, situación a considerar en programas de diagnóstico y seguimiento de SD en hospitales públicos de la Región Metropolitana.

\section{SALA DE ESTIMULACIÓN PRECOZ DOWN SUR}

\section{Figueroa $V^{\prime}$, Vivanco $A M^{2}$}

${ }^{1}$ Pediatra, ${ }^{2}$ Educadora Diferencial. Hospital San Francisco, Pucón.

Es sabido que el pronóstico cognitivo, motor y social de los niños con síndrome de Down y otras patologías que afectan el normal desarrollo cerebral depende de una temperana y efectiva estimulación. Las técnicas para desarrollar dicha estimulación pueden ser variadas pero deben responder a un plan o programa previamente organizado. En nuestro país existen varias instituciones que ofrecen este tipo de estimulación con apoyo multidisciplinario, en especial la fundación Teletón, pero la mayoría de ellas se encuentran en las grandes ciudades, dificultando la rehabilitación de niños que viven en zonas más alegadas. Para poder resolver esta problemática en el hospital de Pucón, una asociación de padres con al apoyo económico de la municipalidad crean el 2005 la sala de estimulación DownSur.La sala de Estimulación Temprana Downsur atiende actualmente a 15 niños, de 1 mes a 6 años, 12 con Síndrome de Down, 1 con Síndrome Hipotónico Generalizado, 1 con Síndrome de Williams, 1 con paladar fisurado. Además niños preescolares derivados desde Control Niño Sano del hospital con problemas del desarrollo. La sala cuenta una educadora diferencial, una auxiliar, un kinesiólogo, una educadora experta en lenguaje y la supervisión medica de una pediatra. Los niños tienen terapias individuales 2 a 3 veces por semana y los mayores de 3 años un día de terapias colectivas. En el transcurso de estos 3 años de funcionamiento se han logrado integrar a jardines o escuelas normales 7 de los 15 niños, con gran éxito, manteniendo su apoyo terapéutico en la sala. Esta experiencia de trabajo comunitario donde se une el equipo de salud, los educadores, y los padre puede ser reproducida en muchos otros rincones del país para dar cabida a los niños con necesidades especiales. 
SEGUIMIENTO DE PACIENTES CON SÍNDROME DE DOWN EN DOS
CENTROS HOSPITALARIOS: MORBILIDAD Y MORTALIDAD DURANTE CENTROS HOSPITALARIOS: MOR
EL PRIMER AÑO DE VIDA

Retamales $M N^{1}$, Moreno $A R^{2}$, González $S M^{2}$, Cerda $L J^{3}$, Lizama $C^{1}$ ${ }^{1}$ Departamento de Pediatría, Escuela de Medicina. Pontificia Universidad Católica de Chile. ${ }^{2}$ Servicio de Pediatría, Hospital Hernán Henríquez Aravena, Temuco, Chile.

Objetivos: El síndrome de Down (SD) corresponde a la anomalía cromosómica más frecuente, con mayor riesgo de presentar malformaciones asociadas y mortalidad que la población general.Estudios en Europa y Norteamérica muestran una sobrevida de $90-93 \%$ en el primer año de vida, mayor a lo reportado en Sudamérica alcanzando sólo al $74 \%$. Nuestro objetivo fue caracterizar la morbimortalidad durante el primer año de vida en pacientes con SD. Material y Método: Realizamos un estudio de cohorte prospectivo en niños con SD. Se incluyeron todos los niños nacidos durante el año 2006 con diagnóstico clínico de SD en dos hospitales chilenos. Se realizó registro de morbi-mortalidad, hospitalizaciones y diagnóstico nutricional cada 2 meses hasta los 12 meses de vida. Resultados: Se incluyeron 33 pacientes. El $78,8 \%$ fueron recién nacidos de término. La edad materna promedio fue de $33,2 \pm 7,8$ años. El $84,8 \%$ de los pacientes fueron hospitalizados en período neonatal. El 64,5\% presentó cardiopatía congénita, siendo más frecuentes los defectos aurículo-ventriculares $(25 \%)$ El $35 \%$ requirió cardiocirugía. Las patologías digestivas asociadas se presentaron en el $35 \%$. El $25,8 \%$ presentó hipotiroidismo. Diez pacientes cumplieron los criterios para hipoacusia durante el seguimiento. Un $52 \%$ de los pacientes fue evaluado por oftalmólogo durante el primer año, de ellos, 8 (50\%) presentaron alguna patología ocular, entre ellas estrabismo y obstrucción del conducto lagrimal, ninguno presentó catarata congénita. A los 2 meses el $54,8 \%$ tenía desnutrición. El 22,5\% tenía obesidad/sobrepeso a los 12 meses. Hubo un promedio de 5,38 1,83 infecciones respiratorias agudas (IRA) por paciente/año y $1,22 \pm 1,14$ hospitalizaciones no neonatales por niño/año. El 50\% de las hospitalizaciones fueron por IRA baja. Dos pacientes fallecieron, ambos por causa infecciosa, con una sobrevida de $93,6 \%$ a 12 meses. Conclusiones: El conocimiento de esta información nos permitirá mejorar el seguimiento actual de este grupo de niños, además de hacer evidente la necesidad de crear un programa nacional de evaluación y supervisión estandarizado de salud para niños con SD.

\section{PERFIL CLÍNICO DE PACIENTES HOSPITALIZADOS CON SÍNDROME} DE DOWN

Arancibia GMF, Cortés ZR, Lizama CM.

Servicio de Pediatría, Departamento de Pediatría. Hospital Clínico Pontificia Universidad Católica de Chile.

Introducción: Se conoce que los niños con Síndrome de Down (SD) pueden tener múltiples patologías asociadas y que éstas son motivo de hospitalización. En Chile hay escasa información al respecto. El objetivo de este estudio es caracterizar las patologías y hospitalización en este grupo de niños. Diseño: Estudio prospectivo, descriptivo en niños, menores de 15 años, con SD hospitalizados por cualquier causa en el Servicio de Pediatría del Hospital Clínico UC entre Enero y Agosto del año 2008. Resultados: Se identificó 21 ingresos. Dos presentaron más de un ingreso en el período estudiado. La edad promedio fue 2,3 años, con una estadía promedio de 4 días. El principal motivo de ingreso fue la resolución quirúrgica o estudio de cardiopatía congénita (CC) $(55,1 \%)$. Las principales causas de ingreso no cardiológico fueron neumonía (14\%), estudio de estridor $(9,5 \%)$ y fractura $(9,5 \%)$. De estos pacientes, un $90 \%$ tenía alguna CC. Un 19\% ingresó por causa infecciosa. En la evaluación inicial el 33\% tenía desnutrición o mal incremento ponderal, el 33\% tenía el antecedente de alguna patología gastrointestinal, un $28 \%$ alguna patología nefrourológica y 7 de 14 estudiados tenía patología tiroidea (6 hipotiroidismo). Un 16\% tenía trastorno de deglución que requería de alimentación por sonda nasogástrica o gastrostomía. La relación entre trastorno de deglución y desnutrición fue estadísticamente significativa $(p=0,04)$. Un $38,1 \%$ presentó morbilidad agregada durante la hospitalización, principalmente detección de hipotiroidismo (14,3\%). El 9,5\% presentó complicación infecciosa durante la estadía hospitalaria. El $28 \%$ ingresó a unidad de paciente crítico (UPC). En la serie reportada no hubo mortalidad. Se asoció a estadías mayores a 7 días: la menor edad, cardiocirugía y el haber estado en UPC. Conclusiones: Los pacientes con SD tienen múltiples patologías asociadas, sus principales problemas de salud que motivan hospitalización son las CC patologías gastrointestinales, infecciones respiratorias, como se muestra en nuestra serie. Destaca la alta frecuencia de CC encontrada en el grupo de pacientes ingresados por causa no cardiológica, así como también la alta frecuencia de patología digestiva y nefrourológica, la que es mayor a lo reportado para la población general de los niños con SD. A pesar de ser una serie con un alto número de pacientes cardiológico, la alta frecuencia de patologías asociada motiva a crear programas de seguimiento de prevención en este grupo.
CARACTERISTICAS DE RECIÉN NACIDOS CON SÍNDROME DOWN. HOSPITAL REGIONAL RANCAGUA 2001 AL 2007

Caro VN', Ojeda $B M E^{1}$, Moreno $S R^{1,2}$.

${ }^{1}$ Hospital Regional Rancagua, SS O'Higgins y ${ }^{2}$ SSM Sur y ICBM-Facultad Medicina, Universidad de Chile.

El Hospital Regional Rancagua (HRR) presenta una de las prevalencias más altas de síndrome Down (SD), del país. Se describen las características de los recién nacidos con síndrome Down (SD), en el del período 2001 al 2007. De 32.217 recién nacidos vivos (RNV) en el período en estudio, de ellos 87 tienen SD, con prevalencia de 27 por 10.000 RNV. Se describen las características en promedio o en su frecuencia en porcentaje, del embarazo y del recién nacido. Madres de los casos SD, tienen 32,1 años, 4,6\% 2,56 embarazos y antecedente familiar de SD $12,6 \%$, consanguinidad $1,1 \%$ y recurrencia $2,2 \%$. Embarazo cursa con enfermedad crónica $27,6 \%$ y aguda $52,9 \%$, siendo síntomas de aborto $10,3 \%$, el más frecuente. Parto es cesárea 33,3\%. Existe sospecha prenatal de malformación en $9,2 \%$. Los RNV con SD tienen apellido de origen mapuche $4,6 \%$, son de sexo masculino $55,2 \%$, peso $2.914,1 \mathrm{~g}$, edad gestacional 37,8 semanas, nacen prematuro $25,3 \%$, de estos $36,4 \%$ son pequeños para edad de gestación (PEG), en cambio, los de término son PEG 23,1\%. Presentan en el período neonatal cardiopatía sospechada $62,1 \%$ y confirmada $54 \%$, siendo por frecuencia CIA $24,1 \%$, CIV $16,1 \%$ y Canal AV $8 \%$, hay malformaciones digestivas $10,3 \%$ y otras malformaciones $6,8 \%$, con cataratas en $1,1 \%$. Fallecen $3,4 \%$. Llama la atención que las madres son jóvenes en promedio, habiendo alto porcentaje de casos familiares y recurrencia, mayor proporción de afectados de sexo masculino y de apellidos mapuches, que el 1,1\% que da el Censo 2002 para la región. La sospecha prenatal es baja, en forma concordante con la baja frecuencia de malformaciones que pudiera hacerla sospechar, como las malformaciones digestivas y cardíacas. De estas últimas, evidenciamos predominio de CIA y CIV, que frecuentemente no son AUGE para cardiopatía congénita, habiendo un bajo porcentaje de Canal AV. Los casos con SD del HRR, presentan características de morbilidad que difieren con la literatura internacional, situación a considerar en los programas de seguimiento de estos pacientes.

\section{EVALUACIÓN DE ÍNDICES DE SCREENING PARA BETA-TALASSEMIA} EN LA ANEMIA MICROCÍTICA DEL LACTANTE

Bracho $\boldsymbol{M}^{1}$, Dal Borgo $P^{2}$, Silva $R^{2}$, Cavieres $M^{2}$

${ }^{1}$ Programa Hematología-Oncología Infantil. Hospital Luis Calvo Mackenna. Universidad de Chile. ${ }^{2}$ Unidad de Hematología. Hospital Luis Calvo Mackenna.

Introducción: Anemia ferropriva (AF) y beta-talassemia (BT) son las causas más frecuentes de anemia microcítica, debiendo considerarse ambas en su evaluación, sobre todo en lactantes, donde la alta prevalencia de la primera puede su retrasar el diagnóstico de la segunda. Se han descrito diferentes índices de pesquisa para BT, pero ninguno ha sido evaluado en menores de 2 años. Objetivos: Comparar la sensibilidad y especificidad de las diferentes fórmulas de pesqisa descritas, elaboradas a partir de los índices eritrocitarios del hemograma. Material y Métodos: Se realizó un estudio retrospectivo, de casos y controles, en niños que consultaron por anemia microcítica entre los 6 y 35 meses de vida, definida como $\mathrm{Hb}<11 \mathrm{gr} \%$ y $\mathrm{VCM}<(70+$ edad). Se definió como "casos" a aquellos niños con una $\mathrm{HbA} 2>3,5 \%$ demostrada por electroforesis; como "controles" se designó a quienes normalizaron sus índices hematológicos con terapia hemínica (sulfato ferroso $5 \mathrm{mg} / \mathrm{kg} /$ día) después de 3 meses. Se analizaron los hemogramas de ingreso y después de tres meses de terapia. Se excluyeron a los niños con patología crónica y con información incompleta. Los resultados se analizaron con 11 fórmulas (Tabla 1), determinando la sensibilidad, especificidad, VPP, VPN, efectividad e índice de Youden para cada una. Resultados: Se reclutaron 47 casos y 47 controles, con características demográficas comparables (Tabla 2). Se calcularon los diferentes índices, los cuales no mostraron rendimientos satisfactorios en la pesquisa de BT (Tabla 3). Considerando que $18 / 47(38,3 \%)$ niños con BT presentaron signos de ferropenia, se analizaron los hemogramas después de 3 meses de tratamiento, obteniéndose una mejoría parcial, pero no significativa (Tabla 4). Discusión: Ninguno de los índices analizados fue capaz de discriminar satisfactoriamente entre AF y BT. Estos resultados son más desalentadores que en estudios realizados en adultos, quizás debido a que los valores de corte están establecidos con patrones hematológicos mayores. Un recuento de GR $>5.000 .000$ de GR sería un buen método de screening, pero depende de de los depósitos de hierro, por lo que pierde validez en este grupo etario por la alta prevalencia de ferropenia. Conclusiones: Los índices existentes para el screening de BT no aportan seguridad en el diagnóstico diferencial de las anemias microcíticas en lactantes. La sospecha debe confirmarse mediante electroforesis de hemoglobina, ante un niño que no responde a la terapia hemínica. 


\section{EVALUACIÓN DE "GUÍA PARA LA TRANSFUSIÓN DE GLÓBULOS ROJOS DESPLASMATIZADOS" EN RECIÉN NACIDOS DE MUY BAJO PESO DE NACIMIENTO, HOSPITAL CLÍNICO REGIONAL VALDIVIA, 2005-2006}

Caro D, Kuschel C, Mosqueira L, Folatre I, Cea G, Martínez P, Yilorm M, Ide $A$.

Instituto de Pediatría, Universidad Austral de Chile. Unidad de Pediatría, Hospita Clínico Regional Valdivia.

Introducción: Los Recién Nacidos de Muy Bajo Peso de Nacimiento (RNMPBN) tienen una predisposición a presentar anemia, por una vida media acortada de los eritrocitos fetales, una gran velocidad de crecimiento asociada a un aumento del volumen sanguíneo, producción inadecuada de eritropoyetina y extracciones sanguíneas. En 1998, se elaboró y puso en marcha "Recomendaciones Para la Práctica Transfusional Neonatal, Hospital Clínico Regional Valdivia". Estudios locales evidenciaron que durante $1995-1997$ y $2000-2002$ el $89,4 \%$ y $77,1 \%$ de los RNMBPN fue transfundido siendo la media de transfusiones y exposición a donantes diferentes 4,1 y 2,7 respectivamente. Objetivo: Evaluar la práctica transfusional de GRD en RNMBPN a diez años de la puesta en marcha de las guías locales, vigilar el descenso del porcentaje de las transfusiones y los factores asociados a mayor requerimiento transfusional. Material y Método: Estudio retrospectivo, descriptivo, que incluyó todos los RNMBPN, mayores de $72 \mathrm{hrs}$ de vida, egresados vivos de Neonatología, Hospital Clínico Regional Valdivia entre el 01.01.05 y el 31.12.06. Se determinaron medidas de frecuencia (prevalencia) y de asociación (OR), con un intervalo de confianza de $95 \%$ y un nivel de significación de alfa de un $5 \%$. Los datos fueron analizados mediante el programa Statistix versión 8.0. Resultados: El porcentaje de receptores fue de $67,7 \%$. La media de transfusiones de GR fue de 2,13. Las variables asociadas a un mayor riesgo de recibir una transfusión fueron en primer lugar la Displasia Broncopulmonar (DBP), seguida de la EG menor a 30 semanas y a continuación la Sepsis, Enfermedad de Membrana Hialina $(E M H)$ y el uso de surfactante. Conclusiones: Con la implementación de guías de práctica clínica transfucional se ha logrado reducir de forma significativa el porcentaje de receptores de transfusiones en los RNMBPN en el Hospital Clínico Regional Valdivia. La patología pulmonar del prematuro (DBP, EMH), la EG menor a 30 semanas y la sepsis son las principales variables asociadas a mayor requerimiento transfusional en estos recién nacidos.
SÍNDROME DE TAR: UN CASO CLÍNICO

Bahamonde CC, Alamos LL, Aguilera SG. Hospital Regional Rancagua.

El síndrome TAR es un trastorno hematológico congénito con defecto esqueléti$\mathrm{co}$, caracterizado por una trombocitopenia y ausencia de los radios. Lo característico es la trombocitopenia neonatal asociada a una disminución o ausencia de los megacariocitos. Se inicia el fenómeno hemorrágico como petequias, purpura, epistaxis, melena, hemoptisis, hematuria, o hematemesis antes de la primera semana de vida. Se asocia a labio leporino o palatino, cardiopatías congénitas, anomalías del oído, atresia esofágica, deformidad de Klippel-Feil, anomalías renales, espina bífida. Todos tienen algún otro defecto óseo, las extremidades están más afectadas que el tronco y los brazos más que las piernas. Caso clínico: Fecha de nacimiento: 20/04/2008. Parto por cesárea Apgar 8-9, 38 semanas de gestación. Peso de nacimiento 2.700 grs. Talla $33,5 \mathrm{~cm}$. Sexo Femenino. Sin antecedentes de drogas en el embarazo, consanguinidad o enfermedades genéticas familiares. Destaca al examen físico de RN hipoplasia de extremidades superiores, soplo cardíaco sistólico 2/6. Presenta SDR del cual se recupera. Evoluciona con aparición de petequias y hepatomegalia. Exámenes muestran leucopenia, plaquetopenia, $62 \%$ de granulocitos. Se trata como Sepsis. Rx de extremidades superiores muestran acortamiento óseo (agenesia radial e hipoplasia cubital). Genetista sugiere un Síndrome de TAR. Se realiza cariograma. Es hospitalizada al mes de edad por presentar petequias en pared abdominal, cráneo, cara y tórax. Exámenes muestran Hto 15,9\%, plaquetas 8.000 , mielograma muestra ausencia de megacariocitos con lo cual. se diagnostica Sd. de TAR. Actualmente la paciente tiene 5 meses, ha presentado múltiples hospitalizaciones por trombocitopenia que han sido tratadas con transfusión de plaquetas. Comentario: El síndrome de TAR fue descrito por primera vez en la década del 50 y los primeros casos fueron publicados en 1969, su incidencia es de 0,42 por 100.000 recién nacidos. Hombre: Mujer como 1: 1. El 95\% de de los sangramientos ocurren en los primeros 4 meses, como en nuestro paciente. El tratamiento es sintomático con tranfusiones de plaquetas durante las crisis. Es pronóstico es malo, falleciendo el $40 \%$ en el primer año de vida, por hemorragias digestivas o cerebrales, después, con los años la mortalidad disminuye ya que las hemorragias son menos intensas, incluso con un nivel de sobrevida igual a la población general por lo tanto, es fundamental realizar un diagnóstico precoz de la enfermedad y un manejo correcto en las primeras etapas de la vida.

\section{HEPATOBLASTOMA CON DEBUT METASTÁSICO ATÍPICO; REPORTE DE UN CASO CLÍNICO Y REVISIÓN}

de Mayo $G T^{\prime}$, López $V^{\prime}$, Glaser KP²

1 Internos; Facultad de Medicina Universidad de los Andes. ${ }^{2}$ Servicio Hematooncología infantil, Hospital Militar de Santiago (HOSMIL).

Presentamos el caso de un lactante de 1 años 4 meses sin antecedentes mórbidos previos que consulta en Calama por un cuadro de 4 días de evolución caracterizado por compromiso del estado general, fiebre hasta $39{ }^{\circ} \mathrm{C}$ y diarrea. Al examen físico se evidencia masa abdominal en hipocondrio y flanco derechos. Ecotomografía revela masa hepática de $8 \times 9 \mathrm{cms}$ ubicada en lóbulo derecho, por lo cual es trasladado a HOSMIL para estudio. Destacan niveles de AFP de 112.000, FA de 407,4 y LDH de 766. TAC de abdomen y pelvis revela tumo sólido expansivo que compromete todo el lóbulo hepático derecho, nodular y heterogéneo con centro necrótico y focos de calcificación, sin compromiso vascular. Biopsia percutánea revela tumor constituido por hepatoblastoma de tipo combinado epitelial y mesenquimal. Inmunohistoquímica (+) para Hep Par-1 en el componente indiferenciado, y negativa para el foco tumoral bien diferenciado. Citoqueratina $8(+)$ para ambos focos tumorales. Se concluye hepatoblastoma PRETEXT II. Se inicia protocolo terapéutico PINDA con 4 ciclos de quimioterapia cisplatino. Volumen tumoral disminuye $20 \%$ y AFP baja a 27.700 . Se realiza hemihepatectomía del lóbulo derecho y colecistectomía. Se completan 4 ciclos más de QMT cisplatino acorde a protocolo. Controles posteriores con TAC no muestran evidencias de recidivas, niveles de AFP normales. Nueve meses después, consulta por cuadro febril hasta $40^{\circ} \mathrm{C}$ en contexto de una virosis respiratoria VRS (+). Se agrega además intenso dolor lumbar y en pierna izquierda. Ingresa para estudio en unidad. Destaca AFP en niveles normales, ecotomografía abdominal sin alteraciones, LDH 500 y FA de 774. Cintigrama óseo muestra alteración de la captación en focos T10-T12, parrilla costal bilateral y diáfisis femoral izquierda. RNM revela extenso compromiso sustitutivo de médula ósea. Biopsia ósea concluye metástasis de tumor epitelial sólido indiferenciado compatible con hepatoblastoma. Inmunihistoquímica (+) para citoqueratinas 18, 8, y Hep Par 1. Se comienza con protocolo para recidiva de tumores sólidos sin respuesta, falleciendo meses después. Discusión: Los tumores primarios hepáticos son infrecuentes en pediatría (3\%), siendo el hepatoblastoma el tumor maligno más frecuente (3). Las metástasis óseas aisladas son inusuales, siendo el pulmón el sitio principal. Hallazgos pudieran corresponder a metástasis de componente indiferecniado del hepatoblastoma, donde se ha descrito poca o nula elevación de $\operatorname{AFP}(1,2)$.
ROL DE LA ERRADICACIÓN DE LA INFECCIÓN POR HELICOBACTER
PYLORI EN EL TRATAMIENTO DE NIÑOS CON PÚRPURA PYLORI EN EL TRATAMIENTO DE NIÑOS
TROMBOCITOPÉNICO IDIOPÁTICO CRÓNICO

Villagrán A, González CG, Serrano C, Zúñiga $P$, Wiestruck ME, Harris PR Departamento de Pediatría, Unidad de Gastroenterología y Nutrición, Facultad de Medicina, Pontificia Universidad Católica de Chile.

Introducción: El púrpura trombocitopénico idiopático (PTI) es una patología generalmente benigna y transitoria. Sin embargo, un $10 \%$ de los niños con PTI desarrollarán un cuadro crónico. Recientemente se ha descrito una relación entre la erradicación de la bacteria Helicobacter pylori, agente causal de patologías gastrointestinales; con la mejoría e incluso normalización de las plaquetas en adultos con PTI. Objetivos. Evaluar el rol de la infección por $H$. pylori en niños con PTI crónico y estimar el rol que desempeña su erradicación en el tratamiento del PTI. Materiales y Métodos: Prospectivamente, se reclutaron pacientes menores de 18 años con PTI crónico, previo consentimiento informado por los padres de los niños. Se obtuvo una muestra de deposiciones al momento del ingreso. Todos los pacientes recibieron tratamiento de erradicación por 2 semanas, con claritromicina ( $15 \mathrm{mg} / \mathrm{kg} / \mathrm{día}$ ), amoxicilina ( $50 \mathrm{mg} / \mathrm{kg} / \mathrm{día}$ ) y lanzoprazol (1 mg/kg/día). Luego de 4 semanas se obtuvo una segunda muestra de deposiciones. La infección por $H$. pylori se determinó en ambas muestras por un test de detección de antígenos en deposiciones (HpSA). Recuentos plaquetarios se obtuvieron antes y después de la erradicación. Resultados: Se reclutaron 8 pacientes (50\% mujeres), con una edad promedio de $11,6+3,4$ años. El promedio de las plaquetas al diagnosticar el PTI fue de $32.438+31.124$ plaquetas $/ \mathrm{mm}^{3}$. No se encontraron diferencias significativas en la edad, sexo e índice de masa corporal, entre infectados y no infectados. En total $4(50 \%)$ niños estaban infectados, lográndose erradicar a 3 de ellos $(75 \%)$. No hubieron diferencias en el promedio de las plaquetas entre infectados $\left(17.750+21.500\right.$ plaquetas $\left./ \mathrm{mm}^{3}\right)$ y no infectados $\left(42.124+34.968\right.$ plaquetas $\left./ \mathrm{mm}^{3}\right)(\mathrm{p}=\mathrm{NS})$ al momento del diagnóstico. Los niños erradicados no mostraron diferencias en el promedio de las plaquetas a los 2 meses de seguimiento. Sin embargo, se observa una tendencia al alza luego de la erradicación $(7.333+6.506$ al momento del diagnóstico; $47.333+42.665$ plaquetas $/ \mathrm{mm}^{3}$ luego de la erradicación). Conclusiones: Este estudio reporta el comportamiento de tres pacientes con PTI erradicados para $H$. Pylori, observándose un aumento de las plaquetas luego del tratamiento. Un aumento en el número de casos y tiempo de seguimiento, permitirá confirmar la asociación entre la mejoría en los parámetros sanguíneos de niños con PTI y la erradicación de la bacteria. 


\section{PRESENTACIÓN DE UN CASO: SÍNDROME TAR}

Cisterna C, Neira L, Jaime C, Tobar A, Bajaña G. Hospital Gustavo Fricke. Universidad de Valparaíso.

El síndrome TAR se caracteriza por ausencia radial bilateral con presencia de ambos pulgares y trombocitopenia. Trastorno genético autosómico recesivo (microdeleción 22q11) de incidencia variable de 0,5 a 1/500.000 hasta 1/100.000 RNV. Se pueden asociar además otras anomalías tanto óseas, cardíacas, digestivas y hematológicas. El pronóstico está dado por el nivel de plaquetas: $40 \%$ fallece durante los primeros años de vida por hemorragias y el riesgo disminuye con la edad. El diagnóstico diferencial se establece principalmente con el de Fanconi y el de Holt-Oram. Aún hay pocos casos publicados en el mundo y los grupos con mayor casuística no superan los 65 pacientes. No hay una consenso en el manejo y es empírico, orientado a mejorar el recuento plaquetario. Etiológicamente hay magacariopoyesis y trombopoyesis ineficaz por falta de respuesta a la trombopoyetina a pesar de la expresión normal de su receptor en megacariocitos, atribuido a bloqueo de la diferenciación del precursor megacariocítico. En Chile el primer caso se publicó en 1977 en Coquimbo y fue fatal; el siguiente en 1986 en Santiago, son gemelas que aún viven. Nuestro caso corresponde a una paciente de sexo femenino con diagnóstico antenatal de dismorfia de antebrazos y cardiopatía congénita (CIA, CIV). Nació en Arica, debutó con trombocitopenia severa durante el período neonatal. Se estableció el síndrome, asociado a subluxación de caderas, luxación de rodillas sospecha clínica de intolerancia a la proteína de leche de vaca; sin confirmación genética. A las cinco semanas de vida ingresó a nuestro centro tras descompensarse por diarrea aguda que requirió manejo en $\mathrm{UCl}$ y cursó con falla cardíaca congestiva, HTP severa y hemorragia digestiva. Tres semanas más tarde, ya estable, fue operada en el Hospital Luis Calvo Mackenna: cierre de CIV, CIA y ligadura de ductus, con buena evolución. Luego permaneció hospitalizada en Viña del Ma por varias semanas hasta lograr mejoría nutricional y de sus niveles plaquetarios (sobre 10.000), este último se logró con corticoides orales y transfusiones de plaquetas, que en este momento, a los 7 meses de vida son bisemanales. Conclusión: El síndrome TAR requiere un alto índice de sospecha: ante recién nacidos con dismorfias de sus antebrazos medir plaquetas ya que su evolución sin un manejo adecuado es fatal.

\section{TROMBOCITEMIA ESENCIAL: CASO CLÍNICO}

Lehmann P, Folatre I, Cea G, Martínez P, Yilorm M. Instituto de Pediatría, Universidad Austral de Chile, Servicio de Pediatría, Unidad de Hematooncología, Hospital Clínico Regional Valdivia.

Introducción: En el $82 \%$ de los casos, la causa de recuentos plaquetarios elevados, es reactiva a infecciones, esplenectomía, enfermedades neoplásicas trauma. Los síndromes mieloproliferativos crónicos aportan con $14 \%$. Trombocitemia primaria o esencial, es un desorden adquirido de la médula ósea, que puede presentarse a cualquier edad; el diagnóstico se basa en recuentos plaquetarios elevados, plaquetas morfológica y funcionalmente alteradas y cambios en la médula ósea, con megacariocitos anormales. Este diagnóstico se plantea como uno de exclusión. Objetivo: Reportar la presentación de un caso clínico de Trombocitemia Esencial. Caso clínico: Niña de 8 años, quien inició estudio en enero 2006, por recuentos plaquetarios de 2.877.000, 2.271.000 y $2.394 .000 / \mathrm{mm}^{3}$. Padres no consanguíneos sanos; examen físico y laboratorio normales; mielograma con moderada hiperplasia megacariopoyética de la médula ósea; ecotomografía abdominal normal. Inasistente a controles hasta julio 2007 en que consultó por bronquitis aguda, pesquisándose trombocitosis de $2.953 .000 / \mathrm{mm}^{3}$, con aumento progresivo a $5.404 .000 / \mathrm{mm}^{3}$, asociado a signos de laboratorio de hipercatabolismo, por lo que inició profilaxis de síndrome de lisis tumoral, con buena respuesta. Dentro de los exámenes destacaron: fosfatasas alcalinas leucocitarias aumentadas, hemosiderina medular disminuída, con sideroblastos disminuídos y sideroblastos en anillo aumentados, hemoglobina fetal $0 \%$. Pruebas de coagulación y factor von Willebrand, normal tr (9:22) y jak 2 negativos en sangre medular; exámenes concordantes con síndrome mieloproliferativo crónico: Trombocitemia Esencial. Inició tratamiento con Hidroxiurea con buena respuesta. Último control en septiembre 2008, con recuento plaquetario de $300.000 / \mathrm{mm}^{3}$. Discusión: Trombocitemia Esencial es una enfermedad mieloproliferativa clonal, que compromete la línea megacariocítica, caracterizándose por aumento de megacariocitos maduros en la médula ósea. En sangre periférica se aprecia trombocitosis. La incidencia es de 1-2,5/100.000 individuos al año, sin predilección por sexo. Clínicamente los pacientes son asintomáticos, pero, $25-30 \%$ de ellos presentan antecedentes de episodios subclínicos de trombosis y/o hemorragia. No hay alteración genética específica. Un cariotipo anormal se encuentra sólo en $5-10 \%$ de los pacientes, siendo los más frecuentes: (13q22); $+8 \mathrm{y}+9$. Se ha observado que el ascenso de los niveles plasmáticos de fibrinógeno, sobre $500 \mathrm{mg} / \mathrm{dl}$ y aumento de proteína $\mathrm{C}$ reactiva, son sugerentes de trombocitosis reactiva.
REACCIONES ADVERSAS A L-ASPARAGINASA, EN NIÑOS MENORES DE 15 AÑOS, EN TRATAMIENTO POR LEUCEMIA LINFOBLÁSTICA AGUDA, HOSPITAL CLÍNICO REGIONAL VALDIVIA (2000-2007)

\author{
Oyedo PS, Kyonen LM, Folatre BI, Villa ZL. \\ Hospital Clínico Regional Valdivia.
}

Introducción: En protocolos de tratamiento para Leucemia Linfoblástica Aguda (LLA) un pilar fundamental es el medicamento L-asparaginasa (L-ASP), aún cuando provoca una amplia gama de reacciones adversas (RAM).Objetivo: evaluar y describir el perfil de RAM a E. coli L-ASP en menores de 15 años con diagnóstico de LLA, atendidos en el HCRV. Pacientes y Método: Revisión retrospectiva, de historias clínicas de todos los pacientes tratados por LLA en e HCRV entre Mayo/2000 y Abril/2007 ( $n=91)$. Las sospechas se evaluaron aplicando el Algoritmo de Causalidad del Sistema Español de Farmacovigilancia, para posterior análisis con estadística descriptiva e inferencial y discusión de los resultados. Resultados: Se estudiaron 79 pacientes, 1 a 14 años. Se evaluaron 109 sospechas clasificándose a través del algoritmo como: definitivas, $n=24$; probables, $n=33$; posibles, $n=32$; condicionales, $n=14$ e improbables, $n=6$. En pacientes con sospechas definitivas y probables la incidencia de RAM fue 60 $\%$. A través de un Análisis de Correspondencia Múltiple (ACM) se identificaron gráficamente dos grupos de RAM (inmunológicas y hemostáticas) y variables relacionadas a éstas, como dosis y número de dosis de L-ASP administradas y, asociación a corticoides. El 35,4\% de los pacientes desarrolló RAM Inmunológica destacando eritema (55\%) y anafilaxia (15.2\%); se presentaron en etapa reinducción (19/33), entre la $7^{\text {a }}$ y $12^{\text {a }}$ dosis de L-ASP (25/33), aumentando la probabilidad de RAM desde la $7^{\mathrm{a}}$ dosis $(6,1 \%$ por dosis). Un $27,5 \%$ desarrolló RAM Hemostática, caracterizada por disminución de niveles plasmáticos de fibrinógeno $(95,2 \%)$; ocurrieron en etapa inducción $(20 / 21)$ y entre la $1^{\mathrm{a}}$ y $6^{\mathrm{a}}$ dosis (19/21). Se determinó a través de análisis de varianza (ANOVA) disminución significativa de niveles de fibrinógeno $(p<0,001)$, en distintos períodos de tratamiento, por uso de L-ASP. Se identificaron alteraciones transitorias de test de función hepática $(2,5 \%)$ y alteraciones gastrointestinales $(1,3 \%)$. Se determinó aumento, en más de $50 \%$, de tasas de RAM L-ASP/año, en un período de una década. Conclusiones: Un alto número de pacientes experimenta una o más RAM a L-ASP, de distinta índole y gravedad, cuya incidencia es mayor a la reportada en la literatura. El perfil de RAM a L-ASP encontrado, está dentro de los parámetros publicados internacionalmente por sistema afectado. La aplicación del algoritmo de causalidad, permitió realizar, frente a cada sospecha de RAM, una evaluación sistemática y estructurada.

\section{HISTIOCITOSIS: DESCRIPCIÓN DE UN CASO CLÍNICO}

Reyes $\boldsymbol{B}^{1}$, Pérez $V^{2}$, Varas $M^{2}$

${ }^{1}$ Becada Pediatría. ${ }^{2}$ Pediatra Hemato-Oncóloga. Universidad de Chile. Hospital San Juan de Dios.

Introducción: La Histiocitosis es una entidad poco frecuente caracterizada por la proliferación de células dendríticas de Langerhans $(C L)$. La CL es la principa célula presentadora de antígeno y tiene un importante papel en la fase inicial de la respuesta inmune. La etiopatogenia de esta enfermedad aún no es bien conocida. Sus manifestaciones son variadas, existiendo formas leves a agresivas. Puede afectar a la mayoría de los órganos, siendo las más comunes las presentaciones ósea (lesiones líticas), cutánea, linfática, hepática, esplénica, pulmonar, medular y de SNC (Diabetes Insípida). Los síntomas más frecuentes son dolor y aumento de volumen de partes blandas, lesiones cutáneas, otitis, poliuria, polidipsia y fiebre. Objetivo: Reporte de un caso clínico de difícil diagnóstico en pediatría por su rara frecuencia y presentación multisistémica. Caso Clínico: Paciente de dos años con antecedente de talla baja. Cuadro de un año de evolución caracterizado por aparición de aumento de volumen en las regiones frontal y temporal bilaterales. Asociado presenta polidipsia y poliuria Destaca la aparición de lesiones descamativas y pruriginosas en dorso de espalda y región retroauricular bilateral. Presentó dos episodios de otorragia izquierda espontánea. Desde Atención primaria se deriva para estudio. Se realiza TAC cerebral que demuestra múltiples lesiones líticas del cráneo, peñasco, región mandibular y facial bilaterales concordantes con Histiocitosis. Se realizó biopsia de lesión cutánea compatible con Histiocitosis de células de Langerhans. Se deriva a Oncología para estudio y tratamiento. Se realiza test de supresión hídrica que resultó positivo para diabetes insípida. Inició tratamiento con desmopresina. Cintigrama óseo muestra lesión lítica en vértebra L1. Del estudio destaca ausencia de compromiso hematológico, medular (marcador CD1 negativo), hepático, esplénico, pulmonar ni neurológico. La paciente fue diagnosticada como Histiocitosis en etapa II. Actualmente se encuentra recibiendo cursos de quimioterapia con prednisona y vinblastina según protocolo PINDA. Conclusiones: La Histiocitosis es una patología poco frecuente en pediatría. Sus variadas formas de presentación y el poco conocimiento de éstas hace difícil su diagnóstico en la práctica habitual. Es frecuente la derivación a múltiples especialidades haciendo difícil la unificación del diagnóstico y retrasando el inicio del tratamiento. Es por lo anterior importante como pediatras, conocer esta patología y sus síntomas para realizar un diagnóstico y derivación oportuna. 
PERFIL EPIDEMIOLÓGICO DE LOS CASOS DE RETINOBLASTOMA ENTRE LOS AÑOS 1990-2008 HOSPITAL REGIONAL VALDIVIA

Sánchez CR, Pivcevic CD, Martínez MP, Folatre BI, Cea SG. Hospital Regional Valdivia.

Introducción: Retinoblastoma es una neoplasia maligna de la retina, patología intraocular maligna más frecuente de la niñez con incidencia promedio anual de 11 casos nuevos por millón en menores de 5 años. Representa el $11 \%$ de los cánceres en menores de 1 año y un $3 \%$ de todos lo cánceres diagnosticados en menores de 15 años. Afecta de igual forma a razas y sexo. Se dividen según Lateralidad, Focalidad y Genética y se clasifican según extensión y localización del retinoblasoma intraocular (Reese-Ellsworth Staging for Intraocula Retinoblastoma). Un $40 \%$ son hereditarios y de éstos la mayoría bilateral. E $60 \%$ restante son no hereditarios principalmente unilateral y unifocal. La enfermedad metastásica no es poco frecuente en naciones en vías de desarrollo. Se manifiesta con leucocoria, estrabismo, disminución de la agudeza visual, hifema hemoragia vítrea, etc. El diagnóstico lo hace el oftalmólogo con ayuda imagenológica y el tratamiento el pediatra oncólogo, el cual va a depender de la extensión intra y extraocular de la enfermedad (QMT y RDT sistémica, QMT local y enucleación). La deleción del cromosoma $13 q$ asociado al gen supreso RB1 conlleva a un aumento del riesgo de presentar Retinoblastoma y de desarrollar una segunda neoplasia maligna como el osteosarcoma, melanoma, leucemia, linfoma, y cáncer de mama. Objetivo: Determinar las características clínicas y factores epidemiológicos de los casos de Retinoblastoma- Hemato Oncología Pediátrica del HBV entre los años 1990-2008. Material y Métodos: Análisis retrospectivo-descriptivo. Se revisaron fichas clínicas de los casos en cuestión. Los datos fueron tabulados en planilla electrónica Microsoft Excel 2003 y analizados mediante Epi Info 2000. Resultados: La mayoría de los casos fueron varones (89\%), todos menores de 2 años 6 meses. El $50 \%$ tenía algúnos antecedentes mórbidos a diferencia de sus padres. El principal motivo de consulta es la alteración del brillo ocular en más de la mitad de los casos (56\%) y el signo más recurrente es la alteración del fondo de ojo en el $78 \%$ de los casos seguido de leucocoria en un $45 \%$. En 7 de los 9 casos no había antecedente de malformaciones asociadas. En un $45 \%$ ambos ojos se ven afectados. La lateralidad se da en partes iguales y la focalidad es de predominio unifocal salvo en caso hereditario. Sólo un caso tenía antecedente hereditario, confirmado con estudio genético. La imaginología más usada es la TAC cerebro y orbita en el $100 \%$ de los casos seguido de cintigrafía ósea y Radiografía tórax. El tratamiento más frecuente fue la enucleación + quimioterapia en un $34 \%$ de los casos. Por último en un $67 \%$ no se presento metástasis. Conclusión: Insistir en la importancia de evaluar el rojo pupilar en menores de edad como parte del examen físico ordinario realizado en la práctica médica diaria, y fondo de ojo oportuno con fin de pesquisar alguna alteración a tiempo y disminuir las consecuencias.

\section{CARACTERÍSTICAS CLÍNICAS Y EPIDEMIOLÓGICAS DE PACIENTES EGRESADOS CON DIAGNÓSTICO DE PÚRPURA TROMBOCITOPÉNICO INMUNE (PTI). 2001-2007}

Prüssing SL, Alamos LL, Leiva HH, Almeida TJ, Bunster SN. Lugar de Trabajo: Servicio de Pediatría, Hospital Regional Rancagua.

Introducción: EI PTI es una enfermedad de la hemostasia caracterizada por un aumento en la destrucción de las plaquetas circulantes, provocando una trombocitopenia. Se debe a una respuesta inadecuada del sistema inmune. Su curso en la mayoría de los casos es benigno y autolimitado, existiendo también evoluciones a la cronicidad. El estudio se orienta a descartar una enfermedad en la que la trombopenia es un elemento más del cuadro, lo que cambia el manejo y el pronóstico. Objetivos: Conocer las características clínicas y epidemiológicas de los pacientes hospitalizados con el diagnóstico de PTI, en el Servicio de Pediatría Hospital Regional Rancagua en el período 2001-2007. Material y Método: Revisión y obtención de datos de fichas clínicas de pacientes egresados con el diagnóstico de PTI. Se confecciona una base de datos y se somete a análisis estadístico en el programa SPSS 12.0. Las variables estudiadas incluyeron edad, sexo, comuna de residencia, forma de presentación, recuento plaquetario y tratamiento y evolución. Resultados: Se registran 15.324 egresos (años 20012007) el $2,4 \%$ en la categoría de enfermedades de la sangre, $17,3 \%$ corresponden al diagnóstico de PTI. Se identifican 48 pacientes de un total de 65 casos $58 \%$ hombres, la edad promedio fue de 6,47 años. En el $81 \%$ el recuento plaquetario fue < a 10.000, el promedio de días de estada fue de 5,29 días, el antecedente de factor previo no quedó claramente consignado en la ficha. El cuadro clínico consistió en petequias (97\%) que fueron el motivo de consulta, en el $88 \%$ aparecen equimosis, $36 \%$ sufren epistaxis, y $6,5 \%$ hemorragia digestiva. No se registraron cuadros graves ni hemorragias del SNC. El 8,8\% se manejó con observación, e $91,4 \%$ con corticoides y en $26,4 \%$ con gammaglobulina (asociado a corticoides) en el $45 \%$ se realizó mielograma, $80 \%$ de los pacientes permanecieron en control en el policlínico de hematología del CAE, presentando un curso crónico el $26 \%$ de los casos. Ocho pacientes requirieron de esplenectomía. Conclusiones: En nuestra serie al igual que lo descrito en la literatura no existe diferencia de sexo. Existe concordancia: en la edad de presentación, el carácter benigno de cuadro, la evolución a la cronicidad El promedio días de estada es algo superio a indicadores del servicio. Evaluamos como adecuado el manejo. Insistimos en la necesidad de elevar la calidad de la ficha clínica mejorando el registro de exámenes y signología.

\section{ESCARLATINA RECURRENTE: REPORTE DE UN CASO}

Grob $K^{1}$, Krause $E^{2}$, Täger $M^{1}$, Pontigo $L^{3}$.

${ }^{1}$ Instituto de Pediatría, Universidad Austral de Chile. ${ }^{2}$ Interna de Medicina, Universidad Austral de Chile. ${ }^{3}$ Becado Pediatría, Universidad Austral de Chile.

Introducción: La escarlatina es una enfermedad infecciosa producida por Streptococcus pyogenes, siendo muy poco frecuente su recurrencia. Reportamos un caso con tres episodios ocurridos en un lapso de ocho meses. Caso Clínico: Preescolar eutrófico, sexo masculino, sin antecedentes mórbidos de importancia. A los 5 años y 2 meses consulta por fiebre, destacando al examen físico eritema y micropetequias en faringe y pilares anteriores, además de exantema escarlatiniforme predominante en zonas inguinales. Test pack faríngeo positivo a S. pyogenes. Se trata con amoxicilina por 10 días, con adecuada respuesta. Cuatro meses después, presenta fiebre y odinofagia, con exudado purulento amigdaliano, lengua aframbuesada y exantema escarlatiniforme generalizado. Cultivo faríngeo positivo a $S$. pyogenes y monotest negativo. Se trata con claritromicina por 10 días, con buena respuesta. A los 5 años y 10 meses, evaluado por fiebre y odinofagia, con faringe congestiva, lengua aframbuesada y exantema escarlatiniforme, más intenso en regiones inguinales y periné. Cultivo faríngeo positivo a $S$. pyogenes, hemograma con leucocitosis y proteína $\mathrm{C}$ reactiva aumentada. Examen de orina, inmunoglobulinas GAME, C3y C4 normales. Recibe azitromicina por 5 días, evolucionando satisfactoriamente con descamación furfurácea extensa y cultivo faríngeo post tratamiento negativo. Comentario: Aún reconociendo otros agentes etiológicos de escarlatina, Streptococcus pyogenes sigue siendo el más importante, por lo que se requiere un adecuado diagnóstico y efectivo tratamiento de erradicación. No obstante, puede ocurrir un 7 a $13 \%$ de recaída y menos de un $2 \%$ de reinfección, que explicarían la recurrencia de escarlatina en un paciente.
Landaeta $J^{1}$, Gárate R, Gazmuri $J^{2}$, Mendoza $C^{2}$, Nachar $X^{2}$.

${ }^{1}$ Médico Pediátra, Clínica Privada Hospital del Profesor de Santiago (CHP). ${ }^{2}$ Interna Escuela de Medicina Universidad Finis Terrae. Campus Clínico CHP.

Introducción: La Enfermedad de Kawasaki (EK) es una vasculitis sistémica cuya importancia radica en el riesgo de compromiso cardiovascular. El objetivo de este trabajo es conocer la realidad en nuestro centro. Material y Métodos: Se realizó un estudio descriptivo y retrospectivo con revisión de fichas clínicas cuyo diagnóstico de egreso fue EK entre el 2000 y 2008. Resultados: Se encontraron 12 pacientes, edad 29,6 meses (DS 43,4, rango $2 \mathrm{~m}-14$ años), Sexo Masculino 50\%, Diagnóstico de ingreso: Kawasaki 6 (50\%), Síndrome Febril $3(25 \%)$, Bronconeumonía $2(17 \%)$, Infección urinaria $1(8 \%)$, Encefalitis 1. Hallazgos clínicos: fiebre antes de ingreso $100 \%, 4,5$ días en promedio (2,7 DS), fiebre hasta diagnóstico: 7,7 días (DS 3,2 ), conjuntivitis $83 \%$, cambios en boca $75 \%$, alteraciones de extremidades $75 \%$, exantema $67 \%$, adenopatías $33 \%$. Otros: alteraciones del SNC $58 \%$, artritis $8 \%$, diarrea $8 \%$. Los exámenes de laboratorio mostraron en promedio: Leucocitos 12.489, Plaquetas 636.600, PCR 148 y VHS 58. Alteraciones ecocardiográficas: Aneurismas coronarios en 4 pacientes (33\%), quienes tuvieron 9 días de fiebre en promedio. Se trató a todos los pacientes con gamaglobulina $2 \mathrm{~g} / \mathrm{Kg}$ y ácido acetilsalićlico al 7,7 ds en promedio, en $67 \%$ de los pacientes se inicio al 5,9 día. El paciente que ingresó por encefalitis inició la gamaglobulina al 3er día. Clasificación: EK típica 50\%, EK Atípica 33\% y EK incompleto 17\%. Discusión: Esta serie muestra predominio de EK típica, con inicio de terapia antes del $10^{\circ}$ día y en $67 \%$ antes del 5,9 día. Aun así se presentó aneurisma en el $33 \%$ de los pacientes, cifra mayor que en la literatura. Se sugiere sospechar EK en todo cuadro febril asociado a uno de los signos, a fin de realizar un seguimiento e iniciar precozmente la terapia con gamaglobulina. 
NIÑOS CON VARICELA COMPLICADA, HOSPITAL HERNÁN HENRÍQUEZ ARAVENA, TEMUCO 2002-2007

Muñoz ME', Oliva ID, Sandoval $C \mathcal{J}^{2}$, Soza $C G^{3}$.

${ }^{1}$ Becado Pediatría. ${ }^{2}$ Internas Medicina. ${ }^{3}$ Pediatra-Infectólogo. Hospital Hernán Henríquez Aravena. Temuco.

Introducción: La Varicela es una enfermedad exantemática autolimitada cuyo agente etiológico es el virus Varicela Zoster. Aunque se clasifica como una enfermedad de curso benigno, en el último tiempo se ha desplazado a edades mayores con complicaciones que pueden llevar al fallecimiento, especialmente en inmunodeprimidos. Objetivo: Realizar una caracterización epidemiológica y clínica de los pacientes pediátricos hospitalizados por varicela durante los años 2002 al 2007. Pacientes y Método: Estudio retrospectivo de pacientes egresados con el diagnóstico de varicela en el Servicio de Pediatría del Hospital Hernán Henríquez Aravena en el período señalado. Se obtuvieron los antecedentes epidemiológicos, clínicos y de laboratorio registrándolos en planilla Excel. Resultados: Se analizan 225 pacientes pediátricos; El 90\% presentó complicaciones, el resto se hospitalizó por condiciones de base o factores de riesgo. Rango de edad 20 días a 15 años. El mayor número se presento entre el año y 4 años. E $85 \%$ eran eutróficos. Mayor incidencia en el verano. Un 3\% presentó condición de inmunodeficiencia: S. Nefrótico, LLA; trasplante renal, LES. La principal fuente de contagio fueron los hermanos $58 \%$. Principales complicaciones: Sobreinfección de lesiones piel $(75 \%)$, Neumonía (8\%), Cerebelitis (7\%); Se presentó leucocitosis en el $36 \%$,leucopenia en 2 casos; Trombocitosis $14 \%$ y Trombocitopenia $3 \%$. Se cultivó Sthaphilococcus aureus en un $61 \%$ y Streptococcus pyogenes en $11 \%$. Se utilizó antibióticos en $76 \%$ de los pacientes especialmente la asociación penicilina y cloxacilina con un promedio de 9.04 días. Un 30\% de niños recibió aciclovi ev u oral. Promedio de hospitalización 4,64 días. No hubo fallecimientos en esta casuística. Conclusiones: No existieron casos fatales, pensamos que fue debido a un oportuno diagnóstico y acción medica, ya que sabemos la elevada letalidad en los inmunodeprimidos. Destaca el gran número de pacientes hospitalizados por esta causa, lo cual se encuentra en directa relación con el costo en medicamentos y días de hospitalización. Las repercusiones de sus complicaciones y de sus costos, son argumentos más que válidos para implementar una vacunación universal.

ESTADO ACTUAL DE LA TRANSMISIÓN VERTICAL DEL VIH EN LA REGIÓN DE COQUIMBO. ESTUDIO DESCRIPTIVO DE LA IMPLEMENTACIÓN Y RESULTADOS DE LA NORMA PTV (PREVENCIÓN TRANSMISIÓN VERTICAL)

Vargas $\boldsymbol{P}^{1}$, Guaman $L^{2}$, Álvarez $D^{3}$, Comité SIDA Pediátrico Regional. ${ }^{1}$ Médico Pediatra, Coordinador Regional VIH Pediátrico. ${ }^{2}$ Matrona encargada Programa Regional VIH. ${ }^{3}$ Enfermera Comité SIDA Pediátrico, Hospital La Serena.

Introducción: Se ha comprobado que la pesquisa precoz de la mujer embarazada con VIH, su tratamiento durante embarazo, parto y al Recién Nacido (RN) ha logrado disminuir la transmisión vertical a nivel del mundo y también en nuestro país. Con el protocolo 076 desde el 2000 al 2005 en nuestra Región se trataron a 10 binomios, resultando $10 \mathrm{RN}$ sanos a los 3 meses de edad. Objetivos: Describir la experiencia de la implementación de la norma de PTV de VIH en embarazadas Región de Coquimbo durante los años 2006 a Junio 2008. Material y Métodos: Desde el año 2006 se inicia la oferta del examen Test de Elisa al $100 \%$ de las mujeres embarazadas en sus primeros controles y el tes rápido intraparto. En forma retrospectiva se revisan las actividades de capacitación y resultados estadísticos de la implementación de la norma PTV en las mujeres embarazadas de la Región. Resultados: Se capacitó a 78 matronas (es) de la AP y 49 Profesionales del equipo de salud en el año 2005. El número de Embarazadas del 2006 fue 9.369; año $2007=9.195$ y $2008=4.843$. En el año 2006 se realizaron 9.046 test de Elisa en embarazo y parto $(8.841+205)$, lo que representa el $96 \%$ de test realizados. El año $2007=9.554$ test $(9.336+218)=$ $103 \%$ y el año $2008=4.843$ test $(4.594+249)=97,7 \%$. Esto permitió diagnosticar durante el embarazo el 2006 a 6 Madres más una en el intraparto y una madre VIH conocida: El año 2007 a 4 Madres en embarazo y 2 Madres VIH conocidas. El año 2008 a 3 Madres en el Embarazo y una Madre VIH conocida. El total de la Madres pesquisadas durante el embarazo es de 14 todas con tratamiento de triterapia. Las Madres VIH conocida tratadas fueron 4. Los RN suman 21 (2 partos múltiples = mellizos y trillizos) Todos los RN tuvieron parto programado ( 16 cesáreas) y 2 partos vaginales de urgencia. La edad gestacional fue de 34 a 39 semanas, con pesos de 1.180 a 3.700 grs. Estos RN recibieron tratamiento con AZT durante 6 semanas y actualmente 20 pacientes $(95,3 \%)$ tuvieron PCR VIH negativas a los 3 meses de edad y 1 RN VIH positivo $(4,7 \%)$ Conclusiones: La implementación de la norma PTV, desde el 2006 a Junio 2008 ha resultado exitosa en la pesquisa de las Madres con VIH durante el embarazo y parto $(98,9 \%)$ permitiendo tratarlas así como también al RN, disminuyendo la trasmisión vertical en la Región de Coquimbo.
BROTE POR ENTEROCOCO RESISTENTE A VANCOMICINA EN UNA UCI NEONATOLÓGICA: ASPECTOS CLÍNICOS, EPIDEMIOLÓGICA Y DE MANEJO DE LA INFECCIÓN

Arteaga MC, Ruiz-Esquide F, Chanqueo L.

Hospital San Juan de Dios.

El Enterococcus resistente a vancomicina (ERV) ha adquirido importancia mundial como nuevo germen nosocomial, pese a su baja virulencia. De difícil erradicación, por ser resistente a antibióticos habituales y persistir en el medio intrahospitalario, puede permanecer períodos prolongados en una unidad. Esta infección es factor de riesgo de mortalidad en pacientes vulnerables y aumenta los costos de su manejo. Las medidas de prevención más importantes son: uso racional de antibióticos y lavado de manos. La portación puede durar hasta 6 meses. Desde 2000 hay en Chile un sistema de vigilancia con norma MINSAL desde 2001 en el Hospital San Juan de Dios (HSJDD)- que consiste en tomar muestras de hisopado rectal a pacientes con permanencia prolongada en $\mathrm{UCI}$, para identificar a los colonizados o infectados y usar medidas de aislamiento estrictas para prevenir la transmisión. Objetivos: Describir un brote de infección por ERV en la Unidad de Neonatología del HSJDD, entre Octubre y Diciembre 2007 Revisar los sistemas de vigilancia, técnicas de diagnóstico, manejo y medidas de control. Metodología: Las muestras fueron analizadas mediante Agar VRE-BMX y VITEK en el laboratorio de microbiología. Las positivas fueron enviadas al ISP para confirmar identificación y estudio de susceptibilidad. Los antibiogramas fueron compatibles con Enterococcus faecius tipo Van B, (tabla 1 describe los casos). Se aisló en cohorte a los casos positivos en una sala especial utilizando las medidas de profilaxis adecuadas según CDC. Para el tratamiento del único caso infectado se indicó teicoplanina. Conclusiones: El sistema de vigilancia logró identificar la infección por Enterococcus faecius tipo Van B en 6 de 10 pacientes. Utilizando medidas de aislamiento y tratamiento adecuadas se logró controlar la infección. Desde diciembre 2007 no se detectaron nuevos casos por varios meses. Tabla 1 Casos detectados.

\section{CÁNCER EN PACIENTES VIH: REVISIÓN DE DOS CASOS CLÍNICOS}

Arteaga MC ${ }^{1}$, Reyes $B^{1}$, Álvarez $A M^{2}$, Varas $M^{3}$.

${ }^{1}$ Becada pediatría. ${ }^{2}$ Pediatra Infectóloga. ${ }^{3}$ Pediatra Hemato-Oncóloga. Universidad de Chile. Hospital San Juan de Dios.

Introducción: Los niños VIH positivos presentan una mayor frecuencia de patologías secundarias, dentro de las cuales destacamos la ocurrencia de cánce infantil. La prevalencia de cáncer en estos pacientes es $2 \%$ y se presenta independiente de su estado de inmunosupresión. El grupo PINDA registra ocho casos en Chile, dos de los cuales se diagnosticaron en nuestro servicio. Objetivo: Describir dos casos de cáncer en pacientes VIH diagnosticados en el servicio de Pediatría Hospital San Juan de Dios en el año 2008. Caso Clínico 1: Paciente sexo masculino, 9 años, VIH Etapa B1 diagnosticado a los 3 años de vida, actualmente en terapia antirretroviral. Antecedente de Neumonitis intersticial linfoide en Mayo 2004. Por estudio de daño pulmonar crónico se solicita Cintigrama pulmonar que muestra alteración de la perfusión en LSD con disminución de función pulmonar. TAC de tórax muestra extenso compromiso ganglionar mediastínico e hiliar. Se realizó biopsia por toracotomía compatible con Linfoma de Hodgkin. Evaluado por Oncología ingresa a quimioterapia según protocolo PINDA en mayo 2008 manteniendo su terapia antirretroviral. Caso Clínico 2 : Paciente de sexo femenino, 9 años, portadora de VIH, etapa C3 en terapia antirretroviral. Antecedente de neumonía por mycobacterium atípico (M. abscesus) el año 2004. Ingresa por cuadro de dos semanas de dificultad respiratoria, tos productiva y fiebre. Se solicita Radiografía de tórax que muestra imagen de atelectasia y condensación en LII. Se realiza fibrobroncoscopia evidenciándose aumento de volumen oclusivo en bronquio fuente izquierdo infranqueable, de superficie lisa y color rosado pálido. TAC de Tórax muestra masa oclusiva a nivel de bronquio fuente izquierdo. Por antecedentes se plantea probable neoplasia o infección por germen atípico. Se realiza segunda fibrobroncoscopia rígida más biopsia endobronquial compatible con sarcoma de alto grado. Evaluada por equipo de Oncología se decide realizar resección quirúrgica de la lesión. Posterior a cirugía evoluciona grave falleciendo a los dos días postprocedimiento. Discusión: Debido al aumento en la expectativa de vida secundario a la introducción de la terapia antirretroviral, se ha observado un aumento en la incidencia de cáncer en niños VIH. Los pacientes presentados fueron tratados según protocolo PINDA de manera similar a pacientes oncológicos no VIH, manteniendo terapia antirretroviral y sin evidencia de mayor toxicidad. Ante esta nueva realidad epidemiológica se hace imprescindible considerar el diagnóstico de cáncer para otorgar un tratamiento oportuno. 
INCIDENCIA DE INFLUENZA EN NIÑOS ATENDIDOS EN EL HOSPITAL EXEQUIEL GONZÁLEZ CORTÉS, A TRES AÑOS DEL INICIO DE LA VACUNACIÓN

Arzola $L^{1}$, Szigethi $M^{1}$, Zárraga $P^{2}$, Mena $A^{2-3}$.

${ }^{1}$ Becada Pediatría Universidad de Chile (UCH), ${ }^{2}$ Servicio Pediatría Hospital Exequiel González Cortés, ${ }^{3}$ Departamento Pediatría Sur UCH. Departamento de Pediatría y Cirugía Infantil Sur, Universidad de Chile. Hospital Exequiel González Cortés (HEGC).

Introducción: El virus Influenza (FLU) es responsable anualmente de un alto número de infecciones respiratorias. El MINSAL, desde el año 2006 ha vacunado a los lactantes entre 6 y 23 meses, en una campaña nacional que desde su inicio ha visto postergada la fecha de comienzo. Objetivo: Describir la frecuencia de inmunoflourescencia indirecta (IFI) positiva en aspirados nasofaringeos para FLU, observados en el año 2008 en pacientes atendidos en el HEGC y compararlos con lo observado los años 2006 y 2007, por el mismo equipo investigador. Material y Método: Estudio clínico, descriptivo retrospectivo en tercer año de realización. Se analizaron resultados de IFI correspondientes a aspirados nasofaringeos, realizados en niños el año 2008 en HEGC, correlacionándolos con las semanas epidemiológicas y comparándolos con resultados de los años 2006 y 2007. Resultados: De 1.254 IFI realizadas el año 2008, 335 (38\%) fueron positivas para algún virus respiratorio. De ellas, $70 \%$ correspondió a VRS, $3 \%$ a ADV y $9 \%$ a FLU. Al comparar con años 2006 y 2007 (4.229 IFI), se mantuvo el porcentaje de aspirados positivos y predominando VRS, destacando este año un aumento de FLU (9\% v/s 6,48\%). Además, el peak de FLU se presentó entre las semanas 16 y 22, mientras que años anteriores, el peak fue más tardío: entre las semanas 30-35 el 2006 y entre semanas 24 - 31 el 2007 , similar a observaciones de años previos a la vacunación masiva en lactantes. Conclusiones: En esta serie, el virus más frecuentemente aislado es VRS, seguido de FLU y ADV, igual a lo descrito. Del total de IFI positivas, se observó un aumento del porcentaje de FLU y aparición más precoz del peak del virus respecto a años anteriores. La aparición del FLU año a año es más precoz, a pesar de lo cual la vacunación se realiza en forma más tardía, aumentando el número de susceptibles al término del período; Por ello, sería recomendable adelantar en años sucesivos la vacunación, tal como han venido sugiriendo nuestros análisis el último trienio.

\section{LOXOSCELISMO EN PACIENTES PEDIÁTRICOS HOSPITALIZADOS}

Barraza MP, Cerda DJ, Avila BML, Quintana JR. Servicio de Pediatría, Hospital Clínico Félix Bulnes Cerda.

Introducción: El Loxoscelismo es un cuadro tóxico producido por el veneno de la araña Loxosceles laeta, el cual tiene fuerte poder citotóxico y proteolítico. Puede adoptar la forma cutánea (LC) y cutáneo visceral (LCV). Objetivos: Describir características clínicas, evolución y manejo de pacientes pediátricos hospitalizados afectados por loxoscelismo. Método: Revisión retrospectiva de fichas de pacientes que egresaron con diagnóstico de Loxoscelismo del Servicio de Pediatría del Hospital Félix Bulnes Cerda entre enero 1998 y septiembre 2008. Resultados: Se encontraron 21 casos de loxoscelismo, correspondiendo 15 a LC $(71 \%)$ y 6 a LCV (29\%). El $57 \%$ del total de casos y el $100 \%$ de los pacientes con LCV fueron mujeres. El $76 \%$ de los afectados eran escolares y e $24 \%$ preescolares, con una mediana de 9 años (3-14 años). El tiempo entre la mordedura y la primera consulta fue menor a 6 hrs en 6 pacientes; entre 6 y 11 hrs: 4; de 12 a 23 hrs: 6 , y 24 hrs o más: 5 pacientes. El 52\% refirió síntomas sistémicos transcurridas las primeras 12 horas desde la mordedura; mientras que de los casos con LCV sólo la mitad los presentó. Los motivos de consulta más frecuentes fueron: dolor $(76 \%)$, aumento de volumen $(33,3 \%)$ y lesión violácea $(33,3 \%)$. El principal tratamiento recibido en la primera consulta fue corticoide $(76 \%)$ y antihistamínico $(52 \%)$. Las zonas afectadas fueron: extremidades inferiores (10 casos), superiores (6), cabeza (3), cuello (2). El $71 \%$ presentó placa liveloide al ingreso. La lesión evolucionó con escara en 7 casos de los cuales 3 requirieron cirugía reparadora ( 2 con injerto). De los pacientes con LCV 2 presentaron hemólisis, 4 hematuria, 3 hemoglobinuria y 3 albuminuria; 3 se complicaron con insuficiencia renal aguda y 2 con anemia hemolítica. $\mathrm{E}$ manejo durante la hospitalización fue básicamente con antihistamínico y corticoide parenteral; 2 casos requirieron transfusión de glóbulos rojos y 1 peritoneodiálisis. Siete casos tuvieron infección de piel y tejidos blandos asociada que se trató con antibiótico. El tiempo promedio de hospitalización fue 7,8 días. Ningún pacient falleció. Conclusión: Concordando con la literatura, en nuestra revisión el loxoscelismo afectó más a escolares y principalmente las extremidades. Por otra parte, al ingreso tanto la ausencia de síntomas sistémicos como las características de la lesión no permitieron predecir la evolución del cuadro hacia LCV. El tratamiento más utilizado fue corticoide sistémico y antihistamínico.
INFECCIÓN POR VIRUS INFLUENZA: CARACTERÍSTICAS CLÍNICAS $Y$ EVOLUCIÓN DE NIÑOS HOSPITALIZADOS

Brethauer S, Zamorano J, Herrero D.

Universidad de Los Andes.

La gripe es una importante causa de morbilidad infantil, describiéndose elevadas tasas de hospitalización. Objetivo: Describir las características epidemiológicas y clínicas de infecciones por influenza en niños hospitalizados de la Clínica Santa María e identificar los factores de riesgo para ingresar a la UCI. Metodología: Estudio observacional a través de análisis de fichas clínicas. Se incluyó pacientes con diagnóstico de egreso de infección por virus influenza entre enero de 2005 a diciembre del 2007. La confirmación de infección por influenza se realizó por tres métodos diagnósticos: test pack (Binax®), inmunoflorescencia directa (IFD) y/o cultivo. El análisis estadístico se realizó a través de método de $\mathrm{x} 2$ y $\mathrm{t}$ de student, considerando significativo un error alfa con $p<0,05$. Resultados: Durante los tres años, se hospitalizaron 112 niños con diagnóstico de infección viral por influenza, predominando el tipo A en un $91 \%$. El diagnóstico se realizó en la mayoría con test pack (84\%). Los casos se concentraron en el mes de junio, el $59 \%$ de los casos fue de sexo masculino. Sólo un $4 \%$ había recibido vacuna de influenza. Los lactantes se hospitalizaron con más frecuencia $(38 \%)$ seguidos por los preescolares (32\%). El promedio de hospitalización fue 4 días. La mitad de los niños $(51 \%)$ referían patología previa al momento del ingreso. Los síntomas y signos fueron: fiebre $(92 \%)$, tos $(76 \%)$, rinorrea $(57 \%)$, bronquitis obstructiva (38\%) y convulsiones en el $10 \%$ de los pacientes. Se identificó coinfección viral en un 6\%. En relación a tratamiento sólo $13(11,6 \%)$ recibieron antivirales, $29,5 \%$ oxígenoterapia y el $50 \%$ antibióticos, de ellos $49 \%$ se catalogaron como sobreinfeccion pulmonar, $13 \%$ otitis y $11 \%$ sinusitis. Un $19,6 \%$ de esta serie ingresaron a $\mathrm{UCl}, 2 / 3$ lo hicieron después de haber ingresado a pediatría. Se encontraron como factores de riesgo el antecedente de patología previa (OR: $3,19(1,04-10,13)$, radiografía de tórax alterada (OR: 10,03 $(2,25-47,71)$ y uso de antibiótico previo. Conclusión: Las infecciones por virus influenza son frecuentes en los meses de invierno, siendo su presentación clínica inespecífica. Las convulsiones febriles en este período deben hacer sospechar influenza. Destaca el importante número de pacientes en que se utilizó antimicrobianos por complicaciones pulmonares, lo que podria explicarse por tratarse de pacientes de mayor gravedad y la baja utilización de antivirales, pese a que la recomendación es aplicable.

EVALUACIÓN DE TRES TÉCNICAS RÁPIDAS PARA EL DIAGNÓSTICO DE FARINGITIS POR STREPTOCOCCUS PYOGENES (BETA HEMOLÍTICO GRUPO A) EN POBLACIÓN PEDIÁTRICA

Zamorano RJ, Rojas GM de los A, Urzúa FC, Budnik OI, López AM, Lafoucade M, Porte TL, Braun S, Triantafilo V, Wigant W, Tapia C, Vega C, Hormazabal $X$, Barraza $P$.

Universidad de Los Andes-Clínica Santa María.

Introducción: Las recomendaciones para el diagnóstico de faringitis por Streptococcus pyogenes (SGA) incluyen el uso de técnicas rápidas de detección de antígeno y/o cultivo tradicional. El objetivo del uso de una prueba rápida es descartar a aquellos pacientes con faringitis de causa no bacteriana para un uso racional de antimicrobianos. Objetivo: Evaluar rendimiento en la práctica diaria de 3 técnicas de diagnóstico rápido de SGA en relación al cultivo en niños con faringitis aguda en 3 centros hospitalarios de la RM. Método: Análisis retrospectivo de registros computacionales y manuales de resultados de cultivos faríngeos y de técnicas rápidas de detección de SGA, entre 2006 y 2008, en los 3 centros hospitalarios. Se incluyeron sólo casos que contaban con ambos exámenes tomados el mismo día. Las pruebas diagnósticas rápidas correspondieron a ClearviewStrepA $\AA$ (Clearview), BDDirectigen $\AA E Z$ GroupAStrepTest (Becton Dickinson) y StatusStrepA $\AA$ (Lifesign). Durante el período de estudio, el centro A utilizó 2 técnicas rápidas: desde Enero 2007 a Abril 2008 se utilizó ClearviewStrep $A \AA$ y a partir de Mayo se cambió a BDDirectigen $® E Z$ ZGroupAStrepTest. En los centros B y $C$ se utilizaron StatusStrepA® y ClearviewStrepA®, respectivamente. Se diseñó base de datos con edad, género, fecha de toma de muestra, resultados de técnicas rápidas, cultivo y antibiograma. Resultados: Se obtuvieron 100 exámenes pareados en A, 99 en B y 101 en C. Se detectaron 69 niños con cultivos positivos para SGA (23\%). El porcentaje de cultivos faríngeos positivos para S. pyogenes fue de $24 \%, 27 \%$ y $18 \%$ para los centros A, B y C, respectivamente. La distribución por género fue similar ( $52 \%$ mujeres y $48 \%$ hombres). El promedio de edad fue 8 años. No hubo casos en menores de 2 años y el grupo más prevalente fue el de escolares $(71 \%)$. Se realizó antibiograma en 45 cepas, con $8,8 \%$ de resistencia a Eritromicina y Clindamicina. Los resultados de sensibilidad y especificidad para cada una de las pruebas rápidas fue respectivamente: 76,5 y $97,1 \%$ (ClearviewStrepA $\AA$ ), 100 y $91,3 \%$ (StatusStrepA®) y 87,5 y $75 \%$ (BDDirectigen®EZGroupAStrepTest). El más sensible fue el kit StatusStrepA® $(100 \%)$ y el más específico el kit ClearviewStrepA® $(97,1 \%)$. El con mejor sensibilidad y especificidad fue StatusStrepA®. Conclusiones: Las pruebas rápidas de las marcas evaluadas presentan sensibilidad y especificidad variables en nuestro medio. La solicitud de cultivo en conjunto con la prueba rápida dependerá del kit utilizado. 
ESTUDIO DE RESISTENCIA BACTERIANA EN PACIENTES PEDIÁTRICOS CLÍNICA DÁVILA

Budnik $\boldsymbol{P}^{2}$, Tapia $C^{1}$, Barraza $P^{\prime}$

${ }^{1}$ Clínica Dávila. ${ }^{2}$ Universidad de Los Andes.

Introducción: La resistencia bacteriana es un fenómeno creciente asociado al uso indiscriminado de antimicrobianos. Las infecciones causadas por bacterias multirresistentes generan aumento en la morbimortalidad y en costos hospitalarios. Se han descrito factores de riesgo para desarrollar resistencia antimicrobiana como edad, uso de antibióticos, inmunosupresión, hospitalización prolongada, uso de catéteres y tuvo endotraqueal y enfermedad de base. No existen estudios nacionales que evalúen la tendencia de la resistencia antimicobiana ni factores de riesgo. Objetivos: Analizar tendencia de resistencia bacteriana entre 2005 y 2008 en pacientes pediátricos hospitalizados. Identificar factores de riesgo para adquirir infecciones por bacterias resistentes. Metodología: Se analizó retrospectivamente la resistencia global de $S$. aureus, $S$. coagulasa negativa a oxacilina y de E. coli, Klebsiella sp y P. areuginosa a ceftazidima, ciprofloxacino, amikacina e imipenem en Pediatría y UCI Pediátrica entre 2005-08 en Clínica Dávila. Los datos se obtuvieron mediante EpiCenter 5.0 (Beckton DickinsonTM). Se revisó la ficha clínica de pacientes con hemocultivos positivos entre 2007-08, analizando los resultados e identificando los factores de riesgo. Resultados: El porcentaje de resistencia de S.aureus, disminuyó de 2005 a 2008 (de 24,4\% a 0\% en promedio), al igual que el número de aislamientos durante 2008 , mientras que la resistencia de $S$. coagulasa negativa aumentó sobretodo en UCI pediátrica respecto a años anteriores (de 67,5 a 100\%). Por otra parte, la resistencia global de $P$. aeruginosa a imipenem ha disminuido considerablemente (de 15,7 a $0 \%$ ) al igual que el número de aislamientos. De 24 pacientes con hemocultivos positivos, $54 \%$ presentaron microorganismos resistentes. El grupo etario más afectado fue el de preescolares $(61,5 \%)$, de sexo femenino $(76,9 \%)$ y con algún grado de inmunosupresión $(69,2 \%)$. Los principales factores de riesgo identificados fueron: ser paciente oncológico $(30,7 \%)$ (mayoría leucemia linfoblástica aguda), cirugías mayores $(53,8 \%)$, hospitalizaciones mayores a 3 días $(69,2 \%)$, vías vasculares centrales $(69,2 \%)$, nutrición parenteral $(46,1 \%)$,uso de ventilación mecánica invasiva $(38,4 \%)$, uso prolongado de antibióticos $(23 \%)$ y de corticoides (15\%). Conclusiones: S. coagulasa negativa presenta una tendencia al aumento en los servicios pediátricos por lo que es importante vigilarlo. $P$. areuginosa se ha mantenido sensible, con baja resistencia en pacientes pediátricos.

\section{CARACTERIZACIÓN DE PACIENTES CON FIEBRE DE ORIGEN DESCONOCIDO INGRESADOS A SERVICIO DE PEDIATRÍA HOSPITAL} REGIONAL DE CONCEPCIÓN ENTRE LOS AÑOS 2003 A 2007

Maturana RM, Venthur UC, Martínez CC, Bravo NN. Universidad de Concepción - Hospital Clínico Regional de Concepción.

Introducción: La fiebre en edad pediátrica continúa siendo un motivo de consulta frecuente en la atención de estos pacientes, con alrededor de un $15 \%$ del total de consultas con médicos pediatras. El concepto de Fiebre de Origen Desconocido (FOD) está determinado por criterios que incluyen pacientes con fiebre mayor a 8 días de evolución, con una anamnesis, examen físico y exámenes básicos de laboratorio, que no identifican su etiología. Objetivos: Conocer la incidencia de FOD en el Servicio de Pediatría del Hospital Regional de Concepción (HCRC) y evaluar características epidemiológicas y clínicas de pacientes que ingresan con dicho diagnóstico. Metodología: Se analizaron pacientes pediátricos ingresados por Síndrome Febril al Servicio de Pediatría del HCRC y se seleccionaron a aquellos que cumplieron criterios de FOD. Posteriormente, mediante extracción por ficha clínica se analizaron los datos demográficos, clínicos, etiológicos y de laboratorio de los pacientes seleccionados, analizándose en Tabla Excel. Resultados: Se analizaron un total de 252 fichas correspondientes a ingresos por Síndrome febril al Servicio de Pediatría del HCRC entre los años 2003 a 2007. De esta población, destaca que sólo 30,8\% cumple criterios de FOD. La distribución por sexo en los casos de FOD, corresponde a $56 \%$ femenino; el rango de edad va de los 3 a los 13 años, estando la mayoría de los individuos en edad escolar. Se estudió la incidencia de los casos en relación a estación del año, destacando que la mayoría ocurre en época de verano. En relación al estudio microbiológico, se encuentra que a un $91 \%$ se le realiza hemocultivo, resultando positivo en un $15 \%$ de estos. Por otra parte, el estudio con urocultivo se realizo a más de la mitad de los casos, encontrándose este positivo sólo en 2 pacientes. Dentro de las etiologías encontradas en los pacientes con FOD destacan la causas infecciosas con un $66 \%$ del total, concordando con las distintas series publicadas en literatura internacional. Les siguen aquellas causas secundarias a mesenquimopatías y luego de origen onco-hematológicas y neoplásicas. Persiste también un grupo importante con etiología no aclarada $(13,9 \%)$. Dentro de las causas infecciosas las etiologías bacterianas corresponden a un $66,7 \%$ del total, destacando en este grupo Bartonellosis y Pielonefritis aguda por E. coli. No existió mortalidad inmediata en esta serie. Conclusiones: Los datos encontrados en esta casuística son concordantes con aquellos encontrados en la literatura internacional. Sin embargo, en Chile existen escasas publicaciones de estudios y casuísticas acerca de FOD, por lo que es necesario hacer énfasis en su análisis en distintos centros. La evaluación de las características de los pacientes con FOD permitiría clarificar la utilidad de los test diagnósticos a utilizar, de acuerdo a las etiologías y sospechas diagnósticas.

\section{FACTORES DE RIESGO MATERNO EN NIÑOS CON SEPSIS NEONATAL PRECOZ COMPROBADA}

Alvarado $C^{1}$, Escobar $\boldsymbol{A}^{1}$, Velasco $C^{1}$, Saldes $1^{1,2}$, Vergara $R^{1,2}$. ${ }^{1}$ Escuela de Medicina Universidad de Valparaíso, ${ }^{2}$ Hospital Carlos Van Buren, Valparaíso.

Introducción: La sepsis neonatal precoz (antes de las 72 horas de vida) es una patología de relevancia en el recién nacido $(R N)$ con una incidencia de 1 a 2 1.000 RNs vivos. La principal etiología es el Streptococcus grupo B (SGB). Para su prevención se recomienda el tratamiento a mujeres con factores de riesgo sin embargo, algunos centros han aplicado protocolos basados en cultivo universal para detección de SGB. Objetivos: Evaluar la presencia de factores de riesgo maternos en $\mathrm{RNs}$ que presentaron sepsis precoz comprobada y estimar el impacto de la aplicación de cultivo universal a gestantes en un centro público chileno. Material y Método: Estudio descriptivo retrospectivo. Se seleccionaron los RNs nacidos en el hospital Carlos Van Buren (HCVB) entre el 1 de enero de 2005 y el 15 de septiembre de 2008, con hemocultivos (HC) positivos en las primeras 72 horas de vida. Se revisaron las fichas de estos pacientes y de sus madres buscando la presencia de factores de riesgo y el uso de profilaxis antibiótica en la madre. Resultados: Se encontraron 6 casos de sepsis demostrada de un total de 10.488 RNs obteniendo una tasa de 0,57 sepsis comprobadas/1.000 RN en todo el período. La tasa fue entre $0,3-0,4$ los años 2005 a 2007 y de $1,59 / 1.000$ $\mathrm{RN}$ el año 2008. Cinco fueron por SGB y uno por $E$. coli, 4 se recuperaron sin secuelas, 1 presentó síndrome hipotalámico de causa no precisada y 1 falleció por sepsis fulminante (SGB). Dos casos (1 SGB y 1 E. coli) tenían más de 2 factores de riesgo y recibieron tratamiento antibiótico apropiado. Los otros 4 no tuvieron factores de riesgo, sus madres no recibieron antibióticos intraparto y nacieron por parto vaginal espontáneo. Considerando que la estrategia de cultivo universal tiene eficacia para la prevención de sepsis por SGB de hasta $80 \%$, e agregar cultivo universal al protocolo según factores de riesgo permitiría prevenir 1 caso de sepsis neonatal demostrada por cada 3.144 cultivos tomados y prevenir 1 muerte por cada 9.434 cultivos tomados. Discusión: La incidencia de sepsis neonatal en el HCVB resultó menor a lo descrito, lo que podría explicarse por una baja sensibilidad de los HC en los primeros años. En 2008 se optimizó el volumen de sangre para $\mathrm{HC}$, lo que podría explicar el aumento de la tasa de sepsis. Es necesario continuar vigilando la incidencia de sepsis por SBG en RNs con la optimización de los HCs para entonces estimar el real impacto que tendría la realización de cultivos universales a embarazadas en nuestro centro.

\section{EVALUACIÓN DEL FUNCIONAMIENTO DEL PROTOCOLO DE GARANTIAS EXPLICITAS EN SALUD (GES) EN INFECCIÓN VIH EN} NIÑOS

Osses LP, Osses LA, Parraguez C, Pavez AD, Álvarez AM. Hospital San Juan de Dios. 2005-2008.

Introducción: La infección por virus de la inmunodeficiencia humana $(\mathrm{VIH})$ ingresó al sistema de garantías explícitas en salud (GES), el año 2004. Objetivo: Evaluar aspectos del funcionamiento de la norma GES en la pesquisa de infección VIH en mujeres embarazadas desde su puesta en marcha en el Hospital San Juan de Dios, de Santiago Metropolitano Occidente. Material y Método: El período estudiado alcanzó a 31 meses. Se identificó y revisó las historias clínicas de las madres que resultaron positivas y se determinó el número de niños VIH positivos o sospechosos, dentro de los seis meses post parto y en las madres que calificaron para TAR (terapia anti-retroviral), se midió el ingreso real a ésta y la oportunidad del mismo. Resultados: En el período se realizaron 13.910 exámenes y hubo 15.600 partos, lo que significa que sólo se estudió a $89,2 \%$ de las embarazadas, detectándose una positividad de $0,1 \%$ (18 niños), once de ellos diagnosticados durante el embarazo. Todos recibieron TAR antes del parto y todas las madres la iniciaron en forma oportuna, excepto en dos casos en que el diagnóstico fue tardío (28 y 37 semanas). Conclusiones: Una proporción cercana al $10 \%$ de los embarazos no sería estudiada en este sistema y la mayoría de los niños son detectados durante el embarazo. Además, la totalidad de los casos recibieron TAR antes del parto y la mediana de edad gestacional en las 11 madres en que se detectó positividad durante el embarazo alcanzaba a 22 semanas, cifra que cae dentro de las 24 que establece la norma. A pesar de todo, persiste la dificultad en obtener adherencia al tratamiento. 
DESARROLLO Y EVALUACIÓN DE UN KIT DE REACCIÓN EN CADENA DE LA POLIMERASA EN TIEMPO REAL (PCR-TR) PARA LA DETECCIÓN DE ADENOVIRUS EN MUESTRAS DEL TRACTO RESPIRATORIO

Lizama $L^{1}$, Cifuentes $M^{2}$, Álvarez ${ }^{3}$, Pardo $\mathbf{M}^{1}$, Villegas $K^{1}$, Guajardo $V^{1}$, Torres $J^{1}$, Banfi $A^{3}$.

${ }^{1}$ Bioscan S.A., ${ }^{2}$ Hospital San Borja Arriarán, ${ }^{3}$ Hospital Luis Calvo Mackenna.

Introducción: En Chile, la infección por Adenovirus representa hasta un 5\% de las infecciones respiratorias pediátricas. El método diagnóstico habitual de laboratorio es la Inmunofluorescencia (IF), aún cuando posee dos grandes desventajas: baja sensibilidad y es operador-dependiente. Objetivos: Desarrollar y evaluar un kit de PCR en tiempo real (PCR-TR) para Adenovirus y comparar los resultados obtenidos con IF. Método: Se obtuvo muestra de aspirado nasofaríngeo de 221 niños, de acuerdo a técnicas habituales en 2 Hospitales de la Región Metropolitana, entre marzo de 2007 y junio de 2008. Estas muestras fueron sometidas a IFD con anticuerpos policlonales, en cada laboratorio hospitalario el mismo día de la toma de muestra. Posteriormente, se derivaron a Bioscan para realizar la PCR-TR. En la PCR-TR se usó como blanco el gen del hexon de Adenovirus. Resultados: La edad promedio de los pacientes fue de 7 meses. Del total de pacientes, un $41,9 \%$ fueron menores de 6 meses, un $21,2 \%$ entre 6 y 12 meses, un $13,4 \%$ entre 12 y 24 meses, un $12,9 \%$ entre 24 y 60 meses y el $8,8 \%$ restante corresponden a pacientes mayores de 60 meses. Hubo 28 muestras positivas por IFD $(12,7 \%)$ y 41 muestras resultaron positivas por PCR-TR $(18,6 \%)$. Todas las muestras con resultado positivo por IFD fueron también positivas por PCR-TR. Hubo 13 muestras que sólo fueron positivas por PCR TR, lo que indicaría una mayor sensibilidad de la técnica de PCR-RT. Estos 13 casos positivos de PCR-TR, cuya IFD fue negativa, tenían la clínica altamente sugerente de infección respiratoria. En algunos de estos casos, los amplificados fueron secuenciados y correspondieron al gen del hexon de Adenovirus. Los tiempos de trabajo de la PCR-TR fueron 2,5 hrs. Conclusiones: La sensibilidad de PCR-TR fue superior a la IFD, técnica de rutina utilizada en laboratorios clínicos. Además, los resultados obtenidos fueron más rápidos y fáciles de interpretar que la IFD. El uso de este kit permitiría mayor eficiencia y rendimiento en los laboratorios clínicos en comparación con una de las técnicas más utilizadas actualmente.

\section{DESARROLLO Y EVALUACIÓN DE UN KIT DE REACCIÓN EN CADENA DE LA POLIMERASA EN TIEMPO REAL (PCR-TR), PARA DIAGNÓSTICO DE INFECCIÓN POR BORDETELLA PERTUSSIS}

Lizama $L^{1}$, Cifuentes $M^{2}$, Álvarez $\beta$, Pardo $M^{1}$, Villegas $K^{1}$, Guajardo $V^{1}$, Torres $J^{1}$, Banfi $A^{3}$.

Bioscan S.A., ${ }^{2}$ Hospital San Borja Arriarán, ${ }^{3}$ Hospital Luis Calvo Mackenna.

Antecedentes: En Chile, la infección por B. pertussis sigue siendo frecuente, especialmente en la población pediátrica. El diagnóstico habitual de laboratorio se realiza mediante Inmunofluorescencia directa (IFD). Este es un método operador-dependiente, que tiene baja sensibilidad y especificidad. Objetivo: Desarrollar y evaluar un kit de PCR en tiempo real (PCR-TR) para la detección de $B$. pertussis, comparándolo con IFD y PCR convencional. Método: Se obtuvo muestra de aspirado nasofaríngeo de 157 niños, desde 2 Hospitales con población pediátrica de la Región Metropolitana, entre marzo del 2007 y junio del 2008. Estas muestras fueron sometidas a IFD con anticuerpos policlonales y posteriormente se analizaron mediante PCR-TR con el nuevo kit. Este kit, tiene como blanco el gen IS481 de B pertussis. Adicionalmente, se utilizaron como técnicas de referencia: una reacción de PCR convencional, dirigida al gen de la IS481 y una PCR-TR, dirigida al gen de la toxina pertussis. Se calculó sensibilidad y especificidad, considerando como "verdadero positivo" toda muestra que fuese positiva con el kit y además con una de las técnicas de referencia: PCR convencional, PCR-TR para el gen de la toxina pertussis e IFD. También se consideró que el cuadro clínico fuese concordante con los resultados. Resultados: De las muestras estudiadas, $34,4 \%$ correspondieron a lactantes menores de 2 meses, $55,4 \%$ a niños menores de 12 meses y $9,55 \%$ al rango de 1 a 10 años de edad. Resultaron verdadero positivas el $68,79 \%$ de las muestras y positivas por PCRTR el $64,97 \%$. La sensibilidad de la PCR-TR fue de $92,59 \%$ y $35,19 \%$ para la IFD. Por otra parte, 2 casos positivos por PCR-TR cuyas PCR convencional IFD fueron negativas tenían clínica altamente sugerente de cuadro coqueluchoideo. Hubo 8 casos negativos por PCR-TR pero positivos por IFD, con clínica no sugerente. En pacientes con muestras positivas por ambos PCR, tiempo real y convencional, pero negativas por IFD, se comprobó a través del cuadro clínico la existencia de un síndrome coqueluchoideo. Algunas de las muestras positivas por PCR-TR fueron secuenciadas, demostrando que los amplificados correspondían al gen IS481 de B. pertussis. Los tiempos de trabajo con PCR convencional y PCR-TR fueron de 8 y 2,5 hrs, respectivamente. Conclusiones: La sensibilidad de PCR-TR fue superior a la de IFD, técnica de rutina utilizada en laboratorios clínicos. El hallazgo de muestras positivas por PCR-TR pero negativas por PCR convencional e IFD y con clínica ad-hoc, sugiere que esta técnica superaría a las otras dos. Los resultados obtenidos por PCR-TR fueron más rápidos y fáciles de interpretar que la IFD. Por lo tanto, el uso de este kit, que es operador-independiente, permitiría mayor eficiencia en los laboratorios clínicos, en comparación con los procedimientos habituales.

\section{MASTOIDITIS NECROTIZANTE SECUNDARIA A OTITIS MEDIA AGUDA}

Cárdenas $A^{1}$, Mery $A^{2}$, Gutiérrez $F^{3}$, Zlatar $Y^{3}$

${ }^{1}$ Pediatra. Servicio de Pediatría. Hospital Regional de Antofagasta. ${ }^{2}$ Becado Pediatría. Facultad de Medicina y Odontología Universidad de Antofagasta. ${ }^{3}$ Internos Carrera de Medicina. Facultad de Medicina y Odontología Universidad de Antofagasta.

Introducción: La mastoiditis corresponde a la infección de las celdillas mastoideas del hueso temporal, siendo una de las etiologías la infección del oído medio. Afecta inicialmente al mucoperiostio, pudiendo evolucionar a osteítis y destrucción osea. Clínicamente se caracteriza por otorrea, dolor, tumefacción y eritema retroauricular, borramiento del surco retroauricular con antepulsión y despegamiento del pabellón auricular. Caso Clínico: Es derivada a nuestro Servicio, lactante femenino de 1 año de edad, por cuadro de otitis media supurada de 1 mes de evolución, que no responde al tratamiento con Amoxicilina, con persistencia de supuración y fiebre. Ingresa afebril, en buen estado general. Al examen presenta aumento de volumen doloroso y eritema retroauricular derecho con protrusión leve pabellón auricular. Abundante secreción purulenta por el conducto auditivo externo que impide observar el tímpano. Destaca leucocitosis (22.200/ $\left.\mathrm{mm}^{3}\right)$ y PCR alta $(11,6 \mathrm{mg} / \mathrm{dl})$. Hemocultivos negativos. La tomografia axial computada muestra aumento de volumen de partes blandas en relación a mastoides derecho con pérdida de arquitectura de peñasco y de alineación de CAE y celdilla mastoidea. Se plantea el diagnóstico de Otomastoiditis Derecha, iniciándose tratamiento antibiotico con cefotaxima más cloxacilina. Se practica mastoidectomía derecha encontrándose hueso osteomielítico, mucosa muy engrosada y equimótica con espículas óseas en su interior. Se rebaja apófisis mastoídea, regularizándose seno lateral y techo mastoídeo. Evolucionando favorablemente. Comentario: Si bien la mayoría de las otitis media agudas evolucionan favorablemente y podrian no ser tratadas con antibioticos, la presencia de un curso prolongado; nos debe poner en alerta sobre la presencia de complicaciones como la otomastoiditis aqui descrita.

ESPONDILODISCITIS COMO CAUSA DE ALTERACIÓN DE LA MARCHA EN LACTANTE

Cárdenas $A^{1}$, Zlatar $Y^{2}$, Mery $A^{3}$

${ }^{1}$ Pediatra. Servicio de Pediatría. Hospital Regional de Antofagasta. ${ }^{2}$ Interna Carrera de Medicina. Facultad de Medicina y Odontología Universidad de Antofagasta. ${ }^{3}$ Becado Pediatría. Facultad de Medicina y Odontología Universidad de Antofagasta.

Introducción: La alteración aguda de la marcha en el lactante es un cuadro que genera alarma en los padres, y constituye un desafío diagnóstico para el pediatra. Un cuidadoso examen físico y neurológico no siempre puede orientarnos hacia la causa, por lo que cobra vital importancia la imagenología. La espondilodiscitis se manifiesta clínicamente como dolor lumbar que puede irradiarse a la cara anterior del abdomen, que empeora al caminar o sentarse; rigidez e impotencia funcional hasta alteraciones neurológicas. Caso clínico: Lactante sexo masculino 1 año 8 meses de edad, sin antecedentes mórbidos, consulta por cuadro de 6 semanas de evolución de dolor abdominal y constipación asociado a alteración progresiva de la marcha hasta evitar la bipedestación. La última semana se agrega fiebre $38 \stackrel{\circ}{\circ}$ asociado a coriza y tos escasa. Ingresa afebril, examen pulmonar y abdominal normal, destacando al examen neurológico paraparesia de ambas extremidades inferiores. Sin leucocitosis, PCR y VHS normales. Se toman radiografías de pelvis, tórax, columna y una ecografía abdominal que fueron informadas normales. Como persiste con alteraciones de la marcha, se solicita una RNM que muestra una espondilodiscitis de L1-L2, corroborado por un cintigrama óseo. Se inicia tratamiento con ceftriaxona más cloxacilina por 14 días, evoluciona favorablemente, y es dado de alta asintomático. Comentario: Espondilodiscitis es una rara causa de claudicación en el lactante pero que, de acuerdo a lo expuesto, debemos tener presente. En este caso llama la atención la escasa manifestación sistémica para una infección ósea, lo que explica la falta de sospecha clínica y el retraso diagnóstico. 
ENFERMEDAD DE KAWASAKI: SERIE CLÍNICA DE 32 CASOS

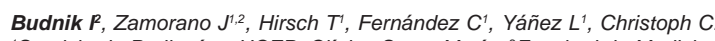
${ }^{1}$ Servicio de Pediatría y UCEP, Clínica Santa María. ${ }^{2}$ Facultad de Medicina Universidad de Los Andes.

Antecedentes: La Enfermedad de Kawasaki (EK), es una enfermedad que ha ido adquiriendo mayor importancia a nivel mundial constituyendo la principal causa de patología cardíaca adquirida en pediatría. Objetivos: Describir la principales características clínicas y el manejo de la Enfermedad de Kawasak en pacientes pediátricos ingresados a Clínica Santa María entre Febrero de 1999 y Mayo del 2007. Metodología: Análisis retrospectivo de revisión de fichas clínicas de 32 pacientes pediátricos hospitalizados con diagnóstico de egreso de Enfermedad de Kawasaki. Se recolecto la información en un protocolo ad-hoc. E análisis de la información se hizo por $\chi^{2}$ y test de fisher. Resultados: La frecuencia promedio anual fue de 5 casos por año. La edad media de los pacientes al momento del diagnóstico fue de 1,5 años (rango 0,4 a 8,8 ), el $69 \%$ son menores de 2 años y el $87,5 \%$ menores de 5 años. La razón hombre: mujer fue de 1,46:1. Los casos se concentraron en primavera, mayormente en el mes de Septiembre. Los criterios diagnósticos se presentaron en $87,5 \%$ para conjuntivitis, $87,5 \%$ compromiso de mucosa oral y/o labios, $81,2 \%$ compromiso de extremidades, $87,5 \%$ exantema y un $56,2 \%$ presentaron linfadenopatía cervical. Se presentó en forma típica en un $68,7 \%$, los casos atípicos se presentaron en lactantes. Se observo en el transcurso de la hospitalización compromiso de arterias coronarias en un $21,8 \%$, dilatación en $15,6 \%$ y aneurismas en $6 \%$. E tratamiento se hizo con gammaglobulina endovenosa y aspirina en el $100 \%$ de los casos. Sólo 4 pacientes requirieron una segunda dosis, siendo el $75 \%$ mayor de 5 años. No hay letalidad en esta serie. Se identificó agente infeccioso concomitante en tres pacientes; Virus respiratorio Sincicial, Pielonefritis por E. coli, y coinfección por Enterovirus y Parvovirus. Al ingreso se identificaron como factores de riesgo significativos de EK grave (tiempo de hospitalización mayor a 7 días, dilatación o aneurismas coronarios y segunda dosis de gammaglobulina) hipoalbuminemia (RR: 4,76) y VHS mayor de 100 (RR: 2,86 ) No se encontró asociación con trombocitosis ( $>400.000$ ), leucocitosis $(>15.000)$, presencia de BCGitis y Ecocardiografia alterada. En el seguimiento de esta serie, la mayoría de los niños se encuentran sanos, y sólo 2 presentaron persistencia de los aneurismas. Conclusiones: La EK es una patología poco frecuente, de claro predominio estacional en nuestro pais, se concentra en niños menores de 5 años, en la mayoría de los casos de presentación típica. Existen factores que orientarían a su evolución de mayor gravedad como hipoalbuminemia y VHS elevada. Importante su manejo precoz y alto índice de sospecha.

\section{CARACTERIZACION PARASITOLOGICA DE SUELOS Y SU RELACIÓN} CON PARASITOSIS INTESTINALES INFANTILES EN MENDOZA

Carrizo LC, Santos GE, Tonelli R, Salomón C.

U.N.cuyo, Facultad de Ciencias Médicas, Dpto de Patología, Áreas de Parasitología.

En diferentes áreas de la provincia de Mendoza hemos demostrado previamente un alto porcentaje de parasitosis intestinales en niños (36-80\%) dependiendo de área geográfica estudiada. Por otra parte, estudios preliminares demuestran que los suelos contaminados constituyen un factor de riesgo importante para la transmisión de éstas infecciones a la población. Objetivos: Recuperar e identificar elementos parasitarios en muestras de suelos y determinar la frecuencia relativa de hallazgos. Evaluar si existe relación con datos previos de prevalencia en infecciones intestinales de niños que viven en las áreas a investigar. Realizar la proyección a la comunidad. Métodos: Se realizaron métodos de concentración de parásitos para muestras de suelo y posterior observación microscópica e identificación. Resultados: Se analizaron 120 muestras en las cuales se observaron 69 elementos parasitarios, siendo el $42,04 \%$ protozoos, 34,78 huevos de helmintos y el $23,18 \%$ larvas de nematodos. Las especies más frecuentemente recuperadas fueron Blastocistis hominis, seguido por Hymenolepis nana, Toxocara $\mathrm{sp}$, Coccidios intestinales, Amebas, Enterovius vermicularis, y Áscaris lumbricoides. Cuando se compararon estos resultados con los de parasitosis intestinales se observó que las especies más frecuentes en el suelo son también especies prevalentes en materia fecal. Conclusiones: Se demostró contaminación de los suelos con parásitos de origen humano y animal, estableciéndose una relación directa entre las especies prevalentes en las muestras de suelo y materia fecal. Manifestamos la necesidad de implementar planes de prevención y profilaxis ya que, el tratamiento de las parasitosis como única forma de profilaxis no es suficiente para controlar las parasitosis intestinales principalmente en el caso de las protozoosis como es el nuestro.
CARACTERIZACIÓN DE LA SENSIBILIZACIÓN A AEROALÉRGENOS HABITUALES EN LOS PACIENTES PEDIÁTRICOS CON PRICK TEST (+) DEL HOSPITAL EL PINO

Muñoz MC, Sepúlveda TJ, Sobarzo AR, Sanhueza GP, Raby AP. Unidad de Inmunología, Departamento de Medicina Respiratoria Infantil, Hospital y CRS EI Pino. Universidad de Santiago de Chile. Universidad Nacional Andrés Bello.

Introducción: El prick test es una prueba cutánea usada para evaluar una respuesta de hipersensibilidad inmediata (IgE-mediada) frente a alérgenos determinados (sensibilización). Es el principal método para diagnóstico de alergia en la práctica clínica. Se ha descrito que la prevalencia de sensibilización aumenta con la edad. Se ha visto que ésta es mayor en hombres, diferencia más marcada en menores de 8 años según estudios. Estudios en niños chilenos han mostrado que los alérgenos predominantes son ácaros de polvo doméstico y polen de gramíneas. En el Hospital El Pino estos datos se desconocen. Objetivos: $\mathrm{Ca}$ racterizar prevalencia de sensibilización a aeroalérgenos en población pediátrica del Departamento de Medicina Respiratoria Infantil del Hospital El Pino en período de un año. Materiales y Métodos: Estudio descriptivo retrospectivo mediante análisis de todos los informes de prick test realizados en la población ya mencionada entre Septiembre 2007 y Septiembre 2008. El examen fue realizado según técnica clásica y normas actuales, usándose batería de 12 alérgenos habituales. Resultados: De un total de 281 pacientes, $143(50,9 \%)$ eran hombres y 138 $(49,1 \%)$ mujeres, divididos en grupos etáreos: lactantes $(n=6 ; 2,1 \%)$, preescolares $(n=76 ; 27 \%)$, escolares $(n=142 ; 50,5 \%)$ y adolescentes $(n=57 ; 20,2 \%)$. $117(41,6 \%)$ pacientes mostraron prick test positivo para uno o más alérgenos; de ellos, $59(50,4 \%)$ fueron hombres. La prevalencia de sensibilización fue: lactantes $16 \%$, preescolares $28,5 \%$, escolares $43,9 \%$ y adolescentes $69,1 \%$. En menores de 8 años 38 pacientes con prick test positivo; de ellos, 19 (50\%) fueron hombres. En mayores de 8 años, 79 sensibilizados; de ellos, 36 (45,5\%) de sexo masculino. Las sensibilizaciones a alérgenos más prevalentes fueron: Dermatophagoides pteronyssinus $(19,5 \%)$, polen de gramíneas $(17,9 \%)$, polen de malezas $(16,7 \%)$, D. farinae $(14,2 \%)$ y caspa de gato $(11,4 \%)$. Conclusiones: La prevalencia de sensibilización aumenta con la edad. No hubo diferencias significativas de sensibilización según sexo en distintos grupos etáreos. No se observó diferencias en menores de 8 años, sin embargo, hubo un leve aumento a partir de esta edad en mujeres. Los aeroalérgenos más frecuentemente positivos fueron $D$. pteronyssinus y polen de gramíneas. Este estudio es destacable ya que la población estudiada pertenece a la zona Sur de Santiago, no caracterizada previamente, no encontrándose diferencias con estudios anteriores a nivel nacional.

\section{PÚRPURA DE SCHÖNLEIN-HENOCH: UN CASO DE PRESENTACIÓN} INFRECUENTE

Álvarez D, Orellana G, Chadid J.

Becados de Pediatría Universidad de Chile; Infectóloga Unidad de Segunda Infancia, Hospital Exequiel González Cortés.

Introducción: El púrpura de Schönlein-Henoch (PSH) es la vasculitis más frecuente de la infancia. Corresponde a una vasculitis leucocitoclástica de pequeño vaso mediada por IgA, que se manifiesta como un púrpura palpable de predominio en extremidades inferiores, acompañado de compromiso articular, renal, digestivo, o una biopsia que muestre depósito de lgA. En general se presenta en forma secuencial, primero con compromiso cutáneo para extenderse luego a otros órganos. Objetivo: Dar a conocer un caso de presentación infrecuente. Caso Clínico: Paciente, sexo femenino, de 6 años, con historia de 4 días de dolor abdominal, compromiso del estado general, rechazo alimentario parcial que no remite pese a manejo sintomático en policonsultas. Al quinto día es derivado a nuestro SU, siendo operado a la brevedad con diagnóstico de apendicitis aguda. Se observa apéndice de aspecto normal, destacando íleon Terminal edematoso y petequial a $20 \mathrm{cms}$. de la válvula íleocecal. Al ingreso destaca PCR $45 \mathrm{mg} / \mathrm{dl}, 17.400$ leucocitos con predominio segmentados $72 \%$, plaquetas 245.000 $\mathrm{K} / \mathrm{uL}$ y sedimento de orina normal. 24 horas post intervención presenta lesiones purpúricas rojizo violáceo confluentes palpables, vitriopresión negativa, no dolorosas en pies, glúteos y piernas. A las pocas horas, asocia aumento del dolor abdominal y hematoquezia, manejándose con corticoides sistémicos, reposo intestinal y protección gástrica. Evolución posterior favorable, sin presentar nuevos episodios de hematoquezia, cede dolor abdominal, con estudio de función renal normal. Dado de alta en buenas condiciones. Informe anatomopatológico revela apéndice cecal con hiperplasia folicular linfoide y microhemorragias focales en mucosa. Conclusión: Recordar que, aunque poco frecuente, existen presentaciones que no son las clásicamente descritas, es decir, que no tienen compromiso cutáneo como primera manifestación y que por lo tanto, dificultan el planteamiento diagnóstico, incluso, como este caso lleva muchas veces a intervenciones quirúrgicas por sospecha de otras patologías como apendicitis aguda, resultando cirugías en blanco que en la evolución del post operatorio presentan otras manifestaciones que hacen evidente el diagnóstico clínico. 


\section{CASO CLÍNICO INMUNODEFICIENCIA}

Contardo PMV, Cuevas GC, Navarrete SCL. Hospital Roberto del Río. Santiago, Chile.

Caso Clínico: Paciente asintomático hasta los 6 meses de vida, evaluado po adenitis axilar izquierda. Se realiza biopsia que muestra TBC ganglionar con baciloscopia (+) cultivo (-). No tolera tratamiento antibiótico. Se realiza estudio inmunológico con subpoblación linfocitaria e Inmunoglobulinas normales. Presenta peso y talla estacionarios y dermatitis atópica refractaria. Aumento de perímetro cefálico en rangos patológicos, retraso del desarrollo psicomotor y fiebre intermitente. Se diagnostica alergia a la proteína de leche de vaca con test de parches y prick test positivos. A los 8 meses TAC cerebro muestra múltiples lesiones nodulares parenquimatosas en tronco cerebral y cerebro, con edema vasogénico perilesional y múltiples lesiones líticas en cráneo y calota. Radiografía de columna muestra múltiples imágenes radiolúcidas de contornos escleróticos, de aspecto no agresivo, ubicadas en costillas, alas ilíacas y fémures que podrían corresponder a diseminación de BCG. Biopsia parrilla costal: obs. Histiocitosis de Langerhans. Baciloscopia (-), PCR mycobacteria tuberculosis (). Cintigrama óseo: fémures, costillas y mandíbula con imágenes sugerentes de infiltración maligna. Ecografía abdominal normal Biopsia vértebra (10 meses) proceso granulomatoso inflamatorio, no necrotizante, no caseoso. Tinción kinyou (-) para mycobacterias. Biopsia cerebral (11 meses) en 2 muestras se observa un proceso inflamatorio linfohistiocitario con áreas de aspecto granulatorio y organización incipiente, sin granulomas. Con tinción de Ziehl Nielsen se observan abundantes mycobacterias alcohol ácido resistente. Conclusión Micobacteriosis diseminada. RMN cerebro: múltiples lesiones encefálicas hipercelulares intraparenquimatosas supra e infratentoriales y en base de cráneo de similar naturaleza. Estallido respiratorio normal. Estudio de LCR con PCR para Mycobacteria tuberculosis negativa. Al año se da tratamiento para micobacteriosis diseminada. Se diagnostica déficit parcial del receptor de INF gama. Se inicia tratamiento con INF gama y se mantiene isoniazida, rifampicina y claritromicina. Actualmente tiene 2 años y presenta un retraso del desarrollo psicomotor global.

\section{INTERVENCIÓN PILOTO EN NIÑOS DE EDUCACIÓN BÁSICA PARA MEJORAR LA RESILIENCIA}

Ebner CS, Escárate SMJ, Calderón RL, Corsi SJ, Ellwanger WA, McColl CP. Universidad de Valparaíso, Valparaíso, Chile.

La resiliencia es la capacidad de enfatizar las potencialidades y los recursos personales que permiten enfrentar situaciones adversas y salir fortalecido, a pesar de estar expuesto a factores de riesgo. El objetivo del presente trabajo fue promover actitudes y valores resilientes en los escolares (como el autoestima, confianza en recursos personales y capacidad de proyección a futuro), que los preparen para enfrentar adversidades. La intervención fue desarrollada por un grupo de 5 estudiantes de $2^{\circ}$ año de medicina de la Universidad de Valparaíso entre los meses de octubre y diciembre de 2007, en un tercero básico de la Escuela Básica D-314 Joaquín Edwards Bello, Rodelillo, Valparaíso. El proyecto constaba de 6 sesiones de dinámicas grupales monitoreadas de una hora y treinta minutos, cada una de éstas buscaba fortalecer una característica resiliente en los niños. Se aplicó un instrumento, el cual fue confeccionado previamente, en base a revisiones bibliográficas y opinión de expertos. En éste se asignó un puntaje a las distintas características resilientes, las cuales fueron medidas al inicio y después de la intervención. La aplicación del instrumento confeccionado para medir resiliencia arrojó un puntaje promedio del curso de 15,95 puntos (de un total de 31). La segunda aplicación del instrumento, después de las 6 sesiones, entregó un puntaje promedio de 19,57 puntos, lo que significó un alza de aproximadamente 3,6 puntos. Si bien el aumento en los niveles de resiliencia fue importante, también lo fue la impresión de la profesora jefe y los tutores respecto a los cambios positivos que se produjeron en el curso. Durante la realización de proyecto se encontraron falencias en la sensibilidad del instrumento y la ejecución, las cuales podrían ser modificadas en una futura intervención; es por ello que consideramos el trabajo realizado más bien un proyecto piloto con resultados que invitan a efectuar futuras intervenciones más acabadas. Se concluyó que diversas actividades que apunten a reforzar características resilientes en niños pueden mejorar el nivel de resiliencia global de un determinado curso.

\section{MANIFESTACIONES CLÍNICAS Y DE LABORATORIO EN PACIENTES PEDIÁTRICOS CON LUPUS}

Cuevas GC, Contardo PMV, Navarrete SCL.

Hospital Roberto del Río.

Introducción: Lupus eritematoso es una enfermedad multisistémica autoinmune poco frecuente en edad pediátrica, de difícil diagnóstico, que se caracteriza por presentarse con múltiples manifestaciones clínicas e inmunológicas. Objetivo: Determinar la frecuencia y las características de los síntomas, signos clínicos y hallazgos de laboratorio de los pacientes con lupus del HRR al momento de diagnóstico de la enfermedad. Materiales y Métodos: Trabajo retrospectivo de revisión de fichas clínicas de pacientes con diagnóstico de LES. Resultados: Se encontraron 22 pacientes con diagnóstico de LES, siendo más frecuente en mujeres $(6,3: 1)$. El tiempo promedio para el diagnóstico de enfermedad desde el inicio de los síntomas fue de 10,7 meses. La edad promedio de diagnóstico fue 11 años 4 meses. Los principales motivos de consulta a médico fueron artralgias, síndrome febril y la presencia de lesiones cutáneas. Las manifestaciones clínicas más frecuentes son artritis $(45,4 \%)$, rash malar $(50 \%)$, nefritis $(36.3 \%)$ Dentro de los hallazgos de laboratorio más frecuentes $100 \%$ de los pacientes tienen ANA (+), $77 \%$ tienen anti DNA (+), 36\% tiene VHS > 100 y $63 \%$ tiene hipocomplementemia. Conclusiones: La realización del diagnóstico requirió de un tiempo prolongado de sintomatología (10,7 meses). Las manifestaciones y hallazgos de laboratorio encontrados en los pacientes son comparables con otras series.

\section{INDICIOS DE DEPRESIÓN EN ESTUDIANTES DE POSTÍTULO DE ESPECIALIDADES MÉDICAS}

Concha VM', Duffau $T G^{2}$.

${ }^{1}$ Hospital San Juan de Dios. ${ }^{2}$ Departamento de Pediatría y Cirugía Infantil, Campus Norte, Facultad de Medicina Universidad de Chile, Santiago.

Objetivo: Explorar la existencia de signos de depresión en médicos de staff y mayormente en aquellos desarrollando estudios de postítulo. Método: Se incluyeron 100 médicos de diferentes hospitales, 80 de ellos cursando programas de entrenamiento de postítulo, los que se estudiaron por medio de la escala de Zung, autoaplicada voluntaria y anónimamente. El puntaje máximo de la escala es 80 y se considera anormal cualquier valor sobre 40 puntos. Se compararon los médicos con puntaje normal con aquellos que lo tenían elevado, utilizando los resultados obtenidos en la escala que aparecieron más o menos decidores de alteración: 14-17-18-19 vs 2-4-8-13. Para ello se empleó la prueba de Fisher-Irwin. Resultados: En el grupo completo, el 17\% mostró puntaje anormal. La cifra mayor, $25 \%$, se encontró en el grupo de médicos de staff de los servicios clínicos.En la comparación de grupos según rubros seleccionados, se encontró una diferencia significativa con $p=0,0002$ para las preguntas $14-17-18-19$ y no significativa, con $\mathrm{p}=0,5859$ para $2-4-8-13$. Esto, se consideró sugerencia de establecer ponderación para las diferentes preguntas que indaga la escala. Conclusiones: 1) Las evidencias de depresión fueron detectadas en el $17 \%$ de los casos estudiados y $25 \%$ en el subgrupo de médicos de staff; 2) Habría argumentos para recomendar estudios que agreguen un factor de ponderación en cada pregunta de la escala de Zung. Comentarios: En este estudio, de carácter indagatorio, encontramos: 1) Desde luego, en el grupo completo estudiado la prevalencia puntual encontrada de probables trastornos del animo fue de $17 \%$, cifra que ascendió a $25 \%$ en el primer subgrupo, de médicos de staff. En estos podrá ser planteado que han tenido más tiempo de contacto con la realidad profesional y personal, han evaluado "en terreno" lo que es muy probable puedan esperar para el futuro. Como tales cosas quedan habitualmente bajo las expectativas que se tenía, podría justificarse un menor entusiasmo como evolución casi natural; 2) La escala de Zung explora 20 aspectos y pensamos que habría argumentos para recomendar estudios que agreguen un factor de ponderación a cada área interrogada; 3) En uno de los estudios citados, se verificó la confiabilidad de la prueba, escala de Zung, con el índice alfa de Cronbach, lo que seria criticable habida consideración que para ello se requiere variables de intervalo o razón, que no se encuentran disponibles ya que en la escala estudiada son categóricas. 
CALIDAD DE VIDA: REPORTE DE LOS MÉDICOS RESIDENTES DEL PROGRAMA DE FORMACIÓN DE ESPECIALISTAS EN PEDIATRÍA

Schonhaut BL, Rojas NP, Millán KT.

Departamentos de Pediatría Norte y Occidente, Universidad de Chile.

Introducción: En busca de mejorar las oportunidades laborales y calidad de vida (CDV), los médicos optan por los Programas de Formación de Especialistas (PFE); no obstante, este proceso los enfrenta a una serie de factores estresantes que podrían afectar, a corto plazo su salud y bienestar. El objetivo de presente estudio es explorar aspectos relacionados con la CDV profesional y factores estresantes de los residentes del PFE de Pediatría de las universidades públicas chilenas. Metodología: Se diseñó, validó y aplicó una encuesta semiestructurada, previamente validada, que se aplicó a una muestra de oportunidad de 79 residentes de pediatría de las universidades públicas chilenas (37,6\% del universo total). Los residentes fueron contactados en congresos de la especialidad y en visitas en sus centros de formación, entre noviembre/2006 y marzo/ 2007. Resultados: $65 \%$ provenían de Centros Formadores de la Región Metropolitana 35\% de de provincia. Los residentes se sintieron agradecidos de poder emitir su opinión. "Gracias y jauxilio!". 78,5\% era de sexo femenino, edad promedio 29 años (rango 25 a 40). La mitad estaba endeudado, la mayoría siendo proveedores de su grupo familiar, sin diferencia entre tipo de financiamiento de PFE. 6 de cada 10 residentes trabajaba horario extra, promedio de 18,2 horas semanales y 4 de cada 10 realizaba guardias nocturnas. La mitad manifestó algún problema de salud física. Un tercio declaró problemas de salud mental, sin relación con los factores sociodemográficos estudiados. Entre los factores estresantes nombrados espontáneamente, destacan factores de estrés profesional y académico, como la carga asistencial excesiva, asociado a falta de docencia y de adecuada supervisión. $71 \%$ refirió interés por continuar con una subespecialidad y, pese a que a uno de cada dos residentes de pediatría le gustaría trabajar en hospitales, sólo uno de cada cuatro pensaba que efectivamente lo haría. Conclusiones: El presente estudio, nos brinda una visión sobre la percepción de CDV y salud mental de los residentes de pediatría de nuestro país. Sin duda, sería interesante continuar con esta línea de investigación, incorporando instrumentos estandarizados y aspectos cualitativos, para indagar en profundidad sobre los factores estresantes y las fortalezas de los PFE, de modo de implementar mecanismos de apoyo para nuestros residentes, y así asegura una formación integral, no sólo en lo profesional, sino que también en el plano personal.

\section{PRESENCIA DE DISFUNCIÓN FAMILIAR EN PACIENTES DEL CENTRO DE RESPONSABILIDAD MÉDICO-QUIRÚRGICO PEDIÁTRICO DEL HOSPITAL REGIONAL RANCAGUA}

Rubio M, Gajardo C, González Y, Riffo C, Iturrieta E, Leiva H. CR Médico-Quirúrgico Pediátrico Hospital Regional Rancagua.

Introducción: La existencia de una familia disfuncional favorece la aparición de enfermedades infantiles, las hace más complejas y dificulta su tratamiento. Propósito: Evaluar el funcionamiento de las familias de los niños consultantes en el Policlínico de Pediatría-Cirugía Infantil y de los pacientes hospitalizados en los Servicios de Pediatría y Cirugía Infantil en el mes de agosto de 2008. Material y Método: Se aplicó la encuesta denominada APGAR familiar a los acompañantes de los pacientes y se analizó mediante SPSS 12.0. Cada acompañante recibió la encuesta de parte de una Enfermera Universitaria y la contestó autónomamente y en forma anónima. Resultados: Se aplicaron 147 encuestas 66 a familiares de Pediatría, 31 en Cirugía Infantil y 50 a madres de niños consultantes en el Policlínico de especialidades pediátricas. El $51,7 \%$ de los pacientes eran varones; el promedio de edad fue de 5,6 años y la edad promedio de los encuestados fue de 34,5 años. Se encontró que el $43,5 \%$ no presentaba disfunción familiar, mientras que el $38,1 \%$ tenía una disfunción leve en 20 casos la disfunción fue moderada y el $4,8 \%$ padece de una disfunción familiar severa. Al comparar la incidencia de disfunción familiar por los servicios del CR, ésta es menor en el Servicio de Cirugía Infantil. Las diferencias son estadísticamente significativas $p=0,01$ en el caso Cirugía Infantil vs Pediatría y Cirugía vs Poli. También, se preguntó respecto de la existencia de amigos y se constató que e $38,7 \%$ declaró no tener la ayuda de amigos. En 21 pacientes crónicos, apareció disfunción familiar de algún grado en el $61,9 \%$ de las encuestas. Conclusiones: Los resultados representan un desafío para el equipo de salud que debe considerar el funcionamiento familiar para conseguir la meta de recuperar la salud de los niños consultantes u hospitalizados. Esto es particularmente necesario en las familias de los pacientes crónicos.
¿ES EL CONSENTIMIENTO INFORMADO COMPRENDIDO POR LOS PADRES EN EL HOSPITAL ROBERTO DEL RÍO?

Delamarre MG, Duffau G, González N.

Hospital Roberto del Río, Santiago, Chile.

Introducción: El consentimiento informado $(\mathrm{Cl})$ es un concepto relativamente nuevo mencionado a nivel legislativo pero aplicado sobre una base fundamentalmente ética. La comprensión del mismo, por el paciente o sus tutores, refleja no sólo la relación médico-paciente sino también la relación a nivel institucional. Objetivo: Evaluar la comprensión de los padres del $\mathrm{Cl}$ firmado al ingreso hospitalario de sus hijos en el Hospital de niños Roberto Río. Pacientes y Métodos: se realizó una encuesta, en base al $\mathrm{Cl}$ vigente en el hospital, de 15 preguntas a 268 padres de niños hospitalizados. El gold standard de las respuestas correctas fueron las entregadas por los médicos del hospital. Individualmente, se definió como encuesta correcta a 9 o más respuestas acertadas. Globalmente, se consideró entendimiento correcto del $\mathrm{Cl}$ si 160 o más encuestas fueron respondidas correctamente. Resultados: Sólo un tercio $(32,8 \%)$ de los padres obtuvieron encuestas correctas comparados con el $100 \%$ de los médicos. El $18,6 \%$ de los $\mathrm{Cl}$ fueron firmados por medio de lectura más explicación médica. La mayoría obtuvieron información de la lectura del $\mathrm{Cl}(47,1 \%)$. Las preguntas peor contestadas por los padres (<30\% correctas) fueron en relación a vocabulario técnico. Las más fáciles (> 70\% correctas) fueron en relación a la enfermedad de sus hijos/as (complicaciones, secuelas, etc). Existe concordancia moderada entre la comprensión (objetiva) medida por la encuesta y la auto-evaluación (subjetiva) paterna. A mayor nivel educacional de los padres, mayor número de encuestas correctas. Conclusión: Los padres no comprenden el Cl que firman al ingreso hospitalario de sus hijos. Esto parece asociarse al vocabulario utilizado en el CI como así también a la falta de explicación médica. Por tanto, la validez de este procedimiento tanto desde el punto de vista ético como legal es cuestionable.

DIÁLISIS PERITONEAL PEDIÁTRICA EN CHILE. REPORTE DEL COMITÉ DE DIÁLISIS PERITONEAL DE LA RAMA DE NEFROLOGÍA, SOCIEDAD CHILENA DE PEDIATRÍA

Barrera $P^{1}$, Vogel $A^{2}$, Villagra $\mathcal{~}^{\beta}$, Valenzuela $M^{4}$, Contrera $A^{5}$, Zambrano $P^{6}$, Cano $F^{7}$

${ }^{1}$ Hospital Sótero del Río, ${ }^{2}$ Hospital Clínico Pontificia Universidad Católica, ${ }^{3} \mathrm{Hospital}$ Base de Osorno, ${ }^{4} \mathrm{Hospital}$ Regional de Concepción ${ }^{5} \mathrm{Hospital}$ Roberto del Río, ${ }^{6}$ Hospital Dr. Exequiel González Cortés, ${ }^{7}$ Hospital Luis Calvo Mackenna.

La diálisis peritoneal es la principal terapia de reemplazo renal en Pediatría, en Chile como programa existe desde 1995 y cada vez se ha incrementado el número de pacientes pediátricos lo que ha permitido un mejor manejo de la insuficiencia renal crónica terminal IRCT. El objetivo de este estudio es evaluar retrospectivamente los pacientes sometidos a esta terapia durante el último año. Se recolectaron los datos de los pacientes pediátricos que se encuentran en diálisis peritoneal en Chile (excepto los datos del Hospital de Temuco) entre el 01 de Junio de 2007 al 31 de Junio de 2008. Se evaluaron características epidemiológicas y demográficas, crecimiento, parámetros metabólicos, adecuación dialítica y complicaciones. Durante el período de estudio se dializaron 76 pacientes, $62 \%$ varones, la edad promedio al ingreso fue 6,3 años siendo el $29,5 \%$ menores de 6 años. Las etiologías más frecuentes fueron las malformaciones ( $46 \%$ ) seguida de glomerulopatías $26 \%$, en $14 \%$ no se conoció la causa de la insuficiencia renal. La hemoglobina promedio fue de $11,7+1,8 \mathrm{~g} / \mathrm{dL}$; el BUN promedio fue de $47,8+8,4 \mathrm{mg} / \mathrm{dL}$; bicarbonato $23,9+3,5 \mathrm{mEq} / \mathrm{L}$; la PTH promedio fue $343+200 \mathrm{pg} / \mathrm{mL}$; el calcio en promedio fue $9,2+0,9 \mathrm{mg} / \mathrm{dL}$; el promedio de fósforo fue $5,3+1,4 \mathrm{mg} / \mathrm{dL}$. El clearance promedio del paciente al ingreso fue 15, $9 \mathrm{ml} / \mathrm{min} / 1,73$; el clearance dialítico promedio fue $130 \mathrm{l} / \mathrm{sem} / \mathrm{sup}$ corp (clearance peritoneal 54 y clearance residual 76); el Kt/v total promedio fue $3,5+$ $1,1(1,8 \mathrm{Kt} / \mathrm{v}$ peritoneal y $1,7 \mathrm{Kt} / \mathrm{v}$ residual); el $76 \%$ de los pacientes tuvo función renal residual. Un $4 \%$ de pacientes se encuentran en CAPD, $56 \%$ con APD con día seco y $40 \%$ con APD día húmedo; el volumen promedio de los baños fue $1050+130 \mathrm{ml}$. El test de equilibrio peritoneal mostró que el $66 \%$ fue transportador bajo o promedio bajo y el $54,4 \%$ fue ultrafiltrador bajo o promedio bajo. El Z $\mathrm{P} / \mathrm{E}$ al ingreso fue de $-2,2 \mathrm{y}$ al egreso de $-2,3 \mathrm{y}$ el $\mathrm{Z}$ IMC fue de 0,36 al ingreso $y$ 0,32 al egreso; del total $31,7 \%$ recibieron suplemento nutricional oral, $12 \%$ por SNG y $1,3 \%$ por gastrostomía; $55 \%$ no recibió aporte nutricional. El tiempo en diálisis en promedio fue de 1,6 años siendo el trasplante renal la principal causa de egreso $(64,8 \%)$ seguido de cambio a hemodiálisis (12\%) por falla en la ultrafiltración. Un 76\% requirió hipotensores siendo los IECA/ARA II los más utilizados seguido por bloqueadores de canales de calcio (28\%); del total, $76 \%$ requirió de fármacos para el manejo de su IRCT; $1,3 \%$ utilizó hormona de crecimiento. La mortalidad fue 1,3\%. Conclusiones: La Diálisis Pediátrica es el método de elección en pediatría siendo nuestros resultados similares a publicaciones internacionales, a pesar de los avances tecnológicos el crecimiento es un problema aún no superado, la osteodistrofia renal y la HTA son un problema importante que probablemente se ven agravados por la falta de adherencia al tratamiento. 
PÉRDIDAS PROTEÍCAS PERITONEALES EN PACIENTES PEDIÁTRICOS CON SÍNDROME NEFRÓTICO EN DIÁLISIS PERITONEAL

Quiroz $L^{1}$, Azócar $M^{1}$, Dinamarca $H^{1}$, Emilfork $M^{2}$, Cano $F^{\prime}$

${ }^{1}$ Facultad de Medicina, Universidad de Chile, Hospital Luis Calvo Mackenna, Servicio Pediatría, Clínica Santa María, Santiago, Chile.

El Síndrome Nefrótico (SN) afecta niños principalmente entre 2 y 8 años, y en general responde favorablemente a corticoides $(90 \%)$. Los casos cortico resistentes evolucionan a insuficiencia renal crónica (IRC). Desde 1974 se ha reportado la presencia de un factor de permeabilidad (FP) en el plasma de estos pacientes. El efecto de éste FP debería ser sistémico, incluyendo la membrana peritoneal. Objetivo: Evaluar las pérdidas proteicas peritoneales en niños con $\mathrm{SN}$ en diálisis peritoneal (DP). Material y Método: Estudio retrospectivo, años 2003 a 2007 en pacientes portadores de SN (grupo 1) en DP. Se evaluaron a mes 1 y entre los meses 6 y 12 de su ingreso a DP variables clínicas: ingesta proteica, peso, talla, SC y bioquímicas: creatinina nitrógeno ureico (BUN), calcio, fósforo, hormona paratiroidea (IRMA-PTH), albúmina y proteínas plasmáticas Se midieron las proteínas de 24 horas en el dializado y en orina al inicio y al fina del período de seguimiento. Se midieron KtV residual, peritoneal y total y PET. Se usó como grupo control pacientes de la misma edad y sexo en diálisis peritoneal que no eran portadores de SN (grupo 2). Se comparó los grupos por t de student. Un $p<0,05$ fue significativo. Resultados: Se incluyeron 9 pacientes en el grupo 1 y 12 pacientes en el grupo 2. Los grupos fueron similares respecto a edad género, peso, superficie corporal, tiempo en DP, concentración de dextrosa utilizada, modalidad dialítica y dosis de diálisis. No se observó diferencias en los parámetros bioquímicos. La PTH fue significativamente menor en el grupo con SN que en el control $(164+144$ vs $564+454 \mathrm{pg} / \mathrm{dl})$ al final del período, y la albúmina fue menor en los pacientes con SN al inicio $(2,27 \pm 0,63 \mathrm{gr} / \mathrm{dl}$ vs $3,62 \pm$ $1,45 \mathrm{gr} / \mathrm{dl})$ y al final de la evaluación $(2,8 \pm 0,5 \mathrm{gr} / \mathrm{dl}$ vs $3,9 \pm 0,86 \mathrm{gr} / \mathrm{dl},(\mathrm{p}<0,05)$ Las pérdidas proteicas peritoneales fueron significativamente mayores en el grupo de pacientes con SN al inicio: $3,41 \pm 2,01 \mathrm{gr} / \mathrm{m}^{2} /$ día $v s 1,76 \pm 1,45 \mathrm{gr} / \mathrm{m}^{2} / \mathrm{día}$ y al final del estudio: $4,27 \pm 3,47 \mathrm{gr} / \mathrm{m}^{2} /$ día vs $1,66 \pm 1,31 \mathrm{gr} / \mathrm{m}^{2} /$ día $(\mathrm{p}<0,05)$, al igual que las pérdidas urinarias. No hubo diferencias en la ingesta proteíca, KtV peritoneal ni total entre los grupos, mientras que el KtV residual fue significativamente menor en los pacientes nefróticos al término del estudio, sugiriendo una caída más precoz de la función renal residual. No se observó diferencias respecto a las tasas de peritonitis en el período estudiado. Conclusión: Las pérdidas de proteínas por peritoneo en pacientes en DP portadores de SN, son significativamente mayores que en el resto de los pacientes en DP. Los resultados son consistentes con el posible efecto sistémico de un FP en estos pacientes.

\section{CALIDAD DE VIDA EN ADOLESCENTES CON ENFERMEDAD RENAL CRÓNICA}

Peredo $M^{1,2}$, Kraus $\mathrm{J}^{3}$, Labbé $M^{4}$, Vogel $A^{1,2}$, Inzunza $C^{5}$

Unidad de Nefrología Pediátrica, ${ }^{2}$ Departamento de Pediatría, ${ }^{3}$ Médico-Cirujano, ${ }^{4}$ Interna de Medicina, ${ }^{5}$ Unidad de Psiquiatría del Niño y Adolescente, Departamento de Psiquiatría, Escuela de Medicina, Pontifica Universidad Católica de Chile.

Introducción: Gracias a los avances tecnológicos y de la Medicina, la sobrevida de los pacientes con Enfermedad Renal Crónica (ERC) ha aumentado. Estudios han demostrado que adultos que presentaron una Enfermedad Renal Crónica Terminal (ERCT) en su niñez logran en forma incompleta y más tardía los hitos de su desarrollo personal, al mismo tiempo que perciben una menor calidad de vida. Esto hace fundamental velar no sólo por su cuidado médico, sino tambié por su calidad de vida. Objetivo: Determinar la percepción de calidad de vida en adolescentes chilenos con ERCT y peritoneodiálisis o trasplante renal. Métodos: Se realizó un estudio descriptivo de corte transversal. Se reclutó a 8 pacientes con antecedentes de ERCT y peritoneodiálisis o trasplante renal (edad media 15,7 años, rango 13-19 años) en tratamiento y control en la unidad de Nefrología Pediátrica de la Pontificia Universidad Católica de Chile. Se implementó la encuesta PedsQLTM, validada para evaluar la autopercepción de calidad de vida en pacientes sanos y portadores de enfermedades crónicas. Este cuestionario estudia 4 dominios: físico, emocional, social y escolar. Resultados: El área física se encuentra escasamente afectada; el 100\% no tiene dificultades para caminar y sólo el $25 \%$ refiere a veces cansancio. En el dominio emocional, destaca que el $75 \%$ tiene sensación de enojo y el $87,5 \%$ presenta preocupación por lo que le puede ocurrir en el futuro. En el ámbito social, el $87,5 \%$ refiere tener buenas relaciones con sus pares, pero el $62,5 \%$ tiene dificultades en realizar las actividades propias de su edad. Por último, en el área escolar, al $75 \%$ le cuesta estar al día en las materias, mientras que el 62,5\% falta al colegio por no sentirse bien y el $100 \%$ debe faltar a lo menos una vez a mes para acudir a sus controles médicos. Conclusiones: Este estudio, el primero realizado en su materia en nuestro país, muestra que pacientes con ERCT presentan alteraciones en las áreas emocionales, sociales y escolares, lo que podría determinar en el futuro la aparición de psicopatología. Recomendamos incorporar la evaluación de la calidad de vida en pacientes pediátricos con ERCT a través de la encuesta PedsQLTM, para detectar precozmente alteraciones que puedan llevar a problemas psicológicos. En un futuro, se intentará pesquisar la presencia de psicopatología en estos pacientes.
CARACTERIZACIÓN DE INFECCIONES DEL TRACTO URINARIO HOSPITAL DEL COBRE SALVADOR ALLENDE G., CALAMA

Moscoso P, Araya N.

Unidad del Niño, Hospital del Cobre Salvador Allende G. Calama.

Introducción: Se define Infección del Tracto Urinario (ITU) como la colonización, invasión y multiplicación en la vía urinaria, de microorganismos patógenos, especialmente bacterias, que habitualmente provienen de la región perineal. La incidencia exacta de ITU en el niño no se conoce bien debido especialmente a problemas de definición de infección, diagnóstico clínico y bacteriológico. La certificación exacta del diagnóstico es muy importante en el manejo clínico posterior, evitando sobrediagnóstico o daño renal futuro por un diagnóstico y tratamiento tardío. Objetivos: Caracterizar las ITU en pacientes menores de 15 años hospitalizados y ambulatorios en el Hospital del Cobre durante el segundo semestre del año 2007. Definir estudio radiológico realizado. Método: Estudio descriptivo. Se revisan retrospectivamente las fichas informatizadas de los pacientes con urocultivo positivo durante el período que abarca desde el 01 de julio al 31 de diciembre del año 2007. Se analizó edad, sexo, etiología, hospitalización, antecedentes ITU, estudio radiológico. Resultados: Durante el período de estudio se realizaron 639 urocultivos en menores de 15 años. De los urocultivos procesados fueron confirmados como ITU un total de $52(8,13 \%)$ que corresponden a 47 pacientes, siendo una recidiva en el $40 \%$ de los casos. Cuarenta y un pacientes $(78,8 \%)$ corresponden a mujeres. La edad promedio fue de 5.4 años. El $86,5 \%$ ( 45 pacientes) fueron tratados en forma ambulatoria. El germen aislado más frecuente fue Escherichia colicon un $90,4 \%$. De los 47 pacientes que presentaron ITU un $19,1 \%$ se encuentra en control en policlínico de Nefrología Infantil. En relación al estudio radiológico el $44,7 \%$ tiene ECO renal tomada y sólo un $27.6 \%$ tiene Uretrocistografía miccional. Según edad, sexo y antecedentes de ITU, el $70,2 \%$ no se realiza estudio radiológico de acuerdo a las recomendaciones de la Rama de Nefrología. Conclusiones y Discusión: Coincidente con la bibliografía existente, en nuestro medio, las ITU, fueron más frecuentes en el sexo femenino, siendo el germen más frecuentemente aislado la Escherichia coli con un $90,4 \%$. Siendo el reflujo vesico-ureteral una causa importante de Insuficiencia Renal Crónica en pediatría, el estudio radiológico (Ecotomografía RenalVesical y Uretrocistografía Miccional) se hace perentorio. En nuestro medio, a pesar de contar con los recursos técnicos, según los resultados expuestos, sólo en el $29,8 \%$ de los pacientes se estudió con imagenología de acuerdo a las recomendaciones de la Rama de Nefrología de la Sociedad Chilena de Pediatría.

\section{ASPECTOS CLÍNICOS DEL SÍNDROME HEMOLITICO UREMICO. EXPERIENCIA DE 5 AÑOS HOSPITAL LAS HIGUERAS DE TALCAHUANO}

Saavedra $\mathbf{M H}^{1}$, Muñoz $P \mathcal{J}^{2}$, Ruiz $\mathrm{OM}^{1}$, Arancibia $\mathrm{CM}^{1}$, Rojas $\mathrm{Bl}^{1}$. ${ }^{1}$ Internos de Medicina Universidad de Concepción. ${ }^{2}$ Nefrólogo Infantil Hospital Las Higueras de Talcahuano.

El Síndrome hemolítico urémico (SHU) es una entidad nosológica poco frecuente, pero clínicamente reviste mucha gravedad, representando lacausa más frecuente de insuficiencia renal aguda en los menores de 2 años, por loque un diagnóstico precoz y un tratamiento adecuado es muy importante. Se caracteriza por anemia hemolítica microangiopática, plaquetopenia y alteraciones multisistémicas claramente explicables por la fisiopatología de la enfermedad, la que afecta prácticamente todos los órganos. Se presenta la experiencia de 5 años del Hospital Las Higueras de Talcahuano. En este período de tiempo se presentaron 15 casos, de loscuales53, 3\% fueron varones, y 46,7\% mujeres. El 93,3\% fue SHU Típico $(\mathrm{D}+)$ y el6,7\% Atípico (D-), pero se comportó clínicamente igual a los D+. La edad promedio fue de 1,85 años, con un rango de edad de 0,75 a 4,3 años. El $100 \%$ presentó anemia hemolítica, requiriendo transfusión sanguínea el $73,3 \%$, Con una $\mathrm{Hb}$ mínima promedio de $6,05 \mathrm{gr} / \mathrm{dL}$. El $80 \%$ tuvo trombocitopenia y el $26,7 \%$ hiperkalemia. El $85 \%$ presentó insuficiencia renal aguda, con una creatininemia máxima promedio de $3,75 \mathrm{mg} / \mathrm{dL}$. El $40 \%$ presentó HTA,mientras que el $6,7 \%$ tuvo oliguria y un $13,3 \%$ cayó en anuria. Un $13,3 \%$ del total requirió diálisis peritoneal, con un promedio de 11 días. No se presentaron casos fatales en nuestro grupo. El promedio de hospitalización fue de 8 días. El $80 \%$ se ha mantenido en controles, todos ellos sin presentar hematuria, hipertensión ni alteraciones de la función renal. 
MONITORIZACIÓN AMBULATORIA CONTÍNUA DE PRESIÓN ARTERIAL EN NIÑOS Y ADOLESCENTES CHILENOS

Aglony $\mathbf{M}^{\boldsymbol{1}}$, Peredo $\mathrm{S}^{1}$, Cerda $\mathrm{J}^{2}$, Pérez $V^{\prime}$

Unidad de Nefrología. Departamento de Pediatría. ${ }^{2}$ Departamento de Salud Pública. Pontificia Universidad Católica (PUC) de Chile.

Introducción: La hipertensión arterial (HTA) en la edad pediátrica esta íntimamente relacionada con riesgo cardiovascular, sin embargo, es aún una enfermedad subdiagnosticada (1-2\%). El uso de la monitorización ambulatoria continua de presión arterial (MAPA) es un método de gran utilidad, el cual permite la evaluación de las presiones arteriales (PA) del niño en condiciones cotidianas durante un período de tiempo prolongado, evitando el efecto de delantal blanco. Pese a estas ventajas, la MAPA es un procedimiento aún poco difundido en el ambiente pediátrico. Objetivo: El objetivo de este trabajo fue describir y correlacionar la PA tomada clínicamente y por MAPA en un grupo de niños y adolescentes chilenos derivados al Programa de HTA PUC con indicación de MAPA por sospecha de HTA. Método: Se realizó un estudio transversal de 127 pacientes, a los cuales se realizó toma de PA clínica (promedio de 3 mediciones) y MAPA. Sólo $113(89 \%)$ pacientes cumplieron el requisito de tomas técnicamente satisfactorias. Resultados: La población en estudio fue $52,2 \%$ de sexo femenino, edad promedio 11,7 (4-20) años y peso de nacimiento (PN) promedio 3.191 (1.250-4.910) g. Según el diagnóstico nutricional $2,7 \%$ de los pacientes fueron clasificados como bajo peso, $46 \%$ eutróficos, $24,8 \%$ sobrepeso y $26,5 \%$ obesos. Clínicamente los pacientes se clasificaron según sus cifras tensionales (sistólicas/diastólicas) en: normotensión (51,3\%/74,3\%), pre-hipertensión (20,4\% $2,7 \%$ ) e HTA (28,3\%/23\%). El 70,8\% de los MAPA resultaron alterados: $38,1 \%$ por alteración de la PA, 15\% por pérdida del ritmo circadiano (ausencia de DIP nocturno) y $17,7 \%$ por ambas alteraciones. Al contrastar los diagnósticos de PA clínicas con los de MAPA, se logra establecer que un 27,4\% presentaban HTA sistólica enmascarada, 45,1\% HTA diastólica enmascarada y 5,3\% HTA de delantal blanco. La concordancia de PA clínica alterada, sistólica y diastólica, en relación con los hallazgos de la MAPA, presentó un coeficiente de concordancia de Kappa de 0,35 (aceptable) y 0,25 (aceptable), respectivamente. Conclusión: De este estudio se concluye que el MAPA permite refinar el diagnóstico de HTA en pediatría, especialmente en el grupo de hipertensos enmascarados, de reconocido riesgo cardiovascular asociado, siendo un instrumento confiable y bien tolerado en esta población. Nuestros datos son pioneros a nivel nacional y permiten conocer en mayor profundidad el comportamiento de las PA de nuestros pacientes.

\section{MONITORIZACION AMBULATORIA CONTINUA DE PRESION ARTERIAL: ASOCIACIÓN CON FACTORES DE RIESGO CARDIOVASCULAR Y PERINATAL}

Aglony $\mathbf{M}^{1}$, Arnaiz $P^{1}$, Barja $S^{1}$, Acevedo $M^{1}$, Cerda $J^{3}$, Guzmán $B^{3}$ Berríos $X^{3}$.

${ }^{1}$ Departamentos de Pediatría, ${ }^{2}$ Enfermedades Cardiovasculares $y{ }^{3}$ Salud Pública, Pontificia Universidad Católica de Chile.

Estudios recientes reportan una prevalencia de 3-4\% de hipertensión arterial (HTA) en adolescentes, la cual, aún es clínicamente subdiagnosticada. La Monitorización Ambulatoria Continua de Presión Arterial de 24 hrs (MAPA) tiene mayor sensibilidad diagnóstica y permite detectar más precozmente adolescentes en riesgo futuro de HTA o que ya tienen HTA enmascarada. Objetivo: Determinar la prevalencia de MAPA alterado y su asociación con factores de riesgo cardiovascular clásicos, emergentes, peso de nacimiento $(\mathrm{PN})$ y edad gestacional (EG) y, función endotelial, en una submuestra aleatoria en una población de adolescentes sanos chilenos. Métodos: Se estudiaron con MAPA 31 adolescentes en Santiago. Se les realizó encuesta sobre factores de riesgo cardiovascular personal y familiar, antecedentes perinatales, mediciones antropométricas, medición clínica de presión arterial (promedio 3 mediciones), evaluación puberal y muestra de sangre en ayunas para glicemia, insulinemia, perfil lipídico, proteína $C$ reactiva ultrasensible (PCRus) y adiponectina. Se midió también la función endotelial a través de la dilatación mediada por flujo en arteria braquial post hiperemia (DMF). Resultados: Análisis 29 (93,5\%) MAPA técnicamente aceptables (58,6\% mujeres, edad promedio 13,6 años $r=12-16)$. En la medición clínica de PA, un $89,6 \%$ resultó normotenso sistólico, 10,4\% pre-hipertenso sistólico y todos presentaron PA diastólica normal. Doce adolescentes resultaron con MAPA alterados (41,3\%; todos en el grupo de niños normotensos por medición clínica): 5 por alteración de PA y 7 por pérdida del ritmo circadiano. Se encontró $17,2 \%$ de HTA enmascarada y $10,3 \%$ de pre-hipertensos de delantal blanco. No se demostró asociación entre MAPA alterado y PCRus, adiponectina o disfunción endotelial. Los factores asociados a MAPA alterado fueron: 1) PN $3.000 \mathrm{~g}$ (54,5\% con MAPA alterado y 50\% HTA enmascarada); 2 ) $\mathrm{EG}<38 \mathrm{sem}$ ( $85,7 \%$ con MAPA alterado) y 3 ) Diagnóstico nutricional actual de obesidad (85,7\% presentaron MAPA alterado). Conclusiones: En un grupo de adolescentes previamente sanos, el MAPA permitió el diagnóstico de HTA enmascarada en un porcentaje significativo, similar al reportado en la literatura. Los factores asociados a HTA enmascarada y MAPA alterado fueron el bajo peso de nacimiento y edad gestacional, y el diagnóstico de obesidad. Estos resultados sugieren la importancia del estudio complementario con MAPA en adolescentes seleccionados. Nuestros hallazgos son innovadores en nuestro medio.
COMPARACIÓN DEL GASTO ENERGÉTICO DE NIÑOS EN DIÁLISIS PERITONEAL MEDIDO POR CALORIMETRÍA INDIRECTA VS EL ESTIMADO POR ECUACIONES ESTANDARIZADAS

Macari A, Marín V, Cano F, González M, Azócar M.

Hospital Luis Calvo Mackenna. Facultad de Medicicna Universidad de Chile.

Introducción: Los requerimientos de energía en el niño son parte fundamental del manejo nutricional. El gasto energético de reposo (GER) se puede medir por calorimetría indirecta $(\mathrm{Cl})$ y estimar por medio de ecuaciones. Existen pocos estudios que determinen la utilidad de estas ecuaciones en pacientes pediátricos en diálisis peritoneal (DP). Objetivos: 1) Evaluar el GER en niños urémicos en DP y compararlos con niños normales; 2) Comparar el GER obtenido a partir de ecuaciones estandarizadas y el obtenido a partir de $\mathrm{Cl}$ en el grupo casos y en un grupo control. Material y Métodos: Estudio prospectivo descriptivo no (a) descriptivo no intervencional que incluye a los niños en DP del H. Luís Calvo Mackenna y a un grupo control de niños sanos. Se calculará el GER de cada niño con las ecuaciones de Schofield W-H y FAO/WHO/UNU, y se medirá por Cl. La comparación entre el GER estimado y el medido se realizó mediante ANOVA considerando como estadísticamente significativo un $\mathrm{p}<0,05$. Se utilizó el test de Bland y Altman para el análisis de concordancia. Resultados: Se incluyeron 12 niños en e grupo de los casos (edad 10,4 años $\pm 4,39 ; 6$ varones) y 12 niños en el grupo control pareados por edad y sexo. El promedio del GER medido por $\mathrm{Cl}$ fue de $1.220,3( \pm 347,5)$ y $1.376,4( \pm 287,1) \mathrm{Kcal} /$ día para casos y controles, respectivamente para $248,2) \mathrm{Kcal} /$ día y para la ecuación de la FAO/WHO/UNU fue de 1.167,2 ( $\pm 329,1)$ y $1.272,4( \pm 210,9) \mathrm{Kcal} / \mathrm{d}$ ía. Se encontró una correlación positiva entre GER y $1.272,4( \pm 210,9) \mathrm{Kcal} / \mathrm{di}$. Se encontró una correlación positiva entre GER
medido por $\mathrm{Cl}$ vs el estimado por ecuación de Schofield $\mathrm{W}-\mathrm{H}$ y de $\mathrm{FAO} / \mathrm{WHO} /$ UNU. El análisis por ANOVA del GER medido, estimado por Schofield W-H y por $\mathrm{FAO} / \mathrm{WHO} / \mathrm{UNU}$ entre los casos vs controles no mostró diferencias significativas. Al comparar el GER entre $\mathrm{Cl}$ y Schofield $\mathrm{W}-\mathrm{H}$, así como, entre $\mathrm{Cl}$ y $\mathrm{FAO} / \mathrm{WHO} / \mathrm{UNU}$, no se observaron diferencias significativas. El análisis de los promedios de las diferencias entre $\mathrm{Cl}$-Schofield y entre $\mathrm{Cl}-\mathrm{FAO} / \mathrm{WHO} / \mathrm{UNU}$ no mostró diferencias significativas entre los grupos, tampoco al analizar cada diferencia por subgrupos según edad, género y estado nutricional. El test de Bland y Altman mostró concordancia entre la $\mathrm{Cl}$ y cada una de las ecuaciones tanto para casos como controles, con tendencia de las ecuaciones a subestimar el GER. Conclusión: El GER en niños en DP es similar al de niños no urémicos. Las ecuaciones de Schofield W-H y FAO/WHO/UNU son útiles para determinar GER en este grupo de pacientes lo que permite prescindir de la $\mathrm{Cl}$ para su medición.

OSTEODISTROFIA Y CALCIO IÓNICO EN NIÑOS PORTADORES DE SÍNDROME NEFRÓTICO EN DIÁLISIS PERITONEAL CRÓNICA AMBULATORIA

Carrascal $M^{1}$, Azócar $M^{\dagger}$, Errázuriz $M J^{1}$, Cano $F^{\prime}$

Facultad de Medicina, Universidad de Chile, ${ }^{1}$ Hospital Luis Calvo Mackenna, Santiago, Chile.

Introducción: El metabolismo calcio fósforo se encuentra severamente alterado en los pacientes portadores de Enfermedad Renal Crónica (ERC). En los portadores de Síndrome Nefrótico (SN) en diálisis peritoneal (DP), el manejo de la hipocalcemia resulta de especial dificultad dado la hipoalbuminemia que presentan. En estos niños, la calcemia total debe ser corregida por el valor de la albúmina plasmática, recomendándose idealmente el uso del calcio iónico. Objetivo: Evaluar la utilidad del calcio iónico en el manejo de la osteodistrofia en niños con Síndrome Nefrótico en DP. Pacientes y Método: Estudio retrospectivo 2003-2007 de pacientes en DP por SN (grupo 1). Se evaluó al mes 1 y entre los meses 6 y 12: edad, género, peso, talla, tiempo en DP; creatinina, BUN, calcio total y iónico, fósforo, hormona paratiroidea (PTH), albúmina y proteínas plasmáticas. y el test de equilibrio peritoneal (PET) fueron evaluados cada 3-6 meses. Grupo control (grupo 2): pacientes en DP no nefróticos, pareados por edad y sexo. Todos los pacientes recibieron DP continua cíclica, y un Kt/V total $>2,1$. Los datos fueron reportados como promedio \pm desv st. La diferencia entre grupos fue calculada por t test, un $p<0,05$ fue considerado significativo. Resultados: Se incluyeron 9 pacientes en el grupo 1, y 12 en el grupo control. No se observó diferencias significativas en las características clínicas, nutricionales ni dialíticas. Tampoco se observó diferencias para PTH calcio total y iónico al inicio del estudio. El calcio iónico en el grupo 1 fue de $1,12 \pm 0,15$ y $1,15 \pm 0,19$ en los 2 tiempos estudiados, y de $1,27 \pm 0,02$ vs $1,26 \pm 0,02$ en el grupo control ( $p$ : $n s$ )
(vn: $0,9-1,3$ ). En los pacientes con SN, la calcemia total y corregida fue de $8,9 \pm$ (vn: $0,9-1,3)$. En los pacientes con SN, la calcemia total y corregida fue de $8,9 \pm$
$1,2 / 10,27 \pm 1,6$ vs $9,1 \pm 2,1 / 9,98 \pm 2,1$ en los 2 tiempos evaluados. En el grupo 1 la PTH disminuyó desde $227 \pm 198$ a $168 \pm 138 \mathrm{pg} / \mathrm{ml}$ entre el inicio y final de estudio, mientras que en el grupo 2 fue de $282 \pm 118$ vs $412 \pm 334$ en los mismos tiempos (p: ns), con una diferencia significativa entre ambos grupos al término del período de observación (tabla).

\begin{tabular}{|c|c|c|c|c|c|}
\hline Grupo & $\begin{array}{c}\text { Calcio } \\
\text { total inicio }\end{array}$ & $\begin{array}{l}\text { Calcio } \\
\text { total final }\end{array}$ & $\begin{array}{c}\text { Albúmina } \\
\text { sérica inicio }\end{array}$ & $\begin{array}{c}\text { Albúmina } \\
\text { sérica final }\end{array}$ & $\begin{array}{c}\text { Calcio } \\
\text { corr inicio }\left(^{*}\right)\end{array}$ \\
\hline $\begin{array}{l}\text { SN } \\
\text { Control }\end{array}$ & $\begin{array}{r}8,9 \pm 1,2 \\
10 \pm 0,5\end{array}$ & $\begin{array}{l}9,1 \pm 2,1 \\
10 \pm 0,64\end{array}$ & $\begin{array}{l}2,4 \pm 0,75 \\
3,8 \pm 1,54\end{array}$ & $\begin{array}{l}2,9 \pm 0,56 \\
4,2 \pm 0,48\end{array}$ & $\begin{array}{c}10,27 \pm 1,6 \\
10,1 \pm 1,1\end{array}$ \\
\hline Grupo & $\begin{array}{c}\text { Calcio } \\
\text { corr final (*) }\end{array}$ & $\begin{array}{c}\text { Calcio } \\
\text { iónico inicio }\end{array}$ & $\begin{array}{cc} & \text { Calcio } \\
0 & \text { iónico fina }\end{array}$ & $\begin{array}{ll}\text { PTHPTH } & \begin{array}{l}\text { PTicio } \\
\text { inicio }\end{array}\end{array}$ & final $\left({ }^{\star \star}\right)$ \\
\hline $\begin{array}{l}\text { SN } \\
\text { Control }\end{array}$ & $\begin{array}{l}9,98 \pm 2,1 \\
9,4 \pm 0,6\end{array}$ & $\begin{array}{l}1,12 \pm 0,15 \\
1,27 \pm 0,02\end{array}$ & $\begin{array}{l}1,15 \pm 0,15 \\
1,26 \pm 0,0\end{array}$ & $\begin{array}{l}227 \pm 198 \\
282 \pm 218\end{array}$ & $\begin{array}{l}168 \pm 138 \\
412 \pm 334\end{array}$ \\
\hline
\end{tabular}

(*) Calcio total corregido $\mathrm{mmol} / \mathrm{L}=$ calcio total $\mathrm{m}$

Discusión: En el grupo estudiado observamos una caída de los valores de PTH durante el seguimiento, sugiriendo un riesgo de enfermedad ósea de bajo recambio en los pacientes con SN, a diferencia del grupo control. El calcio iónico se mantuvo permanentemente en niveles normales en los 2 grupos, mientras que el calcio total corregido por la albúmina se situó por sobre las recomendaciones DOQI, lo cual podría correlacionarse a la caída de la PTH observada. 


\section{LUPUS ERITEMATOSO SISTÉMICO EN PEDIATRÍA, SERIE CLÍNICA}

Castañeda $H^{1}$, Chaparro $X^{1}$, Quezada $A^{2}$, Salgado ${ }^{3}$, Salas $P^{3}$, Pinto $V^{3}$, Corta $B^{3}$, Grandy $\mathcal{\beta}^{3}$, González $E^{3}$, Norambuena $X^{2}$, Zambrano $P^{3}$ Hospital Exequiel González Cortés.

El lupus eritematoso sistémico, es un trastorno autoinmune multisistémico, es más frecuente en mujeres jóvenes aunque en pediatría su incidencia ha aumentado en los últimos años, siendo diagnosticados aproximadamente $20 \%$ durante las primeras 2 décadas de la vida. El objetivo de este estudio fue determinar las características clínicas de los pacientes diagnosticados con LES en un hospital pediátrico en Santiago de Chile. Este, es un estudio descriptivo, retrospectivo de todos los pacientes diagnosticados diagnosticados de LES entre 1990 y 2007 que se atienden en el Hospital Dr. Exequiel González Cortés de Santiago de Chile, se analizaron variables demográficas, formas de presentación clínica, mortalidad y evolución. Durante el período de estudio se diagnosticaron 25 pacientes, $92 \%$ de sexo femenino, la edad promedio al diagnóstico fue de 11,5 años ( $r$ : 5,5-14,9); la manifestación clínica más frecuente fue el eritema malar ( $88 \%$ ) seguido serositis (86\%); el valor promedio de C3 al ingreso fue de 101,5 (r 28 a 134) y de C4 11,4 ( $r$ a 24); los anticuerpos antinucleares fueron positivos en $89 \%$ de pacientes. Un $70 \%$ presentó compromiso renal siendo la nefropatía G III la más frecuente (35\%) seguida por nefropatía G V $(24 \%)$, un $53 \%$ evoluciona con proteinuria a pesar de tratamiento con antiproteinúricos, cuatro pacientes evolucionaron a la insuficiencia renal crónica terminal de las cuales dos recibieron un trasplante renal. Todos los pacientes recibieron ciclofosfamifa de inducción. Todos los pacientes se encuentran en tratamiento con prednisona, $70 \%$ además en tratamiento con azatioprina y $28 \%$ además con micofenolato mofetil. Tres pacientes fallecieron $(12 \%)$, dos por compromiso multisistémico, y una paciente por cance gástrico terminal (inactiva desde el punto de vista inmunológico). El diagnóstico de LES no es infrecuente en Pediatría, llama la atención el alto compromiso rena en nuestra serie, la proteinuria se mantiene a pesar de tratamiento; la mortalidad en nuestra serie fue similar a otras series.

DIÁLISIS CRÓNICA EN PEDIATRÍA, UNA MIRADA A LA CALIDAD DE VIDA DEL PACIENTE Y SU FAMILIA

Cerda PM, Farías SL, Cano SchF.

Unidad de Nefrología, Hospital Luis Calvo Mackenna, Facultad de Medicina, Universidad de Chile.

La enfermedad renal crónica terminal (ERC) es un importante problema de salud que requiere una terapia de sustitución renal en forma permanente, y desde el punto de vista biopsicosocial genera una grave alteración del paciente y su familia. Objetivo: Evaluar la calidad de vida (CV) de niños portadores de ERC en diálisis, y de sus familias. Material y Método: Estudio de corte realizado en pacientes entre 2-18 años con ERCT en hemodiálisis (HD) y diálisis peritoneal (DP), y a sus padres. Como instrumento de evaluación se utilizó la encuesta PedsQL 4.0 Generic Core Scales, que consta de 23 preguntas en 4 items (físico, emocional, social y escolar). A cada pregunta se le asigna una escala de respuesta de 0 a 4 aplicada a niños en rangos etáreos de 5-7, 8-12 y 13-18, y padres. Entre 2-4 años: sólo a padres. Se aplicaron las encuestas previo consentimiento/asentimiento informado. Para el análisis de los datos, las respuesta de 0-4 son transformadas a una escala de $0-100 \%(0=100,1=75,2=50,3=25,4=0)$, altos porcentajes indicando mejor CV. Se calculan 3 indicadores finales: Puntaje físico, psicosocial (promedio de emocional, social y escolar) y total (promedio de físico y psicosocial). Se consideró significativo un $\mathrm{p}<0,05$. Resultados: Se evaluaron 16 pacientes, 11 en DP y 5 en HD, tiempo en diálisis entre 2 y 61 meses. Los puntajes se detallan en tabla.

\begin{tabular}{|c|c|c|c|c|c|c|}
\hline \multirow{3}{*}{$\begin{array}{l}\text { Edad } \\
\text { años }\end{array}$} & \multicolumn{5}{|c|}{ Puntaje (\%) calidad de vida para niños en diálisis } & \\
\hline & \multicolumn{2}{|c|}{ Físico } & \multicolumn{2}{|c|}{ Psicosocial } & & \\
\hline & HD & PD & HD & PD & HD & PD \\
\hline 5-7 & 59 & 88 & 43 & 77 & 51 & 82 \\
\hline 8-12 & 70 & 69 & 60 & 62 & 65 & 65 \\
\hline $13-18$ & 56 & 82 & 65 & 59 & 61 & 71 \\
\hline Total & 62 & 80 & 56 & 66 & 59 & 73 \\
\hline \multicolumn{7}{|c|}{ Puntaje (\%) calidad de vida según padres } \\
\hline Edad & \multicolumn{2}{|c|}{ Físico } & \multicolumn{2}{|c|}{ Psicosocial } & \multicolumn{2}{|c|}{ Total } \\
\hline años & HD & PD & HD & PD & HD & PD \\
\hline $2-4$ & 71 & 78 & 75 & & & \\
\hline 5-7 & 56 & 81 & 37 & 72 & 46 & 76 \\
\hline 8-12 & 54 & 55 & 45 & 46 & 50 & 51 \\
\hline $13-18$ & 19 & 89 & 47 & 53 & 33 & 71 \\
\hline Total & 43 & 74 & 43 & 62 & 43 & 68 \\
\hline
\end{tabular}

Al comparar los resultados de PD versus HD se observan mejores puntajes de $C V$ en $P D(p<0,05)$, tanto en padres como en niños. La percepción de la CV por los padres es inferior a la de los hijos $(p<0,05)$, siendo esto más acentuado en HD. Conclusiones: La CV en los 2 grupos evaluados es superior en el aspecto físico que en el psicosocial, y permanentemente superior en los niños en diálisis peritoneal que en hemodiálisis. La percepción de CV es distinta entre niños y padres, siendo peor en estos últimos.En resumen, el impacto de la diálisis en niños portadores de ERC es importante en sus aspectos emocional, social y escolar; y de mediana importancia en sus logros físicos, siempre superior en aquellos pacientes en régimen de DP.
ESTIMULACIÓN TRANSCUTÁNEA DEL NERVIO TIBIAL POSTERIOR (ENTP) EN EL TRATAMIENTO DE LA VEJIGA HIPERACTIVA, URGE INCONTINENCIA Y RESIDUO POST MICCIONAL ELEVADO EN NIÑOS

Cárdenas ${ }^{1}$, Freundlich $\mathrm{O}^{2}$, Saieh $C^{\prime}$

${ }^{1}$ Médico de Unidad de Nefrología Pediátrica, Clínica Las Condes. ${ }^{2}$ Kinesióloga de Suelo Pélvico, Unidad Pediatría, Clínica Las Condes.

Introducción: El nervio tibial es mixto, posee fibras sensitivas y motoras, pertenece al plexo sacro. La ENTP fue creada por Stoller en UCSF, y fue conocida como protocolo SANS se utiliza la raíz nerviosa (S3), pero en el tobillo, produciendo efectos en la vejiga a través de estimulación aferente retrógrada. El objetivo fue crear una alternativa menos invasiva que la neuromodulación sacra. En el año 2000 Stoller reportó en 100 pacientes tratados con el equipo SANS, un $80 \%$ de éxito en el tratamiento de urge incontinencia, urgencia y frecuencia aumentada, observándose inhibición de las contracciones no inhibidas del detrusor, aumento de la capacidad cistométrica máxima y disminución de la sensación de urgencia miccional. ENTP reduce la expresión de un tercer mensajero conocido como proteína C-fos, el que se expresa después de la presencia de algún factor irritante sobre la vejiga o el tracto urinario bajo. Objetivo: Informar la efectividad de la ENTP en pacientes con vejiga hiperactiva, urge incontinencia y residuo post miccional elevado en niños. Material y Método: Se presentan 10 niños, 9 mujeres con edad promedio 10.5 años con un rango entre 6 años 9 meses y 16 años 2 meses, con diagnóstico de vejiga hiperactiva, urge incontinencia y residuo post miccional elevado. Se realiza estimulación tanscutánea del nervio Tibial Posterior con equipo Biomed 2000, con estímulos en modo continuo a $20 \mathrm{~Hz}$ y 200 milisegundos y una intensidad regulada hasta lograr movimiento del ortejo mayor, 10 miliamper o según la tolerancia de la paciente. Los electrodos se sitúan a 3 centímetros hacia cefálico, en la zona medial del maléolo interno, un segundo electrodo neutro a nivel medial del calcáneo. Se realizaron sesiones de 30 minutos, una a dos veces por semana, con un promedio de 8,3 sesiones. Resultados: La frecuencia miccional fue de 9,6 veces al día antes de tratamiento y de 6,7 posteriormente. Ocho del total tenía urge-incontinencia antes de tratamiento y ninguno de ellos lo presentaba después. 50\% tenía residuo post miccional elevado y todos lo disminuyeron después de tratamiento. Conclusión: La ENTP es efectiva en el tratamiento de la vejiga hiperactiva, urge incontinencia y residuo post miccional elevado en pacientes refractarios a terapias tradicionales.

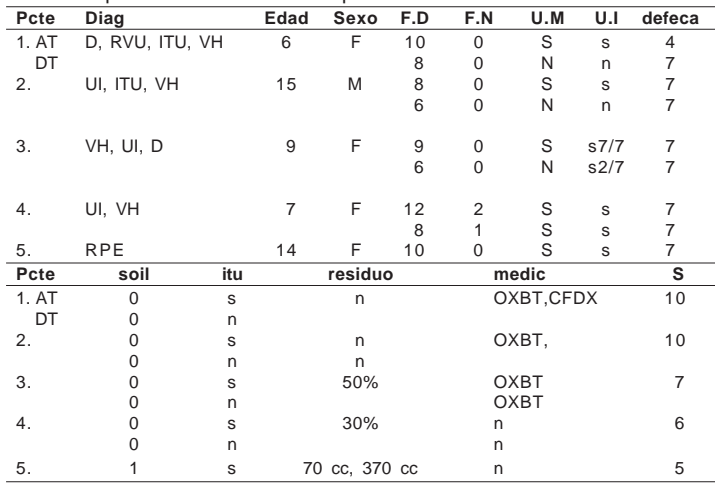

INFECCIÓN DEL TRACTO URINARIO Y REFLUJO VESICOURETERAL EN PEDIATRÍA, UNA DESCRIPCIÓN RETROSPECTIVA DEL HOSPITAL SAN MARTÍN DE QUILLOTA

Acevedo GL, Alarcón ER, Muñoz RL, Stegmaier FP, Urrea AJ. Universidad de Santiago de Chile, Servicio de Pediatría Hospital San Martín de Quillota.

Las infecciones del tracto urinario son la segunda causa de infección bacteriana en pediatría, pudiendo presentarse como episodio aislado o como patología recurrente. Existe acuerdo en enfocar el estudio pediátrico en la detección del reflujo vésico-ureteral (RVU), presente en $20-40 \%$ según literatura. Para ello, la Academia Americana de Pediatría recomienda el estudio con uretrocistografía (UCG) y ultrasonografía renal. Este trabajo corresponde a un estudio observacional de corte transversal, cuyo objetivo es conocer que acontece con las ITU y pesquisa de RVU a nivel local. Se obtuvieron datos de pacientes ingresados con diagnóstico de ITU al servicio de Pediatría Hospital San Martín de Quillota el año 2007. De los 105 pacientes, entre 0 y 14 años, se seleccionaron aquellos con diagnóstico de ITU confirmado mediante urocultivo $(66,67 \%)$. De estos, existentes en proporción Hombre-Mujer $=1: 4$, correspondían a ITU recurrente (ITUrr) el $14,04 \%$ de mujeres y $15,38 \%$ de varones. Fueron realizadas $12 \mathrm{UCG}$, a 9 mujeres y 3 varones. De las mujeres, 1 ITUrr y 8 no ITUrr, en ninguna se encontró RVU. Varones, 1 ITUrr y 2 no ITUrr, se encontró RVU en 1 ITUrr y 1 no ITUrr. Todos los RVU (+) tenían Ecografía sin alteraciones. Destaca la realización de UCG a 3 pacientes con urocultivo negativo. Se concluye que en ITU confirmada predomina el sexo femenino, acorde con literatura, con ITUrr en similar porcentaje para ambos sexos y, que la realización de UCG para pesquisar RVU, considerando que es un recurso escaso, no priorizó población en mayor riesgo, no observándose criterios de selección adecuada. 


\section{RVU MANEJO ENDOSCÓPICO: UNA ALTERNATIVA DE TRATAMIENTO}

Ortega $\mathbf{M}^{3}$, Escala $J M^{2,4}$, Gana $R^{2}$, Saieh $C^{1,4}$

${ }^{1}$ Nefrólogo, ${ }^{2}$ Urólogo, Clínica Las Condes. ${ }^{3}$ Residente Cirugía Infantil Universidad de Chile. ${ }^{4}$ Profesor Asociado Universidad de Chile.

El reflujo vesico ureteral (RVU) corresponde al paso anómalo de orina desde la vejiga hacia los uréteres, y en ocasiones al riñón como consecuencia de una alteración en el mecanismo valvular de la unión vesico ureteral. La infección urinaria febril asociada a RVU es una de las principales causas de daño renal, pudiendo llevar a una insuficiencia renal crónica. Por esto la importancia del diagnóstico precoz y del tratamiento adecuado. El tratamiento médico consiste en la profilaxis antibiótica para evitar nuevas infecciones, mientras se espera la mejoría espontánea con el crecimiento del paciente. El quirúrgico, se basa en e alargamiento del túnel submucoso con éxitos cercanos al $98 \%$. Hoy existe un nuevo manejo vía endoscópica con productos como el polímero de dextranómero en ácido hialurónico (Deflux). Objetivo: Presentar resultados en forma descriptiva obtenidos en el manejo del RVU con tratamiento endoscópico con Deflux. Pacientes y Métodos: En forma retrospectiva se revisaron las fichas de 65 pacientes con RVU tratados con Deflux, en CLC entre los años 2005-2008 de los cuales 46 tenían datos suficientes para ingresar en el presente estudio, analizando sexo, edad del diagnóstico y tratamiento, lateralidad, grado, indicación quirúrgica y resultados. Resultados: $80 \%$ de los pacientes eran de sexo femenino. E $52.17 \%$ correspondió a menores de 2 años. La edad promedio del diagnóstico de RVU fue 2.94 años (1 mes a 12 años) y del tratamiento endoscópico 4,8 años. La mayoría fueron bilaterales (58.7\%). El $61.45 \%$ eran grado 2 y 3 . En todos e estudio se inició a raíz de una ITU, excepto en uno. El diagnóstico se realizó mediante UCG convencional en todos los pacientes. El tratamiento endoscópico se realizó en un $30 \%$ en forma primaria, en un $53 \%$ por persistencia del RVU a los 18 meses de profilaxis y en el $17 \%$ por ITU intratratamiento. El $93,4 \%$ no ha presentado ITU en un período de control de hasta 3 años. En 16 pacientes $(34,7 \%)$ se realizó cisto indirecta de control, y solamente en 2 se constató RVU leve. Conclusión: Este tratamiento es un método seguro y recomendable como una alternativa en el manejo del RVU.
PRESIÓN ARTERIAL EN PEDIATRÍA MEDIDA POR CLÍNICA Y MONITORIZACIÓN AMBULATORIA CONTÍNUA: CORRELACIÓN CON FACTORES DE RIESGO CARDIOVASCULAR

Peredo $\mathbf{S}^{1}$, Aglony $\mathbf{M}^{1}$, Cerda ${ }^{2}$, Pérez $V^{1}$

1 Unidad de Nefrología. Departamento de Pediatría. Pontificia Universidad Católica de Chile. ${ }^{2}$ Departamento de Salud Pública. Pontificia Universidad Católica de Chile.

Objetivo: La hipertensión arterial (HTA) en pediatría es una enfermedad subdiagnosticada (prevalencia 1-2\%). Está determinada por componentes fetales, genéticos y medioambientales, siendo la obesidad, bajo peso de nacimiento e historia familiar de HTA (HF) factores de riesgo conocidos para su desarrollo. Nuestro objetivo fue correlacionar la presión arterial (PA) medida por clínica y por Monitorización Ambulatoria Continua de PA (MAPA) con los distintos factores de riesgo, información desconocida en nuestro país. Método: Estudio transversal de 113 pacientes referidos al Programa de HTA Pediátrico de nuestra institución con indicación de MAPA por sospecha de HTA. Se realizó una encuesta de factores de riesgo cardiovascular personal y familiar, mediciones antropométricas, toma de PA clínica (X 3 mediciones) y MAPA. El diagnóstico nutricional se realizó con Indice peso/talla en niños $<6$ años e Indice de Masa Corporal en $>6$ años. Resultados: Un $52 \%$ de los pacientes fueron de sexo femenino, edad 11.7 (4-20) años y peso de nacimiento $3.191(1.250-4.910) \mathrm{g}$ Según el diagnóstico nutricional $24,8 \%$ pacientes presentaron sobrepeso y $26,5 \%$ obesidad. De acuerdo a la medición clínica de la PA (sistólica/diastólica) se clasificaron en: normotensos $(51,3 \% / 74,3 \%)$, pre-hipertensos $(20,4 \% / 2,7 \%)$ e hipertensos $(28,3 \% / 23,0 \%)$. Se encontró una asociación significativa entre PA clínica elevada (> p 90) e HF (OR 3,33; p < 0,01). Al analizar las MAPA, un $70,8 \%$ resultaron alteradas. Se encontró una asociación significativa entre MAPA alterada y obesidad (OR 3,$49 ; p<0,05)$ e HF (OR 3,6; $p<0,01)$. En el subgrupo de pacientes obesos $(n=30), 26$ tuvieron MAPA alterada: 11 por HTA, 7 por ausencia de DIP nocturno y 8 por ambas. Al relacionar la medición clínica de PA con el resultado de la MAPA, se obtuvo la siguiente distribución: 8 (26,7\%) pacientes normotensos, $15(50 \%)$ hipertensos sostenidos, $4(13,3 \%)$ con HTA enmascarada y $3(10 \%)$ con HTA de delantal blanco. Conclusiones: La MAPA permitió reconocer la asociación existente entre obesidad e HTA, no evidenciada al medir la PA en forma clínica. La frecuencia de pacientes obesos con HTA de delantal blanco y enmascarada es similar a la reportada en la literatura, confirmando la validez del uso de MAPA en esta población. Además, se reafirmó la asociación entre el antecedente familiar de HTA y la presencia de PA elevada en población pediátrica, destacando la importancia de la derivación oportuna de los hijos de padres hipertensos.

\section{HIPOTERMIA CORPORAL LEVE EN 5 RECIÉN NACIDOS CON} ENCEFALOPATÍA HIPÓXICO ISQUÉMICA SEVERA

Ahumada E, Saldes I, Gajardo P, Veas V, Villegas V. Hospital Carlos Van Buren Valparaíso.

Introducción: La encefalopatia hipóxico isquémica es una causa importante de morbimortalidad neonatal. El tratamiento de esta patología esta limitado a un manejo de soporte. La hipotermia en estudios en animales protegue contra la injuria después de un evento hipóxico, sin embargo, la utilidad y efectividad en recién nacidos cercanos al término aun no es clara. Objetivo: Describir la evolución clínica de 5 recién nacidos con asfixia perinatal grave sometidos a hipotermia. Materiales y Métodos: Estudio descripitivo, se evaluaron todos los pacientes que fueron sometidos a hipotermia corporal leve entre los años 2006 2007. Se definió hipotermia: $\mathrm{t}^{\mathrm{a}}$ rectal de $34^{\circ} \pm 0,5$. Protocolo de hipotermia incluye: $\mathrm{RN}$ > de $36 \mathrm{sem}$, Apgar < de 5 a los $10 \mathrm{~min}, \mathrm{pH}$ de cordón < de 7 $\mathrm{mmol} / \mathrm{l}$, exceso de base > de -15 y manifestaciones clínicas de encefalopatía. $\mathrm{RN}$ con malformación mayor, aquellos con más de 6.5 horas de vida, RN con gravedad extrema (bradicardia mantenida, midriasis paralítica, ausencia de reflejo corneal) y pacientes sin consentimiento previo firmado, fueron excluidos. Para la hipotermia se usó cuna servo control en $34^{\circ}$, por 72 horas, con controles de presión arterial, frecuencia cardíaca y temperatura rectal continua. Los antecedentes neonatales, exámenes de laboratorio y datos de los recién nacidos fueron registrados. Resultados: Ingresaron al estudio 5 RN, 2 sexo femenino, 3 masculinos, edad gestacional promedio 39,8 semanas, peso promedio 3.940 grs. El Apgar promedio al minuto fue de $0,8(0-2)$; a los 10 min fue 5 . El pH de cordón fue $6,8(6,7-7,0)$ y EB fue - $24(19,1-27,3)$. De los 5 pacientes 4 se clasificaron con Sarnat III, y 1 Sarnat II. La hipotermia se inició promedio a los 87,5 minutos. La temperatura de ingreso fue entre $34-35,6^{\circ} \mathrm{C}$, y se alcanzó la temperatura deseada a los 82 minutos. La hipotermia se consiguió mediante cuna apagada en 4 pacientes y 1 requirió unidades refrigerantes. Se inició el recalentamiento a $0,5^{\circ}$ por hora. Sólo una leve bradiacardia > de 100 por min se observó en 2 RN. Sin significación clínica. Los 5 pacientes presentaron convulsiones precoces (10 minutos a 3 horas), 3 se conectaron a ventilacion mecánica por apneas. El EEG al alta fue anormal en 4, y la ecografía cerebral fue normal en 4. El examen neurológico fue anormal en 3: 2 con hipertonía y 1 con parálisis braquial. Conclusión: Los 5 pacientes sobrevivieron a pesar de la severidad del evento hipóxico. El enfriamiento fue fácil de efectuar. 
PERFIL DEMOGRÁFICO Y COMPLICACIONES DE LOS RECIÉN NACIDOS CON CATÉTER VENOSO CENTRAL DE INSTALACIÓN PERIFÉRICA. COMPLICACIONES DE LOS RECIÉN NACIDOS CON CATÉTER VENOSO CENTRAL DE INSTALACIÓN PERIFÉRICA

Aravena M, Ahumada E, Saldes MI, Veas V, Vergara R, Estay V, Zabaleta L. Hospital Carlos Van Buren de Valparaíso.

Introducción: Los catéteres venosos centrales de instalación periférica (CVCP), son de uso frecuente en las unidades de neonatología, sin embargo, pueden presentar complicaciones, tanto derivadas de la instalación como infecciosas. Objetivos: Conocer la frecuencia y tipo de complicaciones de los CVCP, insertados en recién nacidos (RN) de una Unidad de Cuidados Intensivos Neonatal (UCIN), durante el período enero 2006 a diciembre 2007. Método: Trabajo retrospectivo, descriptivo. Se revisaron las fichas clínicas de todos los RN, de la UCIN, a los cuales se les insertó CVCP. Se recolectaron datos demográficos y descriptivos de estos RN. Resultados: Se instalaron 203 CVCP a 165 RN. La distribución por peso fue: mayor $1.500 \mathrm{grs} n=65(40 \%), 1.000-1.500 \mathrm{grs} n=$ $58(35 \%)$ y menores de 1.000 grs $n=42(25 \%)$. El tiempo promedio de permanencia del catéter fue 21 días (1-41 días). La principal indicación fue administración de alimentación parenteral $n=161(79,3 \%)$. En el 82,2\% de los casos, la instalación fue en la extremidad superior. De los $165 \mathrm{RN}$, fallecieron $13(7,8 \%)$ y 7 fueron trasladados con el catéter in situ a otros servicios; estos 20 RN fueron excluidos en el análisis de las complicaciones. De los 183 restantes, en $120 \mathrm{RN}$ $(59 \%)$, la causa de retiro fue término de tratamiento y en $63(31 \%)$ complicaciones. Las complicaciones no infecciosas $(n=38)$ fueron: oclusión (18), desplazamiento (6), daño/ruptura (6), infiltración (6), mala posición (2). Las complicaciones infecciosas $(n=29)$, fueron: flebitis (9), bacteremias asociada a catéter (15), bacteremia relacionada a catéter (1) y colonización (3). Los gérmenes aislados fueron Staphylococcus coagulasa-negativo (9), Enterobacter (3), Klebsiella pneumoniae (2), Staphylococcus aureus (1), Salmonella (1), Candida sp (3). La Tasa de infección asociada a catéter fue 7,2 x 1.000/ días catéter. Conclusiones: El mayor número de catéteres se insertaron en RN menores de 1.500 grs. La inserción de un catéter se asocia a complicaciones, siendo las infecciosas las que condicionan una mayor morbilidad en el RN menor de 1.500 grs. E germen más frecuente fue Staphylococcus coagulasa-negativo, concordante con lo descrito en la literatura.

NEURODESARROLLO A LOS 2 AÑOS DE EDAD, DE RECIÉN NACIDOS PREMATUROS MENORES DE 32 SEMANAS DE GESTACIÓN Y/O MENORES DE 1.500 GRS. APLICACIÓN DE LA ESCALA DE DESARROLLO INFANTIL BAYLEY II

Ps. Ramos MJ, Ps. Guerrero A, Arriaza OM, Pittaluga E. Servicio de Neonatología Hospital Dr. Sótero del Río.

Introducción: Los avances en los cuidados neonatales han permitido la sobrevida de niños cada vez más inmaduros, que presentan un alto riesgo de morbilidad neurológica. Una forma de pesquizar alteraciones, comparar poblaciones y evaluar el resultado de nuestras intervenciones, es la medición del desarrollo neurológico mediante test estandarizados internacionalmente. Objetivo general Evaluar el Desarrollo Psicomotor de una muestra de niños nacidos prematuros de $<1.500$ grs $y / 0<32$ semanas de gestación, a los 24 meses de edad corregida, mediante la aplicacion de la Escala de Desarrollo Infantil Bayley II. Objetivo específico: Identificar los factores de riesgo de Retraso del Desarrollo Mental y Motor en una muestra de niños nacidos prematuros de $<1.500 \mathrm{grs}$ y $/ 0<32$ semanas de gestación, a los 24 meses de edad corregida, mediante la aplicacion de la Escala de Desarrollo Infantil Bayley II. Población y Método: De una cohorte de 795 recién nacidos prematuros, egresados vivos, entre 1994 y 2001 , se aplicó la "Escala de Desarrollo Infantil Bayley II" a una muestra por conveniencia de 238 niños $(29,9 \%)$, de 24 meses de edad corregida, de ambos sexos. Se realizó un análisis estadistico de los datos. La escala evalua Desarrollo Mental (MDI) y Desarrollo Motor (PDI). Los resultados se clasifican segun puntaje: Retraso Significativo (Menor de 70), Retraso Leve (70 a 84), Desarrollo Normal (85 a 114), Desarrollo Acelerado (Mayor de 114). Resultados:

Desarrollo Mental y Motor

\begin{tabular}{lcccc}
$\begin{array}{l}\text { Evaluacion } \\
\text { Indice }\end{array}$ & $\begin{array}{c}\text { Desarrollo Mental (MDI) } \\
\mathbf{N}^{\circ}\end{array}$ & $\begin{array}{c}\text { Índice Desarrollo Motor (PDI) } \\
\mathbf{N}^{\circ}\end{array}$ & \begin{tabular}{c} 
\% \\
\hline
\end{tabular} \\
\hline Acelerado & 0 & 0 & 0 & 0 \\
Normal & 132 & 55,5 & 182 & 79,8 \\
Retraso Leve & 71 & 29,8 & 30 & 13,2 \\
Retraso Signifi. & 35 & 14,7 & 16 & 7,0 \\
Total & 238 & 100 & 228 & 100 \\
\hline
\end{tabular}

Factores de riesgo significativos de retraso del índice de desarrollo mental: Displasia Broncopulmonar ( $p=0,001)$, Convulsiones Neonatales $(p=0,004)$ Ductus Arterioso Persistente DAP $(p=0,007)$, Dependencia de Oxígeno al alta ( $p$ $=0,009)$, Duración de la Ventilación Mecánica $(p=0,01)$, Sexo Masculino $(p=0,01)$ Hidrocefalia $(p=0,031)$, Hemorragia Intracraneana Grado III-IV ( $p=0,045)$ Conclusiones: Las características de la población de prematuros, no difieren significativamente de las del grupo evaluado. A los 2 años existe un compromiso en el MDI en el $44,5 \%$ de los niños y un compromiso del PDI en menor grado $(20,2 \%)$. Los factores de riesgo de compromiso en el MDI están referidos a patología pulmonar crónica, a la presencia de un DAP, condiciones neurológicas que implican lesión estructural cerebral y sexo masculino.
VALOR PREDICTIVO DE LA ESCALA DE DESARROLLO INFANTIL DE BAYLEY ॥ EN RELACIÓN A COEFICIENTE INTELECTUAL DE NIÑOS NACIDOS PREMATUROS, DE MENOS DE 1.500 GRS Y/O MENORES DE 32 SEMANAS EN EDAD PREESCOLAR

Arriaza OM, Ps. Guerrero A, Ps. Ramos MJ, Pittaluga E. Servicio de Neonatología Hospital Dr. Sótero del Río.

Introducción: La Escala de Desarrollo Infantil Bayley II, se utiliza ampliamente en el estudio del neurodesarrollo de niños prematuros y segun sus resultados se evaluan los exitos de las intervenciones neonatales. Considerando la importancia de las decisiones que deben tomarse, es necesario conocer el valor predictivo de esta escala (aplicada en el período de lactante) en relacion al Coeficiente Intelectual del niño en edades posteriores. Objetivo: El objetivo de esta comunicacion es evaluar la sensibilidad, especificidad y valor predictivo de la Escala de Desarrollo Infantil Bayley II, aplicada a prematuros a los 2 años de vida y el Coeficiente Intelectual de estos niños evaluados en edad Prescolar. Población y Método: Se aplicó la "Escala de Desarrollo Infantil Bayley II (BSID II)" a los 2 años de edad corregida (La escala evalua un Indice de Desarrollo Mental (MDI) y un Indice de Desarrollo Motor (PDI)) y la "Escala de Inteligencia para Preescolares de Wechsler (WPPSI)" a los 5 años, a una muestra por conveniencia de 125 niños de una cohorte de 795 prematuros sobrevivientes, nacidos entre 19942001. Para el análisis de los datos se uso un sistema de proporciones. Resultados: De los 125 niños, a los 2 años presentaron en la BSID II menos de 70 puntos en MDI un $43 \%$ y en PDI un 20\%. En el grupo en estudio, a los 5 años se encontro un 5,6\% de Retardo Mental. El calculo de sensibilidad, especificidad y valor predictivo fue:

\begin{tabular}{lcc}
\hline & Índice desarrollo mental & índice desarrollo motor \\
\hline Sensibilidad & 1,00 & 0,86 \\
Especificidad & 0,60 & 0,83 \\
Valor Predictivo Positivo & 0,13 & 0,24 \\
Valor Predictivo Negativo & 1,00 & 0,98 \\
\hline
\end{tabular}

Conclusiones: A los 2 años de vida un número elevado de niños presento un puntaje bajo en el Indice de Desarrollo Mental (MDI). A los 5 años de vida un $5,6 \%$ presento un WPPSI en rango de retardo mental, valor mayor que el observado en la población general (1\%). El Indice de Desarrollo Mental, fue sensible, pero poco específico para predecir retardo mental, siendo su valor predictivo negativo su principal fortaleza. El Indice de Desarrollo Motor fue sensible y especifico en predecir Retardo mental y también su valor fundamental fue su valor predictivo negativo. Esto nos indica que si encontramos un Bayley normal, el niño probablemente tendrá un $\mathrm{Cl}$ normal y si encontramos un Bayley alterado, este no se correlaciona directamente con un Retardo mental en el futuro.

COEFICIENTE INTELECTUAL DE PREESCOLARES NACIDOS PREMATUROS MENORES DE 1.500 GRS Y/O $<32$ SEMANAS DE GESTACIÓN CON LA ESCALA DE INTELIGENCIA PARA PREESCOLARES DE WECHSLER (WPPSI)

Ps. Guerrero A, Ps. Ramos MJ, Pittaluga E, Arriaza OM. Servicio de Neonatología Hospital Dr. Sótero del Río.

Introducción: Los avances en Neonatología, especialmente en los cuidados de los niños prematuros, han permitido tasas de sobrevida cada vez mayores y en edades gestacionales cada vez menores, conformando un grupo creciente de alto riesgo de morbilidad y secuelas. Una forma precisa de evaluar los resultados de las intervenciones neonatales y su repercusión neurológica es la medición del Coeficiente Intelectual. Objetivo: Evaluar el desarrollo intelectual de una muestra de niños nacidos prematuros de menos de 1.500 grs y/o 32 semanas de gestación, a los 5 años de edad, mediante una prueba estandarizada y definir factores de riesgo de Retardo mental. Población y Método: De una cohorte de 795 recién nacidos prematuros, egresados vivos, entre 1994 y 2001, se aplicó la "Escala de Inteligencia para Preescolares de Wechsler (WPPSI)", a una muestra por conveniencia de 287 preescolares de ambos sexos. Los resultados obtenidos con la escala se agruparon en 3 rangos: Normal: $>79$ puntos (CI Normal Lento, Normal Promedio y Superior). Limítrofe: Entre 70 y 79 puntos y Retardo mental: (RM) con un puntaje $<70$. Se realiza análisis estadístico para definir factores de riesgo. Resultados: El peso promedio al nacer fue de $1.193 \pm 239$ grs. La edad gestacional promedio fue $29 \pm 2,4$ semanas. Un $88,2 \%$ presentó un Coeficiente Intelectual Total Normal ( $x=99,5$ puntos). El $6,6 \%$ alcanzó el rango Limítrofe ( $x=79$ puntos). El 5,2\% obtuvo Retardo Mental ( $x=52,6$ puntos). De los niños con RM $(n=15)$, el $40 \%$ pesó $<1.000$ grs. El corticoide prenatal fue un factor protector significativo de la capacidad cognitiva. En esta muestra la variable sexo no resultó significativa con respecto a la capacidad intelectual. Los factores significativos de riesgo relacionados con Retardo Mental son: Edad Gestacional, Peso de Nacimiento, Displasia Broncopulmonar, Hemorragia Intracraneana, días de Oxígeno y de Ventilación Mecánica. Conclusiones: E $94,8 \%$ de los prematuros de esta serie mostró un $\mathrm{Cl}$ en el rango normal (incluyendo $\mathrm{Cl}$ limítrofes) y en $5,2 \%$, Retardo Mental, porcentaje mayor que lo descrito en la población general. Los factores de riesgo para RM coinciden con lo descrito en la literatura, destacan el Peso de Nacimiento y la Edad Gestacional en forma inversamente proporcional; así como la presencia de Displasia Broncopulmonar, Hemorragia Intracraneana y un promedio mayor de días uso de Oxígeno y de Ventilación Mecánica. El uso de corticoides prenatales favorece la normalidad cognitiva. 
MARCADORES ECOCARDIOGRÁFICOS DE DUCTUS ARTERIOSO EN RN DE MUY BAJO PESO Y SU RELACIÓN CON LA CLÍNICA

Pacheco CV, Bancalari MA, Giaconi PJ, Flores OM

Unidad Neonatología, Hospital Guillermo Grant Benavente. Concepción.

Introducción: El ductus arterioso persistente (DAP) es una complicación frecuente en los RN prematuros; su incidencia oscila entre 20 a $60 \%$ en $<1.500$ gr. La evaluación de la persistencia del ductus es dificultosa,se han descrito diversos marcadores ecocardiográficos de DAP como: diámetro ductal;diámetro de ventriculo y auricula izquierda; relación Auricula izquierda/Aorta (Al/Ao) y velocidad final de diástole de arteria pulmonar izquierda (VfdAPI). Objetivo: Evaluar marcadores ecocardiográficos en presencia o ausencia de ductus en RN de muy bajo peso y su relación con la clínica. Material y Método: Estudio prospectivo en $45 \mathrm{RN} \leq 1.500$ gr $y / 0 \leq 32$ sem edad gestacional (EG) ingresados a la UCl neonatal entre Marzo a Agosto del 2008. Se realizó Ecocardiograma 2D doppler color al tercer día y al séptimo día de vida. Se consignaron las siguientes variables: Tamaño ductal $(\mathrm{mm}$ kg); Relación Al/Ao; Tamaño ventrículo izquierdo (VI); Tamaño Aurícula izquierda (Al); Velocidad al final de diástole en API y Velocidad al final de diástole en arteria mesentérica superior (VfdAMS) como detector de robo de flujo sistémico. Se realizó correlación con la clínica y necesidad de soporte respiratorio. Resultados: De los $45 \mathrm{RN}$, un $46,7 \%$ (21/45) presentó DAP al tercer día, cuyo peso y EG promedio fue de $1.150 \mathrm{gr}$ y $28 \mathrm{sem}$ respectivamente. De éstos un $42,9 \%(9 / 21)$ correspondió a $<1.000 \mathrm{gr}$. En la tabla se visualizan los marcadores ecocardiográficos al tercer día.

\begin{tabular}{|c|c|c|c|}
\hline Marcadores ecocardiográficos & Ductus & $\mathrm{X} \pm \mathrm{DS}$ & Valor $\mathrm{p}$ \\
\hline Diámetro Ventrículo izq. & Presente & $13,7 \pm 1,5$ & 0,06 \\
\hline Diámetro Aurícula izq. & $\begin{array}{l}\text { Ausente } \\
\text { Presente } \\
\text { Ausente }\end{array}$ & $\begin{aligned} 12,9 & \pm 1,4 \\
7,5 & \pm 1,2 \\
6,8 & \pm 1,1\end{aligned}$ & 0,03 \\
\hline Relación $\mathrm{Al} / \mathrm{Ao}$ & $\begin{array}{l}\text { Presente } \\
\text { Ausente }\end{array}$ & $\begin{array}{l}1,07 \pm 0,2 \\
0,88 \pm 0,2\end{array}$ & 0,001 \\
\hline Vel. final diástole A.P.I. & $\begin{array}{l}\text { Presente } \\
\text { Ausente }\end{array}$ & $\begin{array}{l}0,19 \pm 0,1 \\
0 \quad \pm 0,1\end{array}$ & 0,0001 \\
\hline Vel. final diástole AMS & $\begin{array}{l}\text { Presente } \\
\text { Ausente }\end{array}$ & $\begin{array}{l}0,15 \pm 0,17 \\
0,18 \pm 0,9\end{array}$ & 0,49 \\
\hline
\end{tabular}

Sólo un paciente sin ductus (1/24) presentó VfdAPI mayor de 0. La sintomatología clínica: soplo; precordio activo; y los pulsos amplios estaban presentes en un $48 \%, 24 \%$ y $29 \%$ respectivamente en los pacientes con ductus. Hubo tendencia a mayor soporte respiratorio en los RN con ductus $(p<0,06)$. Discusión: El diámetro de la $\mathrm{Al}$, la relación $\mathrm{Al} / \mathrm{Ao}$ y la $\mathrm{Vfd} \mathrm{API}$ resultaron marcadores ecocardiográficos significativos de ductus persistente.

\section{CARACTERÍSTICAS Y SOBREVIDA DE PREMATUROS DE EXTREMO BAJO PESO AL NACER. EXPERIENCIA DE UN HOSPITAL DEL SUR DE CHILE}

Barría RM', Mendoza $Y^{1}$, Santander $G^{1}$

'Instituto de Enfermería, Facultad de Medicina, Universidad Austral de Chile. Valdivia-Chile. 'Proyecto DID UACH S 2007-59.

Introducción: La mayor cobertura de corticoides prenatales (CPN), el uso de surfactante y las nuevas modalidades de ventilación mecánica (VM), entre otras acciones, han permitido mejorar la sobrevida de niños cada vez más prematuros y de menor peso en la última década. Actualmente los esfuerzos se centran en mejorar las expectativas de vida del niño de extremo bajo peso al nacer (EBPN) y extremadamente prematuro. Objetivo: Caracterizar el perfil de neonatos de
EBPN y estimar su sobrevida. Pacientes y Métodos: Se analizó la cohorte de 100 neonatos de EBPN ingresados a la Unidad de Neonatología del Hospital Clínico Regional de Valdivia entre el 1 de Enero de 2000 y el 31 de Diciembre de 2005. Se exploraron los datos con estadística descriptiva. La condición al egreso (vivo/muerto) se consideró el resultado principal analizándose el efecto de covariables mediante regresión logística univariada y múltiple, y la estimación de sobrevida por curvas Kaplan Meier comparando por grupos de PN y EG mediante test de log-rank. Para el análisis se utilizó el programa Stata v. 8.1 Resultados: El grupo estudiado se caracterizó por una EG media de 27 semanas (DS: 2,04) y un PN de 799,6 g (DS: 124). Se determinó una $E G<28$ semanas en $58 \%$, en tanto que la condición pequeño para la EG alcanzó $51 \%$. Fueron varones $53 \%$. La puntuación Apgar al minuto tuvo una media de 5,0 (DS $2,6)$ observándose puntuación dd3 en $32 \%$ de los niños. A los 5 minutos la media fue 6,9 (DS: 2,1 ), $33 \%$ no superó los 6 puntos. Se administró CPN a $69 \%$ de los neonatos, $84 \%$ de ellos recibieron al menos 2 dosis. Evolucionaron con distrés respiratorio $91 \%$ de los RN requiriendo VM $88 \%$ de ellos. Recibieron surfactante $72 \%$ de los neonatos. La sobrevida global alcanzó $67 \%$ siendo nula a las 23 semanas $(n=5)$, de $57 \%$ a las 24 y $60 \%$ a las 25 . Por categorías de PN la sobrevida mejoró sustancialmente de $33 \%$ en neonatos entre 500 y 599 g hasta $87,9 \%$ en los mayores de $900 \mathrm{~g}$. La estimación de sobrevida mostró que la probabilidad de sobrevivir mejora significativamente luego de las 48 horas, momento donde ocurren casi $60 \%$ de las muertes. Si bien univaridamente se observó asociación estadísticamente significativamente de la sobrevida con las variables PN, EG, puntuación Apgar y CPN, en el análisis multivariado la sobrevida se asoció con mayor PN por cada $100 \mathrm{~g}\left(\mathrm{OR} 1,71 ; \mathrm{IC}_{95 \%} 1,14-2,54\right)$ y mejor Apgar al quinto minuto (OR 1,56; IC 1,21-2,01). Conclusión: Como en otros estudios, se comprueba como el principal predictor de sobrevida de estos neonatos el PN, así como, la recuperación del neonato luego del parto -expresada en el Apgar al quinto minuto- mantiene su capacidad pronóstica.
EFECTOS DE LA ALIMENTACIÓN CON VASITO Y AL SENO MATERNO SOBRE LA SATURACIÓN DE OXÍGENO EN RECIÉN NACIDOS PREMATUROS ESTABLES

Carrasco M, Casafranca E, Surco Y.

Proyecto Perinatal Huaccha Ccolawawa-Cusco-Perú.

Introducción: La alimentación con vasito es un método utilizado en neonatos hospitalizados con el fin de evitar los efectos negativos del biberón sobre la lactancia materna. Objetivo: Determinar los efectos de la alimentación con vasito y al seno materno sobre la saturación de oxígeno, en recién nacidos prematuros estables. Material y Métodos: Se realizó el estudio en el Hospital Regional, el 2005 y 2006, en prematuros de 34 y 36 semanas de edad gestacional, estables, sin patología, malformaciones congénitas o requerimientos de oxígeno, hospitalizados para ganancia de peso, se diseñó un estudio clínico controlado no randomizado, el grupo estudio recibió formula en vasito de plástico y el grupo control fueron los mismos niños, cuando su madre estuvo presente y los amamantó. Se evaluó la saturación de oxígeno. Se utilizó la media y desviación estándar ión, t de Student y Análisis de Varianza con un nivel de significación estadística de $<0,05$. Resultados: Se estudiaron 51 neonatos y 378 episodios de alimentación, ambos grupos fueron comparables estadísticamente; los resultados fueron los siguientes:

\begin{tabular}{lccl}
\hline Variable & Vasito & $\begin{array}{c}\text { Seno } \\
\text { Materno }\end{array}$ & p \\
\hline Peso al nacer, g. (X, DE) & $1.511,8 \pm 265,9$ & $1.649,7 \pm 291$ & $\mathrm{NS}$ \\
$\mathrm{EG}$ al nacer, sem. (X, DE) & $34,8 \pm 0,8$ & $34,6 \pm 0,6$ & $\mathrm{NS}$ \\
Duración de la alimentación, min. (X, DE) & $3,2 \pm 1,7$ & $6,2 \pm 2,1$ & 0,034 \\
$\%$ Sat. $\mathrm{O}_{2}$ previo a aliment. (X, DE) & $93,1 \pm 2,9$ & $92,1 \pm 2,7$ & $\mathrm{NS}$ \\
$\%$ Sat. $\mathrm{O}_{2}$ durante la aliment. (X, DE) & $86,9 \pm 5,3$ & $89,4 \pm 3,4$ & 0,038 \\
$\%$ Sat. $\mathrm{O}_{2}$ después de la aliment. (X, DE) & $90,5 \pm 3,9$ & $91,1 \pm 2,9$ & 0,005 \\
$\%$ Sat. $\mathrm{O}_{2}$ más baja durante alim. (X, DE) & $71,6 \pm 5,4$ & $83,3 \pm 1,9$ & 0,037 \\
Episodios de Sat. $\mathrm{O}_{2}<90 \%, \mathrm{n}(\%)$ & $511(45,1)$ & $968(41,8)$ & 0,043 \\
Episodios de Sat. $\mathrm{O}_{2}<85 \%, \mathrm{n}(\%)$ & $294(18)$ & $225(9,7)$ & 0,0039 \\
Episodios de Sat. $\mathrm{O}_{2}<80 \%, \mathrm{n}(\%)$ & $81(7,2)$ & $0(0)$ & 0,0000
\end{tabular}

El efecto negativo de la alimentación con vasito es mayor en los neonatos de menor edad gestacional, siendo la media de la diferencia a las 34 semanas, 4,17 (p 0,000), 35 semanas, 3,31 ( p 0,019) y a las 36 semanas 2,31 ( 0,027$)$. Conclusión: La alimentación con vasito en recién nacidos prematuros produce mayor número y más severos episodios de desaturación de oxígeno que la alimentación al seno materno. Se debe realizar estudios para determinar la causas de estos resultados.
DIAGNÓSTICO ECOGRÁFICO PRENATAL DE CARDIOPATÍAS CONGÉNITAS EN EL HOSPITAL CLÍNICO REGIONAL ANTOFAGASTA ENTRE LOS AÑOS 2006-2007

Castillo PH, Cañón CR, Almonte ChE, Alonso BE.

Facultad de Medicina y Odontología, Universidad de Antofagasta. Chile.

Objetivos: Conocer la incidencia de cardiopatías congénitas a través de diagnóstico ecográfico en el Hospital Clínico Regional Antofagasta en los años 20062007. Material y Método: Estudio Descriptivo retrospectivo donde se tomó como universo el total de los exámenes ecográficos de segundo y tercer trimestre realizados en el período 2006-2007 en el HCRA. Resultados: Se revisaron un total de 3363 informes ecográficos de segundo y tercer trimestre entre los cuales se encontraron 33 casos de diagnóstico de cardiopatía congénita, con una tasa de 10 casos cada 1000 exámenes ultrasonográficos realizados. La edad materna tuvo un promedio de 22.25 años con una desviación estándar de $\pm 5,02$; la edad gestacional promedio a la que se hizo el diagnóstico ecográfico de cardiopatía congénita fue a las 33 semanas encontrando 27 casos de comunicación auriculoventricular, 3 a tetralogía de Fallot, 1 caso de canal $A-V$ y 1 caso descrito como malformación cardíaca mayor ,incompatible con la vida, 12 de los casos de malformación cardíaca congénita presentaron otras malformaciones asociadas, considerando también la presencia de 10 casos de polihidroamnios y 2 de oligohidroamnios. Conclusiones: La frecuencia de diagnóstico ecográfico prenatal de cardiopatías congénitas en el hospital clínico regional Antofagasta se acerca mucho a la realidad nacional, concentrándose en un grupo de madres jóvenes, y es de diagnóstico prenatal tardío pero que ha sido de utilidad como apoyo en el manejo perinatal de nuestros pacientes. 
¿ES SIGNIFICATIVA LA MORBILIDAD NEONATAL EN PREMATUROS MAYORES DE 34 SEM?

Novoa PJM', Sakovets $I^{1}$, Novoa $B C^{2}$, Gómez $C L^{1}$

UGC Mujer y RN, Hospital Padre Hurtado. ${ }^{2}$ Alumno Medicina Universidad de Chile.

La morbilidad del $\mathrm{RN}$ a partir de las 34 semanas es motivo de inquietud dado que en la práctica son considerados como $\mathrm{RN}$ de bajo riesgo basado en su baja letalidad. ¿Debemos realmente considerar a estos prematuros de bajo riesgo? o es nuestra obligación demostrar la morbilidad asociada y poder aportar información a la decisión de interrupción de estos embarazos versus no interrupción cuando ella no conlleve riesgo mayores en la madre. Objetivos: Evaluar la incidencia de hipoglicemia, membrana hialina y pulmón húmedo a partir de las $34 \mathrm{sem}$ de EG. Evaluar el riesgo relativo de estas patologías y su variación $34 \mathrm{sem}$ de EG. Evaluar el riesgo relativo de estas patologías y su variación
semana a semana. Comparar estas patologías neonatales con los RN de 38 semanas o más. Material y Método: Se evalúa información 57.874 neonato a 2007 en nuestro hospital. Se estudio incidencia de hipoglicemia, membrana hialina y pulmón húmedo según semana gestacional a nacer en forma semanal desde 34 a 37 semanas y para el grupo de $38-42$ sem. Se realiza análisis estadístico de RR con intervalo de confianza 95\% y nivel de significancia. Se compara el RR y p en la semana comparando con la seman inmediatamente siguiente y la semana de prematurez versus los RN mayores
de 38 semanas. Resultados: Se expresan en tabla 1 los números totales de de 38 semanas. Resultados: Se expresan en tabla 1 los numeros totales de
pacientes, pacientes afectados y el análisis estadísticos semana a semana. En
tabla 2 se expresan los RR y nivel de significancia comparado por edad gestacional

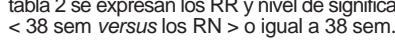

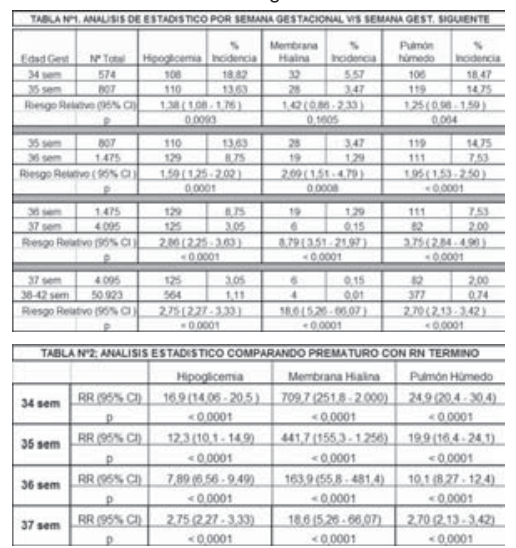

Conclusiones Existe un significativo mayor riesgo de presentar las patologías estudiadas en los prematuros el cual disminuye en forma importante por cada se mana gestacional ga-
nada. Los $\mathrm{RN}$ de 37 semanas se comportan como neonatos inmaduros con riesgo de 2,7 veces de presentar hipoglicemia y pulmón húmedo y aún podemos encontra un $0,15 \%$ de mem brana hialina. Esta información es relevante en lo referido a morbilidad neonatal y pertinente.

INFECCIÓN CONNATAL POR ESTREPTOCOCO GRUPO B. SITUACIÓN POST-INSTAURACIÓN MEDIDAS DE PREVENCIÓN DE CDC

Novoa PJM', Sakovets $I^{\prime}$, Novoa $B C^{2}$, Hidalgo $A L^{\prime}$

'UGC Mujer y RN, Hospital Padre Hurtado. ${ }^{2}$ Alumno Medicina Universidad de Chile.

El Estreptococo Agalactie o ß hemolítico Grupo B (SGB) es un colonizante del tracto gastrointestinal y urinario y significa un problema clínico de trascendencia en perinatología. En estudios nacionales se aísla en mujeres embarazadas por cultivos rectoperinales o vaginales en $16 \%$ y en otros paises entre 5-35\%. E cambio de manejo referido a "Prevención de Infección connatal por SGB" se ha establecido con dos estrategias que corresponden a Prevención basada en cultiVo a las 35-37 semanas y Prevención basada en factores de riesgo. La prevalencia global de Sepsis Neonatal previo a instauración de medidas de prevención es de 1-3 por mil, aumenta a 14 por mil en caso de colonización y a 41 por mil s además posee factores de riesgo. La letalidad de esta infección en período neonata es de 5-15\%. El manejo actual ha modificado esta situación y hoy los factores de riesgo y condiciones de presentación requieren ser reevaluados. Objetivos: Evaluar características prenatales de pacientes con Infección connatal por SGB. Cumplimiento de Estrategia de prevención de Infección por SGB en paciente que presentaron sepsis demostrada con hemocultivos. Determinar incidencia de Infección connat por SGB. Material y Método: Se revisan la totalidad de neonatos que presentaron hemocultivos positivos a SGB en el período Noviembre 1998 a Agosto 2008 con 62.626 RN vivos. La profilaxis antenatal con Ampicilina o Penicilina se realiza en nuestro Hospital desde año 2001 en relación a pre rionn de re de riesgo queson: RN pr Rotura de me qu dos: De los 62.626 neonatos estudiados se encontraron se encontraron 36 neonatos con hemocultivo positivo a SGB. Ningún de ellos tenía condición conocida de portacion de SGB. Cuatro cesárea con trabajo de parto y RPO entre 7-12 hr. Fórceps 12 RN (36\%), con RPO 1 - 16 hrs, de elos 2 pueron inducción. Parto eutocico en 20 casos, uno caso con inducciôn, el resto espontáneos. El liquido amniótico fue claro (80,5\%), 1/36 meconio espeso, 6/36 con meconio fluido. En ningún caso se sospecho infección ovular, una madre recibió 1 dosis de antibióticos previo a parto por RPO 12 horas. La T en preparto fue normal en $80,5 \%, 6 / 36$ $(16,7 \%)$ subfebriles. Sólo 1 caso tenia fiebre $38,5{ }^{\circ} \mathrm{C}$ con taquicardia fetal y mate y uno con RPO 16 hrs $(2,7 \%)$. Las edad materna entre $16-30$ años,

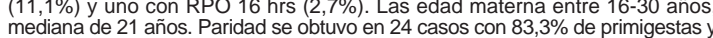
$16,7 \%$ multípara de 1 . La edad gestacional osciló entre $36-41$ sem con mediana de $39 \mathrm{sem}$. En relación a síntomas de $\mathrm{RN}: 4(11,1 \%)$ fueron asintomáticos, $7(19,4 \%)$ desde nacimiento presentaron SDR, 12 nacieron en buenas condicio-
nes y presentaron síntomas en primeros 6 horas de vida, 9 pacientes fueron sintomáticos entre los 6 a 24 hrs de vida, 4 presentaron síntomas después de 24 hrs de vida con un promedio de 49 hrs. Los síntomas fueron variables entre paciente asintomático, sólo alzas térmicas y compromiso sistémico de variable grado. En casos asintomáticos, 2 pacientes se pidieron exámenes de laboratorio por parto prematuro 36 semanas sin causa precisada y 2 por fiebre materna en puerperio. Ningún paciente tuvo alteración de función hepática, sólo uno con alteración de función renal y 4 cursaron con meningitis. No hubo fallecidos. Conclusiones: La incidencia fue de 0,575 por mil nacidos vivos. Asociación con Conclusiones: La incidencia fue de 0,575 por mil nacidos vivos. Asociación con
meningitis en $11,1 \%$. La forma de presentación actual es coincidente con lo meningitis en $11,1 \%$. La forma de presentación actual es coincidente con lo
descrito en la literatura. Llama la atención un $33 \%$ de fórceps, $3-4$ veces mayor descrito en la literatura. Llama la atención un 33\% de forceps, 3-4 veces mayor
que en población general (9\%). La alta sospecha en población de riesgo por que en poblacion general ( $9 \%$ ). La alta sospecha en poblacion de riesgo por prematurez, fiebre materna en puerperio con pesquisa dirigida permitio trata-
miento precoz. Enfrentamiento terapéutico actual evitó letalidad. Desde inicio de protocolo de prevención infección por SGB por factores de riesgo esta se cumplió en $100 \%$ casos afectados. No es posible identificar factores de riesgo que eventualmente pudiesen haber evitado estos casos. Dado cumplimiento de prevención por factores de riesgo la única forma de evitar estos casos en conociendo condición materna de portación.

\section{ENFRENTAMIENTO DEL EQUIPO OBSTETTRICO Y NEONATAL ANTE EL NACIMIENTO DE PREMATUROS EXTREMOS CON EDAD}

Jodorkovsky RM, Salas NR, Vallejos MA, Muñoz MP, Lavín AP. Servicios de Neonatología y Gineco-Obstetricia Hospital Barros Luco, Facultad de Medicina Sur- Universidad de Chile.

Introducción: El límite de la viabilidad (LV) no está claramente definido, considerándose una «zona gris gestacional» entre las 23 y 25 semanas. La sobrevida de los recién nacidos (RN) en el LV depende del manejo obstétrico y neonatal, no los recién nacidos (RN) en el LV depende del manejo obstétrico y neonatal, no dad del producto de la gestación. Objetivo: Comparar el enfrentamiento de los dad del producto de la gestación. Objetivo: Comparar el enfrentamiento de los equipos obstetrico y neonatal respecto a la predicción de viabilidad de prematuros estos RN Método: Estudio descriptivo en el que se analizaron las fichas maternas y neonatales de los RN vivos con edad gestacional (EG) obstétrica entre 23 y $25+6$ semanas, nacidos en el Hospital Barros Luco entre Enero de 2004 y Diciembre de 2006 . Una comisión integrada por obstetras y neonatólogos determinó ciembre de 2006. Una comision integrada por obstetras y neonatólogos determinó si el equipo obstétrico y neonatal actuó en el momento del parto considerando que el producto de gestación sería viable (V) o no viable (NV). El análisis estadístico se efectuó mediante $\chi^{2}$, y se utilizó coeficiente Kappa para evaluar la concordancia
entre el enfrentamiento obstétrico y neonatal. Resultados: En el período estudiado nacieron $34 \mathrm{RN}$ vivos con EG obstétrica entre 23 y $25+6$ semanas. El peso nacieron $34 \mathrm{RN}$ vivos con EG obstétrica entre 23 y $25+6$ semanas. El peso
promedio fue 706 grs (512-950). En el $70,6 \%$ de los casos se utilizó corticoides prenatales, lográndose maduración completa (2 dosis) en el 32,4\%. En el 58,8\% la resolución del parto fue vía vaginal, y en el $41,2 \%$ vía cesárea. La sobrevida al alta fue de $7 \mathrm{RN}(20,6 \%)$; fallecieron previo a su ingreso a UCIN $12 \mathrm{RN}(35,3 \%)$ y durante su hospitalización $15(44,1 \%)$. Veinticuatro RN presentaron APGAR dd3 al minuto $(70,6 \%)$, de los cuales fallecieron el $83,3 \% ; 15$ presentaron APGAR dd3 a los 5 minutos $(44,1 \%)$, de los cuales fallecieron el $100 \%$. En el $79,4 \%$ de los casos el equipo obstétrico actuó considerando V el producto de la gestación, y en $20,6 \%$ registró sobrevida en aquellos RN en que obstetras y neonatólogos concordaron en considerarlos viables. Conclusiones: Se observó una moderada concordancia entre el enfrentamiento de los equipos obstétrico y neonatal respecto a la predicción de viabilidad. La concordancia entre ambos equipos es fundamental para lograr sobrevida en RN que nacen en el LV.

\section{MORTALIDAD EN PREMATUROS DE EXTREMO BAJO PESO: ANÁLISIS} DE MÚLTIPLES VARIABLES DE RIESGO PERINATAL

Salas R, Sanhueza L, Lavín P, Pastén N.

Servicio de Neonatología. Hospital Barros Luco.

Introducción: Los recién nacidos de extremo bajo peso (RNEBP) o menores de 1.000 gramos han alcanzado una sobrevida cercana al $80 \%$ en países desarrollados y alrededor del $55 \%$ en el sector público de Chile, sin embargo, constituyen el 40 a $50 \%$ de la mortalidad infantil. Objetivo: Buscar asociación entre la muerte en RNEBP y algunas variables perinatales seleccionadas tales como terapia de maduración pulmonar, test de Apgar, edad materna, vía del parto, sexo y gemelaridad. Pacientes y Método: Estudio de tipo longitudinal que incluye a todo recién nacido menor de 1.000 gramos de los años 2000 al 2006, excluyendo a los menores de 500 grs o menos de 24 semanas de edad gestacional pediátrica, que se distribuyen por cuartil de peso de nacimiento en 2 grupos: 500-749 y 750 an de homogeneidad $\left(\chi^{2}\right)$. Se consideró maduración pulmonar completa el recibir 2 ó más dosis de betametasona y no completa a 1 o ninguna dosis, test de Apgar bajo a los 5' a un puntaje dd3, edad materna se dividio en dd16 años, 17-34 y ed35. Resultados: Durante el período estudiado de 6 años se enrolaron 290 prematuros RNEBP, el $41,4 \%$ (120) correspondió al grupo de 500 a 749 grs y el prematuros de $500-749$ grs la sobrevida global fue de $38,8 \%$ ( 37 niños), y se prematuros de $500-749$ grs la sobrevida global fue de $38,8 \%$ (37 niños), y se observó que su sobrevida depende directamente de la maduración pulmonar

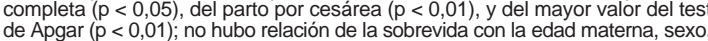
de Apgar $(p<0,01)$; no hubo relacion de la sobrevida con la edad materna, sexo, ni gemelaridad. En el grupo de $750-999$ grs la sobrevida global fue de $59,4 \%$ (1) $0,05)$, vía cesárea del parto $(p<0,05)$, test de Apgar $>3(p<0,05)$, edad materna ed35 años $(p<0,05)$ y del sexo femenino $(p<0,05)$; sólo la gemelaridad no se asoció con la sobrevida. Conclusiones: En ambos grupos la sobrevida se asocia directamente con la maduración pulmonar completa, puntaje de Apgar $>3$ a los 5' y parto por cesárea. Además en los de 750 a 999 grs hay asociación positiva con la edad materna ed35 y sexo femenino. Para saber cuál variable pesa más como predictora de sobrevida, será necesario ampliar el n y realizar un análisis multivariado. 
RESULTADOS AUDITIVOS $Y$ DESARROLLO DE LENGUAJE EN NIÑOS CON IMPLANTE COCLEAR

\section{Sanhueza CS.}

Hospital Naval de Viña del Mar.

Los niños que nacen con sordera profunda bilateral no poseen capacidad de percibir sonidos, independiente de la intensidad de éste, por lo que su comunicación se restringe al uso de señas, sin posibilidad de desarrollar lenguaje. E desarrollo del lenguaje se puede segmentar en seis categorías, siendo la categoría 1 sólo la percepción de las vibraciones de los sonidos ambientales y su respuesta en base a sonidos, hasta la categoría 6 , que representa la comunicación oral normal, con desarrollo de lenguaje estructurado suprasegmental. Se presenta la experiencia en 50 niños con sordera profunda bilateral, confirmada mediante otoemisiones acústicas y potenciales evocados auditivos, los que fueron sometidos a cirugía de Implante Coclear entre los años 2002/2007 en el Hospital Naval de Viña del Mar, utilizando Implantes Nucleus 24 k. Nucleus Contour y Nucleus Advance, los que han sido posteriormente rehabilitados en centros de integración a lo largo del país. Se estudia su capacidad auditiva postimplante y el desarrollo alcanzado en términos de lenguaje, considerando como variables la edad de implantación, handicaps asociados a la sordera y tiempo de rehabilitación. El 76\% de ellos se encuentran en una condición de integración escolar normal, el $21 \%$ está bajo esta condición y $6 \%$ supera esta variable, con desarrollo precoz de un segundo idioma.

\section{CONSENTIMIENTO INFORMADO EN UCI NEONATAL}

Álvarez $H D$, Muñoz LD.

Hospital San Juan de Dios. Servicio de Pediatría Unidad de Neonatología.

La Calidad de los procesos clínicos ha cobrado gran relevancia con la autogestión hospitalaria y la garantía de calidad, asociada a la Ley 19.966. Esta entrará pronto en vigencia y transformará dicho proceso en un derecho exigible. La autorización sanitaria (ámbito equipamiento e infraestructura), por una parte, y el cumplimiento de los Estándares de Calidad de Atención para Prestadores Institucionales (ámbito de procesos clínicos) serán los instrumentos que aseguren el cumplimiento de dicha calidad. El respeto a la dignidad del paciente se convierte en fundamental para los establecimientos y el consentimiento informado $(\mathrm{Cl})$ en un componente esencial de su cumplimiento. Según el Colegio Americano de Médi$\mathrm{cos}$, el $\mathrm{Cl}$ es "la explicación a un paciente atento y mentalmente competente, de la naturaleza de su enfermedad, así como del balance entre los efectos de la misma y los riesgos y beneficios de los procedimientos terapéuticos recomendados, para a continuación solicitarle su aprobación para ser sometidos a esos procedimientos". Es un Derecho, un proceso médico inalienable y su desarrollo ha sido una gran contribución y oportunidad de mejoría en la relación medicopaciente. La Unidad de Neonatología del Hospital San Juan de Dios evaluó el C como acto habitual, debidamente registrado en la historia de todo paciente que ingresa a la Unidad de Cuidados Intensivos (UCl). Materiales y Métodos: Desde febrero a septiembre 2008 se supervisó, sin aviso previo, las historias clínicas de los hospitalizados en $\mathrm{UCl}$, para verificar el registro del $\mathrm{Cl}$ (implementado en 2004), entendiendo por "debidamente registrado" el documento con todos los datos solicitados y firmas correspondientes. La UCl cuenta con 10 camas y el medico tratante es el responsable del proceso. El Cl implica "sentarse a conversar, entregando información clara a los padres o representante legal del niño enfermo". Se controló el registro 3 veces al mes, excepto en Junio (2) y Agosto (1). Resultados: En el período estudiado se produjeron 200 ocasiones para solicitar y registrar el $\mathrm{Cl}$. En $78,5 \%$ se encontró registro completo del $\mathrm{Cl}$, variando entre $60 \%$ (Junio) y $86 \%$ (Marzo y Septiembre). En 5 de 8 meses, el cumplimiento superó el $80 \%$. Discusión: Los estándares de calidad de la Reforma de Salud exigen a los establecimientos "proveer una atención que respeta la dignidad del paciente y resguarda principios éticos esenciales en el trato que se otorga". Por tanto, cumplir un $100 \%$ del indicador expuesto no es sólo obligación legal, sino un principio básico y esencial en toda atención de cualquier centro asistencial. Este trabajo tiene la limitación de ser observaciones instantáneas, pero permite evaluar el cumplimiento. El mejor cumplimiento debe hacerse dentro de las 48 horas después del ingreso; lo que se acogerá en la supervisión futura. Esta continuará el monitoreo periódico mensual, con meta del $100 \%$, y cortes trimestrales para evaluar.

\section{CAUSAS DE HOSPITALIZACIÓN EN NEONATOS QUE CONSULTAN} A UN SERVICIO DE URGENCIA INFANTIL DEL SISTEMA PÚBLICO

Villagrán ZJ, Tapia VM, Zúñiga UM.

Complejo Asistencial Dr. Sotero del Río, Servicio de Neonatología.

Introducción: Las estadísticas de hospitalización y las enfermedades que afectan a la población neonatal egresada de las maternidades no son de fácil acceso, debido a la falta de registros, publicaciones y monitorización de estas variables a nivel de red asistencial. Conociendo estos datos se podrían diseñar estrategias de prevención más eficientes enfocadas a las necesidades reales de este grupo de riesgo. Objetivo General: Identificar las causas de hospitalización de neonatos que consultan al servicio de urgencia infantil. Objetivos específicos: Identifica la semana de mayor riesgo de hospitalización. Señalar la gravedad del paciente según el lugar de hospitalización. Revisar la distribución trimestral de las hospitalizaciones. Identificar la incidencia de rehospitalización. Material y Método: Se realizó un trabajo descriptivo, analizándose retrospectivamente la base de datos de consultas de un servicio de urgencia infantil durante el año 2007 y se seleccionaron a los neonatos de hasta 28 días que fueron hospitalizados (tota partos 6.981). Se obtuvieron los datos personales, el diagnóstico y el servicio de hospitalización. Se revisaron 90 fichas clínicas para completar los antecedentes pendientes de la base de datos. Resultados: Se identificaron 212 hospitalizaciones, correspondientes a 207 neonatos. Las causas de hospitalización fueron: Infección respiratoria baja $(41 \%)$, RN febril $(22 \%)$, apnea $(14 \%)$ hiperbilirrubinemia $(10 \%)$, otras infecciosas $(8 \%)$, hipoalimentación $(6 \%)$ cardiopatías $(4 \%)$, neurológicas $(3 \%)$ y otras $(5 \%)$. Durante la primera semana de vida se constataron 29 hospitalizaciones, 51 la segunda, 56 la tercera y 64 la cuarta semana. De las 212 hospitalizaciones se obtuvo el lugar de internación en 200 de ellas: en sala común 132 (66\%), 30 (15\%) en intermedio, $22(11 \%)$ en neonatología, $14(7 \%)$ en UCl y $2(1 \%)$ corresponden a traslados a otros centros. La distribución de las hospitalizaciones fue: primer trimestre un $26,4 \%$, un $19,8 \%$ en el segundo, un $34,4 \%$ en el tercero y un $19,3 \%$ en el cuarto trimestre. Se produjeron 5 rehospitalizaciones en 4 pacientes, 3 de ellas por causa respiratoria, una por causa neurológica no relacionada con la hospitalización previa y la otra por reingreso luego de una cardiocirugía. Conclusiones: Las enfermedades infecciosas constituyen la principal causa de hospitalización y en conjunto suman un $71 \%$. La hiperbilirrubinemia podría estar subrepresentada por consultas directas al servicio.

\section{HIPOGLICEMIA PERSISTENTE COMO DEBUT DE RECIÉN NACIDOS CON PANHIPOPITUITARISMO CONGÉNITO, 2 CASOS}

Mühlhausen MG, Benavides Cl, Flores HR, Bravo CE.

Servicio de Neonatología Hospital San José y Servicio de Neuroradiología del Instituto de Neurocirugía.

El panhipopituitarismo congénito es una causa infrecuente de hipoglicemia persistente neonatal. Se presentan 2 casos de recién nacidos que debutaron con hipoglicemia en las primeras horas de vida y que debido a la persistencia de ésta se efectuaron diversos exámenes metabólicos, hormonales y de neuroimagen que comprobaron la ausencia de la adenohipofisis. 1er caso: Recién nacido hijo de madre primípara de 23 años sin antecedentes mórbidos durante el embarazo, nace por vía vaginal con forceps en buenas condiciones. Apgar 8-9, se observa polidactilia en las 4 extremidades. Se envía con su madre la cual nota que en relación al llanto presenta cianosis y apnea. Se decide hospitalizar para monitorizar una probable apnea. Se toman exámenes resultados el HGT de $17 \mathrm{mg} / \mathrm{dl}$ manejándose con SG al 12,5\%. Por persistencia de hipoglicemia se descarta una enfermedad metabólica pero los niveles hormonales de cortisol, tiroxina, THS e insulina resultan bajos. Se efectúa RMN que muestra la ausencia de adenohipofisis y neurohipófisis ectópica. Se apoya con hormonoterapia mejorando la glicemia dándose de alta al mes de vida con buen incremento pondo estatural. 2do caso: Recién nacido hijo de madre primípara de 22 años sin patología durante el embarazo. Nace por vía vaginal con 14 horas de RPO y período expulsivo de 1 hora, algo deprimido con Apgar 2-8-9. Es enviado a puerperio normal con su madre donde no se alimenta bien, flojo, hipoactivo. Se intenta apoyar el pecho con fórmula.A las 16 horas de vida presenta episodio de bradicardia, cianosis y apnea. Se recupera con ventilación a presión positiva: Se toma HCT $<20 \mathrm{mg} / \mathrm{dl}$. Se indica bolo de glucosa $300 \mathrm{mg}$, ev normalizán-dose su glicemia. Se inicia apoyo con fleboclisis con carga de $4,8 \mathrm{mg} / \mathrm{k} / \mathrm{min}$. Se intenta apoyo con alimentación oral con mala tolerancia. Presenta en su evolución ictericia de predominio colestásica. A los 21 días presenta un nuevo episodio de apnea y bradicardia en relación a una glicemia de $8 \mathrm{mg} / \mathrm{dl}$. Se plantea hipopituitarismo congénito el cual se comprueba por niveles bajos de cortisol, hormona de crecimiento y tiroxina. Se inicia tratamiento poli hormonal mejorando rápidamente su tolerancia alimentaria y su desarrollo ponderal dándose de alta. El pensar en esta causa de hipoglicemia persistente pudo salvar la vida a estos niños y además evitó un daño neurológico permanente. 
HIPOALIMENTACIÓN E ICTERICIA NEONATAL EN EL RN DE TÉRMINO

Brethauer MS, González BA.

Clínica Dávila, Santiago.

Introducción: En el RN de término la ictericia es fisiológica, sin embargo, sobre determinados niveles, esta debe ser tratada. Dentro de las causas está la enfermedad hemolítica, alimentación con leche materna exclusiva, prematuridad, hematomas y diabetes materna. Objetivo: Analizar las causas de hiperbilirrubinemia neonatal y su relación con la hipoalimentación en el servicio de neonatología de una clínica privada. Pacientes y Métodos: Estudio observacional recopilando datos a través del análisis de fichas clínicas. Se incluyeron 89 recién nacidos mayor o igual a 37 semanas de edad gestacional ingresados al servicio de neonatología con diagnóstico de hiperbilirrubinemia, desde enero del 2007 a julio del mismo año. Se redefinió hipoalimentación como la pérdida de más del $3 \%$ del peso diario e ictericia por leche materna, a partir de quinto día de alimentación con leche materna exclusiva. Los 3.516 en ese período se dividieron en dos grupos dependiendo de la pérdida de peso. Un grupo de hipoalimentados y un grupo control. Se buscó la incidencia de hiperbilirrubinemia en ambos grupos, calculando el OR para ingresar a fototerapia. Resultados: Del total de RN ingresados por hiperbilirrubinemia $(n=89), 31,5 \%(n=28)$ fue por hipoalimentación, $18 \%(n=16)$ por hiperbilirrubinemia asociada a incompatibilidad de grupo sin hemólisis, 16,8\% ( $n=15)$ por hiperbilirrubinemia idiopática, $14,6 \%(n=13)$ por enfermedad hemolítica por incompatibilidad ABO, $11,2 \%(n=$ 10) por leche materna, un $4,4 \%$ por cefalohematomas $(n=4)$ y $1,1 \%(n=1)$ po poliglobulia, 1,1\% enfermedad hemolítica por grupo Rh y por último 1,1\% po incompatibilidad por $\mathrm{Rh}$ sin hemólisis. De los 3516 recién nacidos analizados, se encontró una frecuencia de hipoalimentación de un $51,5 \%$, con un riesgo de 3,57 veces más de hiperbilirrubinemia $(\mathrm{OR}=3,57)$ con IC del $95 \%(2,04-7,36)$ y un "p" muy significativo < 0,0001. Conclusión: Hipoalimentación es la causa más frecuente de hiperbilirrubinemia en nuestra serie, siendo tres veces más probable ingresar a fototerapia por esta causa. La sigue en frecuencia la hiperbilirrubinemia asociada a incompatibilidad por grupo $A B O$, aunque sin hemólisis, lo que podría considerarse de causa idiopática, ya que debemos recordar que es la hemólisis la causa de la hiperbilirrubinemia. De todos los RN, es alarmante el porcentaje de éstos que se encuentra hipoalimentado, pudiendo ser evitado con una intervención precoz en el fomento y correcta técnica de lactancia.

PROBABILIDAD DE ICTERICIA EN RN HIPOALIMENTADOS

González BA, Brethauer MS

Clínica Dávila, Santiago.

Introducción: La causa más conocida es la enfermedad hemolítica, que ha ido disminuyendo considerablemente con el uso profiláctico de lg anti D. Otras causas conocidas son la hipoalimentación, prematuridad, y hematomas entre otros Objetivo: Analizar las causas dehiperbilirrubinemia neonatal y su relación con la hipoalimentación en el servicio de neonatología de una clínica privada. Pacientes y Métodos: Se realizó un estudio observacional, sin intervención. Se analizan los 3.516 recien nacidos de 37 semanas o más, alimentados al pecho, nacidos entre Enero y Julio del 2007 y se calcula la pérdida de peso por día, se separan en dos grupos, los casos de 1.810 niños hipoalimentados, definidos por la pérdida de más de $3 \%$ diario y un grupo control de 1.706 niños con pérdida de peso menor. y sin incompatibilidades, ni enfermedad hemolitica, ni hematomas. Se analiza la frecuencia de hospitalización por ictericia en cada grupo y se calcula el riesgo de ingresar a fototerapia en el grupo de hipoalimentación, en relación a los controles (O: R: con IC del 95\%, por el programa STATA). Además se analizan las causas de ingreso a fototerapia de 89 recién nacidos mayo o igual a 37 semanas de edad gestacional ingresados al servicio de neonatología con diagnóstico de hiperbilirrubinemia, en el mismo período. Se redefinió hipoalimentación como la pérdida de más del $3 \%$ del peso diario e ictericia por leche materna, a partir del quinto día de alimentación con leche materna exclusiva. Resultados: De los 3.516 recién nacidos analizados, se encontró una frecuencia de hipoalimentación de un 51,5\% (1810 RN), con un riesgo de 3,57 veces más de hiperbilirubinemia en el grupo de hipoalimentados que en el grupo que no está hipoalimentado (OR = 3,57) con IC del $95 \%(2,04-7,36)$ y un "p" muy significativo $<0,0001$, osea el estar hipoalimentado implica tener entre 2 y 7 veces más probabilidad de ser hospitalizado por hiperbilirrubinemia De los 89 recién nacidos ingresados por hiperbilirrubinemia $31,5 \%(n=28)$ fué asociado a hipoalimentación, $18 \%(n=16)$ por incompatibilidad de grupo $A B O$ sin hemólisis, $16,8 \%(n=15)$ idiopático, $14,6 \%(n=13)$ por enfermedad hemolítica $A B O$, y el resto por otras causas. Conclusión: Del total de recién nacidos alimentados al pecho en la clínica durante seis meses, más del $50 \%$ se encuentra hipoalimentado, considerando una perdida de peso del $3 \%$ diario.La hipoalimentación es la causa más frecuente de hiperbilirrubinemia en nuestra serie y aumenta el riesgo de ingresar a fototerapia en casi 4 veces, siendo desde 2 y hasta 7 veces más probableLa hipoalimentación puede ser evitada con una intervención precoz en e fomento y correcta técnica de lactancia materna y con esto disminuir en forma indirecta las hospitalizaciones por hiperbilirrubinemia secundaria a esta causa.
TRATAMIENTO DE LA HIPERBILIRRUBINEMIA POR ENFERMEDAD HEMOLÍTICA ABO Y RH CON INMUNOGLOBULINA G

Bancalari A, Díaz E, Peters C, Rojas $D$.

Unidad de Neonatología, Servicio de Pediatría, Hospital Guillermo Grant Benavente, Universidad de Concepción.

Introducción: Desde la introducción masiva de la profilaxis con inmunoglobulina anti-D en la prevención de la sensibilización de madres $\mathrm{Rh}(-)$, la incidencia de enfermedad hemolítica por $\mathrm{Rh}$ ha caído significativamente Sin embargo, persiste la enfermedad hemolítica $\mathrm{ABO}$, en las cuales muchas veces se requiere exanguinotransfusión. Para evitar este procedimiento invasivo y que tiene morbilidad, se ha utilizado la inmunoglobulina G (IVIG). Objetivo: Evaluar el efecto de la inmunoglobulina $G$ en la hiperbilirrubinemia por enfermedad hemolítica. Material y Método: Estudio descriptivo retrospectivo. Se revisan las fichas clínicas de $31 \mathrm{RN}$ con incompatibilidad $\mathrm{ABO}$ o $\mathrm{Rh}$ en los cuales se utilizó gamaglobulina EV (Flebogamma) a dosis de 0,5-1 gr/kg, como tratamiento de la hiperbilirrubinemia por enfermedad hemolítica, en conjunto con la fototerapia entre el $1^{\circ}$ de Enero 2005 al 30 de Junio 2008. Se compararon los valores de bilirrubinemia pre y post IVIG, utilizándose la t-student. Resultados: El promedio y DS de peso de los RN fue de $3.448 \pm 535$ grs y la edad gestacional de 38,4 \pm 2 , sem (rango $32-40 \mathrm{sem}$ ). El promedio y DS de bilirrubinemia pre IVIG fue de $19,5 \pm 6,2 \mathrm{mg} / \mathrm{dl}$ descendiendo significativamente $(\mathrm{p}<0,05)$ a $16,9 \pm 4,8 \mathrm{mg} / \mathrm{dl}$ a las $15 \pm 6,2$ hrs promedio post IVIG (figura). El $22,5 \%$ ( $7 / 31$ ) eran incompatibilidad $\mathrm{Rh}$ y los restantes por incompatibilidad $\mathrm{ABO}(74,4 \%)$ No se observaron efectos colaterales durante la infusión de inmunoglobulina ni posteriormente. En 5 RN se efectúo exanguinotransfusión, en 4 por Rh (-) y el otro por incompatibilidad O-A. Conclusión: La IVIG es un tratamiento seguro, efectivo y no invasivo, en los RN con hiperbilirrubinemia por incompatibilidad ABC y Rh. No se observaron reacciones adversas a la IVIG.

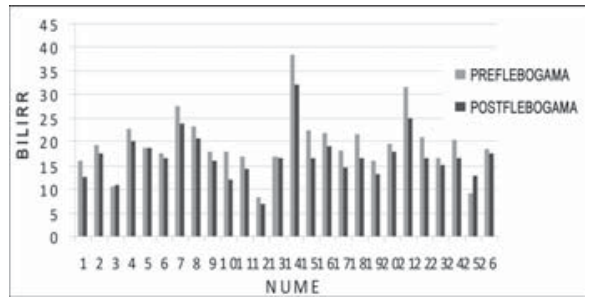

SEPSIS PRECOZ POR STREPTOCOCO GRUPO B

Figueroa A, Darritchon $M$, Toledo $P$, Zamorano $P$. Hospital Clínico Felix Bulnes Cerda.

El Streptococo grupo B sigue siendo la principal etiología de sepsis connatal. Se citan incidencias que varían entre un 0,4 a 0,8/1.000 recién nacidos (RN) vivos. La letalidad descrita es entre un 11 y un $50 \%$. Existen guías de screening prenatal y uso de antibióticos profilácticos en el parto, tendientes a disminuir su incidencia. Objetivo: Determinar la incidencia de sepsis connatal precoz en nuestro servicio. Describir la existencia de factores predictores de infección, y la morbimortalidad asociada. Material y Método: Se hizo un estudio retrospectivo de los pacientes con cultivo positivo para Streptococo grupo B (SGB) en sangre y/o LCR, nacidos entre Enero del 2003 y Julio del 2008 en nuestro hospital. Se revisó la ficha clínica del RN y de la madre. Resultados: Durante el período estudiado se obtuvieron 16 casos de RN con hemocultivo positivo, en uno de los cuales también se aisló el germen del LCR. Se logró obtener la ficha clínica de 14 RN y 13 madres La incidencia global fue de 0,7/1000 RN vivos La edad materna fue entre 16 y 36 años; salvo en uno, todos los embarazos fueron controlados. En una de las madres existía el antecedente de cultivo rectovaginal para SGB y una estuvo febril durante el parto. Ninguna tenía el antecedente de hijo previo con SGB. El promedio de tiempo de rotura de membranas fue de 7,3 horas. Ninguna de las madres había recibido antibióticos previo al parto. La edad gestacional fue de menos de 37 semanas en $4 \mathrm{RN}(28,5 \%)$; el resto de término. No hubo diferencias en la distribución por sexo, $79 \%$ nació por parto vaginal. El $78 \%$ debutó en las primeras 24 horas. El examen que se alteró primero fue el hemograma, siendo la leucopenia el hallazgo más frecuente, la proteína $\mathrm{C}$ reactiva (mayor a $20 \mathrm{mg} / \mathrm{L}$ ) se alteró en el $90 \%$ de los pacientes, pero en forma más tardía. En el $64 \%$ de los casos la forma de presentación clínica fue de Bronconeumonía, requiriendo 6 pacientes de ventilación mecánica. El 28,6\% debutó como Sepsis sin foco. En sólo un paciente se diagnosticó Meningitis. El promedio de estadía fue de 14 días y la mortalidad alcanzó al 14\%, siendo uno de los fallecidos un prematuro extremo. Conclusiones: La incidencia de infección connatal por SGB en nuestro servicio es más alta que la citada como objetivo en la literatura. En 10 de las madres no había factores de riesgo para infección connatal. Creemos que si se hubiese practicado el screening prenatal se habría pesquisado la colonización y se podría haber evitado la enfermedad del RN con la adecuada profilaxis AB materna. La letalidad es baja pero la morbilidad asociada es importante. El hemograma resultó ser el examen de laboratorio más útil como predictor de infección, por ser el más precoz y sensible. Discusión: Tomando en cuenta que la mayor parte de las pacientes carecían de factores de riesgo para sospechar infección, la clínica sigue siendo un elemento vital para un diagnóstico precoz. La toma de cultivo rectovaginal en el control prenatal debiera ser un examen obligatorio. 
MORTALIDAD Y FACTORES PREDICTORES DE MORTALIDAD EN SHOCK SÉPTICO NEONATAL

Ahumada E, Gajardo P, Saldes MI, Aravena M, Estay V, Casanova D. Hospital Carlos Van Buren, Universidad de Valparaíso.

Introducción: La sepsis es una patología prevalente en las unidades de cuidados intensivos neonatales y constituye una de las mayores causas de morbimortalidad durante el período neonatal. Las tasas de mortalidad fluctúan entre un 10 y $18 \%$; los factores de riesgo determinantes de su ocurrencia son e peso de nacimiento y la presencia de sepsis precoz. El desarrollo de shock en el contexto de una sepsis aumenta el riesgo de muerte en pacientes pediátricos y se asume que esta tendencia se mantiene en recién nacidos. Sin embargo, existen pocos estudios que avalen este supuesto. Los factores pronósticos de mortalidad cuando se produce shock séptico no han sido determinados. Objetivo: Determinar la mortalidad de los pacientes que sufren shock séptico durante e período neonatal en una unidad de cuidados intensivos neonatales e identificar los factores que afectan la sobrevida. Materiales y Método: Estudio de cohorte retrospectivo. Se analizaron los pacientes ingresados a la unidad de cuidados intensivos neonatales durante un período de dos años (2006-2007) que cumplieron con los siguientes criterios: hipotensión arterial y/o la necesidad de uso de volumen o drogas vasoactivas para mantener la hemodinamia durante la evolución de una sepsis probada o altamente probable. Fueron evaluados datos perinatales, de la estadía hospitalaria, del evento shock séptico y del egreso hospitalario. Se utilizó test de Mann Whitney para evaluar las variables asociadas a mortalidad y con la prueba exacta de Fisher o $\chi^{2}$ para determinar el riesgo relativo de cada uno de las variables. En variables continuas se utilizo el procedimiento de curvas ROC para determinar puntos de corte. Resultados: Cuarenta y seis pacientes cumplieron con los criterios de ingreso. La mortalidad de grupo de estudio fue de $14 / 46(30,4 \%)$. Los pacientes con shock séptico que fallecieron eran de menor edad gestacional $(p=0,002)$, menor peso de nacimiento $(p=0,01)$, con apgar al minuto y 5 minutos más bajo $(p=0,001$ y 0,06 respectivamente), con catéteres umbilicales arteriales o percutáneos de mayor permanencia ( $p=0,04$ y 0,02 respectivamente) y con $\mathrm{pH}$ arterial durante el shock más bajo $(p=0,005)$. Los factores pronósticos más significativos para mortalidad fueron edad gestacional $<28$ semanas $(R R=4,77 p=0,004$; IC $95 \%$ $1,5$ a 14,5$)$ y presencia de catéter umbilical arterial $(R R=4,2 p=0,04)$. De acuerdo a curva ROC, el punto de corte para predecir mortalidad para CRIB II (sensibilidad $90,9 \%$ y especificidad $94,7 \%$ ) es de 14,5 puntos, para CRIB I, de 8,5 (sensibilidad $83,3 \%$ y especificidad $77,3 \%$ ) y para permanencia de catéter umbilical arterial, 6,5 días (sensibilidad $63,6 \%$ y especificidad $68,4 \%$ ). Conclusiones: El shock séptico en la edad neonatal tiene una alta mortalidad afectando selectivamente al recién nacido prematuro extremo. Acciones de uso habitual en estos pacientes tales como empleo de catéteres de arteria umbilical y percutáneos aumentan no sólo el riesgo de una infección nosocomial sino que también de su consecuencia, el shock séptico. Es significativo además que a mayor número de días de uso de estos dispositivos aumenta el riesgo de muerte por shock séptico. Estudios previos han mostrado resultados dispares respecto a la relación entre el score CRIB y mortalidad; el presente estudio avala su uso pues tanto CRIB como CRIB II muestran una alta sensibilidad y especificidad para predecir mortalidad en los pacientes prematuros que cursan con shock séptico.

\section{IMPACTO DEL PRIMER PROGRAMA DE OXIGENACIÓN CON MEMBRANA EXTRACORPÓREA (ECMO) NEONATAL EN CHILE EN LA SOBREVIDA DE RECIÉN NACIDOS CON HERNIA DIAFRAGMÁTICA CONGÉNITA (HDC)}

Godoy L, Kattan J, González A, Faunes M, Zavala A, Estay A, Toso P, Urzúa S, Fabres J, Becker P, Cerda J, Becker J.

Unidad de Neonatología, Hospital Clínico, Facultad de Medicina, Pontificia Universidad Católica de Chile.

Introducción: Desde el año 1977 se utiliza la terapia ECMO en pacientes neonatales con HDC. Sin embargo, aún existe controversia respecto a si ECMO mejora la sobrevida de estos recién nacidos. El primer programa ECMO neonatal en Chile fue iniciado en nuestra universidad el año 2003. Objetivo: Determinar el impacto de un programa ECMO neonatal en la sobrevida de recién nacidos con HDC. Métodos: Se obtuvieron datos de los recién nacidos con HDC en dos períodos: ECMO no disponible (Julio 1996-Abril 2003) y ECMO disponible (Mayo 2003-Marzo 2007). Se realizó análisis estadístico univariado y multivariado (regresión logística) mediante el programa SPSS 15.0. Resultados: Durante el período de estudio 42 pacientes con HDC fueron tratados en nuestro centro. De éstos, 16 pertenecen al período pre-ECMO (ECMO no disponible) y los 26 restantes al período ECMO (ECMO disponible). Ambos grupos resultaron con características similares en cuanto a peso de nacimiento, edad gestacional, lateralidad de la hernia, ascenso hepático, necesidad de parche, índice de oxigenación, uso de ventilación de alta frecuencia y óxido nítrico inhalado. ECMO fue indicado en el $42 \%(11 / 26)$ de los pacientes con HDC del período ECMO. La sobrevida global al alta fue de un $25 \%$ para el período pre-ECMO y $80 \%$ para el período ECMO. El porcentaje de sobrevida a los 18 meses para ambos grupos fue de $25 \%$ y $76 \%$ respectivamente. En el análisis univariado se encontró un odds ratio (OR) de 12,6 (IC 95\% 2,8-56,1) para sobrevida al alta y un OR de 10 (IC 95\% $2,3-42,7)$ para sobrevida a los 18 meses cuando ECMO estaba disponible. En el análisis multivariado (regresión logística) el OR fue de 7,19 (IC 95\% 0,6-79,7) y 4,2 (IC 95\% 0,5-34,6) respectivamente. Conclusiones: El inicio de un programa ECMO se asoció a un aumento en la sobrevida a los 18 meses de recién nacidos con HDC. ECMO fue exitoso en la mayoría de los recién nacidos con HDC. Esta mejoría en la sobrevida podría deberse, además de la terapia ECMO por sí misma, a un mejor manejo global de este tipo de pacientes.
INDOMETACINA PRENATAL Y SU REPERCUSIÓN EN PREMATUROS EXTREMOS

González A, Tapia L, Juanet Jl, Aedo K. Hospital San José.

Introducción: La indometacina prenatal es usada como tocolítico en amenaza del parto prematuro, produciendo una constricción del ductus in utero con consecuencias después de nacer, tales como hipertensión pulmonar, enterocolitis necrotizante, perforación ileal, hemorragia intracraneana y disfunción renal. Cuando el parto prematuro ocurre a pesar de la tocolisis con indometacina el riesgo de

\begin{tabular}{|c|c|c|c|}
\hline & Casos (n=15) & Controles $(n=30)$ & "p" \\
\hline PN promedio (gr.) & 1161 & 1173 & ns \\
\hline EG (mediana) & 28 & 20 & ns \\
\hline Corticoides prenstalese( $(x)$ & 93,3 & 87,5 & ms \\
\hline Corioamnionitis (x) & 26,6 & 31,2 & ns \\
\hline APGAR $<5$ a los $5 !(\mathrm{S})$ & 6,6 & 0 & ins \\
\hline EMH (2 dosis) (":) & 60 & 63,3 & ns \\
\hline Sepsis clinica ("\%) & 33,3 & 33 & ns \\
\hline Ecocardio (s 24 hrs) (S) & 100 & 100 & ins \\
\hline & $\operatorname{As} 05(\sec 15)$ & CONTROLES (n=)0) & $" p$ \\
\hline 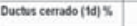 & 7 & 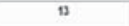 & $<0,05$ \\
\hline HTPP (*) & 52., & 6.6 & $<0.05$ \\
\hline$D A P>1.5 \mathrm{~mm}$ & 52,3 & 16.6 & $<0,05$ \\
\hline Hemorragla pultenonar & 26,5 & - & ne. \\
\hline 2 curas indometaxina & 40 & n & n.s. \\
\hline Cinugla DAP (X) & 01,3 & 22.3 & ns. \\
\hline NEC & 20 & 223 & ns. \\
\hline 0236 remanas & w & 46.6 & ne. \\
\hline HIV INTN & 6.6 & - & as. \\
\hline DAP PP & 0 & 223 & as. \\
\hline Muerte & 20 & w & n.s. \\
\hline
\end{tabular}
secuelas severas es significapuede ir seguido de su reapertura con una limitada capacidad de respuesta a la inda montetacina, lo que posiblemico mico precoz de la pared muscular interna (necrosis citolitica de la media). La constricción crónica y el cierre ductal in utero, puede llevar a cambios morfológicos en la vasculatura pulmonar, resultando en una hipertensión pulmonar. Objetivo: Describir el efecto de la indometacina prenatal en prometacina prenatal en prematuros menores 1.500 grs. Materiales y Método: Se compara un grupo de 15 prematuros expuestos a indometacina prenatal $48 \mathrm{hrs}$ antes del nacimiento con un grupo control de 30 recien nacidos entre Julio y Diciembre del 2007, con un peso de nacimiento menor o igual a 1.500 grs. Se determinan las características bioderíficas biodemograficas de ambos grupos y se compara la incimonar, ausencia de ductus en el primer día de vida, tamaño ductal, hemorragia pulmonar, necesidad de cirugía del ductus, hemorragia intraventricular severa y mortalidad. Se realiza analisis estadistico entre los resultados. Resultados: (ver tablas). Conclusiones: 1 ) Los grupos analizados son en todo comparables; 2) Encontramos una mayor frecuencia de ductus cerrado, mayor frecuencia de hipertensión pulmonar en el primer día de vida y DAP significativo posterior.en el grupo estudiado, lo que no significó un aumento en las complicaciones, ni en la necesidad de cirugía.

\section{HERNIA DIAFRAGMÁTICA CONGENITAL, CIRUGÍA PRECOZ VS TARDÍA}

González BA, Grob F, Tapia L.

Servicio de Neonatología Clínica Dávila.

Introducción: La hernia diafragmatica es una malformación congénita, cuya incidencia de $1 / 3000$ nacidos vivos, siendo el $80 \%$ izquierda. Presenta una alta mortalidad como consecuencia de la hipertensión pulmonar secundaria a la hipoplasia. Se ha tratado de establecer factores pronósticos para evaluar tratamientos médicos y quirúrgicos. Algunos estudios reportan hasta un $60 \%$ de mortalidad en los operados precozmente, sin embargo, estudios de regresion logistica multivariados no lo confirman, destacando la gravedad de los pacientes al ingreso y la necesidad de PMVA mayor de $13 \mathrm{~cm} \mathrm{H} \mathrm{O}$. Objetivo: Mostrar una serie clínica con cirugía precoz (< $48 \mathrm{hrs}$ ) comparados con los de cirugía diferida. con los de cirugía diferida. Materiales y Metodo: Se revisan 11 pacientes con hernia diafragmatica nacidos en el primer día de vida, de acuerdo al indice de oxigenación, la severidad de la presión de arteria pulmonar, presión inspiratoria máxima y media de vía aérea $\mathrm{PaCO}_{2}$ y ubicación de la hernia. Se analizan mortalidad, días de ventilación mecánica, días de oxígeno. Resultados: De los 11 recién nacidos con hernia diafragmatica 3 no se incluyen por muerte precoz.

\begin{tabular}{|c|c|c|}
\hline & Cingola Precos (n 4) & Cirugyh Diterida (n f) \\
\hline Dlagnostico prenutal (sem) & 2 & 2 \\
\hline Edad gestacilonal|(46 sems) & 1 & 0 \\
\hline Peso naciminanto & 3072 & 3483 \\
\hline Apgar < $0=5$ (11) & 1 & 1 \\
\hline Lado de la hernia (iza) & 3 & 3 \\
\hline Maltormaciones mayores & 0 & 0 \\
\hline Dlagnóstico prenstal & 2 & 2 \\
\hline Neumotórax presperatorio & 1 & 1 \\
\hline Higado en tórax & 2 & 3 \\
\hline HTPP severa (>50 mming) & 2 & 4 \\
\hline Requerimiento de PMVA $>13$ & 1 & 1 \\
\hline pas $>25$ & 2 & 2 \\
\hline $\mathrm{P}_{2} \mathrm{CO}>2>60 \mathrm{mmiHg}$ & 1 & 4 \\
\hline $10,>40$ & 0 & 1 \\
\hline
\end{tabular}

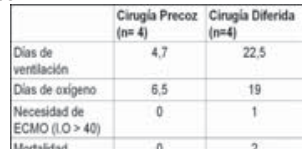
Conclusiones: 1) Los pacientes son comparables en sus caracteristicas biodemográficas, no as en sus signos de gravedad, ya que los aquellos sometidos a cirugía tardía presentaban signos de mayor gravedad; 2) A diferencia de yor gravedad, 2) A diferencia de nuestra serie existen pacientes nuestra serie existen pacientes nos resultados; 3) Creemos que que la mayor mortalidad, más días de ventilación mecánica y de oxígeno en los pacientes operados en forma diferida estaría determinado por su gravedad clínica inicial y no por el momento quirúrgico. 
ESTUDIO COMPARATIVO DE LA EFICACIA DEL TRATAMIENTO DE LA ENFERMEDAD POR MEMBRANA HIALINA, DESPUÉS DE LA APLICACIÓN DE UN PROTOCOLO DE MANEJO EN UNA UNIDAD DE NEONATOLOGÍA

Guzmán MP, Jodorkovsky RM

Neonatología, Hospital Barros Luco Trudeau.

Introducción: La enfermedad por membrana hialina $(\mathrm{EMH})$ constituye la principal causa de morbimortalidad neonatal y el riesgo de padecerla es inversamente proporcional a la edad gestacional del recién nacido. Su letalidad ha disminuido en forma significativa en los últimos años, gracias al gran desarrollo que han experimentado las unidades de cuidado intensivo neonatales, el perfeccionamiento en las terapias de ventilación y al uso de tratamiento con surfactante exógeno. Previo a la publicación de la Guía Clínica de Síndrome de Dificultad Respiratoria en el Recién Nacido, se diseñó un protocolo prospectivo de tratamiento para pacientes con $\mathrm{EMH}$ el cual comenzó a aplicarse en enero del 2005 en la Unidad de Neonatología del Hospital Barros Luco Trudeau. Objetivo: Comparar la eficacia de diferentes pautas terapéuticas para el tratamiento de la $\mathrm{EMH}$, en dos cohortes de recién nacidos prematuros, utilizando como indicadores de evaluación los requerimientos de apoyo ventilatorios y uso de surfactante. Pacientes y Método: Se definió grupo número $1(\mathrm{n}=35)$ a los pacientes con $\mathrm{EMH}$ nacidos entre los meses de Junio a Octubre del año 2004 y grupo número $2(n=34)$ a los pacientes nacidos entre Enero y Mayo del 2005, fecha posterior a la implementación del protocolo de manejo de EMH. Variables de Manejo: En relación al manejo y evolución de los pacientes se analizaron los datos de las siguientes variables: apoyo ventilatorio inicial, tratamiento con surfactante y número de dosis requerida, horas de ventilación asistida y oxígenoterapia posterior al uso de surfactante. Resultados: El estudio reveló mayor número de pacientes que utilizaron CPAP al inicio del tratamiento en el grupo 2, en comparación con el grupo $1(26 \%$ vs $9 \%, p=0,05)$. En cuanto al número de dosis de surfactante utilizadas, el grupo 2 tuvo más pacientes que utilizaron 3 dosis de surfactante $(17 \%$ vs $3 \%, p=0,02)$. Conclusión: La eficacia en el tratamiento de la EMH pre y post implementación del protocolo de manejo fue similar en ambos grupos, considerando el uso de surfactante y necesidad de ventilación mecánica. Destaca una mayor utilización de CPAP nasal en forma precoz, en los pacientes tratados posterior a la implementación del protocolo, lo que constituye una práctica clínica que beneficia el pronóstico del paciente.
USO DE VENTILACIÓN MECÁNICA Y DAÑO PULMONAR CRÓNICO EN RECIÉN NACIDOS PREMATUROS EXTREMOS

Negrete ME, Cares CM, Collins PC, Arellano SML, Medina FM. Hospital Base Los Ángeles, Unidad de Paciente Crítico Infantil.

Introducción: Desde el 2005 el S.S.B.B. cuenta con una UPC Infantil, donde se manejan los pacientes prematuros extremos, queriendo mejorar en ellos nuestros índices de morbimortalidad. Objetivo general: Analizar el perfil de todos los pacientes prematuros extremos entre los años 2005 al 2007. Material y Método: Se revisan las fichas clínicas de todos lo pacientes manejados en la UPCI del hospital los Ángeles nacido entre 01/2005 y 12/2007 según planilla ministerial de prematuros extremos. Resultados: Se analizaron 152 niños, encontrándose en un $13 \%$ fichas con datos inconclusos. Se clasifican según; peso, adecuación, edad gestacional y sexo en los tres años estudiados. Se analiza la sobrevida en los 3 años, diferenciados por grupo de peso, encontrándose en el grupo de $750-999 \mathrm{gr}$, un $66 \%$ a $77 \%$ de sobrevida, lo que es semejante a los resultados nacionales. Al analizar la sobrevida por E.G. también se mantiene estable en los tres años con una incidencia de un $86 \%$, semejante a la nacional y con una mortalidad del $100 \%$ en menores de 24 semanas, siendo el quiebre nacional de 25 semanas. De los 152 niños, 116 (76,3\%) desarrollaron Síndrome de Distress respiratorio (SDR), comparado con el $79 \%$ nacional. La enfermedad de membrana hialina presenta una incidencia de un $76 \%, 71 \%$ a nivel nacional Al analizar el uso de CAP nasal no hay diferencia en los tres años, pero si se logra una disminución significativa de uso de ventilación mecánica invasiva, disminuyendo de un $87,9 \%$ el año 2005 a un $57,8 \%$ el año 2007. La incidencia de DBP se mantiene estable en los tres años con un promedio de $29,6 \%$, siendo la incidencia global nacional de un $33 \%$. Al analizar los pacientes con oxígeno domiciliaro, se mantienen estable en el curso de los tres años con una incidencia de un $24,3 \%$ lo que está muy por sobre el rango nacional. Conclusión: Logramos una mejor sobrevida en los grupos más pequeños, naturalmente asociado a un aumento en las complicaciones. El desafío es disminuir las alteraciones tales como; DBP y dependencia de oxígeno. La ventilación mecánica invasiva ha bajado de un $87,9 \%$ el año 2005 a un 57,8\% el año 2007 , cifra insuficiente para lograr una disminución relevante en DBP, quedando una tarea pendiente en los otros factores de riesgo, asociados a daño pulmonar crónico.

\section{ANALISIS A DOS AÑOS DE SEGUIMIENTO DE UN GRUPO DE PREMATUROS EXTREMOS ESTUDIADOS EN LA DETECCIÓN PRECOZ DE HIPOACUSIA NEUROSENSORIAL}

López MT, Vallejos A, Mardones D, Correa F, Moncada M. Servicio de Neonatología. Complejo Asistencial Barros Luco.

Introducción: Los prematuros son una gran preocupación por su gran morbilidad y secuelas posteriores, es necesario evaluar periódicamente nuestros programas, detectar a tiempo sus complicaciones y comparar su adherencia a los policlínicos de seguimiento. Objetivo: Describir la evolución de dos años de un grupo de prematuros estudiados para detección de hipoacusia entre julio 2005 y junio 2006, evaluación de su estado auditivo, nutricional, DSM, estado neurológico, adherencia al policlínico de seguimiento. Material y Métodos Estudio prospectivo, descriptivo de los prematuros extremos, con edad gestacional (EG) dd 32 semanas y/o peso de nacimiento (PN) dd 1.500 grs. , nacidos en el período descrito y que se controlaron en el Policlínico de seguimiento de prematuros de nuestro Hospital. Se analizo la evolución de este grupo durante el período comprendido entre el 1 er de Julio del 2006 al 30 de junio del 2008. Se obtuvieron datos sobre EG, PN, resultado de Potenciales Evocados Auditivos Automatizados de Tronco cerebral (PEAAT), evaluación por ORL, estado nutricional, estado neurológico, asistencia a controles al policlínico de seguimiento. Resultados: Se reclutaron 118 prematuros en este período, de los que se excluyeron 25 pacientes: 5 fallecidos, 1 trasladado a Hospital de origen, 4 RN ingresados a Casa Nacional de Niño, y dados en adopción, 15 con inasistencia total o parcial a controles (1 ó 2 controles. El promedio de edad fue de 29,1 semanas de EG, con un peso promedio de $1.193,82$ grs. El $63,44 \%$ se catalogó como eutrófico, $26,88 \%$ desnutrido y $0,75 \%$ sobrepeso. Del total, un $38,7 \%$ presentó examen neurológico alterado, de los cuales el $52,7 \%$ sólo correspondía a RDSM leve. Con respecto al estudio auditivo, 14 niños tuvieron el primer PEAAT alterado, lo que corresponde al $13.5 \%$. El $100 \%$ se normalizó en la evaluación por ORL. Conclusión: De los niños estudiados que presentó el primer examen auditivo alterado, la totalidad se normalizó en controles posteriores, por lo que podemos concluir que definitivamente en este grupo se descarto la hipoacusia. El estado nutricional del grupo en seguimiento el mayor porcentaje estaba eutrófico a los 2 años $(63,4 \%)$. De los RN con el examen Neurológico alterado la mayoría correspondía a RDSM leve. La adhesión al policlínico de seguimiento de este grupo fue alta $(86,2 \%)$.

\section{RETINOPATía EN EL PREMATURO EXTREMO TRIENIO 2005-2007} SERVICIO DE SALUD BÍO-BÍO

Negrete ME, Cares CM, Collins PC, Arellano ML, Acuña AF, Caballero MJM, Medina FM, Soto CJC, Gatica JJL, Beltrán AP, Bonacich OL. Hospital Base Los Ángeles, Unidad de Paciente Crítico Infantil.

Introducción: EI SSBB desde el año 2005 cuenta con una UPCI (Unidad de paciente crítico infantil) donde se encuentra inserto el manejo de los prematuros extremos. Quisimos reconocer nuestra incidencia de ROP compararla con el rango nacional publicado en el quinquenio 2000-2004 y con ello proponernos nuevas estrategias de desarrollo. Objetivo: Analizar la incidencia de ROP y compararla con rangos nacionales. Material y Método: Se analizaron las fichas clínicas de todos los pacientes manejados en la UPCI del Hospital Base Los Ángeles, nacidos entre 01/2005 y 12/2007 que corresponden a 152 según planilla ministerial de prematuros extremos. Se registró datos en planilla excell confeccionada para el trabajo a nivel nacional y se analizan los datos según tablas utilizadas en el informe técnico. Resultados: De las 152 fichas analizadas, 13\% datos incompletos. Clasificamos los pacientes según: PN, adecuación, EG y sexo en los 3 años. Analizamos la sobrevida en estos 3 años sin encontrar diferencias significativas, con un promedio de $86 \%$ superior en un $10-15 \%$ al promedio nacional. La sobrevida de los $>500$ grs alcanza al $50 \%$ a nivel local comparado con $30 \%$ nacional. Al analizar la incidencia de ROP ésta se mantiene estable en el curso de los tres años con un promedio de $28,9 \%$, comparado con la cifra nacional de un $23 \%$, la cual tiene una variabilidad de $8-37 \%$. Sin embargo, a pesar de esta alta incidencia se presenta una diferencia de $8,3-15,2 \%$ que llegan a requerir Cirugía Lasser, existiendo por tanto un grupo importante de ROP que regresan espontáneamente. Es por esto, que nuestro porcentaje total de Cirugía Láser es de un 13\%, igual a la cifra nacional.En nuestra serie se presenta 1 paciente c/año con ROP severa que requiere Vitrectomía, y 1 de estos 3 queda con Ceguera bilateral que corresponde al $0,7 \%$ del total, siendo las cifras nacionales un $4-5 \%$ de sobrevivientes $<1.000 \mathrm{gr}$ con ceguera. Conclusiones: Debemos reconocer una alta incidencia de ROP que nos motiva a trabajar en todos los factores de riesgo asociados, y a pesar que se encuentra dentro de los promedios nacionales, debemos disminuirla.Se ha logrado regresión espontánea de ROP en un porcentaje significativo, sin embargo, se debe dar énfasis en la disminución de la incidencia total y mejorar las secuelas en este grupo vulnerable. 


\section{EVOLUCIÓN DE CIRUGía duCtAL EN UN PERíodo dE 10 AÑos}

Osses $\boldsymbol{P}$, Samame MM, Hernández RM, Méndez BC, Acuña R. Hospital San Juan de Dios.

Introducción: El Ductus arterioso es un vaso sanguíneo que conecta la aorta con el tronco de la arteria pulmonar en la circulación fetal, su persistencia ocasiona morbi-mortalidad especialmente en los recién nacidos de menor edad gestacional. Su incidencia se estima en $45-80 \%$ en prematuros $<1.000$ gramos con la introducción de inhibidores de la prostaglandina (indometacina) se logró disminuir la necesidad de cierre quirúrgico. Objetivos: Cuantificar el número de cirugía ductal en los últimos 10 años en nuestra unidad neonatológica, y compararlos luego de la introducción de indometacina a partir de enero 2005. Material y Método: Se realizó estudio descriptivo en el cual se revisó registro de cirugías en forma retrospectiva en el período comprendido desde enero 1999 a agosto 2008, obteniéndose una base de datos Excel (tipo de cirugía, lugar de realización y fallecimiento en relación a cirugía). Resultados: Se realizaron 649 cirugías en el período descrito, un $56(8,6 \%)$ correspondieron a cierre ductal. De éstas, un $66 \%$ fueron realizadas en los primeros 6 años de la revisión, previo al uso de indometacina en nuestra unidad. A partir del año 2005 esta cifra disminuye a un $34 \%$. No falleció ningún paciente en relación a la cirugía. Sólo $9(5,5 \%)$ pacientes han sido operados en $\mathrm{UCl}$ a partir del año 2005. Promedio anual de cirugía ductal 6 . Conclusiones: Está demostrado que la administración de indometacina a prematuros con ductus arterioso persistente ha disminuido la necesidad de cierre quirúrgico. En la última década, contamos con 1.109 prematuros $<1.500$ gramos, de un total de 46.038 recién nacidos vivos, requiriendo un $8.6 \%$ de los prematuros, cierre quirúrgico. A partir del año 2005 se introdujo el uso de indometacina para el cierre ductal disminuyendo el número de procedimientos a $34 \%$, pero desconocemos las dosis utilizadas ya que no existían, en esa fecha protocolos de uso profiláctico ni terapéutico, por tanto no podemos concluir e impacto real de su uso. A pesar del uso de indometacina, el promedio anual de cirugías se ha mantenido estable (6 por año) lo cual interpretamos como consecuencia de la mayor incidencia de prematurez a lo largo de los años. En el año 2005, además, por normativa de la unidad, se modificó el lugar de realización de las cirugías, debiéndose trasladar pabellón a UCI para los prematuros $<1.000$ gramos, pero será necesario un mayor número de procedimientos quirúrgicos para determinar su beneficio.

\section{PROFILAXIS CON PALIVIZUMAB EN PACIENTES CON DISPLASIA BRONCOPULMONAR Y OXÍGENODEPENDENCIA EN LA REGIÓN METROPOLITANA}

Palomino MMA, Prado F, EU Salinas P, EU Moya A, Klgo Mancilla P, Astudillo $P$ y grupo colaborativo DBP (Zamorano A, Wevar ME, Boza L, Daszenies C. Walker B, Rubilar L, Sepúlveda AM, Linares M, Durán F, Valdés I, Martínez $F$, Pittaluga E, Morgues $M$, Vernal P).

Minsal, Universidad de Chile.

El palivizumab es eficaz en prevenir infecciones graves por VRS en prematuros con displasia broncopulmonar (DBP). En abril 2008 MINSAL inició un piloto de profilaxis de VRS con palivizumab en 40 prematuros portadores de DBP y oxígenodependencia (DBP-OD). Objetivo: Disponer de información para realizar estudio de costo-efectividad y establecer el real valor de esta intervención en Chile. Método: Se comparan 2 cohortes de prematuros con DBP-OD: 37 casos con palivizumab del Servicio de Salud Metropolitano Suroriente y 38 controles sin profilaxis, de otros 6 centros de Santiago durante la temporada de VRS 2008 Ambos grupos recibieron educación, vigilancia telefónica de consultas y hospitalizaciones por infecciones respiratorias agudas (IRA) altas, bajas, con y sin VRS, cotejándolo con registro de médico tratante. Se consignaron además datos demográficos. Resultados: Ambos grupos resultaron comparables en sexo, edad gestacional, peso de nacimiento y edad actual. Hospitalizaciones por IRA ocurrieron en $8 \%$ de casos y $15 \%$ de controles; no hubo hospitalizaciones por VRS en casos, sí en 9 controles $(p=0,00)$, con reducción absoluta de riesgo de $23,6 \%$, (NNT 4,2). No hubo diferencias en consultas por SBO e IRA altas entre casos y controles. Conclusiones: La reducción del riesgo de hospitalizar mediante profilaxis con palivizumab fue mayor y el NNT para evitar una hospitalización por VRS fue menor que lo observado en estudios extranjeros. Estos datos son relevantes al analizar costo-efectividad y orientan a expandir esta intervención sanitaria en Chile.
OXIMETRÍA CONTINUA DE PULSO EN PREMATUROS < 32 SEMANAS ANTES DEL ALTA. ¿QUE ES LO NORMAL?

Morgues M, Vernal P, Palomino MA, Valdés I, Montes S.

Universidad de Chile. Hospital San José.

La experiencia en oximetría continua de pulso (OCP) en prematuros es escasa. Desde el 2005 contamos con OCP, observándose 3 patrones: tipo 1 normal u homogéneo, tipo 2 irregular u ondulante y tipo 3 anormal o aberrante. Objetivo: Evaluar aplicabilidad clínica de ellos en estabilidad respiratoria al alta y evolución en primer año de vida. Material y Método: Se evaluaron 222 OCP obtenidas en 18 meses a las 34 a 36 semanas de EG, informadas por consenso y concordancia por 2 neonatólogos, 2 neumólogos y 1 matrona, sin conocer historia clínica. Se evaluó registros y asociación a diagnósticos DBP, oxígenodependencia, edad postnatal, RGE y evolución al año (oxígenoterapia, hospitalizaciones). Se utilizó STATA. Resultados: Las 222 OCP de 118 prematuros mostraron registros distintos entre sí (Wilcoxon, $p<0,000$ ) en saturación promedio y $n \circ$ de eventos, (> 20 segundos, bradicardia y/o taquicardia). El tipo 3 se asoció a DBP (OR = 3 IC95\% = 1,6 a 5,6), el tipo 2 a RGE (OR = 2,5 IC95\% $=1,2$ a 5,1$)$. El tipo 1 mostró $\mathrm{OR}=0,5 \mathrm{IC} 95 \%=0,3$ a 0,9 para $\mathrm{DBP}, \mathrm{OR}=0,32$ $\mathrm{IC} 95 \% \mathrm{IC}=0,15$ a 0,65 para oxígeno dependencia y $\mathrm{OR}=0,29 \mathrm{IC} 95 \% 0,16$ a 0,51 para apneas. Se hospitalizaron por enfermedades respiratorias 39\%, 57\% eran DBP. Las hospitalizaciones en DBP en registro 3 aumentaron de 29 a $74 \%$ ( $p<$ $0,00)$ y días de hospitalización por IRA de 4 a $12(p<0,00)$. Conclusión: Los tipos de registros mostraron asociación con estabilidad respiratoria y tienen aplicabilidad clínica para decidir alta. Aquellos que presentaron OCP 3 , se hospitalizaron por IRA más frecuente y prolongadamente. OCP 3 debería suspender alta principalmente en DBP
SOBREVIDA EN PREMATUROS MENOR DE 1.500 GR EN UN UNIDAD DE NEONA-TOLOGÍA HOSPITAL SAN JUAN DE DIOS ENTRE LOS AÑOS 2000-2007

Parraguez C, Baunin L, Samame $M$, Henríquez $M$ Hospital San Juan de Dios.

Introducción: En los últimos años, con los progresos de cuidado intensivo neonatal, algunos programas e intervenciones, la sobrevida del recien nacido de muy bajo peso al nacer o menor de $1.500 \mathrm{~g}$ ha mejorado. La incidencia de estos es variable, pero oscila en alrededor del $1 \%$ de los nacidos vivos. Objetivos: Analizar la sobrevida neonatal en los prematuros menores de $1.500 \mathrm{gr}$ según grupos de peso. Identificar las causas de mortalidad y los cambios que ellas han registrado a través del tiempo. Material y Métodos: Se analizaron todos los registros de los pacientes menores de $1.500 \mathrm{gr}$ de una Unidad de Neonatología de la Región Metropolitana. Los pacientes se dividieron en 2 grupos principales según peso de nacimiento (entre $1.000-1.500$ gr y los menores de $1.000 \mathrm{gr}$ ) y además se analizaron las causas de muerte agrupándolas en 7 subdivisiones. Se analizaron los datos comparando subgrupos a traves de los años estudiados. Resultados: Durante el período analizado nacieron $36186 \mathrm{RNV}$, de los cuales $583(1,7 \%)$ fueron menor de $1.500 \mathrm{gr}$ y 243 menores de $1.000 \mathrm{gr}(0,7 \%)$. La sobrevida experimento un aumento importante en ambos grupos de peso, de 29 a $43 \%$ en los menores de 1.000 y de 55 a $95 \%$ en el grupo $1.000-1.500 \mathrm{gr}$, sin dejar de considerar que el $\mathrm{n}^{\circ}$ total de prematuros en ambos casos se redujo. Dentro de las causas de muerte, la prematurez extrema experimentó un incremento destacable en los últimos 4 años (5,5 a 37\%) en comparación con las otras etiologías. 


\section{EVOLUCIÓN DEL SÍNDROME ASPIRATIVO MECONIAL GRAVE} MANEJADO CON VENTILACIÓN OSCILATORIA DE ALTA FRECUENCIA

Bancalari MA, Peñaloza PG, Abásolo GA, Troncoso JC, Moraga PAM. Hospital Guillermo Grant Benavente, Universidad de Concepción, Chile.

Introducción: El Síndrome aspirativo meconial (SAM) es una patología responsable de importante morbimortalidad. Cerca del $30 \%$ de los recién nacidos (RN) afectados requerira soporte respiratorio avanzado como ventilación oscilatoria de alta frecuencia (VAFO), uso de surfactante y oxído nítrico inhalado (NOi). Objetivo: Determinar la evolución y complicaciones de los RN con insuficiencia respiratoria secundaria a SAM grave manejados con VAFO. Material y Métodos: Estudio descriptivo realizado entre el 1 de enero de 2000 y el 30 de junio de 2008, que incluyó todos los RN ingresados por SAM grave, manejados con VAFO (Sensormedics $3100 A$ ) por más de 12 horas. Se determinó factores demográficos, asistencia del parto, uso de surfactante, estrategia ventilatoria, uso de NOi, complicaciones y mortalidad. Resultados: En el período analizado se registraron 49 ingresos por SAM grave que requirieron ventilación mecánica (VM). De ellos 43 se manejaron con VAFO como modo ventilatorio primario o de rescate. Edad gestacional (promedio \pm DS) fue $40 \pm 1$ semana. Se realizó cesárea en $24 / 43$ casos (55,8\%). Surfactante se usó en 19/43 (de 1-3 dosis). En $24 / 43(55,8 \%)$ se utilizó VAFO desde el inicio. El IO promedio \pm DS, al inicio de la conexión fue de $21 \pm 6,7$. Los parámetros ventilatorios promedio iniciales en VAFO fueron: PMVA 16,1 $\pm 5,8 \mathrm{cmH}_{2} \mathrm{O}$; amplitud $32 \pm 8 \mathrm{cmH}_{2} \mathrm{O}$ y frecuencia respiratoria $10,7 \pm 1,8 \mathrm{~Hz}$. La permanencia promedio en VAFO fue de $4 \pm 2$ días, retirándose con 10 promedio de $9,2 \pm 8,9$. La extubación directa a Hood fue posible en $22 / 43(51,2 \%)$. La duración de la asistencia ventilatoria mecánica fue de 6.7 + 4.9 días. En $26 / 43(60.5 \%)$ se presentó hipertensión pulmonar persistente (HPP), utilizándose NOi en el $40,9 \%$ de ellos. Diez RN (23,3\%) se complicaron con neumotórax. Se registró sepsis en $8 / 43$. Fallecieron $4 \mathrm{RN}(9,3 \%)$, correspondiendo todos ellos a RN derivados complicados con HPP. Conclusión En nuestra experiencia la VAFO como estrategia ventilatoria es una herramienta segura y eficaz para el manejo de la insuficiencia respiratoria secundaria a síndrome aspirativo meconial severo.

\section{CARACTERIZACIÓN Y SEGUIMIENTO DE CATÉTERES CENTRALES} INSERTADOS PERIFÉRICAMENTE EN NEONATOLOGÍA

\section{León del PJ, Peñaloza PG.}

Unidad de Neonatología, Hospital Guillermo Grant Benavente, Departamento de Pediatría, Universidad de Concepción, Chile.

Introducción: El uso de Catéteres centrales insertados periféricamente (CCIP) es una práctica habitual en las unidades de neonatología, dada su seguridad y efectividad en el manejo del recién nacido $(\mathrm{RN})$ crítico. Este procedimiento no esta exento de riesgos por lo que su colocación, mantención y seguimiento debe ser realizado por personal capacitado. Objetivo: Evaluar el uso de CCIP en una unidad de neonatología. Material y Método: Estudio prospectivo que analizó 200 procedimientos consecutivos de CCIP, entre agosto de 2005 y octubre de 2007 , los cuales se siguieron hasta su retiro, evaluándose indicación, instalación, retiro y complicaciones. Resultados: Se analizó un total de 200 procedimientos. E peso (promedio \pm DS) de los RN fue $1.383 \pm 751 \mathrm{gr}$ y la edad gestacional $30 \pm 4$ semanas. La indicación más frecuente correspondió a aquellas derivadas de la prematuridad en el $72 \%$, seguido de diversas alteraciones congénitas del tubo digestivo de resolución quirúrgica en un $10 \%$. La edad de los RN al momento de la instalación fue 7,2 $\pm 14,2$ días. La duración del procedimiento fue $28 \pm 21$ minutos. En el $52 \%$ de los casos se logró en el primer intento. La vena periférica más utilizada fue la basílica (35\%), seguida por la cefálica (31\%). En el $42 \%$ de los procedimientos se realizó corte de la punta para adecuar la longitud del catéter, práctica que disminuyó significativamente en el tiempo, luego de indicación tendiente a evitarla ( $64 \%$ en los primeros 100 casos vs $19 \%$ en los siguientes 100$)$. El $48 \%$ reubicación de la punta por no hallarse en posición central. E tiempo de permanencia de los catéteres fue $14,9 \pm 9,8$ días, y la causa más frecuente de retiro fue la suspensión de la nutrición parenteral en el $59 \%$. La complicación más frecuente fue la extravasación en un $11 \%$, seguido por flebitis en un $9 \%$. En el $70 \%$ de los casos no se presentaron complicaciones. Se registró cultivo positivo de la punta en el $16 \%$, e infección asociada a catéter en el $6 \%$. Un RN falleció a causa del procedimiento por taponamiento cardíaco. Conclusión En nuestra experiencia los CCIP son una herramienta segura y adecuada para el manejo del RN crítico, especialmente en el prematuro. Su seguimiento ha permitido evitar complicaciones.
FACTORES DE RIESGO ASOCIADO EN HIPOACUSIA NEUROSENSORIAL EN PREMATUROS EXTREMOS

Sanhueza L, Mardones D, López MT, Correa F, Moncada M, Arriagada MI. Servicio de Neonatología. Hospital Barros Luco.

Introducción: Las alteraciones auditivas durante primer año provocan déficit lingüístico con gran minusvalía familiar y social. Alrededor de 1-2 de cada mil nacidos vivos presentaría hipoacusia congénita bilateral severa, esta cifra es 10 veces mayor en las poblaciones con factores de riesgo, siendo los prematuros menores de 32 semanas y/ o menores de 1.500 grs un grupo de mayor vulnerabilidad, por exposición a factores ototóxicos y por su propia condición. Los potenciales evocados auditivos automatizados de tronco cerebral (PEAAT) es un exámen de alto rendimiento, que permite una detección precoz y sin riesgo. Objetivo: Determinar prevalencia y factores de riesgo para hipocusia neurosensorial en prematuro extremo bajo peso. Material y Métodos: Estudio prospectivo en el que realiza PEAAT a las 34 semanas de EGC, a todos los prematuros menor de 32 semanas de EG y/o menor de 1.500 grs, que se encuentran sin ventilación mecánica (VM) al momento del exámen, el que es efectuado por matrona entrenada, con umbral de detección de $35 \mathrm{Db}$. El resultado se informa como "pasa" o "refiere". Repitiéndose entre la $2^{\circ}$ y $4^{\circ}$ semana un $2^{\circ}$ PEAAT, que si persiste alterado (refiere) se deriva a ORL, donde se realiza PEAT (Potenciales evocados auditivos prolongados). Para el análisis de datos se dividió a los prematuros en 2 grupos: PEAAT alterado y PEAAT normales. Se estudian los factores de riesgo asociados en ambos grupos: VM, asfixia, fármacos ototóxicos, hiperbilirrubinemia. Se incluyen en los datos además antropometría. Se efectuó un Análisis de Varianza para muestras con desigual número de casos. Resultados: Ingresaron 206 prematuros entre el 1 de Julio del 2006 hasta el 31 de Diciembre del 2007. Se excluyeron 73 pacientes ya que 57 fallecieron y 16 se trasladaron a sus hospitales de origen, de los 133 enrolados, 123 pasaron el primer exámen y 10 se reevaluaron con segundo PEAAT, de los cuales 9 fueron referidos para realizar PEAT en el Servicio de ORL, de ellos, uno está pendiente y los 9 restantes se informaron con resultado normal. El grupo de PEAAT normal fue comparable con el grupo de PEAAT alterado en peso y EG. Las diferencias en la presencia de los factores de riesgo estudiados entre ambos grupos fue estadísticamente significativo $(\mathrm{p}<0,05)$ en cuanto a asfixia, días de VM, presencia de HIV grado 3-4, LMPV, uso de drogas ototóxicas y valor máx de bilirrubina. Conclusión: Un 8,13\% del grupo estudiado tuvo un 1을 PEAT alterado y aunque no se detectó hipoacusia en este grupo, si hubo diferencia estadísticamente significativa en la prevalencia de los factores de riesgo analizados, concordante con la literatura. Ampliaremos este estudio en series posteriores y la importancia de cada variable.

DISMINUCIÓN EXITOSA Y RÁPIDA DE LA TASA DE CESÁREA, ¿BUENA NOTICIA PARA EL RECIÉN NACIDO?

Toledo SP, Alonso MC, Inta. Aravena MD, Vivanco GG. Hospital Clínico Félix Bulnes.

Introducción: En nuestro hospital, la tasa de cesárea se mantenía alrededor del $40 \%$. En Marzo del 2007 se propuso, disminuir este porcentaje a un $30 \%$; lográndose una baja desde un 40,7\% el 2006 a un 31,3\% el 2007. Concomitante, hubo una impresión subjetiva de un aumento de la asfixia, por lo que se decidió investigar si era real este aumento. Objetivos: Determinar y comparar la incidencia de cesáreas y asfixia en 2006 y 2007. Analizar las características maternas y perinatales de los recién nacidos ( $R N$ ) que cursaron con asfixia en el período de estudio, evaluando la morbimortalidad y secuelas de estos pacientes. Material y Método: Se realizó estudio de cohorte histórica de los $\mathrm{RN}>37$ semanas EG, hospitalizados por asfixia perinatal, nacidos en nuestro hospital, entre el 1 de marzo 2006 y el 28 de febrero 2007 (Cohorte 2006) y entre el 1 de marzo 2007 y el 28 de febrero 2008 (Cohorte 2007). Se utilizaron definiciones de las Guías MINSAL 2005. La información fue obtenida de la ficha clínica materna y neonatal. Resultados: El total de partos fue de 4.132 en el 2006 y de 4.012 en el 2007. En la cohorte 2006 tuvimos 8 pacientes con asfixia y 38 en la cohorte 2007 , lo que da una tasa de asfixia de 1.9 y $9.4 / 1000 \mathrm{RN}$ vivos respectivamente $(p<0,005)$. La EHI estuvo presente en $7 \mathrm{RN}$ en 2006 (tasa de 1,6/1.000) y $32 \mathrm{RN}$ en 2007 (tasa de 8/1000). El compromiso respiratorio se presentó en 2 y 6 RN con tasas de 0,48 y 1,5/1.000 RN vivos en el 2006 y 2007 respectivamente. La incidencia de infección connatal fue de $12,5 \%$ en 2006 y $13 \%$ en 2007 . No hubo pacientes fallecidos en las cohortes estudiadas. En el 2006 ningún neonato presentó secuelas en cambio en el $20075 \mathrm{RN}(13 \%)$, las presentaron. El perfil materno en ambos grupos fue similar: ser primigesta con una media de 20 años de edad. Al comparar la vía de parto el $62,5 \%$ y el $71 \%$ nacieron por parto vaginal (PV) y por cesárea el $37 \%$ y el $29 \%(p<0,046)$ de los RN del 2006 y 2007 respectivamente. La duración del trabajo de parto (TP) fue similar en ambos años, pero al analizar a las cesarizadas la media fue de $13 \mathrm{hrs}$ en el 2006 y $19 \mathrm{hrs} 2007$. En los RN con asfixia las madres presentaron patología obstétrica (PO) en el $25 \%$ del 2006 y en el $53 \%$ del 2007 . Se decidió inducción en $25 \%$ de las madres el 2006 y $31 \%$ el 2007 , y de ellas el $50 \%$ presentaba PO el 2006 y $90 \%$ el 2007. Conclusiones: Hubo aumento de la tasa de asfixia perinatal entre los períodos de estudio. Sólo existió diferencia estadísticamente significativa en el porcentaje de PV entre ambos grupos. El porcentaje de cesárea en el grupo de asfixiados del 2007 fue aún menor que en el grupo total de partos. Discusión: Actualmente existe una fuerte evidencia sobre las ventajas del PV sobre la cesárea, por lo que creemos que se justifica favorecer esta vía; sin embargo, experiencias como la nuestra alertan en la necesidad de descartar variables asociadas a estos resultados y a buscar estrategias más cautelosas al momento de disminuir la cesárea. 


\section{USO DE FORMULAS ESPECIALES PARA PREMATUROS DESPUES DEL ALTA: PARTE}

Vernal $P$, Pittaluga E, Llanos A, Escobar M, Henríquez MT, Veja S, Díaz A, Moncada P, Morgues M, Standen J, Rodríguez L, Ramírez S, Jara A. Hospital San José. Hospital Sótero del Río. Hospital Gustavo Fricke. Hospital San Juan de Dios. Hospital Félix Bulnes. Hospital Rancagua. Hospital San Felipe.

Desde noviembre de 2003 se inicia en todos los servicios de salud del país, la entrega de leches especiales para prematuros menores de $1.500 \mathrm{~g}$ y/o menores de 32 semanas de gestación egresados de los hospitales púbil del Programa Nacional de Alimentación Complementaria (PNAC) focalizado en los prematuros, Objetivo: Evaluar el uso de estas fórmulas especiales (FE) en el crecimiento, composición corporal y mineralización ósea en prematuros alimentados con fórmula especial: Grupo Intervenido (G Int) comparado con prematuros egresados antes de la implementación del programa: Grupo pre-intervención (G prelnt) Desde el año 2000, se implementa en todos los servicios públicos del país, un programa de seguimiento para prematuros, coordinado con la atención primaria con controles establecidos y con protocolo definido. Material y Método: Multicéntrico, incluye 7 centros que participan del seguimiento mencionado. G Int: $n=560$ egresaron entre 1 agosto 2004 al 31 julio 2005 . Se alimentaron con formula para prematuros (FP) como complemento a la lactancia materna desde el alta hospitalaria hasta los primeros 6 meses a la lactancorregida (EC) y formula de continuación (FC) hasta los $12 \mathrm{~m} \mathrm{EC}$. En $<1.000$ y/o con displasia broncopulmonar (DBP), la FP se mantuvo hasta los $12 \mathrm{~m}$ EC. Análisis prospectivo. G Pre Int: $n=529$ egresados entre 1 Agosto 2002 al 31 julio Análisis prospectivo. G Pre Int: $n=529$ egresados entre 1 Agosto 2002 al 31 julio 2003. Se alimentaron con recibieron como complemento a la lactancia materna formula estandar para nino de término o leche Purita Fortificada entregada en e $24 \mathrm{~m}$ EC. Método Estadístico se hizo SPSS con análisis bivariado y covarianza 24 m EC. Método Estadístico se hizo SPSS con análisis bivariado y covarianza ANCOVA con significación de $\mathrm{P} 0,05$ poder $90 \%$. Análisis antropométrico: puntaje $Z$ curvas Pittaluga Juez hasta las 40 semanas y OMS en adelante y Análisis de Modelamiento Estadístico. Resultados: Se logró seguimiento a 2 años en e $91,2 \%$. Se obtuvo información del $98,5 \%$ de los niños. No hay diferencias entre los grupos estudiados: peso al nacer (PN) $1.245 \mathrm{~g} \pm 310$ vs $1.226 \mathrm{~g} \pm 291$ ), edad gestacional (EG) $29,9 \pm 2,4$ vs 29,6 $\pm 2,4$ semanas, sexo masculino $52 \%$ vs $54,8 \%$ y pequeno para edad gestacional (PEG) $44,8 \%$ vs $39,5 \%$ en el Gpre-Int $v s$ $G$ Int respectivamente. Ambos grupos recibieron un porcentaje similar de Lactancia Materna al alta. $(14,6$ vs 14,4 en Gprelnt $y$ Glnt respectivamente y mantuvieron similar \% hasta el Ter mes EC para luego disminuir. El G preint contrariamente a lo esperado, recibió 40 semanas y el en general, ho se observan diferencias signilicativas en Z peso ni $Z$ talla en los primeros 2 anos de EC; las curvas de crecimiento son casi paralelas. En composición corporal, la masa magra y masa grasa son similares. Sin embargo, se encuentran diferencias significativas en la distribución de la grasa corporal, en que observamos menos grasa en tronco en el $G$ Int $14,2 \pm 5 \%$ vs $16,4 \pm 4,9 \%$ a anoy $14,1 \pm 5,7 \%$ vs $17,2 \pm 4,7 \% 2$ anos. La densidad de mineral y el contenido mineral del hueso es similar en ambos grupos. El análisis de modelamiento estadistico para observar el efecto de la alimentación sobre las variable antropométricas en un mismo sujeto en relación al tiempo, mostró que las fórmulas especiales influencian en forma estadísticamente significativa talla y cc no así el peso, sin embargo, esto es clínicamente marginal. Conclusión: El uso de

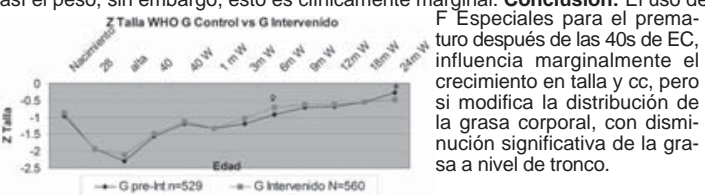

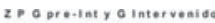

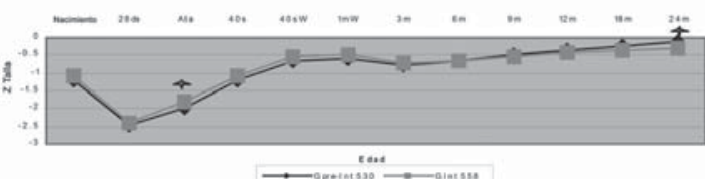

\section{USO DE FÓRMULAS ESPECIALES PARA PREMATUROS DESPUÉS
DEL ALTA: PARTE II}

Vernal $\boldsymbol{P}$, Pittaluga E, Llanos A, Escobar M, Henríquez MT, Veja S, Díaz $A$, Moncada $P$, Morgues $M$, Standen J, Rodríguez L, Ramírez S, Jara A. Hospital San José. Hospital Sótero del Río. Hospital Gustavo Fricke. Hospital San Juan de Dios. Hospital Félix Bulnes. Hospital Rancagua. Hospital San Felipe.

En noviembre de 2003 se inicia en el país, la entrega de leches especiales para prematuros menores de $1.500 \mathrm{~g}$ y/o menores de 32 semanas de gestación, egresados de los hospitales públicos. Objetivo: Evaluar el uso de estas formulas especiales (FE) en el crecimiento, composición corporal y mineralización ósea según adecuación: PEG y AEG, alimentados con formula especial: Grupo Intervenido ( $G$ Int) comparado con un grupo de niños procedentes de la misma población egresados antes de la implementación del programa: Grupo preintervención (G prelnt). Material y Método: AEG Int: $n=339$ egresaron entre 1 agosto 2004 al 31 julio 2005. Recibieron como complemento a la lactancia materna, alimentación con fórmula para prematuros (FP) desde el alta hospitalaria hasta los primeros 6 meses de edad corregida (EC) y fórmula de continuación
(FC) hasta los $12 \mathrm{~m} \mathrm{EC}$. En $<1.000 \mathrm{~g}$ y/o con displasia broncopulmonar (DBP), O2 28 días o más, la FP se mantuvo hasta los $12 \mathrm{~m}$ EC. Análisis prospectivo. AEG Pre Int: $n=292$ egresados entre 1 Agosto 2002 al 31 julio 2003 recibieron como complemento a la lactancia materna, formula estándar para niño de término o leche Purita Fortificada entregada en el PNAC previo a la intervención. Análisis retrospectivo. Se hizo DXA a las $12 \mathrm{~m}$ y $24 \mathrm{~m}$ EC. PEGlnt $n=221$;
PEG prelnt $n=237$. Alimentación igual que AEG. Método Estadístico se hizo SPSS con análisis bivariado y covarianza ANCOVA con significación de P 0,05 poder $90 \%$, puntaje $Z$ de las curvas Pittaluga Juez hasta las 40 semanas y OMS en adelante. Resultados: Se logró seguimiento a 2 años en el $91,2 \%$. No hay diferencias entre los AEG de ambos grupos en: peso al nacer (PN) $1.314 \mathrm{~g} \pm 302$ vs $1.276 \mathrm{~g} \pm 299$ ), edad gestacional (EG) $28,9 \pm 1,9$ vs $28,8 \pm 2$ semanas, sexo masculino $51 \%$ vs $57,6 \%$ en Gpre-Int vs G Int respectivamente. Tampoco hay diferencia en los PEG de ambos grupos: PN $1.145 \mathrm{~g} \pm 256$ vs $1.144 \mathrm{~g} \pm 251$, EG
$31 \pm 2,4$ vs $30,9 \pm 2,4$ semanas, Sexo masc 51,9 vs 48,9 en Gpre-Int vs G Int $31 \pm 2,4$ vs $30,9 \pm 2,4$ semanas, Sexo masc 51,9 vs 48,9 en Gpre-Int vs G Int
respectivamente. Ambos grupos recibieron un porcentaje similar de Lactancia respectivamente. Ambos grupos recibieron un porcentaje similar de Lactancia vieron similar \% hasta el 1 er mes EC para luego disminuir. El G prelnt contraviamente a lo esperado, recibió FP en el $80 \%$, el $71 \%$ y casi en el $50 \%$ al alta, las 40 semanas y el 1 er mes de EC respectivamente. Análisis antropométrico en AEG: El ZPeso es similar al comienzo en ambos grupos, alcanzando el promeAEG: El ZPeso es similar al comienzo en ambos grupos, alcanzando el promesignificativamente más en peso que los del Glnt, ubicándose en promedio por sobre la media de la referencia. El ZTalla tiene un crecimiento similar y más sobre la media de la referencia. El ZTalla tiene un crecimiento similar y mas arrastrado en ambos grupos, siendo mayor significativamente en 2 puntos ( $1 \mathrm{~m}$ talla en el Gpre-int desde el 3er mes EC. En PEG no hay diferencia en el $Z$ peso talla en el Gpre-int desde el 3er mes EC. En PEG no hay diferencia en el Z peso ni en el Z talla entre ambos grupos y el Z P/T es armónico. En relación a $\%$ tejido graso total. Hay tendencia a menor grasa en tronco en el Glnt al año: 15 $\%$ tejido graso total. Hay tendencia a menor grasa en tronco en el Glnt al año: 15 $\pm 5,4 \%$ vs $16,9 \pm 4,8$ y a los 2 años: $14,2 \pm 5,6$ vs $16,6 \pm 4,5$ que no alcanza
significación. En PEG no hay diferencia en composición corporal, pero si en significación. En PEG no hay diferencia en composición corporal, pero si en menor grasa significativa en tronco al año: $14,1 \pm 4,1$ vs $16,8 \pm 5,1$ y a los 2 años:
$13,9 \pm 5$ vs $18,2 \pm 5$. No hay diferencias en contenido ni densidad mineral del hueso por adecuación ni por alimentación. Conclusión: El uso de $F$ Especiales para el prematuro AEG después de las 40 s de EC, resulta en un crecimiento

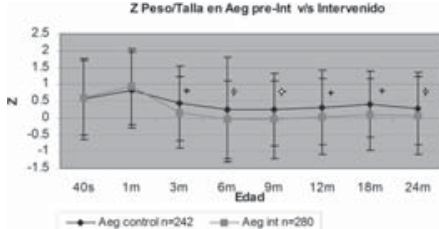
la talla y una tendencia a distribución de tendencia a discon menor porcentaje de grasa en tronco (no significativa) En PEG, no afecta el crecimiento pero favorece distribución de tejido adiposo con significativamente menor conenido de grasa a nivel de tron-

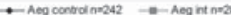
co.

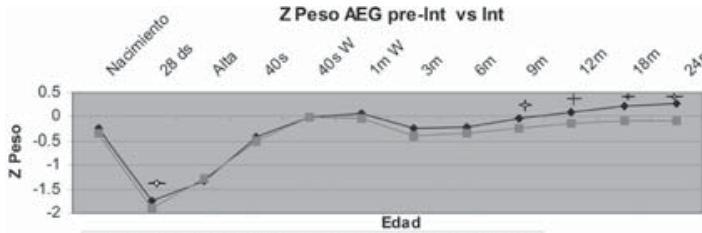

- $-\mathrm{AEG}$ Cont $\mathrm{N}=292-\mathrm{AEG}$ Intervenido $\mathrm{N}=339$

\section{SíNDROME DE RAMSAY HUNT. REVISIÓN DEL TEMA A PROPÓSITO DE UN CASO}

Zamora $\mathrm{CJ}^{1}$, Int. Gajardo $\mathrm{AJ}^{2}$, Int. Martínez $\mathrm{AF}^{2}$, Borlone $\mathbf{R S}^{3}$

${ }^{1}$ Neurólogo infantil, Servicio de Pediatría, Hospital Clínico San Pablo. ${ }^{2}$ Internas de Pediatría, Hospital Clínico San Pablo. ${ }^{3}$ Pediatra, Docente Internado de Pediatría, Universidad Católica del Norte. Servicio de Pediatría, Hospital Clínico San Pablo, Coquimbo, Facultad de Medicina, Universidad Católica del Norte.

El síndrome de Ramsay Hunt consiste en una parálisis facial periférica acompañada de afección cutánea eritemato-vesicular del oído externo producida por la reactivación del virus Herpes Zoster $(\mathrm{HZ})$, latente en el ganglio Geniculado. En algunos casos puede asociarse hipoacusia, mareos o vértigo, acúfenos, otorrea, purito, fiebre y otodinea. La afectación facial en el HZ ótico es inicialmente más severa y con peor pronóstico de recuperación que la parálisis de Bell. Caso clínico: Varón de 12 años, con antecedente de varicela no complicada a los 3 anos. Consulta en el Servicio de Urgencia del Hospital Clínico San Pablo por insidioso, intensa (EVA 10), asociada a otorrea purulenta, sin compromiso del insidioso, intensa (EVA 10), asociada a otorrea purulenta, sin compromiso del estado general ni fiebre. Se diagnostica otitis externa y se indica tratamiento ción, otalgia persiste y se agregan lesiones vesiculares en el pabellón auricular ción, otalgia persiste y se agregan lesiones vesiculares en el pabellón auricular izquierdo y parálisis facial de tipo periférico ipsilateral. Se decide hospitalizar con la sospecha de infección herpética asociada a sobreinfección bacteriana. Al examen destaca tímpano sano, lesiones vesiculosas de contenido purulento que comprometen región anterior de pabellón auricular y conducto auditivo externo, sin compromiso de la cavidad oral. Examen neurológico confirma una parálisis facial periférica, con manifestaciones clínicas compatibles con afección a nivel de ganglio Geniculado. Se indica Aciclovir $800 \mathrm{mg} c / 4 \mathrm{hrs}$, VO, por 5 veces al día por 14 días asociado a tratamiento antibiótico. Estudios realizados: TAC de cerebro con y sin contraste normal, audiometría normal, evaluación por otorrino descarta compromiso timpánico y del VIII par y corrobora infección por $\mathrm{HZ}$, confirmado posteriormente con lgM-lgG (+) para VVZ. Paciente es controlado ambulatoriamente a los 20 días de iniciado el cuadro, evolucionando satisfactoriamente con desaparición de las lesiones cutáneas y resolución completa del riamente con desaparicion de las lesiones cutáneas y resolución completa del compromiso facial. Discusion: Este es un cuadro de baja frecuencia, corresponde a la segunda causa de parálisis facial no traumática. Es importante pensar nes cutáneas y afección vestibular, puesto que el diagnóstico y tratamiento precoces aminoran las secuelas de esta enfermedad. 
EVALUACIÓN PSICOMÉTRICA DE NIÑOS CON FENILQUETONURIA DE DIAGNÓSTICO NEONATAL EN SEGUIMIENTO EN CHILE

de la Parra A, Cabello JF, Castro G, Fernández E, Valiente A, Colombo M, Raimann E, Cornejo V.

Laboratorio de Genética y Enfermedades Metabólicas, INTA, Universidad de Labor

Introducción: Desde 1992 se realiza diagnóstico neonatal de Fenilquetonuria (PKU) e Hiperfenilalaninemia (HFA) en Chile, detectándose cada año entre 14 a 20 nuevos casos. Sin tratamiento, esta enfermedad produce retardo mental seve20 nuevos casos. Sin tratamiento, esta enfermedad produce retardo mental severo. El programa de seguimiento del INTA, incluye evaluaciones medicas,
nutricionales, bioquímicas, neurológicas y psicológicas según indica el Progranutricionales, bioquímicas, neurologicas y psicologicas segun indica el Progra-
ma Ministerial. En la experiencia internacional se destaca la importancia del ma Ministerial. En la experiencia internacional se destaca la importancia del desarrollo psicomotor e intelectual de los pacientes PKU diagnosticados po pesquisa neonatal. Metodología: Se comparan los resultados de las evaluaciones realizadas a 12 y 36 meses de edad, 4 y 7 años de edad de niños con PKU (n: 116) e HFA (n: 86). Se utilizó prueba de Desarrollo Infantil Bayley que entrega coeficientes de desarrollo mental (MDI) y motor (PDI) (VN 85-115) Rendimiento intelectual en preescolares con WPPSI y escolares con WISC-R entregan $\mathrm{Cl}$ verbal, $\mathrm{Cl}$ manual y total (VN 90-110) y resultado de subpruebas y factores (VN 8-12). Resultados: Todos los valores promedio en ambos grupos y para todas las pruebas aplicadas se encuentran dentro de los rangos normales. y para todas las pruebas aplicadas se encuentran dentro de los rangos normales. Se observaron diferencias significativas entre PKU e HFA. A los 12 meses MD $92,7 \pm 11,1$ (PKU) vs $98,3 \pm 8,4$ (HFA); a los 36 meses MDI: 85,7 $\pm 13,4$ (PKU) vs $93,1 \pm 14$ (HFA) y PDI: $87,1 \pm 14,5$ (PKU) vs $94,4 \pm 21,1$ (HFA); a los 4 años CIT 95,8 14,4 (PKU) vs 105,4 $\pm 13,1$ (HFA); a los 7 años CIM: $88,6 \pm 13,9$ (PKU) con PKU se desarrollan dentro de rangos normales pero con valores más bajo que las HFA en las diferentes escalas. Estas diferencias podrían atribuirse a nivel promedio de fenilalanina en sangre durante el seguimiento. Conclusión: $E$ diagnóstico e inicio de tratamiento precoz de la PKU e HFA logran que estos pacientes tengan un desarrollo psicomotor dentro de rangos de normalidad, en un fuerte contraste con la evolución natural (sin tratamiento) de esta enfermedad.

\section{TRAUMATISMO ENCÉFALO CRANEANO LEVE EN PACIENTES PEDIÁTRICOS: SERIE CLÍNICA}

Herrada L, Zambrano P, Lozano J, Lapadula M, Yáñez L, Fernández C. Clínica Santa María. Unidad de Paciente Crítico Pediátrico.

Introducción: El traumatismo encéfalo craneano (TEC) es muy común en la población pediátrica. Según el compromiso neurológico y utilizando la Escala de Coma de Glasgow, se clasifica en leve = ECG 13-15, moderado = ECG 9-12 y severo $=$ ECG 8 o menos. Objetivo: Caracterizar la población de niños que se hospitalizaron con diagnóstico de TEC leve en Unidad de Intermedios de la Clínica Santa María. Pacientes y Método: Análisis retrospectivo de las fichas médicas de los pacientes egresados con diagnóstico de TEC leve desde Enero de 2002 a Diciembre de 2007. Se consideró TEC leve aquellos pacientes con Glasgow entre 13 y 15 con antecedente de un trauma de cráneo secundario a cual el paciente presentó alguna de las siguientes condiciones: pérdida o disminución del estado de conciencia, amnesia, fractura del cráneo, alteración del examen neurológico o neuropsicológica o lesión intracraneana. Resultados: El promedio de días de hospitalización fue de 1,98 días ( $r$ : 1-14 días). El mecanismo más frecuente de la lesión fueron las caídas de altura. En el hogar es donde ocurrieron la mayor cantidad de accidentes con 90 casos $(36,44 \%)$. La sintomatología más frecuente al ingreso al servicio de urgencia fueron vómitos y cefalea, se registro perdida de conciencia en un $19 \%$ de los pacientes. A todos los pacientes se les realizo TAC cerebral de ingreso un $70 \%$ de estos fue normal, sin embargo, en un $30 \%$ de estos existió una alteración subyacente. Conclusiones: Nuestros resultados confirman que los pacientes con TEC leve TAC normal tienen evolución favorable; en ellos no se justificaría TAC cerebral de control y podrían ser dados de alta luego de 24 horas de evolución o incluso ser observados en su domicilio. Aunque la indicación de TAC cerebral en los TEC leve continúa siendo motivo de controversia.
PESQUISA DE SÍNDROMES NEUROGENÉTICOS EN PACIENTES CON RETARDO MENTAL SIN ETIOLOGÍA CONOCIDA

Garrido EV, Lagunas MJ, Figueroa RC, Reyes BP.

Hospital Regional de Antofagasta.

Introducción: La prevalencia de retardo mental (RM) es de 3\%. Entre sus etiologías se encuentran distintos síndromes neurogenéticos con características fenotípicas clásicas y estudio molecular confirmatorio disponible. Dentro de estos síndromes se encuentran el Síndrome de X frágil (SXF), Síndrome de Angelman (SA) y Síndrome de Rett (SR). EI SXF es la causa más común de retraso mental familiar, su prevalencia se estima entre 1:3.000 a 1:8.000 varones casi exclusivamente $(5,9 \%$ varones versus $0,3 \%$ mujeres con $\mathrm{RM})$, se caracteriza por la asociación de RM y dismorfias faciales (cara alargada, orejas grandes), hiperlaxitud y macroorquidismo. Su herencia es ligada al cromosoma $X$ con estudio molecular positivo para la repetición del triplete CGG mayor a 200. EI SA, de prevalencia de hasta 1 en 10.000 , se caracteriza por la presencia de $\mathrm{RM}$, trastornos del lenguaje y del movimiento y/o equilibrio y un comportamiento único (en el $100 \%$ de los pacientes). Se debe a falta de expresión de la región q11.2-q13 del cromosoma 15 materno. El SR tiene una prevalencia de 1:15.000 mujeres, presenta un fenotipo clásico de mujeres con regresión del desarrollo psicomotor asociado a microcefalia, crisis convulsivas y pérdida de la funcionalidad manual. Su diagnóstico se confirma con la presencia de la mutación en el gen MECP-2. Objetivos: Pesquisar la presencia de síndromes neurogenéticos causantes de RM en niños sin etiología conocida. Materiales y métodos: Se analizan los pacientes con diagnóstico de RM en control en el policlínico de Neurología Infantil del Hospital Regional de Antofagasta durante los meses de enero a septiembre del año 2008 . Se realiza screening de las características clínicas de SXF, SA y SR. Resultados: Se evaluaron 27 pacientes con diagnóstico de RM, de entre 7 y 18 años de edad actualmente, a los que se les aplicaron test de screening para SXF, SA y SR, en relación a sus características fenotípicas y conductuales. Cinco pacientes presentan características de SA, 3 varones y 2 mujeres, 5 varones con características de SXF y 1 mujer de SR. Sólo 1 paciente con SA tiene confirmación genética. Conclusiones: Los síndromes estudiados no son entidades poco frecuentes. La importancia del reconocimiento temprano de las características fenotípicas de los síndromes neurogenéticos causantes de RM del estudio, radica en la aproximación diagnóstica y el posterior consejo genético correspondiente, permitiendo ofrecer una mejor calidad de vida del paciente y su familia.

\section{DiASTEMATOMYELIA. REPORTE DE UN CASO CLíNICO}

Lobo R, Peña L.

Hospital Sótero del Río, Servicio Radiología Infantil.

Introducción: La diastematomyelia es una lesión disráfica poco común de la médula espinal, carcterizada por una separación longitudinal de ésta en uno o más niveles vertebrales. Reporte del caso: RNT, 8 días, varón. Presenta mchón de pelo en región lumbosacra. Se le realiza ecografía de columna lumbar, diagnosticándose diastematomyelia. Discusión: Es un trastorno poco común, que afecta más frecuentemente, columna dorsal baja y lumbar alta (más de un nivel). La etiología es controvertida, pero se cree que está relacionada con con falla de la diferenciación del tubo neural, falso desarrollo del notocordio, produciéndose división y transfijación del canal medular y formación de espícula ósea (fibrocartilaginosa)o barra en numerosas vertebras. Va desde dorsal del cuerpo vertebral hasta arco neural correspondiente. El diagnóstico es importante porque con el crecimiento del niño el ascenso normal de la médula espinal se inhibe por la espícula ósea (fibrocartílago). La consecuencia es un estiramiento de la médula espinal (extensión de columna)y desplazamiento asociado a caudal del cerebelo y médula. La clínica presenta deficit neurológico de extremidades inferiores, curvatura anormal de columna, alteraciones cutaneas (mechón de pelo, hoyuelos cutaneos, lipomas). El tratamiento es quirúrgico: extirpación de la espícula ósea. 
POLINEUROPATIA SENSITIVA DOLOROSA AGUDA: CASO CLÍNICO

Orellana SG, González GJE, Galeno R

Becario Pediatría, Universidad de Chile, Sede Hospital Exequiel González Cortés; Neurólogo Infantil, Servicio de Neurología Infantil, Hospital Exequiel González Cortés, Becado de Neurología de la Universidad de Santiago de Chile.

La polineuropatía sensitiva aguda es una condición muy rara en pediatría. Las etiologías a plantear en la infancia son variadas e incluyen distintas causas, pasando desde las tóxicas, trastornos metabólicos o hereditarios (enfermedad de Fabry) o una polineuropatia sensitiva criptogénica. Nuestro objetivo es presentar un caso de polineuropatía sensitiva dolorosa aguda, autolimitada (de un mes de evolución) en el cual no fue posible lograr claramente el diagnóstico, además de ser un de muy difícil manejo del dolor. Paciente escolar de 10 años de edad que el 16 de abril, a las horas de pintarse las uñas de los pies con un plumón permanente que retira a la brevedad con una colonia; comienza con dolor agudo severo, paroxístico en dedos de los pies, con pésima respuesta a antiinflamatorios no esteroidales, que sólo cede al colocar los pies en agua fría. Una semana después se le suma paroxismos de dolor en dedos de las manos. Evaluado en servicio de urgencia infantil, se decide su ingreso para manejo del dolor el 26 de abril. Al examen neurológico destaca paciente con dolor de tipo neuropático recurrente y episódico con compromiso funcional variable, sin otros hallazgos. Se plantea probable etiología tóxico metabólica, solicitando estudio para arsénico, talio y plomo, que resultan negativos; estudio de alfa galactosidasa, negativo para enfermedad de Fabry. Evoluciona con aumento de los paroxismos de dolor, con mala respuesta a analgesia de primera y segunda línea, motivo por el cual se requiere instalar cateter peridural con fentanilo y bupivacaina. Se solicita evaluación por psiquiatría infantil que resulta normal. La Electromiografía revela velocidad motora en extremidades inferiores con discreto aumento de la latencia con velocidades de conducción de 25 a $30 \mathrm{mt} / \mathrm{seg}$, lo que sugiere compromiso sensitivo predominantemente desmielinizante, concluyendo una polirradiculoneuropatía sensitiva de predominio en EEIl, posiblemente desmielinizante a lo que se suma la resonancia nuclear magnética que evidencia una radiculomielopatia tipo ¿Guillain-Barré? ¿post PL?. A las dos semanas de hospitalización ceden paroxismos y severidad de ellos, para finalmente dar alta médica en buenas condiciones, en tratamiento con gabapentina, la cual se suspende en el control ambulatorio. No ha presentado recurrencia de estos episodios. Presentamos el caso por lo infrecuente y el difícil manejo analgésico. Creemos que correspondería a una probable etiología criptocogénica.

\section{ESTUDIO RETROSPECTIVO PARA EVALUAR LAS CARACTERÍSTICAS EPÍDEMIOLÓGICAS DE TRAUMATISMO ENCEFALOCRANEANO EN NIÑOS}

Sobarzo $A R^{1}$, Neumann $C F^{1}$, Muñoz $M C^{1}$, Sanhueza GP

IInternos de Medicina, Universidad de Santiago de Chile. Hospital El Pino.

Introducción: Se entiende por Trauma Encefalocraneano (TEC) a la lesión de encéfalo y/o sus envolturas provocada por una descarga de energía directa o secundaria a la inercia. La lesión se puede manifestar de forma clínica y/o po imágenes. Las cifras epidemiólogicas reales son difíciles de obtener, ya que existe un número importante de casos de TEC menores o leves que no solicitan atención médica. En Chile no se dispone de estadísticas acabadas sobre la epidemiología local. Objetivos: Evaluar e identificar las características epidemiologicas de pacientes pediatricos ingresados con diagnóstico de TEC en el contexto de un servicio de urgencias pediátrico. Materiales y Métodos: Se realizó un estudio tipo retrospectivo, descriptivo, con programas EPICENTER y OMEGA seleccionando a pacientes con diagnóstico de TEC del total de ingresos en el servicio de urgencia pediatrico del hospital El Pino, durante el período de Enero del 2006 y Marzo del 2008. Resultados: Se revisaron 2.548 casos, de los cuales 104 tenían TEC como diagnóstico, correspondiendo a un $4,08 \%$ del total. $57(54,8 \%)$ fueron varones, y $47(45,2 \%)$ niñas. La edad varió entre 5 meses y 15 años de edad. $28(26,92 \%)$ eran menores de 2 años, de los cuales 11 eran menores de 1 año; $2-5$ años $=36(34,6 \%) ; 6-10$ años $=28$ (26,92\%); $11-15$ años $=11(10,57 \%)$. La estadia hospitalaria inmediata varió entre 1 y 6 días, con un promedio de 1,7 días de hospitalización. 87 casos fueron catalogados como TEC leve $(83,6 \%)$, y 17 como TEC moderado $(16,3 \%)$. No hubo casos de TEC severo no fallecimientos por TEC durante el período estudiado. Conclusiones: La epidemiología internacional del Traumatismo Encefalocraneano se correlaciona notablemente con nuestro estudio. Hubo mayor incidencia en niños varones y en edad preescolar, además que más del $80 \%$ en nuestra serie se catalogó como TEC leve.
COMPROMISO NEUROLÓGICO EN PACIENTES PEDIATRICOS VIH POSITIVOS DERIVADOS A CENTRO DE REHABILITACIÓN DE REFERENCIA NACIONAL

Ávila BML, Neculhueque ZX, Díaz MA

Instituto Nacional de Rehabilitación Pedro Aguirre Cerda (INRPAC).

Introducción: El año 1989 se reportó en Chile el primer caso de VIH en niños Según distintos estudios se estima que entre el 30 a $70 \%$ de los niños con SIDA manifiestan clínicamente algún grado de afectación del SNC. Actualmente el SIDA ha pasado a ser una enfermedad crónica con el avance de las terapias aplicadas tanto en Chile como a nivel mundial, lo que implica llevar a cabo un manejo orientado a atender las múltiples necesidades que se van presentando en estos pacientes. Objetivo: Conocer las manifestaciones neurológicas de los niños con VIH - SIDA atendidos en el INRPAC. Método: Estudio retrospectivo con revisión de fichas clínicas de pacientes con VIH que son derivados al INRPAC para rehabilitación desde diciembre 2006 hasta septiembre 2008. Resultados: En el período revisado ingresaron 8 pacientes para rehabilitación, de los cuales el $50 \%$ fueron mujeres. La mediana de la edad del diagnóstico de la infección por VIH fue 5 meses (4-12 meses), sin embargo, este dato estaba disponible en sólo 5 de los 8 pacientes. La mediana de edad al momento de ingresar a rehabilitación fue 4,5 años (7 meses- 8 años). Todos los pacientes habían sido contagiados por transmisión vertical y todos estaban en terapia antirretroviral. Todos los pacientes presentaron retraso del desarrollo psicomotor global, 2 tenían síndrome convulsivo el que además se asoció a alteración del estudio de neuroimagen, y dentro del grupo de los mayores de 3 años todos tenían retraso del lenguaje. Del grupo de pacientes 6 tenían paraparesia espástica, la que incluso llegó a requerir tratamiento quirúrgico en todos los casos. Discusión: Dentro de la revisión destaca la tardía derivación de los pacientes a un programa de rehabilitación. Se sabe que el compromiso neurológico de los pacientes con SIDA es frecuente por lo que es importante el diagnóstico y manejo oportuno de este aspecto para contribuir a la mejor calidad de vida de la población infantil afectada.

\section{PARO CARDIORESPIRATORIO 2a A CONVULSIÓN, 3 CASOS}

Briones Y, Pimstein M, Erazo R, Mellado N. Unidad de Cuidados Especiales Pediátricos (UCEP). Clínica Los Coihues.

La asociación de Paro CardioRespiratorio (PCR) y convulsión es poco frecuente. Se conocen alteraciones en funciones autonómicas durante episodios convulsivos. Cambios cardiovasculares y electrocardiográficos (ECG) pudieran tener relación con la entidad conocida como SUDEP: muerte súbita de causa no explicada en pacientes con epilepsia. Presentamos 3 casos de pacientes en UCEP, todos con traqueostomía (TQT) y Ventilación Mecánica Invasiva Crónica (VMICr), estables en su condición basal, control de signos vitales 30 a 60 minutos previos al evento normales. Todos presentaron PCR inmediato a inicio de convulsión sin status epiléptico ni hipoxia. Todos ellos se encontraban monitorizados con saturación y ECG normales, TQT permeable y Ventilador Mecánico (VM) ciclando adecuadamente, evento presenciado y con reanimación cardiopulmonar (RCP) con masaje cardíaco y ventilación por bolsa de reanimación a TQT inmediata. Se constata PCR por trazado monitor, ausencia de latidos y pulso, cianosis intensa, y monitor de equipo desfibrilador que corrobora asistolía. Visualización de evento desencadenante categórico de convulsión. Posterior a evento, condición neurológica de los 3 pacientes, sin cambios significativos. Caso 1: $4 \mathrm{~m}$, Sd hipotónico, malformación pontocerebelosa, Sd Febril central, VMIC por TQT, Sd. Convulsivo con actividad eléctrica persistente, en tratamiento con Fenobarbital (FNB). Presenta hipertonía 4 extremidades, desviación de mirada y flexión cervical a der con rotación cabeza, se constata asistolía brusca en el monitor, se inicia RCP, recupera latido y ritmo sinusal a los $3 \mathrm{~min}$, antes de administrar adrenalina y paralelamente se administra midazolam y 2 cargas de FNB. Reactivo inmediato. GSV y ELP N Electroencefalograma (EEG) posterior: actividad epileptiforme. Niveles FNB concomitantes 17,8. VideoEEG muestra correlación de actividad eléctrica convulsiva, manifestaciones clínicas y bradicardia severa. Caso 2: 4 a 8 m, Sd G Barré en rehabilitación y destete ventilatorio, sin antecedentes convulsivos, VMCr, TQT. Exs control 30 min antes GSV y ELP N. Presenta súbito dolor abdominal, flexión de tronco sobre piernas y posteriormente opistótonos e hiperextensión de las 4 extremidades, trismus y desviación de la mirada a izq asociada en forma inmediata a asistolía en trazado de monitor. Se realiza RCP y tras 1 dosis de adrenalina más 1 dosis de diazepam (por evidencia convulsiva), recupera ritmo $1^{\circ}$ complejos anchos e inmediato sinusal. Duración 5-7 minutos. Reactivo de inmediato. Se carga con FNB. Post PCR inmediato: GSA y ELP N láctico 9,9 CKT 7419 CKMB 113. EEG 24 hrs (con FNB) sugerente de actividad epileptiforme. Caso 3: 2 a dg Distrofia muscular merosina deficiente, sd hipotónico severo en VMICr, TQT, Sd convulsivo en tratamiento con FNB. Presenta brusca hipertonía en semiflexión de 4 extremidades, cianosis y asistolía. RCP inmediata, múltiples dosis de adrenalina, lidocaína, calcio, bicarbonato, atropina, defibrilación/cardioversión (2) y finalmente carga FNB, recupera ritmo sinusal tras $25 \mathrm{~min}$ de RCP $\left(1^{\circ}\right.$ ritmo nodal ancho, extrasistolía supraventricular y posteriormente ritmo bigeminado) inmediatamente reactiva. Exámenes post PCR GSV y ELP N EEG posterior daño hipóxico agudo. Discusión: La asociación entre PCR y convulsión es poco frecuente y/o poco documentada. En estos casos, por antecedentes, presentación, dg de los pacientes y manejo asociado, es atribuible asistolía a evento convulsivo, eliminando la hipoxia $2^{\circ}$ como causal del PCR. Por lo que, según contexto y presentación clínica es importante considerar el manejo de episodio convulsivo durante la reanimación. 
MANEJO DE SIALORREA SEVERA: INFILTRACIÓN CON TOXINA BOTULÍNICA A EN PACIENTE TRAQUEOSTOMIZADO, REPORTE DE CASO CLÍNICO

Gutiérrez T, Pimstein M, Briones $Y$

Unidad de Cuidados Especiales Pediátricos. Clínica Los Coihues. Santiago, Chile.

La sialorrea (S) es un problema importante en pacientes neurológicos, con trastorno de la deglución y/o paresia de musculatura estabilizadora cervico-craneal, siendo en portadores de Parálisis Cerebral, $10 \%$ a 37\%. La (S) afecta la calidad de vida del paciente y sus cuidadores, produce lesiones de piel, de traqueostomía (TQT) en portadores de ésta, y pulmonares, con un alto costo derivado. Existe gran variedad de tratamientos, con diferentes resultados, efectos adversos, costos, requerimiento de pabellón, etc. Hasta ahora los resultados de tratamiento de (S) se basan en evaluación clínica subjetiva. Uno de los tratamientos más innovadores de la (S), es la aplicación de Toxina Botulínica tipo $A$ en las glándulas salivales (GS), produciendo bloqueo neuromuscular presináptico de la liberación de acetilcolina y nervios parasimpáticos, disminuyendo la producción de saliva. Caso clínico: RG 14 a, secuela TEC grave, TQT, Ventilación Mecánica dependiente, trastorno deglución, Bronconeumonías graves a repetición. Cognitivo indemne. (S) severa que afecta su vida diaria, autoestima. Diseño: Cuantificación de volumen aspirado exclusivo de saliva en 24 hrs por 7 días pre y post infiltración, controles semanales hasta 16 semanas post. Realización encuesta de calidad de vida (CV) pre y post infiltración, según CV WHOQOL-BREF, derivada del WHOQOL-100, OMS. Procedimiento: Se realizan 2 infiltraciones separadas por 15 días con Toxina Botulínica tipo A, a cargo de fisiatra y cirujano máxilo-facial. $1^{\circ}$ infiltración a GS parótidas (GSP), $2^{\circ}$ a GS submaxilares (GSSM). No requirió sedación, ni guía ecográfica. Dosis: 25U GSP, 25U GSSM bilateral. Total 100U. Resultados: Cuantificación S: Se aplica estadística descriptiva, se comparan los 2 tiempos post tratamiento, observando descenso de volumen medio de saliva $1^{\circ}$ dosis ( $684 \mathrm{cc}$ a $428 \mathrm{cc} / 24 \mathrm{hrs}$ ) y reducción máxima con la 2 dosis(a $305 \mathrm{cc} / 24 \mathrm{hrs}$ ), con una duración efectiva de 16 semanas. Se comparan resultados con t de Student, nivel de significancia ( $p$ ) y cálculo de \% de variación para c/dosis. Se encuentran diferencias significativas $\left(1^{\circ}\right.$ dosis $=$ diferencia: 255,56, t: $-6,76, \mathrm{p}:, 000 ; \mathrm{y} 2$ dosis = difrencia: -378.07 , t: $-14.64, \mathrm{p}: .000)$, con una disminución de la (S) de $37,40 \%$ y $55,33 \%$ respectivamente. Calidad de vida (CV): WHOQOL-BREF (escala de 0 a 100); Relaciones Sociales, sin diferencias pre y post aplicación, Aspecto (A) Psicológico mejora 37 puntos; (A) Físico mejora 31 puntos; (A) Ambiental mejora 25 puntos. Percepción de CV Global mejora de 1 a 4 ptos y en CV en Salud mejora de 2 a 3 ptos (escala Lyket : 0 a 5 ) Conclusiones: La inyección con TXB-A disminuye la producción de saliva, po un período superior a 16 semanas, siendo necesario la infiltración de las GSP y GSSM para un mayor efecto. Este procedimiento, al pie de la cama, sin complicaciones descritas, no requiere pabellón ni ecografía, pudiendo realizarse sólo con técnica de palpación, resultando sólo el costo de operador y medicamento.

\section{SÍNDROME DEL "HOMBRE EN EL BARRIL" PRIMER CASO DESCRITO} EN UN NIÑO

Cardoso I, Mellado P, Meza M, Rodríguez M.

Hospital Clínico Pontificia Universidad Católica de Chile.

Introducción: El "Síndrome hombre barril" está caracterizado por paresia bilateral de extremidades superiores con función motora intacta en extremidades inferiores. El aspecto clínico del paciente impresiona estar atrapado en un barril, pudiendo movilizar sólo las porciones distales de las extremidades superiores. Su etiopatogenia más frecuente es una hipotensión arterial sistémica asociado a una estenosis de las arterias carótidas internas, lo que produce isquemia de territorio limítrofe. No se han descrito en la literatura casos en niños. Describiremos el caso de un "síndrome hombre barril" en un niño después de un TEC grave con disección crítica de carótida izquierda. Historia clínica: Paciente de 12 años, sin antecedentes mórbidos. Cae accidentalmente desde un tercer piso, Ingresa al Servicio de Urgencia en Glasgow 11. TAC de cerebro muestra fractura base cráneo, de piso orbita izquierda, fracturas costales y de pelvis. TAC posterior evidencia infartos de sustancia blanca de hemisferio izquierdo. Angiorresonancia demuestra disección carótida izquierda crítica, con perfusión adecuada por polígono de Wilms. Clínicamente presenta paraperesia braquicrura derecha, con predominio importante de extremidad superior derecho, pudiendo movilizar sólo los dedos de la mano derecha. Se realiza exclusión de carótida con coil, sin incidentes. Evoluciona con hemianopsia izquierda sin mejoría y recuperación progresiva de la fuerza completa del hemicuerpo derecho. Discusión: El humúnculo motor de las extremidades superiores atraviesa la zona límite entre la arteria cerebral anterior y cerebral media y cuando ocurre hipoperfusión puede producirse paresia bibraquial. Su enfrentamiento terapéutico se basa en mejorar el flujo sanguíneo encefálico. El pronóstico es variable según los distintos reportes, llegando incluso a su resolución completa. Conclusión: Este es el primer caso descrito de Síndrome hombre barril en un niño. Además, destacamos la importancia de descartar estenosis crítica de la arteria carótida interna en un paciente que presenta infarto limítrofe encefálico.
PREVALENCIA DEL TRASTORNO POR DÉFICIT DE ATENCIÓN E HIPERACTIVIDAD EN EL HOSPITAL UNIVERSITARIO DR. JOSÉ ELEUTERIO GONZÁLEZ

Castilleja ZMA, Espinoza CAI, Coronado JSS, Sánchez LI, Villarreal VHJ. Hospital Universitario Dr. José Eleuterio González.

Introducción: La tasa de prevalencia en el trastorno por déficit de atención e hiperactividad (TDAH) es un tema controvertido. En el DSM-IV se establece un intervalo entre el 3 y el 5 . En los últimos años hemos notado aumento en nuestra consulta, por lo que decidimos realizar este trabajo para conocer nuestra estadística y población. Objetivo: Describir la casuística de este trastorno en consulta externa del servicio de neurología en un período de tres años de enero 2005 a diciembre del 2007. Material y Métodos: Se revisaron la base de datos de la consulta en un período de tres años, recabándose en base de datos y se analizaron los resultados. Resultados: Se encontraron 183 casos nuevos en tres años, 42 casos en 2005, 56 en el 2006 y 85 en 2007. La edad promedio de diagnóstico fue a los 7,4 años, el $74 \%$ con subtipo clínico mixto, $15 \%$ hiperactivo y 11 inatento. $85 \%$ género masculino, comorbilidad más frecuente fue enuresis, los trastornos del lenguaje y la epilepsia. Un $70 \%$ cuenta con manejo medicamentoso y $90 \%$ tiene apoyo escolar. Un $40 \%$ se reporta EEG anormal. Discusión: El TDAH se ha incrementado como motivo de consulta, probablemente por la expansion de información dada a padres y maestros, es importante conocer bien esta patología para un diagnóstico precoz e instaurar apoyo y manejo más adecuado.

EVALUACIÓN DEL TRASTORNO POR DÉFICIT DE ATENCIÓN E HIPERACTIVIDAD POR MÉDICOS DE PRIMER CONTACTO EN UNA POBACIÓN DEL NORTE DE MÉXICO

Coronado JSS, Castilleja ZMA, Espinoza CAI, Sánchez LI, Villarreal VHJ. Hospital Universitario Dr. José Eleuterio González.

Introducción: El trastorno por déficit de atención e hiperactividad es un trastorno neurobiológico frecuente en la consulta de neuropediatría. El diagnóstico es clínico mediante encuesta del DSM IV. Es uno de los problemas que refieren los médicos de primer contacto para su evaluación y los interconsultan con una batería de exámenes, sin justificación plena. Por tal motivo realizamos el trabajo para conocer la frecuencia de estudios paraclínicos solicitados por el medico de primer contacto. Material y Métodos: Se revisaron los expedientes clínicos de los pacientes de primera vez con diagnóstico de TDAH en un período de tres años, recabándose en base de datos y se analizaron los resultados. Resultados: Se encontraron 183 casos nuevos en tres años, de estos un $55 \%$ fueron referidos por médicos y/o psicólogos con exámenes ya solicitados por ellos. El EEG fue el examen más solicitado en un $85 \%$, de las cuales el $72 \%$ fueron reportadas como normales y el $28 \%$ como anormales. La RMN de cerebro fue solicitada en un $45 \%, 90 \%$ reportadas como normales. Discusión: El diagnóstico de TDAH es clínico, es importante la educación continua de médicos pediatras, psicólogos y de primer contacto para la evaluación y manejo correcto de estos pacientes y así evitar gastos innecesarios en estos infantes. 


\section{EPILEPSIA Y TRASTORNO DE DÉFICIT DE ATENCIÓN E HIPERACTIVIDAD EN HOSPITAL UNIVERSITARIO DE MONTERREY}

Espinoza CAI, Castilleja ZMA, Coronado JSS, Sánchez LI, Villarreal VHJ. Hospital Universitario Dr. José Eleuterio González.

Introducción: El trastorno por déficit de atención e hiperactividad (TDAH) es un trastorno del comportamiento infantil, de origen genético, en el que se encuentran implicados factores neuropsicológicos. Se caracteriza según el DSM IV por un conjunto de síntomas de hiperactividad e impulsividad y/o desatención. Hay tres subtipos: el TDAH tipo desatencional; tipo hiperactividad y mixto. Respecto a la asociación de TDAH y epilepsia, Dunn y cols, revisaron 175 niños con epilepsia y evidenciaron que estos niños presentaban un mayor riesgo y síntomas de TDAH, especialmente de las características del tipo inatento. En el presente estudio mencionaremos la asociación de TDAH con epilepsia ya diagnosticada en nuestra población. Material y Métodos: Es un estudio retrospectivo y descriptivo donde se revisaron los expedientes con diagnóstico de epilepsia en un período de cuatro año (2004-2008). Se incluyeron aquellos pacientes que cumplieran con los criterios del DSM IV para el TDAH. Se estudió la edad de inicio del trastorno y los factores o antecedentes encontrados y la asociación con epilepsia ya diagnosticada por clínica y EEG. Resultados: Se encontró un total de 350 registros con diagnóstico de epilepsia,. Se obtuvo un número de 34 pacientes con TDAH diagnosticado por el DSM IV. El tipo mixto fue el más frecuente en el $60 \%$ de los niños. La edad promedio fue de 8,7 años con edad de inicio de trastorno de 5.4 en promedio. El $60 \%$ se indica metilfenidato y el $40 \%$ atomoxetina. Ninguno de estos pacientes se exacerbaron las crisis. La actividad lenta con ondas delta, la parcial e interictal son los hallazgos sobresalientes en el EEG. Discusión y Conclusión: Es importante una valoración minusiosa de los niños con epilepsia, ya que un porcentaje cursa con comorbilidades asociadas, en nuestro estudio se encontró que un $10 \%$ de ellos tiene TDAH asociada, esto es importante para el manejo integral que se le da a nuestros pacientes.

ENCEFALITIS POR VIRUS HERPES 6, SERIE DE CASOS

Figueroa $V$, Rivera G.

UCl pediatrica Clínica Alemana Temuco CAT

Introducción: El virus herpes 6 es un virus de la familia herpes viridae, lifotropo y citopatico. Actualmente se conocen 2 variantes $\mathrm{A}$ y $\mathrm{B}$, este último se adquiere tempranamente en la vida y es responsable en su primo infección del exantema súbito y convulsiones febriles. La variedad $\mathrm{A}$ se adquiere más tarde en la vida y no se asocia a un síndrome definido, tiene propiedades neurotrópicas. La infección por VH6 permanece latente en glándulas salivales monocitos y macrófagos. Objetivos: Nuestro objetivo es presentar una serie de 4 casos clínicos de encefalitis por herpes 6 que ingresaron a la $\mathrm{UCI}$ pediátrica CAT en el período de noviembre 2007 a febrero 2008. Caso 1: Lactante de 3 meses previamente sano, que ingresa por cuadro de 6 días de evolución corisa y congestión nasal y el día del ingreso sufre 2 crisis atonica, desviación de la mirada y desconexión de medio, afebril. Ingresa somnoliento irritable al estimulo táctil con tendencia al retrocoli, hiperreflexia y clunus. Caso 2: Escolar de 8 años previamente sano que consulta por cuadro de 2 días de evolución de cefalea, vómitos y deposiciones liquidas, afebril. El examen Glasgow 15 signos meníngeos +. Caso 3: Escolar de 5 años previamente sano que ingresa por cuadro de 2 días de evolución de cefalea frontal intensa, fotofobia, compromiso del estado general, afebril Al examen destaca paciente en Glasgow 15 con signos meníngeos +. Caso 4: Adolescente de 14 años previamente sana con cefalea de 2 semanas de evolución en los últimos días se asociado a déficit motor parecía braqueocrural izquierda y e día del ingreso se agrega afásia, compromiso de conciencia parcial y vomitos explosivos. Los cuatro pacientes tuvieron TAC y RNM normal, scrining infeccioso normal y LCR con 40 a 90 células $90 \%$ mononucleares PCR para herpes 6 + (en 2 laboratorios) y neg. para herpes 1,2 y enterovirus. Sólo el lactante se trató con aciclovir. Los 4 evolucionaron favorablemente con mejoría de los síntomas en un promedio de 4 días sin secuelas. Discusión: Encefalitis por HV6 es una entidad probablemente subdiagnosticada en pacientes inmunocompetentes. El caso uno correspondería a una primoinfección por VH6. En los otros caso es difícil hacer un diagnóstico de certeza etiológica ya que se requiere serología que no esta disponible en nuestro medio, no pudiendo descartar un fenómeno de inclusión cromosomal.
EDAD DE DIAGNÓSTICO Y CARACTERÍSTICAS TEMPRANAS PRESENTES EN PACIENTES CON TRASTORNOS GENERALIZADOS DEL DESARROLLO

Figueroa RC, Lagunas MJ, Garrido EV, Reyes BP.

Hospital Regional de Antofagasta. Antofagasta. Chile.

Introducción: Los trastornos generalizados del desarrollo (TGD) representan un espectro amplio y contínuo de alteraciones cognitivas y del comportamiento caracterizadas por la presencia de alteraciones de la interacción social, alteraciones de la comunicación y por la presencia de patrones de conducta, actividades e intereses restringidos, repetitivos y estereotipados. Su prevalencia se estima en 6 por 1000. Diferentes trabajos han estimado la edad de su diagnóstico en los 61 meses. Diversos test de screening han sido desarrollados para ser realizados a niños menores de 2 años para pesquisar la presencia de características tempranas o "banderas rojas" que representan una indicación absoluta de inmediata evaluación médica. Estas "banderas rojas" corresponden a: (1) ausencia de comunicación verbal (balbuceo) y/o no verbal a los 12 meses; (2) ausencia de palabras simples (disílabos) a los 16 meses; (3) ausencia de frases simples, de 2 palabras, no ecolálicas, a los 24 meses y (4) pérdida del lenguaje o de hitos del desarrollo social a cualquier edad. La temprana identificación de los pacientes permite una intervención precoz, la investigación etiológica y la realización de consejo genético del riesgo de recurrencia. Objetivos: Determinar la edad de diagnóstico y las características presentes en los pacientes con TGD. Materiales y Métodos: Se analizan los pacientes con diagnóstico de TGD realizado en el policlínico de Neurología Infantil del Hospital Regional de Antofagasta, entre los meses de enero a septiembre del año 2008. Resultados: Se encontraron 7 pacientes con diagnóstico de TGD. El promedio de edad al diagnóstico corresponde a 57 meses, siendo el motivo de consulta alteración del lenguaje en 5 pacientes y alteración de la interacción social en 2 pacientes. Los profesionales que derivaron a neurólogo infantil fueron 4 médicos generales, 2 pediatras y 1 educadora de párvulos. En la evaluación del especialista los rasgos predominantes fueron alteración del lenguaje en 4 pacientes, de ellos 1 con pérdida de lenguaje y otro con lenguaje muy articulado, 2 pacientes con autoagresividad, 1 paciente con irritabilidad y 1 con conducta restringida, repetitiva y estereotipada. Conclusiones: LoS TGD corresponden a una patología que no es poco frecuente. El conocimiento de las características tempranas y la aplicación de test de screening permiten su detección temprana, para posterior estudio etiológico, precoz intervención terapéutica y consejo genético.

\section{INTOXICACIÓN POR MONÓXIDO DE CARBONO, CASO CLÍNICO} PEDIÁTRICO: CARACTERÍSTICAS CLÍNICAS Y NEUROPSICOLÓGICAS

Godoy PX, González GJE.

Hospital Exequiel González Cortés.

Introducción: La intoxicación aguda por Monóxido de Carbono (CO) constituye una causa importante de mortalidad y de morbilidad en la infancia.Se ha planteado que el uso de oxígeno hiperbárico (OHB) mejora el pronóstico y las secuelas. Objetivo: Describir la evolución de un caso pediátrico con intoxicación severa por $\mathrm{CO}$, en la cual se usó OHB, durante el 1er año postevento. Caso clínico: Niña de 14 años,sufre intoxicación severa por CO siendo encontrada 1,5 horas después, inconsciente, con ventilación espontánea. Es llevada al HEGC donde llega en Glasgow 5, intubándose. Medición de Carboxihemoglobina $(\mathrm{CHb})$ reveló $44 \%$. Con ventilación a presión positiva,y ventilación mecánica(VM), posterior $\mathrm{CHb}$ control fue $2 \%$. Recibe VM, drogas vasoactivas por 36 horas.A las 48 horas se encuentra vigil, confusa y agitada, afásica, atáxica con paresia severa de extremidades superiores. En días siguientes, evoluciona con recuperación del sensorio, alteración del habla, comportamiento, mejora fuerza pero permanece con ataxia global.A los 15 días recibe $\mathrm{OHB}$, que se correlaciona con una mejoría posterior: motora, del lenguaje y en general de sus habilidades cognitivas. Al mes de evolución estaba sin déficit motor y con leve alteración del habla.RNM Cerebral mostró compromiso cortico-subcortical, temporoccipital bilateral mayor a izquierda, y frontal izquierdo.Se observan lesiones en hemisferios cerebelosos y núcleos Pálidos. Evolución neurológica posterior estable, leve alteración del habla. Evaluación neuropsicológica: Se aplica batería de pruebas y se observa: Disminución en la capacidad de memoria de trabajo, la atención y comprensión. Test de Luria Nebraska muestra valores alterados (9 de 11 escalas eran anormales) déficit en la articulación de palabras, memoria y funciones motoras. A los 6 meses la evaluación muestra mejoría en todas las áreas evaluadas excepto: atención y memoria, con disminución marcada respecto a la evaluación post OHB. Discusión: La Intoxicación por CO presenta formas específicas de lesiones, importantes por su consecuencias. Existe el síndrome neurológico tardío, con un daño a nivel tisular que podría ser modificado por el uso de OHB, cuyo efecto es fuente de controversia. Se presenta un caso el cual se ha estudiado su evolución, planteándose como un modelo de seguimiento integral para evaluar las funciones neuropsicológicas. Se observa deterioro de la memoria en forma sostenida y progresiva al cabo de un año que se correlaciona con daño estructural en la neuroimagen. 
CARACTERÍSTICAS CLÍNICAS DE SÍNDROME DE GUILLAIN BARRE (SGB), DIFERENTES PRESENTACIONES EN PEDIATRÍA

Jeldres E, Von Freeden J, Leiva $H$

Servicio de Pediatría Hospital Regional de Rancagua.

EI SGB es la neuropatía aguda más frecuente, y puede expresarse a través de diferentes formas clínicas. Se presentan tres casos pediátricos diagnosticados en el Servicio de Pediatría del Hospital Regional de Rancagua en período Agosto-Septiembre 2008. Caso № 1: Paciente sexo masculino, 4 años de edad, sin antecedentes de cuadro infeccioso previo, inicia dificultad respiratoria progresiva y severa que requiere conexión a ventilación mecánica dentro de primeras 24 hrs. Evoluciona con tetraplejia fláccida arrefléctica. Estudio electrofisiológico compatible con polirradiculoneuropatia motora tipo axonal. Caso № 2: Paciente sexo masculino, 9 años de edad. Cursa cuadro respiratorio previo al ingreso. Clínica inicial: parestesias y debilidad en extremidades inferiores. Evoluciona con paraparesia y arreflexia en extremidades inferiores. Velocidad de conducción sugerente de polirradiculoneuropatia sensitivo motora de tipo desmielinizante y axonal. Caso № 3: Paciente sexo femenino, 9 años. Presenta trastorno de la marcha progresivo, asociado a ptosis palpebral. Posteriormente compromiso de pares craneales VI, VII, IX, X y XII bilateral asimétrico y hemiparesia doble, hiporrefléctica. Velocidad de conducción normal en extremidades inferiores. Sólo en el caso № 2 hubo disociación albúmino citológica. Los tres pacientes recibieron Ig ev en dosis habituales con respuesta clínica favorable en casos 2 y 3 . E paciente № 1 persistía con deficit motor significativo al momento del alta (etapa 4 de Hughes). Si bien el estudio del comportamiento del SGB requiere la implementación de herramientas de análisis más precisas creemos que la descripción de estos casos contribuye a evidenciar variadas formas de presentación clínica del SGB en la infancia.

\author{
SÍNDROME DE ONDINE, A PROPÓSITO DE UN CASO CLÍNICO
}

González I, Carmona O, Arancibia J, Tobar RA, Jaime C, Bajaña G. Hospital Dr. Gustavo Fricke, Servicio de Pediatría, Universidad de Valparaíso.

Se presenta caso de lactante de 9 meses con hipercapnia, en el cual se diagnosticó Síndrome de Ondine, definido como Síndrome de hipoventilación central congénita secundario a trastorno del sistema nervioso central en el cual el control autonómico de la respiración está ausente o se encuentra deteriorado en ausencia de una enfermedad primaria que lo justifique. Lactante ingresa a los 2 meses de vida a UEI por cuadro respiratorio y cianosis. Cursa con pausas respiratorias, murmullo pulmonar disminuído y requerimiento de oxígeno, en laboratorio destaca leucocitosis con PCR baja. Evoluciona con crisis de cianosis, fascie bultuosa, hipoventilación e hipercapnia. Gases venosos previo ingreso a UCIP: pH 7,2, $\mathrm{CO}_{2} 85 \mathrm{mmHg}, \mathrm{HCO} 340,9$. Se conecta a VM por 10 días con dificultad para la desconexión. Se realizó evaluación por Neurología, Cardiología, Oftalmología y Broncopulmonar. Al examen neurológico con hipotonía axial moderada. Eco cerebral normal, EEG normal y hormonas tiroideas normales. Screening metabólico normal y TANDEM negativo.TAC y RNM de cerebro sin alteraciones. Se descarta cardiopatía congénita e HTP. Es dada de alta reingresando a los 5 meses por cuadro de 15 días de evolución con las mismas características de la hospitalización previa, en regulares condiciones generales, dificultad respiratoria moderada, necesitando $\mathrm{O}_{2}$ por halo. Evoluciona con compromiso de conciencia, edema facial importante, llanto débil y ventilación con muy poco esfuerzo, gases de urgencia reflejan retención de $\mathrm{CO}_{2}$ de $119,9 \mathrm{mmHg}$. Se ingresa nuevamente a UCIP y se conecta a VM. Se solicitan gases venosos en vigilia y sueño con pCO2 de 65 y 74 respectivamente. Se traslada a sala de lactancia para continuar estudio realizando Saturometría nocturna y polisomnografía nocturna, ambas alteradas y fibrobroncoscopia donde se pesquisa malasia de bronquio fuente derecho. Con estos antecedentes se ingresa paciente a programa de VNI domiciliaria. Antes del alta presenta nueva descompensación respiratoria debiendo ingresar nuevamente a UCIP, sin necesidad de VM. Diagnóstico de egreso: Síndrome de Hipoventilación Central-Ventilación no invasiva BiPAP nocturno, Malasia bronquio fuente derecho, Eutrofia. Pendiente estudio genético de paciente y de su madre en la cual se sospecha este síndrome. Se ha controlado en forma periódica en su domicilio, paciente estable, eutrófica, desarrollo psicomotor normal, no ha vuelto a reingresar.

\section{OPSOCLUNUS MIOCLONUS CASO CLÍNICO}

Sánchez $\boldsymbol{A}^{1}$, Montoya $M^{1}$, Martínez $G^{1}$, Escobar $P^{2}$, Maturana $M^{\beta}$. ${ }^{1}$ Becadas Servicio de Pediatría Universidad de Concepción, ${ }^{2}$ Unidad de Genética HGGB, ${ }^{3}$ Infectólogo Servicio de Pediatría HGGB. Hospital Guillermo Grant Benavente, Concepción.

El Síndrome Opsoclonus Mioclonus, se caracteriza por mioclonias, movimientos oculares conjugados y multidireccionales y ataxia cerebelosa. Las causas son variadas. En un $50 \%$ de los casos es una manifestacion para neoplasica infecciosa. La evolución es variable e imprevisible, y se pueden producir remisiones espontáneas, parciales o totales, o prolongarse en el tiempo. Niña de 3 años de edad, con antecedente de cuadro de Guillain Barre no confirmado, 1 año antes. Cursando con infección respiratoria presenta cuadro de inicio brusco de ataxia cerebelosa, afasia, tetraparesia y movimientos oculares. Se descarta Sd Guillaín Barré y Encefalitis herpética y se plantea diagnóstico de Opsoclonus Mioclonus. Se realiza estudio de LCR que resulta normal. Aminoacidemia, Aminoaciduria y TANDEM, normales. Ácido láctico y piruvico en sangre normales. Ácidos orgánicos en orina Negativo. RNM de cerebro y médula espinal Normal. TAC tórax, abdomen y pelvis normal. IgM para Mycoplasma, Ebstein Barr y Virus herpes negativos. EMG normal. El síndrome opsoclonus Mioclonus corresponde a numerosas etiologías, siendo el neuroblastoma la causa más frecuente. Habiéndose descartado las principales causas conocidas, se inició prednisona oral, egresando con regresión parcial de su sintomatología. Actualmente se encuentra en rehabilitación física.

\section{MIASTENIA GRAVIS: PRESENTACIÓN CLÍNICA EN DOS PREESCO- LARES HOSPITAL HERNÁN HENRÍQUEZ ARAVENA}

Venegas $\boldsymbol{P}^{1}$, Rivera $G^{2}$, Arias $R^{1}$, Martínez $A^{3}$, Prieto $X^{3}$. ${ }^{1}$ Pediatra, ${ }^{2}$ Neurólogo Infantil, ${ }^{3}$ Becado de Pediatría. Hospital Hernán Henríquez Aravena de Temuco.

Introducción: La Miastenia Gravis (MG) es una enfermedad autoinmune caracterizada por debilidad esquelética fluctuante y fatiga de grado variable, secundaria a una alteración de la transmisión sináptica, generada por la destrucción de los receptores de acetilcolina de la unión neuromuscular debido a la presencia de anticuerpos antireceptor de acetilcolina (acs antiR de ACH). Objetivo: Presentamos los casos de 2 preescolares (PE) con cuadros clínicos y diagnóstico de MG, realizados el año 2007 y 2008 respectivamente. Caso clínico 1: PE de 3 años 9 meses, mujer, con historia de 8 meses de debilidad progresiva y fatigabilidad fácil predominio vespertino, con disparesia facial, principalmente parpebral. Examen: fascie hipomímica, ptosis papebral a la mirada vertical extrema y debilidad proximal de las 4 extremidades.Se realiza Test de Estimulación repetitiva del Nervio (+), TAC Tórax normal. Evaluada en HLCM por neuromuscular se diagnostica MG Generalizada Juvenil, se indica piridostigmina con buena respuesta clínica. Pendiente resultado de acs antiR de $\mathrm{ACH}$. Caso clínico 2: PE de 5 años 10 meses, mujer, con historia de 10 días de cefalea, debilidad muscular progresiva, diplopia, trastorno de deglución vespertina, disfagia y disartria. Examen: ptosis parpebral bilateral, disparesia facial, voz rinolálica, reflejo faríngeo disminuido y debilidada muscular proximal. Test de Estimulación repetitiva del Nervio (+),RNM normal. Se diagnostica MG Generalizada, se inicia neostigmina con buena respuesta clínica. Evaluada por neuromuscular en HLCM confirma diagnóstico. Pendiente resultado de acs antiR de ACH. Comentario: PE sin antecedentes familiares de MG, que presentan cuadros clínicos compatibles con MG, realizandose diagnóstico por clínica y exámen de estimulación repetitiva del nervio. Ambas mejoran con piridostigmina y neostigmina respectivamente. Conclusión: La presentación de MG en la población infantil representa un 10-20\% del total de los pacientes miasténicos, donde la clínica es fundamental en el diagnóstico, predominando la debilidad muscular y fatiga fácil, que aumanta con el ejercicio y mejora con reposo, comprometiendo principalmente músculos oculares, faciales y bulbares. Fundamental en el diagnóstico es la prueba de estimulación repetitiva, títulos de acs antiR de $\mathrm{ACH}$ y EMG. Su manejo principal se basa en el uso de inhibidores de acetilcolinesterasa, corticiodes, inmunosupresores y timectomía. 


\section{PRONÓSTICO DE LACTANCIA A 6 MESES EN EL PREMATURO MENOR DE 1.500 GRAMOS}

Martínez JL, Rossel M, Castro S, Avaria MJ, Villalón H.

Clínica Las Condes.

Las estrategias de fomento de lactancia materna (LM) en las Unidades de Cuidado Intensivo Neonatal (UCIN), no se pueden evaluar con facilidad en el largo plazo, debido a la pérdida de contacto con los pacientes una vez egresados. Se realiza un estudio con el objetivo de evaluar dichos resultados, y analizar factores de riesgo de fracaso de lactancia en los prematuros menores de $1.500 \mathrm{~g}$. Se realizó un estudio retrospectivo, de todos los prematuros menores de $1.500 \mathrm{~g}$ egresados durante los años 2005-2007 ( $n=49)$, y se evaluó la prevalencia de LM al alta, 3 y 6 meses de edad cronológica. A través de revisión de fichas y encuesta telefónica, se registró la presencia de cuidadoras en domicilio, asistencia a clínica ambulatoria para estos fines y características de LM exclusiva (LME) o mixta. El grupo general tuvo un peso promedio de $1.017+299 \mathrm{~g}$, con una mediana de edad gestacional (EG) de 29 semanas (24-33). Un $8.1 \%$ de los niños (4/49) se fue de alta con fórmula exclusiva, prevalencia que aumentó a $24,5 \%(12 / 49)$ a los 3 meses y $53,1 \%(26 / 49)$ a los 6 meses. Con una tasa de abandono de $17.8 \%(8 / 45)$ y $37,8 \%$ (14/37) respectivamente. A los 6 meses, el $46,9 \%$ de los niños (23/49), aún estaba con lactancia. De éstos, 11 (11/49, 22,4\%) en modalidad exclusiva, lo que no difiere de aquellos nacidos a término sanos ( $46,9 \%$ vs $47,8 \%$, NS y $22,4 \%$ vs $33,4 \%$, NS), evaluados en una serie propia. Un mayor riesgo relativo (RR) de fracaso, se encontró en el grupo de los gemelos a los 6 meses de edad (RR 1,48), pero no significativo a los 3 meses (RR 1,07). A momento del alta, todos estaban con LM. Al comparar el grupo con LME vs fracaso de ésta, a los 6 meses, no se encontraron diferencias significativas en peso, edad gestacional, tiempo en ventilación mecánica y duración de la hospitalización. Diferencias significativas, se observaron en relación a la asistencia po cuidadoras, como un factor de riesgo de fracaso $(48 \%, 12 / 25$ vs $18,2 \%, 2 / 11$, p < $0,05)$. Factor protector de LM a los 6 meses, es la lactancia directa al pecho $(90,9 \%, 10 / 11$ vs $13,6 \%, 3 / 22, p<0,01)$. No se pudo concluir acerca de la utilidad de la clínica ambulatoria de lactancia, debido a la baja concurrencia a ésta (16,3\%, 8/49). Conclusión: Las tasas de LM a los 6 meses, no difieren de aquellas observadas en niños nacidos a término sanos, por lo que no se podría concluir que con la metodología utilizada actualmente en las UCIN, la prematurez extrema constituya un riesgo de fracaso de lactancia. La lactancia directa al pecho, como factor protector, se podría promover con derivaciones sistemáticas a una clínica de lactancia ambulatoria. Llama la atención, el efecto negativo de las cuidadoras en domicilio, razón por la cual debe existir una tuición por parte de los equipos de salud.

\section{IMPACTO DE INTERVENCIONES EN LACTANCIA SEGUNA PARIDAD}

Martínez JL, Rossel M, Avaria MJ, Castro S, Villalón H. Comité de Lactancia. Clínica Las Condes.

Las intervenciones en lactancia tienen un impacto variable, dependiendo de las múltiples condiciones involucradas. En un universo más homogéneo, la paridad es una de ellas, por lo que intentamos objetivar el impacto de una intervención, mediante la aplicación de la metodología de los 10 pasos de la UNICEF, para as definir futuras estrategias. Se analizó el resultado de una encuesta aplicada a 362 primigestas y 746 multíparas, en los años 2000 (previo a la intervención), y 2007 (posterior). Se evaluó lactancia materna, mixta y exclusiva (LME), a los 6 meses, así como la introducción de fórmulas lácteas y abandono de lactancia en el período neonatal y a los 3 meses. Diferencias estadísticamente significativas, se observan en ambos grupos, al analizar los resultados de los años 2000 y 2007 , en lactancia materna mixta $(51 / 133,38,3 \%$ vs $79 / 128,61,7 \%, p<0,007$ en primigestas y $83 / 274,30,3 \%$ vs $100 / 246,40,6 \%, \mathrm{p}<0,014$ en multíparas), LME $(31 / 133,23,3 \%$ vs $50 / 128,39,1 \%, p<0,02$ en primíparas y $28 / 274,10,2 \%$ vs 75 $246,30,4 \%, p<0,001$ en multíparas). Una disminución significativa se registró en ambos grupos, en el abandono de lactancia a los 3 meses $(32 / 133,24,1 \%$ vs $13 / 128,10,1 \%, p<0,01$ en primíparas y $82 / 274,29,9 \%$ vs $41 / 246,16.6 \%$, $p$ 0,01 en multíparas) y en la introducción de fórmulas en el período neonatal (25 $133,18,8 \%$ vs $7 / 128,5,5 \%, p<0,01$ en primíparas y $83 / 274,30,3 \%$ vs $34 / 246$, $13.8 \%, p<0,001$ en multíparas). No hubo diferencias significativas en abandono de lactancia en el período neonatal en primíparas (11/133, 8,3\% vs $3 / 128,2,34 \%$, NS), aunque sí en multíparas (37/274, $13,5 \%$ vs $14 / 246,5,7 \%, p<0,01)$. Mayo impacto se observó en primíparas, en lactancia mixta a los 6 meses $(61,7 \%$ vs $40,6 \%, p<0,0001)$, en la menor tasa de introducción de fórmulas en el período neonatal $(5,37 \%$ vs $13,8 \%, p<0,02)$ y en la modalidad de libre demanda $(57,8 \%$ vs $31.3 \%, p<0,001)$. No se registraron diferencias significativas en el abandono de lactancia en el período neonatal ni a los 3 meses. Conclusión: El impacto de las intervenciones es significativo en ambos grupos. Sin embargo, en las primíparas, se observa un mejor resultado en ciertos aspectos, como la persistencia de la lactancia a los 6 meses y la menor introducción precoz de fórmulas. Particularmente positivo, es el efecto de largo plazo de las intervenciones, que 6 años después de realizadas, mantienen las diferencias esperadas.
PREVALENCIA DE RIESGO PARA TRASTORNOS DE LA CONDUCTA ALIMENTARIA (TCA) EN ADOLESCENTES OBESOS UTILIZANDO DOS INSTRUMENTOS DE EVALUACIÓN

Agurto DP, Ceballos OML, Marín BV, Aguirre CML, Sommer K. Hospital Luis Calvo Mackenna.

Introducción: La relación de la obesidad con los TCA hasta ahora no ha sido plenamente aceptada. En Chile no disponemos de información sobre la prevalencia de estos trastornos. Los cuestionarios autoaplicados y entrevistas estructuradas son los dos principales instrumentos para evaluar riesgo, sin dar un diagnóstico específico. Dentro de estos, tenemos el Eating Disorder Inventory (EDI-2), test validado en nuestro país y el test SCOFF. Objetivo: 1) Cuantificar la prevalencia de riesgo de TCA en adolescentes obesos pertenecientes al área oriente de la Región Metropolitana; 2) Comparar la prevalencia riesgo de TCA con la aplicación de dos instrumentos de evaluación. Materiales y Métodos: Estudio prospectivo, observacional. Se ingresaron al estudio pacientes obesos (IMC > percentil 95 para edad y sexo), entre 11 y 19 años, pertenecientes al área oriente de Santiago, previo consentimiento informado. Criterios de exclusión: Enfermedades con compromiso orgánico (excepto hipertensión arterial, dislipidemia y trastornos del metabolismo de los hidratos de carbono) o psiquiátrico ya diagnosticadas, patología oncológica, embarazo y lactancia. Los resultados se analizaron según los puntos de corte establecidos para cada test, considerando riesgo de TCA ed 110 para EDI-2 y ed 2 para SCOFF. Aquellos adolescentes con riesgo de TCA (según EDI-2), fueron enviados a evaluación por psiquiatra infantil para realizar entrevista estructurada y descartar o diagnosticar TCA. Resultados: Ingresaron 51 pacientes, edad $14,1+1,76$ años, $54,9 \%$ sexo femenino, con zIMC 3,07 (rango: 1,91 a 7,7). Según el test EDI-2, 7 (13,7\%) de estos pacientes presentó riesgo para TCA sin diferencias por sexo (Test exacto de Fisher), edad (t-student) ni zIMC (t-student). Según SCOFF 70,5\% presentaron riesgo, sin relación con test EDI-2 (4/7). De las tres primeras escalas del EDI-2, que discriminan el grupo de riesgo de desarrollar TCA, resultaron alterados: (DT) Obsesión por la Delgadez 39,2\%, (B) Bulimia 52,9\%, (BD) Insatisfacción Imagen Corporal 60,7\%. Conclusiones: En este grupo de pacientes adolescentes obesos existe una prevalencia elevada de riesgo de TCA. El instrumento SCOFF sobreestima este riesgo. Los subitemes alterados en EDI-2 tienen relación con la conducta alimentaria, por lo que se requiere evaluación por expertos para concluir si éstas corresponden a respuestas patológicas. Creemos que la utilización de estos test debe ser aplicado e interpretado por profesionales capacitados.

EVOLUCIÓN NUTRICIONAL Y DE LA FUNCIÓN PULMONAR NIÑOS Y ADOLESCENTES CON FIBROSIS QUÍSTICA

Barja S, Espinoza T, Sánchez

Departamento de Pediatría, Facultad de Medicina. Pontificia Universidad Católica de Chile.

Introducción: El estado nutricional influye en la morbimortalidad de los pacientes con Fibrosis Quística (FQ) y su deterioro se asocia al compromiso de la función pulmonar. No se dispone de información sobre el estado nutricional de estos niños en nuestro país. Objetivo: Caracterizar la evolución nutricional de un grupo de pacientes con FQ y estudiar su relación con la función pulmonar. Método: Estudio de cohorte retrospectiva de los pacientes controlados en nuestra institución durante los últimos 15 años. Se consignó edad y forma de presentación al diagnóstico, mutación genética, progreso pondo-estatural, suplementación enzimática, colonización bacteriana, y VEF1 en ese período. Resultados: Se revisaron los antecedentes de 33 pacientes, con diagnóstico a los $24 \pm 45$ meses (rango 1-216), 25\% en período neonatal (íleo meconial, antecedente familiar y prolapso rectal) y posteriormente por cuadros respiratorios recurrentes $(45 \%)$ o desnutrición (30\%). Test de sudor de 92,6 $\pm 13,7 \mathrm{meqCl} / \mathrm{L}$. El $85 \%$ tiene estudio genético, siendo $48 \%$ dF508, el $94 \%$ tiene insuficiencia pancreática. En el último control: $64 \%$ son hombres, con edad de $15+8$ años, zP/E: $-0,72 \pm 1,3$, zT/E: $0,88 \pm 1$, zIMC: $-0,25 \pm 1,2$ y VEF $181,3 \pm 28 \%$. Según IMC, el $73 \%$ está eutrófico, $15 \%$ desnutrido y $12 \%$ sobrepeso. El $18 \%$ presenta Talla Baja. El zIMC es menor en los pacientes con infección por $P$. Aeruginosa $(-1,04 \pm 1,52$ vs $+0,28$ $\pm 1,03, p=0,024)$, pero no presenta diferencia de acuerdo a la edad de diagnóstico, sexo ni tipo de mutación. Evolución: Existe deterioro gradual del peso y estatura después de los 10 años y del zIMC a partir de los 12, el VEF1 disminuye posteriormente. Se observa una correlación positiva entre zIMC y VEF (Spearman, R: 0,48, $p<0,0001$ ). Conclusiones: La prevalencia de desnutrición aguda y crónica en este grupo de pacientes con $\mathrm{FQ}$ es similar a lo descrito en otras series. Se encuentra una correlación moderada entre estado nutricional y función pulmonar. El deterioro nutricional ocurre en forma acelerada a partir de los 12 años y se correlaciona al de la función pulmonar. Se requieren estudios multicéntricos representativos de la realidad nacional. 
APOYO NUTRICIONAL EN PACIENTES PEDIÁTRICOS CON INSUFICIENCIA RENAL TERMINAL (IRT) DURANTE LA PERITONEO DIÁLISIS (PD) CONTROLADOS EN EL HOSPITAL SÓTERO DEL RÍO (20052008)

Cordero BML, Nut. Quevedo SA, Ps. Jara PV.

Complejo Asistencial Dr. Sótero del Río.

Introducción: Los pacientes pediátricos con IRT deben someterse a terapia dialítica, de elección PD, en espera del trasplante renal. Este período es de gran importancia para que lleguen al trasplante en las mejores condiciones posibles. Objetivos: 1) Lograr crecimiento y desarrollo normal durante PD; 2) Adecuar aporte de micro y macro nutrientes; 3) Prevenir y/o manejar morbilidad asociada; 4) Evitar malnutrición por déficit o por exceso. Pacientes y Método: Ingresaron a PD 13 pacientes con IRT. Se controlaron periódicamente efectuándose encuestas de 24 horas y tendencia de consumo y antropometría. Se calculó puntaje Z para los indicadores antropométricos. Se realizaron intervenciones individuales y familiares para lograr las recomendaciones en calorías y proteínas (normas DOQUI 2000). Según resultados de los exámenes se restringió e aporte de fósforo, potasio, sodio, azúcares simples y colesterol en la dieta. Se analizó el estado nutricional, el \% de adecuación de la ingesta calórica y proteica al inicio, a los 6 meses de PD y previo al trasplante renal. Se efectuó evaluación psicológica para cada niño y su familia al ingreso y posteriormente según necesidad. Resultados: Se siguieron 13 niños $(7 \mathrm{H} / 6 \mathrm{M})$, el promedio de edad a iniciar la PD era de 9 años (1 mes-16 años). De este grupo 5 niños se trasplantaron, duración promedio de PD 25,4 meses $\pm 11,8$ DS (12-44 meses). Al inicio de la PD tenían talla baja $54 \%$ (7/13), con Z T/E al ingreso de $-2,25 \pm 1,6 \mathrm{DS}$, a los 6 meses de PD de $-2,24 \pm 1,56$ DS y en los 5 trasplantados el Z T/E pretrasplante de - $2,89 \pm 1$ DS. Estado nutricional al ingreso fue de $61 \%$ (8/13) eutróficos, $30 \%$ (4/13) riesgo o desnutrición y 1 paciente con sobrepeso. A los 6 meses de PD $54,5 \%$ (6/11) eutróficos, $36 \%$ (4/11) riesgo o desnutrición y 1 sobrepeso. En e período pretrasplante 4 eutróficos y 1 en riesgo nutricional. Al ingreso $69 \%(9 / 13)$ tienen \% adecuado de calorías y proteínas y $81 \%$ (9/11) a los $6 m$ de PD. Exceso de proteína al ingreso 1 paciente y 2 a los 6 meses de PD. Por ingesta inadecuada 5 usaron SNG y en 1 se realizó gastrostomía. Con entrevista clínica y algunas pruebas psicológicas se constató $23 \%(3 / 13)$ familias funcionales, $61 \%(8 / 13)$ disfuncionales, $15 \%(2 / 13)$ con problemas conyugales, 2 niños con trastorno adaptativo y 1 adolescente con trastorno oposicionista desafiante en el cuál fracasó la PD. Discusión: El compromiso nutricional en estos pacientes es multifactorial, factores dialíticos, metabólicos, endocrinos y nutricionales se mezclan con factores socioculturales y psicológicos, lo que hace muy complejo e abordaje. El uso de hormona de crecimiento es un tratamiento seguro que ha demostrado ser beneficioso, pero por razones de costo no está disponible en el sistema público.

\section{ASOCIACIÓN DE VARIABLES PERINATALES Y SOCIO-ECONÓMICAS CON LOS RESULTADOS DEL SIMCE 2006}

Mardones F, Himmel E, Infante M, Karzulovic L, Villarroel L.

Facultades de Medicina y Educación, Pontificia Universidad Católica de Chile.

Antecedentes: En países desarrollados los escolares con antecedente de bajo peso al nacer tienen una peor función cognitiva, que se correlaciona con menos años de estudio, menor productividad y menor nivel de ingresos en la adultez. Estudiamos la influencia de variables perinatales en el resultado del SIMCE en cuarto básico. Métodos: Estudio de cohorte retrospectivo de niños que rindieron la prueba SIMCE de $4^{\circ}$ básico en 2006 con variables perinatales completas en el Registro Civil. Se analizaron las pruebas de lenguaje y matemáticas en relación a variables perinatales (peso, talla y edad gestacional de parto) y socioeconómicas (años de ecuación materna y tipo de establecimiento) en tablas de contingencia con $\chi^{2}$. Con regresión logística se calcularon los OR ajustados para nivel de logro inicial. Resultados: 247.648 niños ingresaron al estudio (96,7\% del total de 4 ํ básico con 10-12 años). Los análisis univariados mostraron una asociación inversa del peso, talla y edad gestacional al nacer con el nivel de logro en las pruebas de matemáticas y lenguaje. Los varones tenían mejores puntajes en matemáticas y las niñas en lenguaje. Los OR ajustados mostraron también una asociación inversa del peso y talla al nacer con el logro inicial de ambas pruebas, con mayor fuerza para el peso al nacer y en matemáticas. Conclusiones: Por primera vez en Chile se demuestra una fuerte asociación inversa graduada del logro bajo en el SIMCE que mejora hasta un óptimo de peso al nacer de 3.501-4.000 g en matemáticas que fue independiente de factores socioeconómicos.

\section{ANEMIA Y DÉFICIT DE HIERRO EN NIÑOS CON ENFERMEDADES RESPIRATORIAS CRÓNICAS}

Barja S, Capo E, Jakubson L, Briceño L, Becker A

Hospital Josefina Martínez (ex CEDERI), Hospital Sótero del Río. Departamento de Pediatría, Pontificia Universidad Católica de Chile.

Introducción: Los niños con enfermedades respiratorias crónicas (ERC) tienen mayor riesgo de presentar anemia y déficit de hierro, con frecuencia subdiagnosticado. Objetivo: Estudiar en niños con ERC la presencia de anemia, caracterizarla y evaluar los efectos de la suplementación profiláctica con hierro. Método: Se estudiaron 40 niños del Hospital Josefina Martínez, con: hemograma, VHS, PCR, hierro plasmático, \% Saturación de transferrina, TIBC y Ferritina sérica. Se consignó: historia, estado nutricional, ingesta de hierro en alimentación e infecciones previas o intercurrentes. En 25 niños sin indicación de suplementación con hierro se repitió el estudio a los 3 meses y después de suplementar por un mes. Resultados: El $40 \%$ eran mujeres, edad de 30 meses (1 a 178 meses), $37 \%$ prematuros, $47 \%$ con apoyo ventilatorio y $45 \%$ con oxigenoterapia. Diagnósticos: $25 \%$ DPC post infeccioso, 9\% FQ, 10\% DBP, 17\% alteraciones vía aérea y $13,5 \%$ otros. El $20 \%$ tenía déficit nutricional, $10 \%$ sobrepeso y $40 \%$ retraso de talla. El $95 \%$ tenía adecuada ingesta de hierro en la alimentación. En la muestra basal encontramos 20\% anemia ( $\mathrm{Hb}<-2 \mathrm{DE}), 50 \%$ ferropriva y $12 \%$ alteración del perfil de hierro. Después de 3 meses, en los niños sin suplementación el $5 \%$ desarrolló anemia y $54 \%$ alteró el perfil, la hemoglobina disminuyó $>0,5 \mathrm{mg} / \mathrm{dl}$ en $32 \%$ de los pacientes y aumentó en $>0,5$ $\mathrm{mg} / \mathrm{dl}$ en $40 \%$ de los niños, después de un mes de suplemento con hierro, a igual que $64 \%$ mejoró su perfil de hierro. Conclusión: Los niños con ERC tienen mayor riesgo de anemia, de predominio ferropriva. Sugerimos suplementar en forma profiláctica con hierro a estos pacientes, aún si su ingesta es la recomendada. 
SALUD GINGIVAL Y NECESIDADES DE TRATAMIENTO, NIÑOS DE 6 A 8 AÑOS DE EDAD. REGIÓN METROPOLITANA. (AÑO 20042006)

Varas F, Zillmann G, Hassi J, Muñoz A, Yévenes I.

Facultad de Odontología, Universidad de Chile.

Introducción: La gingivitis, enfermedad de alta prevalencia en la población infantil ha sido poco estudiada en niños chilenos. Estudios epidemiológicos reportan prevalencia entre $40 \%$ y $98 \%$. Existen pocos estudios de vigilancia epidemiológica y datos precisos de prevalencia en niños. Actualmente es mayo que la prevalencia de la caries dental. Objetivo: Evaluar el estado períodontal y necesidades de tratamiento en escolares de 6 a 8 años en R. M. Material y Método: Estudio de prevalencia en niños escolares de 6 a 8 años, c/consentimiento informado: diseño probabilístico, bietápico estratificado por nive socioeconómico, 26 comunas de la R.M. diferentes niveles socioeconómicos (U: 348.041 niños; U: 1.637 niños). Tres examinadores clínicos, (Kappa > 90\%). Evaluación clínica: examen c/sonda períodontal OMS, evaluación de 2 indicadores (hemorragia gingival y cálculo dentario) del Índice Períodontal Comunitario de Necesidades de Tratamiento OMS. (IPCNT). Resultados: Prevalencia de gingivitis: $68,42 \%$, mayor que proporción nacional, $(P=0,00001 ; 95 \%$ IC $=0,66$ $0,70)$. A mayor edad mayor prevalencia $(P=0,0001)$. Sin diferencia por sexo $(P$ $=0,838, \mathrm{OR}=0,97 ; 95 \% \mathrm{IC}=0,78-1,21)$. La prevalencia se mantuvo relativamente constante según niveles socio-económicos y sin diferencia significativa $(P=0,417)$. IPCNT: Niños c/sangramiento gingival: $27,49 \%$, c/cálculo gingival $2,08 \%$. Sextantes afectados: c/sangramiento gingival, I y III; c/cálculo gingival, V Resultados: IPCNT, necesidad de tratamiento: requiere instrucción de higiene oral $27,49 \%$ (Tratamiento I): instrucción de higiene oral y destartraje supragingival, $2,08 \%$. (Tratamiento II). Conclusiones: La prevalencia de gingivitis es mayor que proporción nacional. Una proporción importante de niños requiere tratamiento. Se insiste en reforzar actividades promocionales-preventivas en salud bucal. Referencias Bibliográficas: - MINSAL. Norma en prevención de enfermedades gingivales y períodontales. Dpto. Odontológico. 1998. Chile. - Yévenes I et al. Impacto de la fluoración del agua potable en la Región Metropolitana. Facultad de Odontología, Universidad de Chile - MINSAL. 2006. - OMS. Encuesta de salud bucodental: Métodos básicos. $4^{\circ}$ edición. Organización Mundial de la Salud. 1997. - Nuñez C. Zillmann G. Muñoz A. Echeverría S. Hassi J. Estado períodontal en niños de 12 años. Región Metropolitana. 2004. Rev Soc Chil Odontopediatría 2006; 21 (2): 43

CARIES TEMPRANA DE LA INFANCIA (CTI), DERIVACIÓN OPORTUNA DEL PEDIATRA

Zillmann GG, Cereceda MMA, Ilabaca GMJ.

Facultad de Odontología, Universidad de Chile. Facultad de Odontología, Universidad Andrés Bello.

La Caries Temprana de la Infancia, ("rampante", "circular", o "Síndrome del biberón"), específica en dentición primaria. Prevalencia en RM a los 2 años $17 \%$ y a los 4 años $48,02 \%$. Factores predisponentes: alteraciones en embarazo o en período neonatal, asociados con hipocalcemia, sugieren deficiencias en la mineralización dentaria, factor de riesgo que sumado a factores locales, pueden iniciar el proceso carioso. Factores locales: ingesta prolongada y sostenida de nutrientes cariogénicos líquidos, (lactancia materna muy prolongada, consumo de leche azucarada, jugos, bebidas de fantasías, jarabes medicamentosos); consumo de H. de C. sólidos (galletas, dulces, snacks dulces o salados; higiene bucal ausente o deficiente. Signos clínicos: inicialmente, presencia de áreas blanquecinas (tizosas) en tercio cervical de incisivos anterosuperiores (desmineralización), seguida de cavitación entre 6 y 12 meses. Caso clínico: Niño: 16 meses, sin riesgo social. Madre: Ca mamario, diagnosticado en último trimestre de embarazo, fumadora durante éste. Parto normal. Peso nacimiento: $3.450 \mathrm{~kg}$. Lactancia materna: 15 días, bebé rechaza espontáneamente. Rinitis alérgica en tratamiento. Estado nutricional normal. 5 ingestas de $\mathrm{H}$. de C. al día (madre relata que le da sacarina para evitar alza de peso en exceso). Sin cuidados de higiene bucal. Motivo de consulta: cambio de color en incisivos. Diagnóstico clínico: CTI y gingivitis asociada a placa, por falta de higiene. Plan de tratamiento: a) Instrucción higiene bucal. Cepillado con dentífrico (Permethol 0,250 g, tamaño $1 \frac{1}{2}$ arveja); modificación de dieta; controles periódicos. Eliminación paulatina de la mamadera; b) Tratamiento local: diamino fluoruro de plata, en incisivos y surcos de molares presentes, permitió diagnóstico de caries en molares, por tinción en los surcos; c) Tratamiento restaurativo atraumático (ART): cemento de vidrioionómero, autocurado en molares y fotocurado en incisivos; d Fluoruro: $\mathrm{NaF}$ 0,05\% diario, topicado c/cotonito por la madre. Barniz NaF 5\% inicial, refuerzo bimensual; e) Controles periódicos: mensuales, hasta que tenga edad para rehabilitación más estética y definitiva. Conclusiones: En atención odontológica convencional, es posible evitar el avance de infección bucal y de las $\mathrm{CTI}$ al aplicar cariostáticos, biomateriales e instruyendo a la madre. ART, es solución intermedia favorable, permite adaptar paulatinamente niño-madre a atenciones más complejas. Las condiciones de la madre durante el embarazo, pueden haber influido en la situación dentaria del niño. Pronóstico, favorable siempre que la madre comprenda la importancia de cuidados bucales en el hogar y de los controles odontológicos.
EPIDERMOLISIS BULOSA SIMPLE $Y$ CARIES TEMPRANA DE LA INFANCIA DERIVACIÓN OPORTUNA DEL PEDIATRA. CASO CLÍNICO

Zillmann GG*, Yubero GMJ (Pd), Cereceda MMA.

Facultad de Odontología. Universidad de Chile. Hospital Padre Hurtado, Debra Chile.

La Caries temprana de la infancia (CTI), es una patología bucal que se presenta en niños menores de 71 meses de vida. Factores predisponentes son las hipoplasias del esmalte (H.E.) por trastornos sistémicos en el embarazo o en período neonatal, con hipocalcemia durante la mineralización del esmalte. Hay factores locales asociados que están relacionados con ingesta frecuente de hidratos de carbono, consistencia blanda de alimentos, uso de biberón, ingesta de líquidos dulces, medicamentos azucarados y falta de higiene bucal. La epidermolisis bulosa es una enfermedad genética en que una proteína estructural de la piel (zona de la membrana basal) esta total o parcialmente ausente. La causa de ello es la mutación en el gen correspondiente. En algunos casos estos pacientes presentan alteraciones hipoplásicas del esmalte dentario (H.E.). Las Hipoplasias del esmalte en dientes primarios, se asocian a alteraciones metabólicas, hipoxia, ictericia neonatal, deficiencias nutricionales y concentraciones bajas en calcio. Caso clínico: Niño: niño 24 meses, sin riesgo social, con epidermolisis bulosa simple. Madre: epidermolisis bulosa simple. Embarazo de término, cesárea. Peso nacimiento: $3,250 \mathrm{~kg}$. Lactancia materna exclusiva: 6 meses. Salud general: epidermolisis bulosa simple. Presenta lesiones en las manos. Motivo de consulta: Derivado por pediatra desde Fundación Debra Chile. (Distrophic EB Research Association), que otorga educación y cuidados odontológicos especiales a niños con E.B. Diagnóstico clínico: Caries temprana de la infancia e hipoplasia del esmalte en paciente con riesgo biológico. Plan de tratamiento: a) Educación a la madre; b) Control del medio bucal: higiene, modificación y adecuación de la dieta. Eliminación paulatina de la mamadera; c) Fluor: NaF 0,05\% topicación diaria en hogar. Barniz NaF 5\%, bimensual; d) Tratamiento local: cariostático (diamino fluoruro de plata) en incisivos y molares; e) Controles mensuales y tratamiento restaurador estético en cuanto su comportamiento lo permita (Vidrioionómero). Conclusiones: La condición sistémica de la madre durante el embarazo, cesárea y/o las condiciones biológicas del paciente en sus primeros meses de vida pueden haber influido en la salud bucal del paciente. Pronóstico: favorable, por derivación oportuna desde un equipo multidisciplinario y el compromiso materno con la salud de su hijo. Palabras claves: Epidermolisis bulosa simple (EB). Caries temprana de la infancia (CTI). Cariostáticos.

PREVALENCIA DE CARIES DENTAL Y FACTORES ASOCIADOS EN NIÑOS Y NIÑAS QUE ASISTEN A LA EDUCACIÓN PREESCOLAR DEL ÁREA NORTE DE LA REGIÓN METROPOLITANA. 2007

Rodríguez G, Aranda ChW, Pizarro DV, Zillmann GG. Facultad de Odontología, Universidad de Chile. Facultad de Odontología, Universidad Mayor

La caries es una enfermedad bucal infecciosa de alta prevalencia. En Chile, a los 2 años el $83 \%$ está libre de caries; a los 4 años el $51,98 \%$ (R. Metropolitana). A nivel nacional a los 6 años (dentición mixta) $29,64 \%$ y a los El ceo y el COP refleja el daño dentario (dientes cariados, obturados, perdidos por caries). La distribución del ceo por edad es: los a 2 años $(0,54)$; a los $4(2,32)$. A los 6 años $\operatorname{COP}(0,15)$ y ceo $(3,71$. (MINSAL 2007). EI COP-ceo no revela la inequidad en la distribución real de la enfemedad. Actualmente existe el Indice Significante de Caries (SIC,), establece el daño promedio del tercio de la población que concentra el mayor valor del COP, es complementario al COP. Existen factores de riesgo asociados a caries como: alimentos cariogénicos, higiene oral, lactancia materna prolongada, consumo de bebidas entre otros. En relación con Caries Temprana de la Niñez en la población de niños y niñas entre 2 y 6 años, que asiste a educación preescolar del área Norte de la Región Metropolitana. Objetivos: - Establecer la prevalencia de caries y el índice ceo-d y el índice significante de caries. - Determinar los hábitos relacionados con alimentación e higiene bucal e identificar cuales de ellos se encuentran más relacionados con la presencia de la enfermedad. Material y Método: Estudio observacional de corte transversal. Niños de jardines Infantiles Junji, Integra, municipalizados, particulares subvencionados, de las comunas del área norte de la R.M: Conchalí, Quilicura, Recoleta, Independencia, Huechuraba, Colina, Lampa y Til-Til. Muestra estratificada por conglomerados. U: 23.672 , u: 380 . Registro clínico: criterios y métodos diagnósticos OMS. Un examinador calibrado (Kappa 0,9). Cuestionario para padres autoaplicado: hábitos de higiene, ingesta de alimentos, consumo bebidas, etc. Solicitud de consentimiento Informado. Resultados: Prevalencia de caries: $48,95 \%$. Índice ceo-d: 2,47 y SIC: 6,61 . Los niveles de educación mayor (transición menor y mayor) presentan mayor prevalencia de caries que los menores. El cuestionario detecta: a mayor duración de la lactancia materna mayor porcentaje de caries. Inicio temprano de ingesta de alimentos azucarados. A mayor № de ingestas diarias de HC mayor porcentaje de caries. La frecuencia de cepillado no revela una relación con caries. Conclusiones: Se deben establecer programas de salud bucal de atención muy precoz, desde los primeros niveles del párvulo. 
NIVEL DE CONOCIMIENTOS EN ODONTOLOGÍA INFANTL DE MÉDICOS E INTERNOS DE PEDIATRÍA. ANTOFAGASTA 2007

Pietroboni P, Mundaca S, Muñoz M, Tapia D.

Universidad Santo Tomás, Antofagasta.

Estudios nacionales recientes han demostrado que la patología dental tiene una alta prevalencia tanto en niños como adultos. Se registran cifras tan altas como un $85 \%$ de caries en niños entre 6 y 8 años (MINSAL. Dpto. de Salud Bucal), a igual que las alteraciones dentomaxilares, enfermedades gingivales, enfermedades períodontales y trauma dentario. Objetivo: Evaluar el nivel de conocimiento adquirido por internos de medicina y médicos generales que trabajan en atención primaria de salud (APS) sobre salud y patología oral infantil. Material y Método: Se confeccionó un cuestionario de selección múltiple y reconocimiento de patologías a través de imágenes, el cual se aplicó a una muestra significativa de internos de pediatría y de médicos de APS. Los datos obtenidos se tabularon en Microsoft Excel 2003 y se presentan en tablas y gráficos. Resultado: Los 32 encuestados, en promedio obtuvieron un $47,8 \%$ de respuestas correctas; $59,4 \%$ en la evaluación teórica y un $38,4 \%$ en reconocimiento de imágenes. Expresado en una escala con ponderación al $60 \%$ para nota 4,0 obtuvieron como promedio general una nota 3,3; promedio internos 3,5 y promedio médicos APS 3,0. Discusión: El nivel de conocimiento sobre odontología infantil en internos de pediatría y médicos generales de APS es deficiente. Por este motivo, proponemos incluir dentro del los programas de pediatría, tanto para $V$ año como para el internado de esta especialidad, una unidad que trate los contenidos acerca de este tema.

\section{MADURACIÓN DE LA DEGLUCIÓN EN UNA POBLACIÓN PEDIÁTRICA}

Fernández MA, Álvarez W, Palomino HM, Villanueva $P$.

Facultad de Medicina y Facultad de Odontología. Universidad de Chile.

Introducción: La deglución es una función que se encuentra presente en los seres humanos desde el período fetal, cumpliendo un rol fundamental para la vida. Normalmente existe un patrón de deglución infantil y un patrón de deglución adulta, los cuales tienen características específicas. Sin embargo, aún no existe consenso en relación a la edad en la cual debería ocurrir este cambio, variando entre los 2 a 4 años de edad, lo cual estaría relacionado con la evolución de la dentición y la consistencia de alimentos ingeridos. Este proceso de evolución de la deglución es de suma importancia durante el control sano pediátrico, para poder detectar a tiempo una alteración en este proceso. Objetivo: Comparar los patrones de deglución en un grupo de niños de 2 a 4 años y correlacionar con la consistencia del alimento que el niño consume. Material y Método: Previo consentimiento informado Se aplicó un cuestionario a los padres de 212 menores con oclusión normal. En llos menores estudiados se realizó una evaluación de estructuras y funciones orofaciales. El análisis estadístico se efectuó mediante $\chi^{2}$. Resultados: El $91,2 \%, 72,4 \%$ y $67,1 \%$ de los niños entre $2,0-2,11,3,0-3,11$ y 4,0-4,11 años, respectivamente, presentó deglución infantil. No se encontraron diferencias significativas entre el tipo de deglución que presentaban y la consistencia de alimento que consumían. Conclusión: Todos los grupos etáreos estudiados presentaron una alta frecuencia de patrón deglutorio infantil, sin embargo, éste va disminuyendo a través del tiempo. La consistencia de alimentos no influyó en el tipo de deglución.

\section{PATÓGENOS PERÍODONTALES EN NIÑOS DE 8 A 11 AÑOS DE DOS COLEGIOS DE LA RM. ASOCIACIÓN CON GINGIVITIS}

Palma FP, Gajardo RM.

Facutad de Odontología, Universidad de Chile.

Introducción: Gingivitis y períodontitis, ambas enfermedades períodontales, son infecciones crónicas del conjunto de estructuras que sostienen los dientes y que constituyen el períodonto. Estas enfermedades alteran en gran medida la calidad de vida de las personas ya que inicialmente producen sangrado gingival y halitosis pero luego, cuando la enfermedad progresa, se produce movilidad dentaria y finalmente pérdida de los dientes afectados. Aunque está claro que estas enfermedades son multifactoriales y polimicrobianas, se ha demostrado que una de las principales especies bacterianas involucradas en su inicio y patogénesis, es Porphyromonas gingivalis. Esta es una especie de bacterias Gram negativo, anaeróbicas estrictas, capaces de adherirse, colonizar e invadir los tejidos del hospedero. Además, ya que $P$. gingivalis se asocia a patologías sistémicas, como enfermedades cardiovasculares, diabetes y partos prematuros, es de gran importancia realizar su detección precoz con el fin de contribuir a la prevención de estas enfermedades y de Períodontitis en el niño y el adolescente. Objetivos: Detectar la presencia de $P$. gingivalis en un grupo de escolares chilenos de 8 a 11 años de edad provenientes de la Región Metropolitana, y su asociación con gingivitis. Material y Método: Se tomaron muestras de placa bacteriana de surco gingival, dorso lingual y saliva completa a 30 escolares de 8 a 11 años de edad, provenientes de 2 colegios de la Región metropolitana las que fueron cultivadas en medios no selectivo (agar Columbia) y selectivos (agar Dentaid 1 y CVE). La identificación se realizó por medio de la morfología colonial, pruebas rápidas y uso de baterías bioquímicas comerciales. Resultados: Todos los niños evaluados presentaron gingivitis (60\%gingivitis leve, $40 \%$ gingivitis moderada). $P$. gingivalis fue detectado en un $47 \%$ de los niños. No hubo diferencia significativa entre gingivitis leve y moderada. Conclusión: $P$. gingivalis esta presente en la microbiota bucal de niños con gingivitis, hecho que constituye un factor de riesgo importante para el desarrollo de Períodontitis y de Patologías Sistémicas en el niño, en el adolescente y más tarde en el adulto.

\section{UN MÉTODO RÁPIDO PARA LA ESTIMACIÓN DE LA CAPACIDAD AERÓBICA Y DE UN FACTOR INTRÍNSICO DE RIESGO CARDIOVASCULAR EN ADOLESCENTES, EN LA CONSULTA MÉDICA}

Tapia ZJI, Morales CAA, Araneda GMI, Tapia UPA, Siegmund SD, Tapia UCA. Hospital Guillermo Grant Benavente, Concepción. Facultad de Medicina, Universidad de Concepción.

La prevención primaria de la enfermedad cardiovascular es responsabilidad del Pediatra. Se ha demostrado un vínculo estrecho entre la condición física y riesgo cardiovascular. El tiempo de recuperación de la frecuencia cardíaca es un factor independiente de riesgo, asociado a mortalidad por eventos cardíacos en adultos. Objetivo: Estandarizar un método simple que permita estimar en la consulta médica, la recuperación de la frecuencia cardíaca y el consumo de Oxígeno máximo. Pacientes y Métodos: 27 adolescentes entre 10 y 16 años evaluados con protocolo de Bruce en el Test de Esfuerzo máximo y un Test de extensión de triceps con una mancuerna de $1,5 \mathrm{Kg}$ en 60 según dos. Se calcula el Vo2máx y la curva de recuperación de la Fc en 6 min post Test de esfuerzo, que se correlaciona con el № de extensiones logrados y la curva de Fc en tiempo real, durante el trabajo con la mancuerna. Resultados: La correlación de Pearson para VO2máx con el № de extensiones de triceps fue de 0,60795 y la dos curvas de recuperación de Fc siguen un patrón similar. Conclusión: Es posible discriminar en un box de atención médica, a bajo costo, y con un buen nivel de certeza, los adolescentes que tienen un factor intrínsico de riesgo cardiovascular elevado (tiempo de recuperación prolongado) y un menor consumo de oxígeno, como screnning en la prevención primaria de la enfermedad cardiovascular. 


\section{APLICACIÓN DE ENCUESTA DE CALIDAD DE VIDA A NIÑOS EPILÉPTICOS EN CONTROL EN CONSULTORIO DE APS ADOSADO DE UN HOSPITAL TIPO IV}

Bustos RC, Zagal CD, Andino SP, Orellana PJ.

Hospital La Calera.

Introducción: La calidad de vida es un concepto que engloba los aspectos físico, psicológico y social del bienestar de las personas y que se define por la evaluación, objetiva y subjetiva, que la persona hace de su condición de vida. Po lo anterior es posible plantear que la aparición de una enfermedad puede altera la calidad de vida, especialmente en el caso de una enfermedad crónica y de difícil manejo en el $30-40 \%$ de los casos como es la Epilepsia. Objetivos: Describir la calidad de vida de los niños epilépticos en control en nuestro hospital y determinar cuales son los factores más alterados y en que forma el equipo de salud a cargo de estos pacientes puede actuar para mejorarla. Métodos: Se aplicó Encuesta validada para niños El Salvador al adulto responsable del niño en los controles de epilepsia infantil realizados por Médico. Se excluyeron niños con convulsiones febriles y aquellos sin controles regulares. Resultados: Del tota de niños en control 17, 5 se excluyeron por no cumplir requisitos. La encuesta se aplico a 12 niños fue respondida en el $100 \%$ de los casos fue la madre. La edad promedio de los niños encuestados fue de 11,4 años con un rango desde los 7 a los 14 años. El $50 \%$ de los pacientes correspondieron al sexo masculino. El $25 \%$ (3) de los niños asisten a Escuela especial, $50 \%$ a escuela tradicional y $25 \%$ no asisten a la escuela. El $66,7 \%$ (8) de los niños presentan epilepsia refractaria y $33,3 \%$ (4) epilepsia no refractaria. El 50\% (6) de los niños en tratamiento con monoterapia. Los parámetros a evaluar fueron: conducta, asistencia escolar, aprendizaje, autonomía, relación social, frecuencia de crisis, intensidad de las crisis, cumplimiento de los medicamentos y opinión de los padres. El resultado de la medición de calidad de vida arrojo una puntuación promedio de 33 puntos que refleja una buena calidad de vida con puntajes que van desde lo 18 puntos (mala) a los 41 puntos (muy buena). La autonomía fue el parámetro peor evaluado en el $58,3 \%$ (7) de los pacientes y el mejor evaluado fue el cumplimiento de los medicamentos en el $75 \%$ (9 niños). La opinión subjetiva de los padres de la calidad de vida de sus hijos fue en general buena con un puntaje promedio de 4 puntos. Conclusiones: Este trabajo nos muestra que la calida de vida de nuestros niños epilépticos en control es buena a pesar del alto porcentaje de epilepsia refractaria. La Autonomia el parametro peor evaluado puede se trabajado en conjunto con la familia.
EXPERIENCIA DE UN POLICLÍNICO DE INFECCIONES RESPIRATORIAS AGUDAS EN UN HOSPITAL DE BAJA COMPLEJIDAD

Gálvez ChA, Cáceres VF, Rudolph QC, Bálcazar F.

Médicos Hospital de Laja, Servicio de Salud Bío-Bío.

Las Infecciones Respiratorias Agudas del niño son aún importante fuente de morbilidad y mortalidad infantil. Ha existido una disminución de estas debido a las intervenciones realizadas hasta la fecha como la creación a nivel nacional de Programa IRA, de las salas IRA, la campaña de invierno y la incorporación de algunas patologías al GES. Objetivo: Caracterizar a los niños asistentes al Policlínico IRA del Hospital de Laja según sexo, edad, antecedentes familiares, considerando además otras variables personales y médicas como antecedentes, tratamiento, exacerbaciones y Hospitalización. Metodología: Aplicación de un formulario de ingreso adaptado del que se utiliza en el Servicio de Salud Sur Oriente de Santiago a todos los niños en control y a los niños ingresados hasta el 30 de agosto del 2008. Resultados: Del total de la población menor de 20 años $(n=5.661)$ se encuentran en control en el Policlínico IRA 118 lo que corresponde al $2,08 \%$ de la población mencionada. De ellos $54,23 \%(n=64)$ son del sexo masculino y $45,76 \%(n=54)$ del sexo femenino. El promedio de edad es de 8 años, los que fluctúan entre 6 meses y 17 años. Existe un $27.7 \%(n=30)$ de niños con antecedentes familiares de asma o atopia, siendo principalmente hermanos o abuelos. La Edad de ingreso a la Sala IRA es en promedio de 3 años, con los diagnósticos de: $2,54 \%(n=3)$ Rinitis Alérgica, 4,54\% $(n=5)$ Síndrome Bronquial Obstructivo Recurrente y $93,22 \%(n=110)$ Asma Bronquial. En los asmáticos un $54,54 \%$ corresponde a hombres y un $45,45 \%$ a mujeres. Según edad, 7,27\% lactantes, 23,63\% Preescolares, 34,54\% Escolares, 33,63\% Adolescentes. El primer episodio de SBO fue 38\% antes de los primeros 6 meses de vida y en un $81 \%$ antes del primer año de vida. Antecedentes de hospitalización por IRA presentan $37,27 \%(n=41)$. Dentro de los Síntomas continuos como tos con ejercicio y tos nocturna esta presente en $25,45 \%(n=28)$. Del total de niños con Asma Bronquial se encuentran en control a nivel secundario un 13,64 $(n=$ 15). Dentro de los adolescentes un $32,43 \%$ fuma. Durante el año 2007 un $34,54 \%$ $(\mathrm{n}=38)$ presentaron más de dos exacerbaciones, requiriendo hospitalización un $9,09 \%$. Conclusiones: Se observa que existe un predominio de hombres por sobre las mujeres en el policlínico IRA, siendo la edad promedio de ingreso 3 años. El Asma Bronquial, constituye el diagnóstico principal dentro de los pacientes en control, siendo la mayoría del sexo masculino y su mayor incidencia en escolares. De estos, la minoría requirió hospitalización, secundario a exacerbación del cuadro.
PREVALENCIA DE MALNUTRICIÓN POR EXCESO EN ESCOLARES DEL ÁREA SUR DE SANTIAGO. UN ESTUDIO DESCRIPTIVO

\author{
Martínez J, Fuertes $\boldsymbol{P}$, Villanueva $S$
}

Consultorios "Recreo", "Cóndores de Chile"; HEGC.

Introducción: La malnutrición por exceso (ME) es una patología de alta prevalencia en países desarrollados y en vías de desarrollo, siendo un reto para la salud pública. En EE.UU., un $18 \%$ de los niños son obesos, mientras que en Chile (JUNAEB 2006) es de $19,4 \%$ en $1^{\circ}$ básico; existiendo pocos estudios que describan la prevalencia en etapa escolar. Objetivos: Describir la prevalencia de ME en escolares del área sur de Santiago controlados en atención ambulatoria. Método: Se incluyó escolares entre 6 y 10 años de 3 comunas del área sur de Santiago, atendidos por morbilidad entre mayo y agosto del 2008 , sin patologías crónicas que afectaran su estado nutricional. Se constataron medidas antropométricas, sexo y edad y se calculó IMC. Utilizando las tablas CDC (norma MINSAL), se clasificó estado nutricional y talla. Resultados: Se reclutaron 122 pacientes, 65 hombres (53\%) y 57 mujeres (47\%). Del total, $2,5 \%$ presentó bajo peso; $42,6 \%$ eutrofia y $54,9 \% \mathrm{ME}$, subdividiéndose en sobrepeso $(26,2 \%)$ y obesidad (28,7\%) (Tabla 1). Al comparar estado nutricional y talla se observo talla normal alta en $1,6 \%$ de los eutróficos; $2,5 \%$ en sobrepeso y $5,7 \%$ en obesos. Tabla 1. Distribución de estado nutricional según sexo

\begin{tabular}{lccccccc}
\multicolumn{5}{c}{ Tabla 1. Distribución de estado nutricional según sexo } \\
& \multicolumn{2}{c}{ Hombres } & \multicolumn{2}{c}{ Mujeres } & \multicolumn{2}{c}{ Total } \\
& $\mathbf{n}$ & (\%) & $\mathbf{n}$ & (\%) & n & $(\%)$ \\
\hline Bajo Peso & 0 & 0,0 & 3 & 5,3 & 3 & 2,5 \\
Eutrofia & 25 & 38,5 & 27 & 47,3 & 52 & 42,6 \\
Sobrepeso & 19 & 29,2 & 13 & 22,8 & 32 & 26,2 \\
Obeso & 21 & 32,3 & 14 & 24,6 & 35 & 28,7 \\
Total & 65 & 100 & 57 & 100 & 122 & 100
\end{tabular}

Discusión y Conclusiones: Se encontró mayor prevalencia de ME en relación con estadísticas nacionales previas, sin hallar cifras actualizadas que describan este grupo etáreo. La ME es mayor en los niños respecto de las niñas $(P=0,1)$ destacando que la mayoría de la literatura no entrega valores separados por sexo, aunque el tamaño de la muestra podría influir en esta diferencia. De acuerdo a estos resultados, se hace necesaria la mantención de controles sanos hasta la adolescencia, como es la sugerencia de las Academias Americana y Europea de Pediatría, lo que mejoraría la prevención y el manejo de estos pacientes, aumentar la cobertura del programa EGO Chile, así como la realización de más estudios para conocer nuestra realidad, especialmente en la etapa escolar y que incluyan parámetros como insulinemia basal y edad ósea para relacionarlos con los valores de talla normal alta encontrados.

\section{INTERNACIÓN ABREVIADA-UNIDADES DE TERAPIA INHALATORIA}

Gerolami A, Díaz S, Centurión K, Dalgalarrondo A.

Departamento Emergencia Pediátrica. Centro Hospitalario Pereira Rossell. Montevideo-Uruguay.

Introducción: Dado el incremento en la tasa de mortalidad infantil en Uruguay en el año $2007(11,84 \%$ ) en relación al año $2006(10,50 \%$ ) y vinculado a que una de las principales causas de morbi-mortalidad en menores de dos años, son las infecciones respiratorias, surge desde el Ministerio de Salud Pública la inquietud de desarrollar estrategias para estandarizar la atención de este grupo etario, fortaleciendo el primer nivel de atención, implementando, unidades de terapia Inhalatoria, con régimen de internación abreviada. Material y Métodos: Estudio descriptivo, prospectivo de niños asistidos en 7 Unidades de Terapia Inhalatoria (UTI.) durante el período comprendido entre el 10 de junio y 31 de agosto de 2008. Se incluyeron pacientes entre 1 y 24 meses de edad, con SBOL moderado, sin factores de riesgo, que consultaron en los servicios de emergencia de los centros participantes. Fueron tratados según protocolo preestablecido y valorados mediante score de Tal modificado Se entrenó al personal de enfermería para la realización de la tarea. Los datos fueron procesados mediante el programa estadístico SPSS 15.0. Resultados: Se asistieron 1104 pacientes. Fueron derivados a domicilio $72,55 \%$ de los mismos. El promedio de estadía fue de 3,20 hs. El 59,9\% había presentado 1 o más episodios de SBOL, el $61,3 \%$ tiene antecedentes familiares asma y en el $56,9 \%$ hay antecedente ambiental de tabaquismo. El porcentaje de reconsulta en los 7 días posteriores fue del $8,8 \%$. Discusión: La bronquiolitis afecta preferentemente a niños menores de 1 año de vida $(83 \%)$ y predominantemente al sexo masculino $(1,2 / 1)$.la condición de fumador pasivo es un factor de riesgo tanto para la fase aguda como para las secuelas. El alta a domicilio se otorgó a la mayoría de los pacientes luego de la $2^{\circ}$ hora de tratamiento. Hubo un elevado número de altas domiciliarias y bajo índice de reconsultas lo que evidencia la eficacia del funcionamiento del programa instituido. Conclusiones: Se cumplió el protocolo en el $69,5 \%$ de los casos. La mayor parte de los usuarios asistidos en el primer nivel de atención fueron derivados a su domicilio, con la reducción del riesgo de infecciones intrahospitalarias y el beneficio social y económico que esto implica. Se logró el trabajo coordinado entre el $1^{\circ}, 2^{\circ}$ y $3^{\circ}$ nivel de atención, estandarizando un tratamiento en beneficio del usuario. 
DEPRESIÓN EN PREESCOLARES DE LA REGIÓN METROPOLITANA

Godoy PX, Maggi L, Kimelman M.

Hospital Exequiel González Cortés.

Introducción: La depresión es de gran interés en los estudios clínicos, sin embargo, éstos han sido dirigidos a escolares y adolescentes, pero pocas investigaciones se han orientado a describir los patrones emocionales de los preescolares. A nivel internacional se ha estimado prevalencia de 3 a $9 \%$ de trastornos depresivos. Los cuestionarios como el CHECKLIST tienen un alto valor predictivo, cercano al $95 \%$ y que además permite pesquisar en forma rápida y eficiente en la consulta ambulatoria los niños con depresión. Objetivo general: Determina la prevalencia de depresión en preescolares entre 3 y 5,6 años. Hipótesis: La prevalencia de depresión esperada en los 5 sectores de RM es de 3 al $9 \%$. E valor predictivo de CHECKLIST, es mayor al $80 \%$. Metodología: Estudio prospectivo, que se realizó entre Junio y Septiembre del 2008, en niños de edades entre 3 a 5,6 años en diversos lugares de RM. Se tomó una muestra de 1250 niños, el tamaño muestral fue determinado por EPINFO-STATS y se seleccionó 250 niños por cada área de RM dividida en 5 áreas. De los cuales se seleccionó 100 niños con depresión de acuerdo al puntaje obtenido en la: "SCALE THE PRESCHOOL CHILDREN DEPRESSION CHECKLIST" que consta de 32 preguntas que evalúan el ánimo depresivo. Los resultados fueron comparados con ANCOVA, con un $p<0,05$ y se utilizó el programa estadístico SPSS. Resultados: Se observa prevalencia de aproximadamente $3 \%$ dentro de la población asignada. Con un valor predictivo positivo de $92 \%$ en los 100 casos clasificados como depresión. Se observa con un $p<0,05$ que la presencia de figura vincular, hermanos, asistencia al jardín como factores protectores, y dentro de los factores de riesgo se deben considerar eventos estresantes como duelo, enfermedad crónica, VIF. Discusión: Se establece en este estudio la prevalencia de depresión en RM, los problemas de salud mental continúan siendo subestimados dados la escasez de estudios tanto nacionales como internacionales en este grupo. Este trabajo estima una prevalencia en un 3\% a un $9 \%$ dependiendo de sector. Se observa una tendencia a la depresión en niños sometidos a eventos estresantes. Se ha descrito antecedentes desde época preescolar, en adolescentes y adultos deprimidos, con dificultad en el tratamiento. Otro aspecto relevante es que intervenciones pequeñas logran cambios notables en la conducta y en e desarrollo de los niños concordante con la flexibilidad y los estilos cognitivos y afectivos de este grupo de edad.

\section{ESTUDIO DE LA FUNCIÓN MIOCÁRDICA EN NIÑOS CON SOBREPESO $Y$ OBESIDAD}

Herrera ME, Alburquenque M, Schonhaut L, Villarreal V, Lizama $C$. Departamento de Pediatría Ambulatoria, Universidad de Chile, Sede Norte. Unidad de Cardiología Infantil, Hospital Roberto del Río.

Introducción: En niños con malnutrición por exceso se puede iniciar durante la infancia un compromiso miocárdico secundario a factores hemodinámicos y neurohormonales entre otros. Objetivo: Determinar el efecto del sobrepeso y obesidad sobre la función miocárdica. Metodología: Estudio prospectivo casocontrol. Entre Diciembre 2007 y Agosto 2008, en un Centro de Salud Familiar de área norte de Stgo. se enrolaron 40 adolescentes con IMC > p85 según madurez biológica y 40 eutróficos, que consultaron espontáneamente o fueron derivados a pediatría. Se evaluaron en forma ciega por pediatra y cardiólogo infantil, mediante encuesta biodemográfica y de actividad física, recopilación de antecedentes mórbidos personales y familiares. Evaluación antropométrica, medición de presión arterial, examen físico completo, perfil lipídico, glicemia en ayunas, electrocardiograma (ECG) de reposo y ecocardiograma Doppler color con determinación de grosor de paredes y masa de ventrículo izquierdo $(\mathrm{VI})$.La función diastólica se evaluó con Doppler convencional mitral (E, A, E/A y D/T) y Doppler tisular en anillo mitral (ondas e', a y y e'/a'). La función sistólica se evaluó con medición de fracción de acortamiento y eyección de VI, Doppler tisular (s', strain y strain rate) y determinación del índice de TEI. Para el análisis estadístico se utilizó la prueba de comparación de medianas. Resultados: $30 \%$ de los adolescentes con sobrepeso y obesidad y ninguno de los eutróficos presentaron síndrome metabólico; $30 \%$ de los malnutridos por exceso y $18 \%$ del grupo control presentaron hipertensión arterial. En niños con IMC > p85, el ecocardiograma Dopple convencional reveló mayor masa de $\mathrm{VI}$ en relación a talla $(\mathrm{p}<0,05)$, aumento de grosor de las paredes de VI $(p<0,05)$, menor tiempo de desaceleración mitral ( $p$ $<0,05$ ). El Doppler tisular de anillo mitral septal mostró a y $\mathrm{E} / \mathrm{e}^{\prime}$ de mayor valor ( $\mathrm{p}$ $<0,05$ ). El índice de TEI reveló una relajación isovolumetrica prolongada ( $p<$ $0,05)$. El análisis de strain y strain rate no mostró diferencias como tampoco e ECG. Conclusión: Los adolescentes con IMC > p 85 tienen compromiso estructural y funcional miocárdico, compatible con una etapa inicial de miocardiopatía por obesidad. La técnica de Doppler tisular resultó ser de mayor ayuda que la convencional. Estudiar la función cardíaca en niños con sobrepeso y obesidad es fundamental para determinar precozmente el compromiso miocárdico e iniciar la terapia adecuada.
FRECUENCIA DE MEDIDAS PREVENTIVAS DE ACCIDENTES EN HOGARES DE NIÑOS QUE ASISTEN A CONTROL DE SALUD EN UN CENTRO DE ATENCIÓN PRIMARIA

\author{
Parraguez C, Osses $P$, Pavez D, Osses $A$ \\ Consultorio Domeyko.
}

Introducción: Los accidentes constituyen la causa más frecuente de mortalidad en niño entre edades de 1 a 18 años, siendo un problema de salud pública, con picos bimodales en niños de dos a tres años y adolescentes. El propósito de este estudio fue describir algunas características que definen la magnitud del riesgo de accidente en niños menores de 5 años, en control o atención pediátrica en un consultorio de atención primaria de la comuna de Santiago. Los objetivos fueron: a) Determinar que tipos de medidas preventivas de accidentes se aplican en los hogares de esos niños y b) definir el grado de cumplimiento de medidas preventivas, seleccionadas por la autora, en los hogares de estos niños. Material y Método: Se trata de un estudio descriptivo, transversal, realizado con una encuesta autoaplicada a las madres de menores que acudieron a control o consulta de morbilidad el mes de junio de 2007 en el Consultorio Ignacio Domeyko, de la Municipalidad de Santiago. Resultados: Se encuestó un total de 124 personas, que acudieron con igual número de niños. El sexo de los menores fue, en 68 $(55,3 \%)$ masculino; en $55(44,7 \%)$, femenino y en un caso no se consignó. Noventa niños $(72,6 \%)$ eran menores de 2 años y $34(27,4 \%)$ superaban esa edad. Riesgo en situaciones relacionadas con la alimentación. Un 17,5\% dejaba al menor sólo al comer a menudo o pocas veces; mientras el resto $82,5 \%$ no lo hacía. En cuanto a alimentar al niño/a en el instante en que llora o está inquieto, hubo respuesta afirmativa en $47,2 \%$. Un problema frecuente es la quemadura infantil con líquido caliente mientras se alimenta con él quien sostiene al menor. El 16,3\% admitió esa conducta. Riesgo en el juego. Para este análisis se descartó 19 niños que estaban siendo alimentados a pecho En relación al juego con artículos peligrosos fue admitido en $25 \%$. El juego con bolsas de nylon fue admitido en $8,5 \%$ riesgos cotidianos. Un $71,4 \%$ su casa es de un piso, $15,2 \%$ de dos pisos y tienen protección en las escaleras, y un $13,3 \%(n=14)$ no han podido colocar protección Se detectó uso de pulseras, cadenas y medallas en $13 \%$ y se observa una mayor frecuencia de uso en las mujeres. Un 37,4\% reconoció que cuando cocina o enciende fuego su hija/o se encontraba con el cuidador; sin variación por sexo y un $47,2 \%$ admitió no haber revisado, durante el último año, la instalación eléctrica. Un 20,2\% reconoció que algunos (o la mayoría) de los medicamentos, venenos, productos de limpieza, solventes, pinturas, cosméticos y tinturas, se encontraban al alcance de los niños. En relación a la posición más frecuente para dormir: boca abajo llegó a 12,2\%. Un 63,8\% reconoció que su hija/ o usaba o había usado andador; sin variación por sexo. Conclusión: Conductas de riesgos evitables aún existen pese a diferentes esfuerzos. DESARROLLO PSICOMOTOR: CORRELACIÓN ENTRE AGES \& STAGES
QUESTIONNAIRES (ASQ) Y TEST DE BAYLEY EN LACTANTES DE 8 MESES

Schonhaut L, Salinas P, Armijo I, Álvarez J, Schonstedt M, Manríquez M. Clínica Alemana de Santiago-Universidad del Desarrollo.

Introducción: La pesquisa precoz de alteraciones del desarrollo psicomotor (DSM), mediante cuestionarios aplicados a padres y/o cuidadores, ofrece muchas ventajas y ha demostrado ser un método efectivo y de bajo costo. Ages \& Stages Questionnaires (ASQ) es uno de los métodos mejor validado y estudiado. Es necesario evaluar cómo se comporta esta herramienta de screening en nuestro medio. Objetivo: Evaluar la correlación entre ASQ y test de Bayley en lactantes de 8 meses de edad, de nivel socio económico medio alto y alto. Metodología: Estudio transversal analítico. Se enrolaron, en forma secuencial, 40 lactantes de 8 meses que acudieron a control sano con sus pediatras entre mayo y septiembre 2008. Se excluyeron los prematuros, niños con alteración del DSM previamente conocida, hijos de padres cuyo idioma nativo no era español y los que rechazaron participar. Los lactantes fueron sometidos en forma ciega a ASQ y posteriormente test de Bayley aplicado por terapeuta ocupacional. Se evaluó la correlación entre ambos test, considerando significativo un $r>0,3$. Resultados: Al 30 de septiembre, se enrolaron 38 lactantes, $47 \%$ de sexo masculino. De acuerdo a la evaluación con Bayley, 8 lactantes $(21 \%)$ presentaron riesgo y 2 $(5 \%)$ retraso del DSM, no hubo diferencias entre ambos sexos; salvo un caso, los déficit del desarrollo fueron del área motriz gruesa, todos con buena evolución posterior. La correlación fue significativa en el área de motricidad gruesa ( $r$ $0,66)$ y no hubo correlación en las demás áreas evaluadas: motricidad fina ( $r$ $0,18)$, desempeño cognitivo (r 0,17$)$ y comunicación ( $r 0,12)$. Conclusión: La mayor correlación en la evaluación de motricidad gruesa podría ser esperable, dado que esta es el área cuyo desarrollo es más evidente en este grupo etáreo y, por lo tanto, a la que padres y pediatras prestan mayor atención. El área de la motricidad gruesa concentró además la mayor frecuencia de déficit del DSM, déficit que fue de buen pronóstico gracias a la intervención realizada. EI ASQ debería ser una herramienta costo/efectiva, tiempo/efectiva y factible de implementar en la consulta de pediatría ambulatoria, para la evaluación de ciertos ítems de DSM en lactantes de 8 meses. Aún faltan estudios que permitan ajustar en forma adecuada los puntos de corte para detectar los retrasos de DSM en las distintas áreas que mide el test. Proyecto 2008013 financiado por el Concurso de Proyectos SOCHIPE 2008. 


\section{MANTENCIÓN DE LACTANCIA MATERNA EXCLUSIVA EN MENORES DE 6 MESES HOSPITALIZADOS EN SALA DE PEDIATRÍA DEL HOSPITAL EL PINO}

Muñoz MM, Ints. Muñoz MC, Rojas AS.

Unidad de Hospitalizados, Servicio de Pediatría, Hospital y CRS El Pino. Universidad de Santiago de Chile.

Introducción: La lactancia materna exclusiva (LME) reduce la morbimortalidad infantil y tiene amplios beneficios en la protección de la infancia, siendo la recomendación alimentaria en el menor de 6 meses. En Chile la principal causa de suspensión de la LME corresponde a una insuficiencia primaria (64\%), p. ejemplo, mala técnica de lactancia, mientras que en el resto es debido a hospitalizaciones, enfermedades de la madre y/o hijo, embarazo-maternidad y a la libre prescripción de fórmulas lácteas. La hospitalización al disminuir la prevalencia de LME, hace de su mantención un indicador de calidad. Las exigencias nacionales son lograr una mantención de LME al egreso mayor a 10\% de quienes ingresan con ella. Objetivos: Caracterizar los lactantes menores de 6 meses que ingresan con LME y categorizarlos según días de hospitalización, patología prevalente y edad materna. Materiales y Métodos: Estudio descriptivo retrospectivo mediante revisión de fichas clínicas de los lactantes menores de 6 meses hospitalizados en la Unidad de Sala del Servicio de Pediatría del Hospital E Pino entre Enero-Julio de 2008. Se seleccionaron aquellos pacientes que ingresaron, mantuvieron y egresaron con LME y se compararon con aquellos que ingresaron con LME y egresaron con Fórmulas de Inicio con o sin LM. Resultados: De un total 76 pacientes estudiados, $44(57,8 \%)$ eran hombres. Promedio global de edad 2,2 meses. De ellos $24(31,5 \%)$ pacientes ingresaron con LME; de los cuales, $17(70,8 \%)$ pacientes mantuvieron LME al egreso hospitalario. Las características del grupo que mantuvo LME fueron: días promedio de hospitalización 3,29 días, la patología prevalente fue ITU baja $(n=5 ; 29,4 \%$ y el promedio de edad de la madre 23,8 años. Las características de quienes no mantuvieron LME al egreso fueron: promedio de estadía 4,1 días, patología prevalente fue síndrome diarreico agudo y edad promedio de la madre 23,08 años. Conclusiones: Existe una buena mantención de LME, superior a las exigencias nacionales. No se observan diferencias en cuanto a días de estadía ni edad de la madre respecto a grupo control. De quienes mantuvieron LME la patología prevalente fue ITU baja $(n=6 ; 35,2 \%)$, y de quienes no la mantuvieron fue síndrome diarreico agudo $(n=3 ; 42,8 \%)$. Esto último podría ser atribuido a los meses en que se realizó el estudio.

\section{EFECTO DE LA HOSPITALIZACIÓN SOBRE LA LACTANCIA MATERNA (LM) EN NIÑOS MENORES DE 6 MESES DE EDAD}

Cardoso I, Jaime F, Carrillo D, Valdés V, Soto M, Menchaca $G$.

Hospital Sótero Río, Hospital Clínico Pontificia Universidad Católica de Chile.

Introducción: Es conocida la menor frecuencia de morbilidad y hospitalizaciones de niños alimentados con LM. Nuestro objetivo es conocer la frecuencia de LM previo al ingreso al hospital por morbilidad aguda y posterior al alta. Materia y Métodos: Estudio prospectivo de cohorte, realizado en el Hospital Sótero de Río entre febrero-marzo 2008. Se incluyó todos los lactantes menores de 6 meses hospitalizados en este período. Se excluyó los niños abandonados por sus madres y aquellos con trastorno grave de deglución. Se realizó una encuesta a ingreso sobre el tipo de alimentación recibida previo a la hospitalización. Se registró las características de la hospitalización y se realizó una encuesta telefónica a las 2 y 6 semanas post alta. Resultados: 73 lactantes menores de 6 meses cumplieron con los criterios de inclusión, con edad promedio de 2,4 41,7 meses, $57 \%$ eran hombres. Duración de hospitalización $6,3 \pm 5,5$ días. No hubo diferencia en días de hospitalización entre los alimentados con LME y aquellos sin LME. El 91,7\% de los pacientes recibían LM previo a la hospitalización, de ellos sólo el 19,4\% recibía LM exclusiva (LME). Ningún paciente mayor de 3 meses ingresó al hospital con LME. 37\% de ellos ingresó a la UPC. El promedio de días en UPC fue el doble en los niños que ingresaron sin LME $(4,7$ vs 2,9 días). A las 2 semanas posteriores al alta recibían LME el $29 \%$ y a las 6 semanas el $33 \%$, diferencia no significativa respecto a LME reportada previo a ingreso. Conclusiones: En este trabajo, la hospitalización no disminuyó la LME al alta, incluso hubo un aumento, lo que puede ser reflejo del esfuerzo que hace el personal de salud en promover la LME, y el permitir que la madres puede permanecer las 24 hrs con su hijo. Pero impacta el bajo porcentaje de niños en lactancia exclusiva que ingresan $(19,4 \%)$
PROGRAMA DE PROMOCIÓN DE ESTILO DE APEGO SEGURO Y CONSTRUCCIÓN DEL PRIMER VÍNCULO EN NIÑOS CON HOSPITALIZACIÓN PROLONGADA POR ENFERMEDADES RESPIRATORIAS CRÓNICAS

\section{Castro $M$.}

Hospital Josefina Martínez.

Introducción: El promover el Apego y la estimulación precoz es un derecho que no debe ser vulnerado por hospitalizaciones y enfermedades crónicas. La intervención precoz y en familia asegura un apropiado neurodesarrollo y adaptación social. Los hospitales de estancia prolongada deben colaborar en desarrollar este concepto en los padres y en sus cuidadores, promoviendo ambientes cariñosos. Objetivo: Describir un programa para la promoción de estilos de Apego Seguro en madres, padres y/o cuidadores durante una hospitalización prolongada (> 30 días). Metodología: Un taller de 7 sesiones teórico prácticas para los padres y una sesión teórica para los técnicos paramédicos que incluyan conocimientos básicos en apego, construcción del primer vínculo, estimulación precoz, respuesta sensible, capacitación en técnicas de cuidados básicos y el impacto de estas acciones en el neurodesarrollo. Se realizará una evaluación de procesos y resultados. Comentarios: El programa descrito entrega en forma sistemática herramientas cognitivas, afectivas y pautas conductuales que sustenten la construcción del primer vínculo y estimulación precoz en niños con enfermedades respiratorias crónicas con hospitalización prolongada.

TAMA FAMIL, DIAGNOSTICO PARTICIPATIVO DE LAS NECESIDADES EDUCATIVAS DE PADRES Y/O CUIDADORES DE NINNOS CON ENFERMEDADES RESPIRATORIAS CRÓNICAS

Castro M, Navarro S, Aldana C.

Hospital Josefina Martínez.

Introducción: La escuela para padres/cuidadores se orienta a entregar los contenidos educativos proporcionales a las necesidades de los pacientes en áreas generales de los cuidados pediátricos y específicos de las enfermedades respiratorias crónicas (ERC). La metodología de Educación para Adultos (EA) logra identificar las necesidades educativas (NE) y a su vez planificar y evaluar el impacto de estas intervenciones. Objetivo: Identificar las necesidades educativas (NE) de padres/cuidadores de niños con ERC hospitalizados en el HJM. Metodología: Diagnóstico participativo con dinámicas grupales y plenarias. Resultados: Las NE manifestadas por 18 cuidadores/18 pacientes, se agruparon en 2 áreas, cognitiva y recreación. Área cognitiva (18): cuidados y manejo de la enfermedad (10), desarrollo personal (3), relaciones interpersonales (5). Área recreación (9). Se planificó un calendario de 33 sesiones quincenales de psicoeducación con 2 profesionales/sesión. Desde abril-septiembre 2008 se han realizado 10/33 sesiones (desarrollo personal $=4$, recreacional $=6$ ). Comentarios: El diagnóstico participativo permitió planificar contenidos educativos no sólo centrados en el manejo de la enfermedad, sino que abordando las necesidades integrales de los padres/cuidadores sistematizadas en una escuela con participación interdisciplinaria. 
ESTIMULACIÓN MOTORA EN PACIENTES CON VENTILACIÓN MECÁNICA PROLONGADA Y TRAQUEOSTOMÍA: REVISIÓN DE 3 CASOS UTILIZANDO LA ESCALA DE EVALUACIÓN DEL DESARROLLO PSICOMOTOR (EEDP) Y TERAPIA DE NEURODESARROLLO (NDT)

Mödinger $\boldsymbol{P}$, Moscoso G, Sánchez M, Prado F, Salinas $P$. Hospital Josefina Martínez.

Introducción: Lactantes prematuros con DBP frecuentemente presentan retardo del desarrollo psicomotor pobremente abordado en aquellos con ventilación mecánica prolongada (VMP). Objetivos: Describir la experiencia de planes de estimulación neuromotora en pacientes con DBP y VMP. Pacientes y Métodos: Instrumento de evaluación: EEDP y NDT. Reporte de 1 año seguimiento (20072008) de 3 pacientes con DBP + VMP y RDSM severo de predominio motor Resultados: En todos los niños hubo mejoría en el desarrollo neuromotor con apropiado logro de los hitos en aquellas con mayor retardo para la edad.

\begin{tabular}{|c|c|c|c|c|c|c|c|c|c|}
\hline \multirow{2}{*}{\multicolumn{4}{|c|}{$\begin{array}{l}\text { Tipo evaluación } \\
\text { Año evaluación }\end{array}$}} & \multicolumn{6}{|c|}{ NDT } \\
\hline & & & & \multirow{2}{*}{\multicolumn{2}{|c|}{$\begin{array}{l}2007 \\
\text { Total }\end{array}$}} & \multirow{2}{*}{\multicolumn{2}{|c|}{$\begin{array}{c}2007 \quad 2008 \\
\text { Área } \\
\text { motora }\end{array}$}} & \multirow{2}{*}{\multicolumn{2}{|c|}{$\begin{array}{l}2007 \quad 2008 \\
\text { Control } \\
\text { cefálico }\end{array}$}} \\
\hline Pcte. & $\begin{array}{c}\text { Edad } \\
(\mathrm{m})\end{array}$ & $\begin{array}{c}\mathrm{EG} \\
(\text { sem) }\end{array}$ & $\begin{array}{c}\text { PN } \\
\text { (grs) }\end{array}$ & & & & & & \\
\hline W.P. & $24 m$ & 28 & 1.200 & Rt & $\mathrm{R}$ & $\mathrm{Rt}$ & $R$ & RN & $N$ \\
\hline V.P. & $24 \mathrm{~m}$ & 27 & 954 & Rt & $\mathrm{R}$ & Rt & R & $\mathrm{RN}$ & $\mathrm{N}$ \\
\hline J.L. & $24 \mathrm{~m}$ & 26 & 730 & Rt & $\mathrm{R}$ & Rt & $\mathrm{R}$ & $\mathrm{RN}$ & $\mathrm{N}$ \\
\hline \multirow{4}{*}{\multicolumn{2}{|c|}{$\begin{array}{l}\text { Tipo evaluación } \\
\text { Año evaluación } \\
\text { Pcte. }\end{array}$}} & \multirow{4}{*}{\multicolumn{2}{|c|}{$\begin{array}{c}2007 \quad 2008 \\
\text { Control } \\
\text { Sedente }\end{array}$}} & \multicolumn{6}{|c|}{ NDT } \\
\hline & & & & \multirow{3}{*}{\multicolumn{2}{|c|}{$\begin{array}{l}2007 \quad 2008 \\
\text { Posición } \\
\text { Cuadrupeda }\end{array}$}} & & 007 & \multirow{2}{*}{\multicolumn{2}{|c|}{2008}} \\
\hline & & & & & & & & & \\
\hline & & & & & & & & & \\
\hline \multicolumn{2}{|l|}{ W.P. } & $\mathrm{RN}$ & $\mathrm{N}$ & $\mathrm{RN}$ & Rt & & $\mathrm{RN}$ & \multicolumn{2}{|c|}{$\mathrm{N}(10 \mathrm{~m})$} \\
\hline \multirow{2}{*}{\multicolumn{2}{|c|}{$\begin{array}{l}\text { V.P. } \\
\text { J.L. }\end{array}$}} & RN & $\mathrm{N}$ & & Rt & & $\mathrm{RI}$ & \multirow{2}{*}{\multicolumn{2}{|c|}{$N(7 \mathrm{~m})$}} \\
\hline & & RN & $\mathrm{N}$ & RN & $\mathrm{N}$ & & $\mathrm{RN}$ & & \\
\hline
\end{tabular}

${ }^{*} \mathrm{EG}=$ Edad Gestacional, $\mathrm{PN}=$ Peso Nacimiento, $\mathrm{RT}=$ Retraso, $\mathrm{R}=$ Riesgo,

$\mathrm{RN}=$ Recién Nacido, $\mathrm{N}=$ Normal, ()$=$ edad del desarrollo.

Conclusiones: Los planes de estimulación neuromotora son efectivos en mejorar el neurodesarrollo motor sin dificultar la VMP.
CARACTERIZACIÓN DEL PACIENTE FEBRIL AGUDO SIN FOCO AL INGRESO A SALA DE PEDIATRIA DEL HOSPITAL EL PINO. REVISIÓN DE UN AÑO

Sanhueza GP, Sepúlveda TJ, Muñoz MC, Muñoz MM Servicio de Pediatria, Hospital El Pino. Santiago.

Introducción: La fiebre es motivo frecuente de consulta en Urgencia pediátrica. Se define Síndrome febril agudo sin foco (SFASF), como fiebre $>38,3$, de menos de 7 días de evolución, con compromiso variable del estado general, y tras una cuidadosa anamnesis, examen físico y laboratorio básico, permanece sin etiología evidente al momento del ingreso hospitalario. Habitualmente, los agentes responsables corresponden en su mayoría a etiología viral benigna y autolimitada. Sin embargo, en ocasiones no se identifica la causa específica que la produce. Estos datos en el Hospital El pino se desconocen. Objetivos: Determinar la prevalencia de pacientes con SFASF, al ingreso a sala de pediatría y categorizarlos según variables de sexo, edad y etiologías prevalentes en los diagnósticos de egreso hospitalario. Materiales y Métodos: Estudio descriptivo retrospectivo mediante análisis de fichas clínicas y datos estadísticos hospitalarios, de todos los pacientes ingresados al servicio de pediatría del Hospital El Pino entre Enero a Diciembre 2007. Del total de pacientes, se seleccionó los ingresados con diagnóstico de SFASF. Resultados: De 1619 pacientes, 85 ingresaron con SFASF $(5,25 \%), 51(60 \%)$ eran hombres y $34(40 \%)$ mujeres. E promedio de edad fue 2,9 años. La prevalencia según etiología fue: infecciosa ( $=59,69 \%)$, mesenquimopatía $(n=2,2,3 \%)$, quirúrgicas $(n=1,1,1 \%)$ y $\sin$ diagnóstico $(n=23,27 \%)$. Dentro de la etiología infecciosa $(n=59)$ : viral $(n=$ $39,66 \%)$; bacteriana $(n=19,32,3 \%)$ y parasitaria $(n=1,1,7 \%)$. Las causas bacterianas correspondieron a: Pielonefritis aguda $(n=12,63 \%)$, neumonía ( $n=$ $4,21 \%)$, síndrome disentérico $(n=1 ; 5,2 \%)$, meningitis $(n=1 ; 5,2 \%)$, enfermedad por arañazo de gato $(n=1 ; 5,2 \%)$. Dentro de las virales: infección respiratoria alta $(n=17 ; 43,6 \%)$, Infección respiratoria baja $(n=8 ; 20,5 \%)$, síndrome diarreico agudo $(n=7 ; 18 \%)$ y exantemas $(n=6 ; 15,4 \%)$. Conclusiones: SFASF corresponde al $5,25 \%$ del total de ingreso a sala de pediatría. De ellos, $73 \%$ se identifica el foco febril. Dentro de las etiologías identificadas, la infecciosa es más prevalente, siendo la etiología viral $(66 \%)$ más frecuente sobre la bacteriana (32\%) y de esta última la PNA su principal causa, concordante con estudios nacionales. Sin embargo, en un $27 \%$ de los casos no se pesquisa etiología, a pesar del estudio inicial. Esto se puede atribuir por la característica autolimitada y benigna de la mayoría de ellos que no induce a realizar mayores estudios sobre la etiología inicial.

CARACTERIZACIÓN DE ALTE EN EL HOSPITAL DR. SÓTERO DEL RÍO: MIRADA RETROSPECTIVA PARA UNA INTERVENCIÓN

Valdebenito SC, Carrillo VD, Calderón CG, Menchaca OG, Capo VE, Cavagnaro SP, Brockmann VP, Sandoval SG.

Pontificia Universidad Católica de Chile.

Introducción: Los eventos de aparente amenaza a la vida (ALTE) generan grandes conflictos. La incidencia es variable; se describen alrededor de $0,6 \mathrm{ca}-$ sos/1000 nacidos vivos, no conociéndose la real prevalencia en Chile. Sus etiologías son múltiples; un alto porcentaje serían idiopáticos y otros secundarios a reflujo gastroesofágico (RGE), infección respiratoria viral, convulsión y mala técnica de lactancia. Aún no existe consenso sobre cómo manejar a estos pacientes ni su repercusión a largo plazo. Objetivo: Describir la situación en relación al diagnóstico, estudio, manejo y complicaciones de ALTE. Pacientes y Métodos: Estudio descriptivo entre Enero 2007 y Marzo 2008, en el que se incluyeron pacientes que ingresaron con diagnóstico de ALTE y aquellos que, por historia, cumplían criterios pese a ingresar con otro diagnóstico. Se excluyeron: SBO diagnosticado la semana previa, historia clásica de coqueluche y malformación mayor de vía aérea. Resultados: Se preseleccionaron 131 fichas obteniendo sólo 97. Veintisiete cumplían criterios de ALTE, excluyéndose una por información incompleta. La edad promedio fue 46,6 días; $34,6 \%$ eran pretérminos (EG promedio 34,3 semanas) sin diferencia por género. $61,5 \%$ tenían antecedentes familiares predominando epilepsia $(30,8 \%)$. Sólo $11(42,3 \%)$ ingresaron con diagnóstico de ALTE. Las manifestaciones clínicas más frecuentes fueron: apnea y cianosis $(38,5 \%)$, cianosis y cambio de tono muscular $(19,2 \%)$ y sólo cianosis $(11,5 \%)$. Veintitrés pacientes requirieron maniobras de reanimación básica y sólo 2 avanzadas. El promedio de hospitalización fue 9.6 días. Siete pacientes presentaron alguna infección intrahospitalaria. A todos se les realizó Cell dyn, PCR, Gases, PBQ y Glicemia, solicitando otros procedimientos y evaluación por especialistas según sospecha clínica. Once pacientes (42,3\%) tenían RGE, sólo 1 relacionado a evento respiratorio; hubo 19,2\% idiopáticos, 15,4\% de patología neurológica y 7,7\% IRA. Se realizó educación en reanimación a 73,1\% de los familiares; 6 pacientes fueron dados de alta con monitor cardiorrespiratorio. Conclusión: La distribución de patologías encontradas en este estudio es similar a lo descrito en la literatura; destaca el alto porcentaje de familiares con epilepsia y la prolongada hospitalización en comparación al promedio general de nuestro centro. Este estudio nos permitió evaluar la situación actual y plantear un proyecto prospectivo basado en un algoritmo que optimiza el estudio y manejo de ALTE. 
HIPOMELANOSIS DE ITO. UN SÍNDROME NEUROCUTÁNEO HETEROGÉNEO Y POSIBLEMENTE SUBDIAGNOSTICADO

Flández A, Tager M, Cárdenas R, Viejo $L$.

Hospital Clínico Regional de Valdivia.

Introducción: La hipomelanosis de Ito $(\mathrm{HI})$ o incontinencia pigmenti achromians es un trastorno neurocutáneo multisistémico que se asocia a complicaciones neurológicas en un alto porcentaje de pacientes. Objetivo: Revisar dos casos clínicos que presentaron las características más relevantes de la enfermedad que permitieron sospechar el diagnóstico. Pacientes y Método: Se analizaron 2 casos clínicos en los que finalmente se concluyó el diagnóstico de Hl y se realizó una puesta al día de la enfermedad. Resultados: Paciente 1: niño de 3 años 8 una puesta al día de la enfermedad. Resultados: Paciente 1: niño de 3 años 8
meses. Manchas hipopigmentadas en tronco y extremidades inferiores desde los meses. Manchas hipopigmentadas en tronco y extremidades inferiores desde los
3 meses. A los 2 años comenzó con convulsiones. No tiene desarrollo del len3 meses. A los 2 años comenzó con convulsiones. No tiene desarrollo del lenguaje. Ingresó al hospital de Valdivia con crisis epilépticas subintrantes. Se diagpor retraso moderado a severo del lenguaje. Ella había consultado por manchas hipomelanóticas dermatoméricas, sin respuesta. Se confirma con la opinión de dermatólogo una HI. Conclusiones: La manifestación cutánea no siempre es notoria el retraso psicomotor es lo más frecuente y dado que no existe marcador biológico de la enfermedad, es fundamental considerarla para no subvalorar su prevalencia.

\section{CRIPTOSPORIDIOSIS EN INMUNOCOMPROMETIDOS EN EL HOSPI-} TAL LUIS CALVO MACKENNA

Noemí $\boldsymbol{I}^{1}$, Mercado $R^{2}$, Ozaki $L S^{3}$, Cerva $J^{1}$, Gomez $H^{1}$. 'Laboratorio de Parasitología, Hospital Luis Calvo Mackenna, ${ }^{2}$ Unidad Docente de Parasitología. Facultad de Medicina. Universidad de Chile. ${ }^{3} \mathrm{De}$ partamento de Microbiología e Inmunología, Virginia Commonwealth University, USA.

Los inmunocomprometidos son el principal grupo de riesgo para la criptosporidosis, ya que en ellos, la infección es frecuentemente una amenaza vital. La parasitosis ha sido descrita en niños con desnutrición severa o infectados por VIH, tanto infantes como adultos. En este trabajo comunicamos por primera vez en Chile la presencia de criptosporidiosis en niños transplantados y un ensayo de Reacción de la Polimerasa en Cadena (PCR) que permite diferencia las especies Crytosporidium parvum y C.hominis con el fin de contribuir al las especies Crytosporidium parvum y C.hominis con el fin de contribuir al
diagnóstico de laboratorio precoz en estos pacientes. Pacientes y Método: diagnóstico de laboratorio precoz en estos pacientes. Pacientes y Método: de criptosporidosis en niños trasplantados. Las edades de los pacientes variaron entre 2 y los 14 años, los que recibieron transplantes de: médula ósea(6), hígado (4) y riñon(1). La búsqueda de ooquistes de Cryptosporidium sp. se hizo mediante tinción de Ziehl-Neelsen modificada (Z-N). Partidores para PCR especie C.parvum y especie C.hominis fueron diseñados en USA y se probaron con aislados chilenos de un paciente VIH con criptosporidosis. Resultados: Exámenes aislados chilenos de un paciente $\mathrm{VIH}$ con criptosporidosis. Resultados: Exámenes de deposiciones de los 11 niños mostraron abundantes ooquistes de Cryptosporidium sp. en extendidos teñidos con Z-N. Controles post-tratamiento (espiramicina) en dos de ellos mostraron negativización. Mediante PCR se determinó que la especie presente en el aislado chileno correspondió a $C$. hominis. Conclusiones: La criptosporidosis en Chile es relevante causa infecciosa protozoaria de cuadros digestivos (diarrea) en inmunocomprometidos (bajo percentil 10 de CD4). Se requiere efectuar estudios epidemiológicosmoleculares que contribuyan al diagnóstico precoz, tratamiento efectivo y control en este grupo de pacientes de alto riesgo. Partially supported by funds from National Institutes of Health grant U01 Al46418.

\section{GASTO ENERGÉtICO EN EL PACIENTE CRíTICO PEDIÁTRICO}

Rybertt V, Acuña L, Marín V.

Hospital luis Calvo Mackenna.

La determinación del gasto energético en el niño críticamente enfermo es escencial para el soporte nutricional adecuado y así evitar las consecuencias adversas de la hiper o hipoalimentación. En estos pacientes la utilización de ecuaciones predictivas no ha demostrado una buena concordancia con el gasto energético medido (GEM) por calorimetría indirecta. Objetivos: 1) Determinar el GEM al medido (GEM) por calorimetría indirecta. Objetivos: 1) Determinar el GEM a
ingreso a UCl y compararlo con el gasto energético estimado (GEE) por ecuaciones comúnmente usadas en pediatría; 2) Analizar asociación del GEM con índice de gravedad y parámetros de stress metabólico. Pacientes y Método: Estudio observacional de cohorte transversal. Criterios de ingreso: pacientes en ventilación mecánica con menos de $36 \mathrm{hrs}$ de ingreso a UCl. Criterios de exclusión: requerimiento de $\mathrm{O}_{2}>60 \%$, filtración a través de TET $>10 \%$, pacientes en hemodiálisis y/o ventilación de alta frecuencia. Se utilizó fórmula OMS Schofield para cálulo de GEE cuyos resultados se compararon con por calorimetría indirecta. El índice de gravedad se determ II score. Además se evaluó albúminemia, glicemia y proteina $C$ reactiva. S utilizó metodo de Bland- altman para determinar la concordancia del GEE con e GEM, considerandose una diferencia de $10 \%$ entre ambos metodos, como clínicamente aceptable. Resultados: Se estudiaron 15 pacientes entre 1 mes y 14 años. Ninguna de las ecuaciones utilizadas mostró concordancia con GEM observándose una amplia dispersión de los límites de concordancia. El porcentaje de GEM sobre el GEE por OMS varió entre un $50 \%$ a $134 \%$ y por Schofield $54 \%$ a $136 \%$. 8 pacientes fueron hipometabólicos (GEM/GEE < $90 \%$ ), 5 normometabólicos (GEM/GEE 90-110\%) y 2 hipermetabólicos (GEM/GEE > $110 \%)$. Hubo diferencia significativa en los valores de glicemia $(112,425,8)$ entre pacientes hipometabólicos versus los normometabólicos $(157,8 \pm 49 ; p<$ entre pacientes hipometabolicos versus los normometabolicos $(157,8 \pm 49 ; \mathrm{p}<$ Conclusiones: El gasto energético en el niño críticamente enfermo muestra gran variabilidad y los métodos predictivos comunmente utilizados para su estimación no lo valoran adecuadamente, lo que puede conducir a aportes nutricionales inadecuados. La Calorimetría indirecta sigue siendo el método más adecuado para programar un apoyo nutricional óptimo en estos pacientes.
CARACTERISTICAS EPIDEMIOLÓGICAS DE PACIENTES PEDIÁTRICOS HOSPITALIZADOS POR CUADROS DE INTOXICACIÓN AGUDA EN EL SERVICIO DE PEDIATRÍA DEL HOSPITAL CLÍNICO REGIONAL ANTOFAGASTA

Castillo PH, Cañón CR, Almonte ChE, Alonso BE. Servicio Pediatría de Hospital Clínico Regional Antofagasta Dr. Leonardo Guzmán. Antofagasta-Chile.

Método: Estudio Retrospectivo trasversal en pacientes pediátricos hospitalizados en el servicio de pediatría del Hospital Clínico Regional Antofagasta con diagnósticos de intoxicación aguda durante los 2006-2007. Resultados: Entre los años 2006 y 2007 se registraron en el Hospital Clínico Regional Antofagasta 100 hospitalizaciones a causas de intoxicación aguda, registrándose 47 casos en el año 2006 y 53 casos en el año 2007. Del total de pacientes se pesquisa que el $34 \%$ correspondieron a varones y el $66 \%$ fueron mujeres, cifras que se mantuvieron constantes si se desglosaban los datos según año; la edad promedio para las mujeres afectadas por cuadro de intoxicación aguda fue de 6,82 años con SD 4,48 y para hombres fue de 6,42 años con SD 4,40 , se invirtieron entre ambos años un total de 365 días/cama para la atención de estos pacientes, el promedio de días de hospitalización para el año 2006 fue 3,78 días con SD 3,04 y para el año 2007 de 3,52 días con SD 2,87, también se analizo si existía diferencia entre el promedio de días de hospitalización según sexo, encontrándose un promedio para las mujeres de 3,53 días con SD 2,96 y para los varones de 3,88 días con SD 3,01 ; en los 2 años analizados se encontraron 3 causas de los cuadros de intoxicación aguda, ellas eran accidentales con un total de 60 casos, intento de suicidios con 36 casos y producto de un cuadro depresivo sin precisamente ser un intento de suicidio, casos que correspondieron a intoxicaciones alcohólicas, produciéndose 4 casos. Destaca en las causas catalogadas como intento de suicidio que el $77,7 \%$ de los casos correspondieran a mujeres; dentro de los agentes causales de intoxicación se pueden encontrar 5 grandes grupos, medicamentos con 52 casos, hidrocarburos presentes en los hogares con 26 casos, venenos de animales o insectos con 14 casos, químicos de uso industrial y alcohol, estos últimos cada uno con 4 casos; de los intentos de suicidio femeninos el $92,8 \%$ de los casos fue producto de una ingesta medicamentosa. A 54 de nuestros de pacientes en unidad de emergencia se les realizo lavado gástrico y uso de carbón activado antes de ser derivados a sala de hospitalización, resto sólo quedo con la indicación de observación; en el período analizado sólo 2 pacientes tuvieron la necesidad de ser llevados a unidad de cuidados intensivos producto de una intoxicación aguda, destacando que ambos casos correspondieron a pacientes de sexo femenino producto de un intento de suicidio con ingesta de medicamentos. Conclusiones: Los cuadros de intoxicación aguda son una importante causa de ingreso hospitalario en la 2da región, no ha habido modificación de las estadísticas a través de los años, destacando el alto porcentaje de ellos que se deben a intentos de suicido, urgiendo la necesidad de campañas para evitar su ocurrencia.

CORRELACIÓN ENTRE ÍNDICE CARDÍACO CON MARCADORES SISTÉMICOS DE DISOXIA: DIFERENCIA VENOARTERIAL DE CO $\mathrm{Y} \mathrm{SVCSO}_{2}$

Cruces $\boldsymbol{P}$, Díaz F, Donoso A, Carvajal C, Salomón T, Torres M, Erranz B. Hospital Padre Hurtado. Facultad de Medicina Clínica Alemana Universidad del Desarrollo.

Introducción: La medición invasiva del Indice Cardíaco (IC) no es un estándar de cuidado en cuidados críticos pediátricos. Sin embargo, existen métodos indirectos de estimarlo, destacando entre ellos la diferencia veno-arterial de $\mathrm{pCO}_{2}$ $\left(\triangle \mathrm{VACO}_{2}\right.$ ) y la saturación venosa de oxígeno en vena cava superior $\left(\mathrm{SvcsO}_{2}\right)$ por su facilidad, accesibilidad y baja complejidad. Objetivo: Determinar la correlación entre el IC y el $\triangle \mathrm{VACO}_{2}$ y $\mathrm{SvCSO}_{2}$ en un modelo experimental pediátrico. Método: 30 cerdos anestesiados, traqueostomizados y conectados a ventilación mecánica convencional. Se realizó canulación vena yugular izquierda y línea arterial con cateter PiCCO. Se midieron gases arteriales y venosos centrales e IC por termodilución transpulmonar (TDTP) en forma simultánea al inicio, 1, 2 y $4 \mathrm{~h}$ en distintas situaciones hemodinámicas. Los valores fueron expresados como media \pm DS (rangos). Estadígrafos utilizados: Correlación de Pearson y regresión no lineal ajustada. Se utilizó test de Kruskall Wallis para comparar grupos. Consideramos significativo un $p<0,05$. Resultados: Se realizaron un total de 120 mediciones. El IC fue $3,69 \pm 1,08 \mathrm{l} / \mathrm{min} / \mathrm{m}^{2}$ (rango $\left.1,6-8,41\right)$. El $\triangle \mathrm{VACO}$ fue $6,57 \pm 4,38$ (rango 0-19) y la SvcsO $78 \pm 8 \%$ (rango $53-94 \%$ ). Hubo una correlación inversa entre el $\Delta \mathrm{VACO}_{2}$ e IC $(r=-0,21, p=0,019)$ y su fórmula fue de regresión no lineal: $I C=(-27)+31^{*} 0,99 \Delta \mathrm{VACO}_{2}(p=0,03)$. La correlación de $\mathrm{SvcsO}_{2}$ y IC fue $\mathrm{r}=0,31(\mathrm{p}<0,01)$ y su fórmula de regresión fue lineal: $\mathrm{IC}=$ $0,65+3,89 * \mathrm{SvcsO}_{2}$. En el cuartil más bajo $(<\mathrm{p} 25)$ de IC $(2,46 \pm 0,37)$, la $\mathrm{SvcsO}_{2}$ fue $75 \pm 8 \%$ y DVACO fue $^{2}, 5 \pm 5,4$, mientras que en el cuartil superior $(>p 75)$ de $\mathrm{Cl}(5,1 \pm 0,79)$ fueron $83 \pm 7 \%(p<0,001)$ y $5,3 \pm 3,2(p=$ $0,2)$ respectivamente. Discusión: $\mathrm{El}_{\Delta} \mathrm{VACO}_{2}$ y $\mathrm{SvcsO}_{2}$ son herramientas simples, de bajo costo, que se correlacionan con el GC. Éstas pueden ser empleadas como estimación complementaria a otros marcadores metabólicos (exceso de base, lactato, relación lactato/piruvato) en el seguimiento temporal de un estado de disoxia tisular. A su vez, puede guiar al clínico para inicio de terapia de apoyo inotrópico. Financiamiento por Proyecto Fondecyt 11075041. 


\section{SDRA POR VIRUS VARICELLA ZOSTER EN PACIENTE INMUNOCOMPETENTE. REPORTE DE CASO}

Arriagada $D^{1}$, Donoso $A^{2}$, Cruces $P^{2}$, Wilhelm ${ }^{3}$, Díaz $F^{2}$.

'Becada Pediatría Universidad del Desarrollo-Clínica Alemana. ${ }^{2}$ Área de Cuidados Críticos. Hospital Padre Hurtado. ${ }^{3}$ Área de Cuidados Básicos. Hospital Padre Hurtado.

Introducción: La infección por virus varicella zoster (VVZ) es común en niños. Sin embargo, el SDRA por virus varicella zoster es una complicación grave (mortalidad cercana a $30 \%$ ) y poco frecuente en niños, especialmente en inmunocompetentes. Objetivo: Reportar caso de paciente que cursó con SDRA y SDOM por VVZ. Caso Clínico: Paciente de sexo masculino, 9 años, secuela de meningitis bacteriana a los seis meses de vida. Ingresa por varicela hemorrágica, shock séptico, leucopenia de $5.000 \mathrm{~mm}^{3}$, trombocitopenia de 21.000 $\mathrm{mm}^{3}$. PIM2 55,9\% y PELOD 99,1\%. Se instaló monitorización invasiva, iniciando tratamiento con clindamicina, cefotaxima y aciclovir. No se demostró sobreinfección. Reanimado con $>200 \mathrm{ml} / \mathrm{kg}$ fluidos, monitorización PiCCO con patrón de vasoplejia e hipodébito marcado (norepinefrina $1 \mathrm{mcg} / \mathrm{kg} / \mathrm{min}$, epinefrina $0,5 \mathrm{mcg} / \mathrm{kg} / \mathrm{min}+$ milrinona $0,7 \mathrm{mcg} / \mathrm{kg} / \mathrm{min}$ ) recibe suplementación suprarrenal Falla renal aguda (HDFVVC por 10 días), SDRA grave, refractario a VM convencional $(I O>30$, LIS 4, ELWI 38). Requiere VAFO con posicionamiento en prono. PCR VVZ (+) en LBA, TAC de tórax con lesiones nodulares características de neumonía varicelatosa. Con soporte ventilatorio por dos semanas. Po sospecha de inmunodeficiencia se suplementó con inmunoglobulina. Se objetivó hipotiroidismo grave, el cual se suplementó. Presentó neumonía fúngica en etapa de convalecencia con buena respuesta a fluconazol. Alta a los 28 días. Comentario: Reportamos el caso de un complicación grave e inusual por VVZ. E tratamiento precoz y agresivo, es la estrategia más importante para cambiar significativamente el curso de la enfermedad. Como medida de prevención, debe considerarse la aplicación de la vacuna en la población susceptible a complicaciones.
SÍNDROME HEMORRAGÍPARO OCASIONADO POR TROMBOCITOPENIA GRAVE INDUCIDA POR VARICELA. COMUNICACIÓN DE CASO

Bertrán K, Donoso A, Díaz F, Cruces $P$, Arriagada $D$.

Área de Cuidados Críticos. Hospital Padre Hurtado.

Introducción: La infección por varicela zoster usualmente se presenta con síntomas leves, siendo frecuente que la varicela presente grados leves de trombocitopenia, aunque pueden presentarse complicaciones hematológicas fatales. Infrecuentemente se observa trombocitopenia grave. Objetivo: Presentar un caso clínico de varicela con trombocitopenia grave en un adolescente. Caso Clínico: Paciente sexo masculino, 14 años, previamente sano, que cursó con varicela, epistaxis recurrente y hematuria mascroscópica. Ingresó al Área de Cuidados Críticos con lesiones de piel en distintos estados mácula, pápula, vesículas y costras, gingivorragia, equimosis, petequias y hematomas en EEII, examen neurológico con escala de Glasgow 15 puntos, sin otros hallazgos. Recuento plaquetario de $0 / \mathrm{mm}^{3}$, resto del hemograma normal. TP y TTPK en rango normal. Se inició aciclovir ev. TAC de cerebro normal, Rx. Tórax y ecografía abdominal sin hallazgos patológicos. Al segundo día de evolución presentó nuevamente recuento plaquetario de $0 / \mathrm{mm}^{3}$. Se realizó transfusión de tres unidades de plaquetas, iniciándose tratamiento con prednisona $1 \mathrm{mg} / \mathrm{kg} / \mathrm{d}$. Al tercer día de evolución presentó recuento plaquetario en $7.000 / \mathrm{mm}^{3}$. Plaquetas en progresiva recuperación. Alta a los 9 días de ingreso. No se efectuaron test serológicos para confirmar infección por varicela. Comentario: La existencia de trombocitopenia en una infección por varicela se debe probablemente a una similitud molecular entre antígenos virales y glicoproteínas de superficie plaquetaria, con el subsecuente incremento del clearance de plaquetas (PTI). Entre las opciones terapéuticas se incluyen gammaglobulina ev y corticoides en altas dosis.

\section{USO EXITOSO DE LA HEMODIAFILTRACION MEJORADA CON} ALBÚMINA EN INTOXICACIÓN GRAVE POR CARBAMAZEPINA

Arriagada $D^{1}$, Donoso $A^{2}$, Cruces $P^{2}$, Carvajal $C^{3}$.

Becada Pediatría Universidad del Desarrollo-Clínica Alemana. ${ }^{2}$ Área de Cuidados Críticos. Hospital Padre Hurtado. ${ }^{3}$ Alumno Medicina Universidad del Desarrollo-Clínica Alemana.

La intoxicación por carbamazepina (CBZ) es frecuente de observar como causa de ingreso a $\mathrm{UCl}$, siendo en algunas ocasiones grave, ameritando terapia de remoción extracorpórea. La opción terapéutica de múltiples dosis de carbón activado es útil, pero siempre que se administre dentro de la primera hora. El uso de hemodiálisis convencional y peritoneodiálisis son escasamente eficientes dados el alto grado de unión a proteína de la CBZ. La adición de una concentración fisiológica de albúmina al fluido de diálisis puede mejorar el clearance de la droga unida a proteína. Objetivo: Dar a conocer el uso exitoso de HDF mejorada con albúmina en un caso de intoxicación grave por CBZ. Caso Clínico: Paciente sexo masculino, 13 años, $60 \mathrm{~kg}$, analfabeto, quién ingresó a Servicio de Urgencia en GCS 7-8 e hipoventilación, sin otros antecedentes. Al examen físico RFM (-) ROT (-) PAM $73 \mathrm{mmHg}$. Se intuba endotraqueal, recibe lavado gástrico y luego carbón activado. TAC cerebral normal. A las 2 horas de ingresado se obtiene antecedente de estar recibiendo CBZ desde hace 6 meses por síndrome de déficit atencional, con dudosa adherencia a tratamiento con probable sobredosis de CBZ y compromiso de sensorio y cefalea las 12 horas previas. Se toman niveles plasmáticos los cuales son $282 \mathrm{mcg} / \mathrm{ml}$ (RTO: $4-12 \mathrm{mcg} / \mathrm{ml}$ ), se inició HDFAV, dentro de las primeras 6 horas de ingresado. La composición de diálisis $(1,5 \%$ ) fue ajustada para albúmina de $4 \mathrm{~g} / \mathrm{dL}$ (albúmina $20 \%$ ) la cual se mantuvo por 24 horas. Además carbón activado 12,5 g/h. Se observó descenso progresivo de niveles plasmáticos de CBZ en conjunto con mejoría progresiva del sensorio, se extubó a las 48 horas. No hubo complicaciones miocárdicas, medulares y electrolíticas. Se derivó a asistencia social y psiquiatría. Alta del hospital a los 7 días. Comentario: Reportamos el caso de una intoxicación grave, no encontramos en la literatura valores plasmáticos de esta magnitud, donde se demostró la eficacia del soporte extracorpóreo con HDF mejorada con albúmina. La relación costo beneficio debe de ser analizada individualmente. Esta debe ser considerada una opción real, la cual debe estar disponible en UCI.

\section{SÍNDROME FEBRIL COMO PRESENTACIÓN DE HEMATOMA SUBDURAL CRÓNICO}

Bertrán K, Donoso A, Díaz F, Vallejos ME. Área de Cuidados Críticos. Hospital Padre Hurtado.

Introducción: El hematoma subdural (HSD) es causado por el sangrado en e espacio entre la duramadre y la aracnoides. La mayoría de los casos resulta de la ruptura de vasos venosos. Causas frecuentes son traumatismo del parto y el maltrato infantil. Objetivo: Comunicar un caso clínico de un paciente de edad escolar con una presentación atípica de hematoma subdural crónico. Caso Clínico: Paciente sexo masculino, de 12 años, consultó a urgencia por cuadro de dos semanas de evolución con fiebre hasta $38^{\circ} \mathrm{C}$, recibiendo paracetamol. En sus exámenes destacaba hemograma: Hto: $44 \%$, Leucocitos: $11.300 \mathrm{~mm}^{3}$ (Seg 71\%), Plaquetas: $277.000 \mathrm{~mm}^{3}$, PCR: $101 \mathrm{mg} / \mathrm{l}$ (VN: 0-5 mg/l), PL en rango normal (células $0 / \mathrm{mm}^{3}$ ). Paciente continuó febril hasta $39^{\circ}$, consultó en urgencia donde recibió ceftriaxona. Persistió febril por $72 \mathrm{~h}$ por lo que se decidió hospitalizar como síndrome febril en estudio. A las pocas horas de ingresado presentó cefalea intensa y vómitos explosivos. Se realizó TAC cerebral que evidenció hematoma subdural crónico fronto-temporo-parietal reagudizado. Se efectuó drenaje de hematoma subdural. Postoperatorio afebril y hemodinámicamente estable, sin focalización neurológica. Recibe fenitoína profiláctica. TAC de control satisfactorio. Se obtuvo antecedente de traumatismo craneano un año atrás, sin pérdida de conciencia, no consultó en esa oportunidad. Luego con cefalea inespecífica y deterioro del rendimiento escolar. Evolucionó sin compromiso neurológico, se descartó maltrato infantil, pero continuó febril (4 días), hemograma normal, hemocultivo (-), PCR en disminución, procalcitonina $<0,5 \mathrm{ug} / \mathrm{dl}$ (normal). Se descartó foco infeccioso. Ecocardiograma normal. Alta al noveno día de hospitalización. Controles posteriores en neurología, paciente con cefalea recurrente e insomnio. Comentario: EI HSD crónico es infrecuente en población infantil. Su presentación suele ser insidiosa, como lo aquí comunicado (deterioro rendimiento escolar). La fiebre obedece en ocasiones a causa neurológica no necesariamente infecciosa. EI HSD crónico debe considerarse en las causas infrecuentes de síndrome febril prolongado. 


\section{CONVULSIÓN NEONATAL POR TROMBOSIS VENOSA CEREBRAL PRIMARIA. COMUNICACIÓN DE CASO}

Bertrán K, Donoso A, Díaz F, Cruces $P$

Área de Cuidados Críticos. Hospital Padre Hurtado.

Introducción: La trombosis de los senos venosos cerebrales (TSVC) es un hallazgo infrecuente en pediatría. El seno longitudinal superior es el vaso más frecuentemente implicado ( $80 \%)$. La TSVC se ha relacionado con situaciones clínicas de hipercoagulabilidad. Varios estudios demuestran la presencia de alteraciones congénitas en el sistema fibrinolítico. Objetivo: Presentar un caso clínico de TSVC en un neonato. Caso Clínico: Neonato de 8 días de vida, sexo masculino, embarazo fisiológico, padres sanos, 39 semanas EG, drogas (-), PN: $2.570 \mathrm{~g}$, Apgar 8-9. Al cuarto día de vida irritable, rechazo alimentario por $48 \mathrm{~h}$ presenta convulsiones tónico-clónicas en brazo derecho. En Servicio de Urgencia presenta nueva crisis convulsiva por lo que recibió midazolam $(0,35 \mathrm{mg} / \mathrm{kg})$ fenobarbital $(10 \mathrm{mg} / \mathrm{kg})$ ev. TAC demostró "extensa trombosis de seno sagital superior con obstrucción completa de vena de Galeno y rémora venosa a nivel de la vena basal de Rosenthal y venas cerebrales internas". Al ingreso al Área Cuidados Críticos: signos vitales estables, examen físico sin hallazgos. A las 24 $\mathrm{h}$ vuelve a convulsionar. TAC de control "persisten imágenes trombosis extensa seno sagital superior asociado a cambios hemorrágicos profundos periventriculares con compromiso talámico". Se efectuó PL la cual fue normal, EEG: normal, TP y TTPK normales. Se decidió no iniciar heparinización sistémica. Perfil de trombofilias demuestra un déficit de proteína C (22\%) (VN: $35-54 \%)$ Paciente evolucionó en buenas condiciones, siendo dado de alta a los 22 días de hospitalización. Seguimiento a los 9 meses revela un adecuado desarrollo psicomotor. Comentario: La TSVC es una entidad de diagnóstico difícil dado sus múltiples formas de presentación. Se describe asociado a factores locales (meningitis, sinusitis), sistémicos (sepsis, vasculitis), estados de hipercoagulabilidad, entre otros. La técnica de elección para el diagnóstico es el TAC con contraste endovenoso. La opción terapéutica debe de evaluarse individualmente. Es imprescindible un alto índice de sospecha para un oportuno diagnóstico.

\section{APLICACIÓN DE MODELO BUNDLE EN IIH MEDIANTE LA SU- PERVISIÓN DE PROCEDIMIENTOS INVASIVOS EN CUIDADOS IN- TENSIVOS}

Fuentes I, Donoso A, Chacón E.

Área de Cuidados Críticos. Hospital Padre Hurtado.

Introducción: Las infecciones intrahospitalarias (IIH) son un problema de gran impacto; su prevención es objetivo fundamental dentro de las políticas de salud. El modelo BUNDLE fue propuesto por el Institute for Healthcare Improvement, concentrando el cumplimiento confiable de un grupo de las mejores prácticas relacionadas al evento adverso que se quiere prevenir. Objetivo: Reportar la experiencia en la prevención de IIH en pacientes con catéteres venosos centrales (CVC) y ventilación mecánica (VM), mediante la utilización de un protocolo de supervisión a través de modelo BUNDLE. Material y Método: Estudio prospectivo con aplicación de supervisión por modelo BUNDLE en el Área de Cuidados Críticos, período 2007-2008. Se realizó capacitación previa al equipo de salud sobre el concepto BUNDLE y se estandarizaron las prácticas a supervisar incluyendo hasta 5 prácticas, consideradas como muy relevantes para la prevención de IIH. Se aplicó esta supervisión a todo paciente que requirió CVC (instalación CVC-I y mantención, CVC-M) y/o VM (mantención VM-M) según normativa vigente del Área, definiéndose dos indicadores, $\mathrm{A}$ : indicador de cumplimiento de la supervisión (adherencia) y B: cumplimiento de las medidas seleccionadas. Se identificaron las medidas incumplidas y se realizaron intervenciones para su control. La información obtenida se cruzó con el período 2006-2007. Resultados: Durante el período analizado ingresaron 754 pacientes, $161(21 \%)$ requirieron CVC y 151 (20\%) VM. Se obtuvo un total de 168 BUNDLE CVC-I, 1070 BUNDLE CVC-M y 652 BUNDLE VM-M, lo que representa el $100 \%$ de los catéteres instalados y de los días de exposición para ambos procedimientos (indicador A). Para indicador B se obtuvo un 91\% (73-100\%) para instalación de CVC, para mantención fue $98 \%(96-100 \%)$ y para mantención de VM $94 \%$ (82$100 \%)$. Se identificó que la medida incumplida más frecuente en CVC-I fue uso de técnica aséptica máximas barreras (6\%),en CVC-M justificación de la mantención de este $(1,3 \%)$, y en VM circuitos sin condensado en vía inspiratoria $(4,4 \%)$. Al comparar la presencia de IIH con el período previo, hubo $7 \mathrm{IIH}$, (3 ITS CVC, 3 NAVM y 1 ITS/NPT) a diferencia del período de estudio donde se aplicó la supervisión donde se notificó 3 IIH (3NAVM) $p<0,05$. Conclusiones: La realización de este tipo de supervisión es útil, el equipo adquiere fácilmente una buena adherencia a este tipo de supervisión, se logra mejorar los procesos al identificar medidas incumplidas. Se debe estimular al equipo para mantener este modelo en el tiempo y medir su impacto en un plazo mayor.
QUILOTÓRAX A TENSIÓN. REPORTE DE DOS CASOS

Pinochet $C$, Donoso A, Cruces $P$.

Área de Cuidados Críticos. Hospital Padre Hurtado.

Introducción: El daño del ducto toráxico que ocasiona un quilotórax $(Q)$ es una bien conocida complicación de cirugía cardiotoráxica. Sin embargo, el desarrollo de quilotórax a tensión (QT) es raramente reportado, siendo una complicación que puede poner en riesgo la vida del paciente. Objetivo: Reportar dos pacientes quienes desarrollaron compromiso hemodinámico y respiratorio por QT. Caso clínico 1: Lactante de $2 \mathrm{~m}$, sexo femenino, antecedente de RNPT de $36 \mathrm{sem}$. Se diagnosticó ductus arterioso persistente, que se operó a las cinco semanas. Postoperatorio $(\mathrm{PO})$ inmediato sin intercurrencias, lográndose extubación. A las $48 \mathrm{~h}$ del PO presentó taquicardia, oliguria, polipnea y requerimiento de oxígeno $(40 \%)$, evolucionando con falla respiratoria aguda, por lo cual se conectó a VM. Rx tórax evidenció opacidad del campo pulmonar izquierdo. Se instaló drenaje pleural, que dio salida a $100 \mathrm{ml}$ de líquido espeso a gran presión. El líquido compatible con Q. Luego de la toracocentesis se logró reexpansión completa del pulmón, con rápida disminución de los parámetros ventilatorios y normalización hemodinámica. Se logró la extubación a las 12 h post drenaje. A los 6 días de evolución, se retiró drenaje, sin reproducción posterior del Q. Recibió tratamiento dietético por tres semanas. Alta a los 46 días. Caso clínico 2: RNT de 10 días, sexo masculino, con diagnóstico prenatal de ventrículo único. A los 12 días de vida se efectuó Norwood-Sano, sin inconvenientes. Posterior a la cirugía requirió VM por 10 días, alcanzándose a alimentar durante una semana. A los 19 días del PO presentó polipnea, desaturación (60\%), evolucionando con insuficiencia respiratoria aguda. Se trasladó a UCI con cianosis generalizada, pulsos débiles y disminución del murmullo pulmonar a derecha, además de acidosis respiratoria ( $\mathrm{PaCO} 2135 \mathrm{mmHg}$ ) por lo que se conecto a VM. La Rx tórax con imágenes de ocupación pleural a derecha. Se efectuó toracocentesis que dio salida a presión de $239 \mathrm{ml}$ de líquido de aspecto lechoso durante el primer día, con citoquímico compatible con QT. Evolución clínica posterior fue satisfactoria, extubándose a los 3 días desde la instalación del drenaje y este se pudo retirar definitivamente a la semana de evolución. Recibió tratamiento dietético dieta por tres semanas. Alta, asintomático al día 35. Comentario: Los casos aquí reportado nos señalan que el quilotórax puede presentar efectos deletéreos en lo hemodinámico y respiratorio. El pronto reconocimiento y tratamiento de esta entidad son esenciales para el óptimo pronóstico del paciente.

ESPECTRO CLINICO-EPIDEMIOLOGICO DE LA ENFERMEDAD MENINGOCÓCICA EN MENORES DE SEIS MESES DE EDAD

Pinochet C, Donoso A, León J, Cruces $P$ Área de Cuidados Críticos. Hospital Padre Hurtado.

Introducción: La Neisseria meningitidis es uno de los agentes bacterianos más frecuentes de sepsis en niños y adolescentes; al ocurrir una baja de los anticuerpos transplacentarios circulantes aumenta su prevalencia en lactantes pequeños, presentándose habitualmente en este grupo etáreo en forma invasiva. Objetivo: Conocer el espectro clínico y epidemiológico de la enfermedad meningocóccica (EM) en niños menores de 6 meses. Método: Se revisaron retrospectivamente las fichas clínicas de los pacientes $\leq$ a 6 meses con diagnóstico de EM definida como cultivo (+) para Neisseria meningitidis en un líquido estéril, hospitalizados en el ACC del Hospital Padre Hurtado durante el período 1999-2007. Resultados: En el período analizado hubo un total de 140 pacientes con EM, de estos 14 pacientes $\leq$ a 6 meses, edad promedio de 3,1 meses $(9 d-6 m), 57 \%$ de sexo masculino, uno con antecedente de prematurez ( $36+3 \mathrm{sem}) .7 / 14$ ocurrieron en fin de invierno-primavera. De la presentación clínica: el 100\% con fiebre e irritabilidad, $71 \%$ con meningitis (ninguno con convulsión), $28 \%$ con rush purpúrico petequial, $28 \%$ con shock séptico. El agente etiológico se aisló en: sangre (36\%), LCR + sangre (36\%) y LCR (28\%). Serogrupo B (10), serogrupo C (2) y serogrupo $Y(1)$, en uno de los casos no se obtuvo el serotipo. Al ingreso con recuento leucocitario de $9.800 / \mathrm{mm} 3(2.800-26.400 / \mathrm{mm} 3)$, leucopenia (3/14) y leucocitosis (2/14); ninguno con trombocitopenia. Todos con PCR elevada $158 \mathrm{mg} / \mathrm{l}$ (VN: 0-5 $\mathrm{mg} / \mathrm{l})$. Once de los pacientes fueron tratados con ceftriaxona y tres con cefotaxima, la duración de la antibioterapia fue de $7 \mathrm{~d}$, pero en uno de los pacientes se extendió por complicaciones (absceso cerebral). En terapia de soporte el $43 \%$ requirió VM (3 d) y DVA en el $36 \%$. En las complicaciones tres pacientes presentaron convulsiones, uno absceso cerebral y uno infarto cerebral. El promedio de días en UCI fue de 3 (1-10d) y de hospitalización de 9d (5-23 d). No hubo fallecidos. En el seguimiento 10 pacientes sin secuelas neurológicas, 2 (14\% total y $20 \%$ de los con meningitis) con déficit auditivo (unilateral y bilateral, ambos casos con meningitis y absceso e infarto cerebral), en 2 de ellos no se pudo completar el seguimiento neurológico. Discusión: La EM se presenta en lactantes pequeños en forma inespecífica y puede ser difícil de diferenciar de síndromes virales, pudiendo rápidamente progresar con deterioro clínico. 
ENFERMEDAD MENINGOCÓCCICA NEONATAL. REPORTE DE TRES CASOS

Pinochet C, Donoso A, Cruces $P$, León J.

Área de Cuidados Críticos. Hospital Padre Hurtado.

Introducción: La Neisseria meningitidis, si bien es poco común como agente etiológico de sepsis neonatal, también debe de ser considerada en este grupo etáreo. En la era antibiótica la meningitis meningocócica neonatal es muy escasa de observar. Objetivo: Reportar tres casos de recién nacidos a término (RNT) en quienes presentaron enfermedad meningocóccica (EM). Casos Clínicos: Se presentan en la tabla adjunta las principales características epidemiológicas, clínicas y de laboratorio.

\begin{tabular}{lccc} 
& Caso 1 & Caso 2 & Caso 3 \\
\hline Edad $(\mathrm{d})$ & 15 & 9 & 25 \\
Sexo $(\mathrm{m} / \mathrm{f})$ & $\mathrm{f}$ & $\mathrm{f}$ & $\mathrm{f}$ \\
PN/EG $(\mathrm{g} / \mathrm{sem})$ & $3.240 / 39$ & $3.320 / 39$ & $3.550 / 40$ \\
Fiebre & $\mathrm{Si}$ & $\mathrm{Si}$ & $\mathrm{Si}$ \\
Irritabilidad & $\mathrm{Si}$ & $\mathrm{Si}$ & $\mathrm{Si}$ \\
Púrpura & $\mathrm{No}$ & $\mathrm{No}$ & $\mathrm{Si}$ \\
Rcto leucocitario $\left(\mathrm{mm}^{3}\right)$ & 7900 & 11000 & 10000 \\
PCR $(\mathrm{mg} / \mathrm{l})$ & & & \\
(VN: $0-5 \mathrm{mg} / \mathrm{l})$ & 89 & 54 & 25 \\
LCR & Normal & Anormal & Normal \\
Cultivo sangre/LCR & \pm & \pm & \pm \\
Serogrupo & $\mathrm{B}$ & $\mathrm{B}$ & $\mathrm{B}$ \\
Cefotaxima/días & 7 & 7 & 7 \\
Complicaciones & $\mathrm{No}$ & shock & No \\
VM/DVA & No/No & $\mathrm{Si} / \mathrm{Si}$ & No/No \\
Secuelas & $\mathrm{No}$ & $\mathrm{No}$ & $\mathrm{No}$ \\
Pronóstico & Vivo & Vivo & Vivo \\
\hline
\end{tabular}

Discusión: Los tres casos de EM de 15, 9 y 25 días de vida (meningococcemia [2], meningitis meningocóccica) presentaron una evolución favorable. La presentación clínica fue inespecífica (fiebre, irritabilidad), como es de esperar para este grupo etáreo. La baja prevalencia de Neisseria meningitidis en esta etapa de la vida se explica en parte por los anticuerpos bactericidas transferidos en forma pasiva in útero. La EM también debe ser considerada como parte del diagnóstico diferencial de sepsis en el período neonatal.

\section{COMA HIPOTIROIDEO. CASO CLINICO}

Von Freeden J, Orellana $C$

Servicio de Pediatría. Hospital Regional Rancagua.

Introducción: El coma hipotiroideo es la manifestación extrema de esta patología y constituye una emergencia médica con una alta mortalidad (aprox $60 \%$ ). Caso clínico: Se presenta el caso de una paciente de sexo femenino, de 11 años de edad, descrita como "floja" por su familia, con baja tolerancia al frío, sin antecedentes mórbidos de importancia. Su historia comienza 3 días antes de ingreso, con congestión nasal a lo que se agrega en las últimas 24 horas la presencia de mialgias, disminución progresiva de las fuerzas, llegando a la postración, además de frialdad de piel y compromiso del sensorio. Ingresa a la Unidad de Cuidado Intensivo Pediátrico en estado de shock con hipotermia de < $35^{\circ}$ rectal, tetraparética con reflejos normales, sensibilidad aumentada, Glasgow 12, saturación límite, pálida y con piel seca. Los exámenes de laboratorio muestran CK elevada, hipokalemia severa, acidosis metabólica, creatininemia levemente aumentada y leucocitosis de 29.000 células. La radiografía de tórax revela un infiltrado intersticial y en la TAC cerebral se aprecia atrofia cerebral. Evoluciona en condiciones críticas, por el compromiso cardiovascular, con bradicardia extrema y déficit neuromuscular. Se solicitan pruebas de función tiroidea que demuestran un hipotiroidismo primario por lo que se inicia tratamiento de sustitución hormonal lográndose una adecuada evolución hacia la mejoría clínica progresiva y normalización de los parámetros de laboratorio. Comentario: A pesar de reconocer que el hipotiroidismo tiene una baja incidencia, es imprescindible sospecharlo en aquellos pacientes sintomáticos ya que el tratamiento debe ser precoz para evitar la aparición de complicaciones graves como es el coma hipotiroideo y porque el inicio del tratamiento cambia radicalmente no sólo la signología y sintomatología agudas, sino que el futuro de estos niños, evitando las secuelas de la disminución de las hormonas tiroideas en el desarrollo de los pacientes.
SHOCK SÉPTICO EN UNIDAD DE CUIDADOS INTENSIVOS PEDIÁTRICA HOSPITAL FÉLIX BULNES CERDA

Zamora $\boldsymbol{A} \boldsymbol{M}^{1}$, Garate $O N^{1}$, Barraza $M P^{2}$, Ordenes $P M C$

${ }^{1} M e ́ d i c o$ Pediatra. Servicio Pediatría Hospital Felix Bulnes. ${ }^{2}$ Becado Pediatría Servicio Pediatría Hospital Felix Bulnes. Unidad de Cuidados Intensivos (UCI) Servicio de Pediatría Hospital Félix Bulnes Cerda.

Introducción: El shock séptico corresponde a un estado de disfunción cardiocirculatoria de origen infeccioso que involucra un alto índice de morbimortalidad que requiere diagnóstico precoz y manejo oportuno; y en este último aspecto en los últimos años ha habido esfuerzos en actualizar y protocolarizar. Objetivo: Caracterización de algunos aspectos clínicos y epidemiológicos de pacientes con shock séptico ingresados a nuestra unidad. Metodología: Revisión retrospectiva de ficha clínica de pacientes con diagnóstico de shock séptico ingresados a UCl entre los años 2004 y 2008. Se objetivaron datos referentes a edad, sexo, foco de origen, positividad de cultivos, conducta terapéutica, días de hospitalización, mortalidad. Resultados: Se encontró un total de 34 casos, de los cuales 55,9\% (19 casos) correspondió a sexo masculino. El promedio de edad fue de 3,5 años, predominando los lactantes con $53 \%$ ( 18 casos). Los principales focos asociados fueron: cutáneo (26,5\%), digestivo $(23,6 \%)$, meníngeo (20,6\%) y respiratorio (17,6\%). En 58,8\% (20 casos) se aisló patógeno, siendo los más frecuentes: meningcoco $(25 \%)$, neumococo $(20 \%)$ y Streptococo grupo A (15\%). Del manejo realizado $70,5 \%$ (24 casos) se conecta a ventilación mecánica invasiva con promedio de 3,3 días. Las drogas vasoactivas se usaron en promedio de 3,25 días. $64,8 \%$ recibieron corticoides. El promedio de hospitalización en UCl fue de 5,8 días. La mortalidad en esta serie fue de 11,8\%(4 casos). Conclusiones: La mayor incidencia se presentó en el grupo de lactantes, de predominio sexo masculino. El foco cutáneo fue el más prevalerte $(26,5 \%)$ con bajo porcentaje de casos con foco no precisado. Se pesquisó un alto porcentaje de aislamiento de patógeno $(58,8 \%)$, valor significativo de acuerdo a publicaciones extranjeras. Se registra una baja mortalidad, menor a la de otras publicaciones.
PERTINENCIA DE INTERCONSULTAS (IC) DERIVADAS DESDE ATENCIÓN PRIMARIA DE SALUD (APS) A UNIDAD DE EMERGENCIA

Velasco J, Dattas JP, Muñoz B, Mihovilovic C.

Pediatras Unidad de Emergencia, Hospital de Niños Dr. Roberto del Río, Santiago.

Introducción: Entre los compromisos de gestión está la Coordinación de la Red de Urgencia. Estos compromisos están más orientados a la atención de adultos. Objetivo: Investigar la pertinencia de derivación y la coincidencia diagnóstica de las IC recibidas en la Unidad de Emergencia (UE) del Hospital de Niños Dr. Roberto del Río desde los consultorios APS, Sapus y Postas rurales pertenecientes al área norte de Santiago, para sugerir medidas de mejoramiento, tanto en aspectos técnicos como administrativos. Material y Método: Se analizaron IC solicitadas entre el 01 al 10 de octubre del 2007. Se revisaron datos demográficos y motivos de consulta registrados en sistema informático del Hospital. Debido a que el documento de IC se devuelve al paciente al terminar su consulta, se solicitó a Admisión que realizara fotocopia las IC. Se vaciaron en formulario ad hoc datos personales, datos de la IC e información del dato de atención urgencia (DAU). Resultados: Las consultas totales UE durante el año 2007 fueron 107.774. De esas, 18.311 fueron registradas en el sistema informático como IC (16,9\%). Las IC de APS de los días seleccionados fueron 494 que representan el 2,7\% de todas las IC. Después de eliminar aquellas IC que tenían algún problema de registro u otro, se dispuso de 457 que equivale al $92.5 \%$ de las IC recolectadas en el período de estudio. Las IC se recibieron más frecuentemente de las comunas de Colina $(28,2 \%)$ y Quilicura $(25,4 \%)$. Los diagnósticos por los cuales los pacientes fueron principalmente derivados fueron sospecha de abdomen agudo (14\%), SBO o sospecha de bronconeumonía $(14,4 \%)$, sospecha de fractura (12,5\%) y sospecha de TEC (8,5\%). De total de IC, al $57,1 \%$ se les realizó al menos un examen, radiografía, TAC o ecografía. La hospitalización se produjo en pediatría $(17 \%)$ Cirugía $(11,2 \%)$ y traumatología $(6,1 \%)$, siendo el $12,5 \%$ del total de IC. La concordancia diagnóstica fue $58,6 \%$ y la pertinencia $87,3 \%$. Conclusiones: No es fácil determinar la pertinencia de las IC ya que no existen protocolos de derivación. La concordancia fue menor que la pertinencia. Dado que el $49,5 \%$ de las IC están concentradas más del $50 \%$ en dos comunas y en 4 diagnósticos, se debería realizar capacitación en esas comunas y en dichos temas, que no son los propuestos por el ministerio. Deben acordarse protocolos de derivación entre la UE y la APS. 
EPIDEMIOLOGÍA DEL TRAUMA EN EDAD PEDIÁTRICA

Correia G, Alcoholado I, Zavala A.

Clínica Alemana, Urgencia Escolar.

El Servicio de Urgencia Escolar atiende niños que suscriben un convenio de atención por lesiones de origen traumático, el promedio de convenios es de 70.000 anual. Presentamos la experiencia adquirida en el manejo de estas lesiones entre los años 2002 y 2007 para 632.176 atenciones. Estos convenios generan entre 200 a 500 atenciones diarias entre consultas y controles, dado que es un servicio que no sólo diagnostica sino que trata y controla hasta la recuperación de la lesión (1,4 por asegurado). La variabilidad de consultas diarias se debe a la baja en las vacaciones escolares. El grupo más accidentogeno por edad es el comprendido entre los 4 y 6 años. Los lugares de ocurrencia de las lesiones son colegio $37 \%$, recreación $14 \%$, deporte $12 \%$. Las causas más frecuentes son golpes $42,3 \%$ dolor $18,2 \%$ caídas $17,2 \%$, torciones $11,3 \%$. La actividad que ocasionó el accidente es jugando $39 \%$, deportes $14 \%$, los accidentes del tránsito en este grupo sólo representan el $1 \%$ de las consultas y el $72 \%$ de ellos es como pasajeros. Los deportes más accidentogenos son fútbol $39 \%$, basquetbol $16 \%$, voleibol $10 \%$ y rugby $10 \%$. Los diagnósticos más frecuentes son esguince de tobillo, contusiones de cráneo, esguinces de dedos, esguince de rodilla y heridas. El $45 \%$ de las contusiones son de la región supraclavicular, el $23 \%$ es de las extremidades inferiores y un $22 \%$ de las superiores. Las heridas son en un $53 \%$ abrasivas y un $34 \%$ cortantes las quemaduras son un $60 \%$ tipo $A B$ y un $34 \%$ tipo A, sólo un $6 \%$ son tipo $B$, su extensión es un $77 \%$ menor a $5 \%$ de la superficie corporal y sólo el $1 \%$ tiene más de $5 \%$ de superfiecie corporal comprometida. En relación a las heridas por animales el $88 \%$ las causan los perros con un $69 \%$ de perros conocidos, les sigue el gato con un $8 \%$ y otros animales con un $3 \%$. Las fracturas más frecuentes son las de manos y dedos con un $37 \%$, luego la extremidad superior con un $29 \%$ y los pies y ortejos con un $14 \%$. Los esguinces más frecuentes son de dedos de la mano, y luego los de tobillo. Los cuerpos extraños representa otro importante motivo de consulta siendo un $43 \%$ en ojos un $15 \%$ en los pies y un $14 \%$ en pabellon auricular y canal auditivo externo. Las causa de hospitalizacion, representan el $0,4 \%$ de las consultas y sus principales causas son fracturas $49,6 \%$ que requieren reducciones ortopedicas o quirúrgicas, heridas complejas $17 \%$, contusiones graves $10 \%$ (viserales), quemaduras $3,5 \%$ TEC neuro quirúrgico $2,1 \%$, politraumatizado $1,4 \%$ y shock anafiláctico por picada de insecto.

\section{CARACTERÍSTICAS DE LAS CONSULTAS Y CONSULTANTES EN} UN SERVICIO DE URGENCIA PEDIÁTRICO PRIVADO

Rubio $P$, Romero MI, Díaz FJ, Rubio $X$.

Hospital Clínico FUSAT y Pontificia Universidad Católica de Chile, Facultad de Medicina, Depto. Salud Pública.

Introducción: La atención de urgencia (AU) está determinada por la percepción de «apremio» de la familia y no necesariamente por la gravedad del cuadro clínico. A veces la atención en Servicios de Urgencia (SU) refleja la falta de respuesta a la demanda en APS. EI SU del Hospital Clínico FUSAT (HCF) es un sistema semicerrado, atiende a beneficiarios de ISAPRE FUSAT $(60 \%$ población cautiva sin restricciones), FONASA, otras ISAPRES, privados y convenios gratuitos. Objetivos: Caracterizar los consultantes según edad y sexo; y la AU según su variación diaria, semanal y estacional. Analizar diagnósticos más frecuentes. Método: En base datos ad-hoc se registraron las características de los pacientes (sexo, edad), de la consulta (hora, estacionalidad) y los diagnósticos. $\mathrm{El}$ análisis estadístico fue realizado con Epilnfo®. Para cada grupo etáreo y las variables adicionales obtenidas, se calculó la razón de porcentajes de consultas (RPC $=\%$ consultas $/ \%$ del grupo etáreo en la población). Para los grupos etáreos extremos, se calculó el RR. Se analizan los treinta diagnósticos más frecuentes que corresponden al $72 \%$ de las consultas. Resultados: En el año 2007 hubo 20.924 consultas generadas por 7.383 niños, promedio de 2,8 (rango 1 a 33); $39 \%$ con 3 o más consultas fueron responsables del $70 \%$ de las AU. $52,3 \%$ sexo masculino. La razón de consultas fue: en menores de 1 año: 1,9, en 1 a 4 años 1,5 , en 5 a 9 años 0,88 y en el grupo 10 a 14 años 0,7 . El RR de consultar de los menores de 1 año fue 2,7 veces más que los de 10 a 14 años. La mayor demanda fue en junio y mayo (razón 1,4 y 1,3), los lunes y sábado $(1,2$ y 1,1$)$ y entre las 17 y 21 hrs y entre 12 y 14 hrs (RPC 1,83 y 1,79 ). La menor demanda en febrero (RPC 0,6 ) y los jueves (RPC 0,9). 7,5\% de los consultantes se hospitalizaron: $21 \%$ eran menores de 1 año, $21 \%$ eran niños 1 y 2 años. Los diagnósticos fueron Respiratorios $42 \%, 12 \%$ Digestivos y $4 \%$ Dermatológicos. Las causas respiratorias más frecuentes fueron virosis respiratorias altas $(41 \%)$, Bronquitis $(32 \%)$ y patología faringoamigdaliana (19\%), en las digestivas $85 \%$ eran diarrea aguda. $35 \%$ de las dermatológicas fueron reacciones alérgicas y dermatitis. Conclusiones: Existe probablemente una sobreutilización del SU por un $39 \%$ de los consultantes. 7,5\% del total consultantes se hospitaliza. Un mayor riesgo de consultar y hospitalización de los menores de un año. Los grupos de diagnósticos más frecuentes son Enfermedades Respiratorias, Digestivas y Dermatológicas.
FIEBRE EN LACTANTE < DE 3 MESES, EXPERIENCIA EN EL SUI DEL CSSBA

Godoy FE, Ballesteros BN, Quiroga VAM

Servicio de Urgencia Infantil Complejo Salud San Borja Arriarán.

Introducción: La consulta por fiebre en SUI es muy frecuente (20-30\%) y en el $<3$ meses representa un desafío mayor dada la asociación con enfermedades bacterianas severas (7-10\%). Objetivos: 1) Conocer las características de la población $<3$ meses que consulta por fiebre en el servicio de urgencia (SUI) del Complejo de Salud San Borja Arriarán (CSSBA). Material y Método: Revisión de la ficha clínica de los lactantes $<3$ meses atendidos en el SUI, CSSBA, entre Enero y Diciembre del 2007; de un total de 337 lactantes < 3 meses se analizan las siguientes características: sexo, edad, cuantía de la temperatura, hospitalizaciones, diagnósticos de ingreso/egreso y estudio de laboratorio habitual. Resultados: De un total de 337 lactantes que consultan por fiebre, $143(42 \%)$ sexo femenino, $194(58 \%)$ masculino, 19\% corresponde al grupo etario < 29 días y $81 \%$ entre 1 a 3 meses. El promedio de temperatura observado en el grupo $<29$ días fue 38,3 axilar (rango 37,5-40) y entre 1 a 3 meses fue 38,7 rectal (rango $38-40,2)$. Del total de consultas se hospitalizaron 194 lactantes $(58 \%)$, siendo < 29 días $53(27,8 \%)$ y entre 1 y 3 meses 141 (72,6\%). En relación a los < 29 días febriles se hospitaliza el $82,8 \%$ (53 de 64), y en el grupo > de un mes se hospitaliza 51,6\% (141 de273). Los diagnósticos de ingreso fueron: Síndrome febril sin foco $63 \%$ (87), IRA baja 16\% (22), ITU 13\% (18), Meningitis $1 \%(2)$ y los de egreso: IRA baja $63 \%$ (96), ITU $16 \%$ (25), Síndrome febril sin foco $14 \%$ (22), Síndrome diarreico agudo $5 \%$ (7), Meningitis $1 \%$ (2) y Celulitis $1 \%$ (1). Se realizó exámenes de laboratorio al $75 \%$ de los pacientes, los más utilizados fueron Recuento de blancos y PCR $(70 \%$ y $72 \%)$, Rx TX (39\%), Sed orina y urocultivo $(27 \%)$ y Hemocultivos (23\%). En el grupo hospitalizado se observo Recuento de blancos $>15000 / \mathrm{mm} 3$ sólo en un $17 \%$ y PCR sobre $80 \mathrm{mg} \%$ en un $6 \%$. Los hemocultivos (+) fueron $16 \%$. Conclusiones: Al igual que lo observado en otras publicaciones, el criterio clínico es lo más importante en el enfrentamiento de los lactantes febriles \&\#8804; tres meses. Los reactantes de fase aguda y la cuantia de la temperatura no son concluyentes en la pesquisa de infección bacteriana severa. La presente revisión reafirma la necesidad de establecer protocolos clínicos destinados a optimizar el apoyo de laboratorio en la pesquisa de enfermedad bacteriana severa.

\section{ESTUDIO DEL TRIAGE, TEMPERATURA, FRECUENCIA CARDÍACA $Y$ SATURACIÓN DE O, EN LA CLASIFICACIÓN DE PACIENTES ATENDIDOS EN UN SERVICIO DE URGENCIA PEDIÁTRICO}

Méndez EBM, Duffau TG, Herrera LP. Hospital Roberto del Río. Santiago.

Introducción: La casi totalidad de pacientes que consultan en el SU del HRR, cuentan con información sobre su Triage (Tr)-Frecuencia cardíaca (FC), temperatura $\left(\mathrm{T}^{\circ}\right)$ y saturación $(\mathrm{S})$. Decidimos indagar acerca de la asociación posible entre los mencionados elementos de juicio y el destino -alta u hospitalizacióndel paciente. Como es común que la presencia de taquicardia (t) en algunos niños atendidos en el SU, sea inicialmente interpretada como compromiso hemodinámico y evidencia precoz e inminente de shock, postulamos la hipótesis que es posible asociaciones de otros factores con el aumento de la FC: $T^{\circ}$ y $S$, según grupo etario. Material y Método: Se reunieron los consultantes en los meses de junio y julio del 2007, seleccionando al azar 10 días de cada mes, configurando así un grupo de 1.863 pacientes. Se revisaron los antecedentes clínicos de todos, su relación con el destino final, hospitalización o alta. Para ello se empleó las razones de riesgo $(\mathrm{OR})$ y análisis estratificado por grupos de edad, incluyendo < 2 m; 3-12 m; 13-36 m; 37-60 m; 61-120 m; 121-187 m. Estos mismos grupos fueron estudiados desde el punto de vista de la FC. Se usó Chi cuadrado como prueba de significación estadística y se aceptó como significativo un valor $p<0,05$; los OR con sus IC $95 \%$ fueron usados como medida de asociación. Resultados: La probabilidad de ser hospitalizado fue mayor si el consultante es < de $6 \mathrm{~m}(\mathrm{OR}=5,42 ; \mathrm{IC} 95 \%=3,9-7,6)$. Así como si el Triage < 2 (OR: 6,94 IC95\%: 4,7-10,2). Los niños con sat. < a 93\%, tienen una probabilidad elevada de hospitalización (OR=23,68; IC95\%=14,6-38,3). No se encontró asociación entre fiebre y hospitalización (OR=1,31; IC95\%=0,9-1,8; NS) La sat. $<93 \%$, se asocia con la presencia de taquicardia en todas las edades (OR ponderado= 3,$62 ;$ IC95\% $=2,09-5,79 ; p<0,000$ ). Igual situación ocurre cuando hay fiebre, (OR ponderado $=6,74 ;$ IC95\%= 5,07-8,67; $p<0,000$ ). El $51,8 \%$ de los niños febriles estaban taquicardico y el $22,8 \%$ de los afebriles. Comentarios: Queda claro en este estudio, que el riesgo de hospitalización en un niño es evidentemente mayor si tiene $<6 \mathrm{~m}$, sat. $<93 \%$ y Triage $<2$. En más de 600 niños taquicardico (33\% de la muestra) ninguno evolucionó al shock, incluso los que además tuvieron Triage $<2$ y saturación $<93$. La taquicardia por tanto, como signo relativamente aislado, no es un elemento sólido para plantear alteración hemodinámica de magnitud y menos aún, tratarlo como si fuere. 


\section{USO DE KETAMINA EN UN SERVICIO DE URGENCIA PEDIÁTRICA}

Concha I, Hirsch T, Figueroa MJ, Luengo V.

Servicio de Urgencia. Hospital Clínico, Departamento de Pediatría Pontificia Universidad Católica de Chile.

Introducción: Con frecuencia en los servicios de urgencia se requiere realizar procedimientos. Para minimizar el dolor y lograr un estado adecuado de cooperación se utilizan medicamentos que provocan distintos grados de sedación y analgesia. Ketamina produce un estado único de disociación en que el niño mantiene el control cardiorrespiratorio, está inmóvil, sedado y sin dolor. Objetivos: Analizar el uso de Ketamina como método de sedoanalgesia en el servicio de urgencia pediátrica evaluando sus efectos inmediatos y a las 24 horas de evolución. Material y Método: En forma prospectiva se enrolaron los pacientes que requerían sedoanalgesia por algún procedimiento doloroso previo consentimiento informado entre agosto del 2007 y septiembre del 2008. Se registraron a través de un protocolo los datos biodemográficos, signos vitales, grado de sedación, eventos adversos, tiempo de efecto y calidad estimada de sedación. Se hizo seguimiento telefónico. En el análisis estadístico se realizaron tablas de frecuencia para las variables categóricas y se buscaron los estadísticos descriptivos para las variables continuas. Resultados: Se enrolaron 96 pacientes cuyo promedio $(x)$ de edad fue 3,8 años (DS $\pm 2,5$ ), $53 \%$ de sexo masculino ASA I y II. Los procedimientos que requirieron sedación fueron suturas $74 \%$, reducción traumatológica $11,5 \%$, extracción de uña $2,1 \%$, y otros. El $87,5 \%$ de los operadores calificaron de excelente o buena la sedación recibida versus el $81,2 \%$ de los padres. $86,5 \%$ volvería a aceptar este tipo de sedación. El x de ayuno previo fue de 3,65 hrs (DS $\pm 1,96$ ). Los efectos colaterales fueron $11,5 \%$ vómitos; $2,1 \%$ apneas, y en el $1 \%$ se observó hipotensión que no requirió tratamiento, ningún paciente necesitó de hospitalización. Conclusiones: Ketamina es una excelente opción de sedoanalgesia para realizar procedimientos dolorosos en niños. Es un agente seguro que produce pocos efectos adversos, los cuales son transitorios y no requieren de hospitalización.
UTILIDAD DE LA PROTEÍNA C REACTIVA EN EL DIAGNÓSTICO DE APENDICITIS AGUDA EN PEDIATRIA

López $D F^{1,2}$, Jaramillo $M Y^{1}$, Gutiérrez $M^{1}$, Valdivieso $M J P^{1}$, Inostroza $L G^{1}$, Gutiérrez $C^{1}$.

${ }^{1}$ Servicio de Emergencia y Pediatría Hospital Clínico Universidad de Chile. 2Servicio de Pediatría. Hospital Clínico San Borja Arriarán.

Introducción: La apendicitis aguda representa la principal causa de ingresos quirúrgicos agudos en los servicios de emergencia pediátricos. Su diagnóstico es fundamentalmente clínico y se beneficia con estudio complementario en casos de duda diagnóstica. La proteína $C$ reactiva $(\mathrm{PCR}$ ) sintetetizada en el hígado en respuesta a estados inflamatorios, sépticos o de daño tisular. El objetivo es efectuar un análisis del la utilidad de la PCR en el diagnóstico de apendicitis aguda, ante el caso que la historia y el examen físico no sea del todo claro. Material y Métodos: Desde Enero de 2003 hasta Julio del 2008, 879 pacientes fueron ingresados y intervenidos en nuestro hospital con el diagnóstico de apendicitis aguda, solicitándose a $616(70,1 \%)$ una PCR pre operatoria. El valor considerado normal en el laboratorio es < a $5 \mathrm{mg} / \mathrm{dl}$. Resultados: El valor promedio de la PCR en pacientes que consultaron entre 0 a 12 horas de evolución fue de $8,56 \mathrm{mg} / \mathrm{dl}$, el cual aumentó a $42,4 \mathrm{mg} / \mathrm{dl}$ en aquellos que lo hicieron entre 12 a 24 horas. La situación cambió en aquellos pacientes que acudieron a servicio de emergencia con una historia de entre 24 a 48 horas de evolución con un promedio de 106,6 mg/dl. Se correlacionó pacientes con un recuento de leucocitos mayor a 20.000 y con consultas después de 48 horas de evolución con valores de PCR en promedio de 176,4 mg/dl. Conclusiones: 1) La PCR no ofrece ninguna ayuda en pacientes con consulta precoz por apendicitis aguda; 2) La PCR constituye un examen de utilidad diagnóstica en apendicitis aguda, especialmente en pacientes que consultan con una historia de más de 24 horas de evolución; 3) En estados tardíos se asocia a cuadros de apendicitis complicada y con más riesgo vital.

\section{DESCUBRIENDO MITOS Y CREENCIAS SOBRE EL INTENTO SUICIDA DE ADOLESCENTES EN LOS TÉCNICOS PARAMÉDICOS QUE TRABAJAN EN EL SERVICIO DE URGENCIA INFANTIL/SERVCIO DE PEDIATRİA DEL HOSPITAL SAN BORJA ARRIARÁN}

Cuñado PP, Suárez MA.

Servicio de Urgencia Infantil del Hospital San Borja Arriarán, Santiago, Chile.

Introducción: En HSBA, dada la ubicación del servicio de pediatría ( $8^{\circ}$ piso), nos vimos en la necesidad de hospitalizar a los pacientes con intento de suicidio en el servicio de urgencia, teniendo como promedio de estadía 2-3 días, lo cual lleva a una mayor interacción con ellos, relación que es más permanente con los técnicos paramédicos, ya que ellos los acompañan y brindan apoyo; función imprescindible para la evolución del paciente. Objetivos: Determinar el grado de conocimiento de los técnicos paramédicos (TP) del servicio de urgencia (SUI) con respecto al servicio de pediatría (PED) del HSBA, en relación al tema de intento de suicidio (IS) en adolescentes y a sus creencias en mitos arraigados en la población. Conocer su actitud frente a estos pacientes y su disposición a acompañarlos durante la hospitalización. Material y Método: Se aplicó una encuesta anónima al $90 \%(n=25)$ de TP de SUI y a 27 TP del servicio de PED como control. Los resultados fueron expresados en porcentaje y comparados estadísticamente con test exacto de Fisher. Resultados: En relación a las siguientes creencias, no hay diferencias significativa entre ambos grupos; cuando un paciente habla de suicidio no lo va a llevar a cabo: $56 \%$ SUI y $51,85 \%$ PED dice que es verdadero; cuando un paciente esta deprimido preguntarle sobre sus ideas de suicidio lo induce a intentarlo: $56 \%$ SUI Y 51,8\% PED cree que es verdadero; el suicidio se produce con aviso: $68 \%$ de SUI Y $63 \%$ de PED, dice que es falso. Encontramos diferencias en; los pacientes que realizan IS con medios de baja letalidad no están pensando seriamente en la idea de matarse: $76 \%$ SUl y $48,5 \%$ PED cree que es verdadero. En relación al sentimiento frente a un paciente con IS; tristeza: $44 \%$ de SUI y $48,2 \%$ de PED, angustia: $20 \%$ SUI y $18,5 \%$ PED, rabia: $36 \%$ SUI y $11 \%$ PED con diferencia estadística. Preguntar y escucha a los pacientes $56 \%$ SUl y $77,8 \%$ PED, y el $44 \%$ en ambos grupos les gusta sólo escuchar. En cuanto a acompañar al paciente: lo evitan el $48 \%$ SUl y $44,4 \%$ PED, le agrada $32 \%$ de SUI y 40,7\% PED. Conclusiones: Vemos que no existe diferencia significativa entre un grupo y otro, aun cuando los TP del SU permanecen y acompañan al $75 \%$ de los pacientes hospitalizados por IS. Supimos que los TP hombres (8) del SUl evitan acompañar a las adolescentes en sala de hospitalización por aprensiones legales. Creemos que seria muy beneficioso charlas y capacitación en cuanto al tema de IS junto al psiquiatra y asistente social.

\section{ANÁLISIS EPIDEMIOLÓGICO DE APENDICITIS AGUDA EN PACIENTES PEDIÁTRI-COS EN UN HOSPITAL CLÍNICO UNIVERSITARIO}

López $D^{1,2}$, Jaramillo $M Y^{1}$, Gutiérrez $M^{1}$, Valdivieso $M J P^{1}$, Gutiérrez $C L^{1}$. ${ }^{1}$ Servicio de Emergencia y Pediatría Hospital Clínico Universidad de Chile. ${ }^{2}$ Servicio de Pediatría. Hospital Clínico San Borja Arriarán.

Introducción: La apendicitis aguda en una enfermedad frecuente con 40.000 egresos hospitalarios en Chile por año, de los cuales un $25 \%$ corresponde a pacientes entre 0 a 15 años. Su diagnóstico es fundamentalmente clínico y se beneficia con estudio complementario en casos de duda diagnóstica. El objetivo es efectuar un análisis retrospectivo de los casos de apendicitis aguda ingresados al Servicio de Emergencia Pediátrico de un hospital clínico universitario. Material y Métodos: Desde Enero de 2003 hasta Julio del 2008, 879 pacientes fueron ingresados y intervenidos en nuestro hospital con el diagnóstico de apendicitis aguda. Hubo 519 hombres (59\%) y 360 mujeres (41\%). El promedio de edad fue 10,2 años con un rango entre 0 a 15. Los datos se ordenan en una base de datos computacional. Resultados: El estudio histopatológico demostró apendicitis aguda en el en 847 pacientes (96,4\%). En 629 pacientes $(71,6 \%)$ se presentó apendicitis no complicada. En 250 hubo complicaciones, fundamentalmente peritonitis, e infección de herida operatoria. En 712 pacientes (81\%) hubo leucocitosis entre 10000 y 15000 y en 167 mayor a 20.000, en relación directa a una apendicitis complicada. El grupo de pacientes no complicados y complicados tuvieron una hospitalización promedio de 1,9 y 4,5 días respectivamente. El tiempo operatorio global fue de 35 minutos. No hubo mortalidad en esta serie. Conclusiones: 1) Apendicitis aguda constituye la principal causa de ingresos quirúrgicos agudos en el Servicio de Emergencia Pediátrico; 2) El retardo en el diagnóstico se asocia a mayores complicaciones; 3) Una historia clínica completa más un soporte de laboratorio e imágenes de alta complejidad, reducen al mínimo el error diagnóstico. 
PARO CARDIORRESPIRATORIO EN EL SERVICIO DE URGENCIA. HOSPITAL PADRE HURTADO. ANÁLISIS CLÍNICO-EPIDEMIOLÓGICO. PERÍODO 2000-2008

Pinochet C, Donoso A, León J, Urioste S.

Unidad de Emergencia Pediátrica Hospital Padre Hurtado.

Introducción: Si bien la mortalidad pediátrica ha disminuido en los últimos decenios, pacientes que ingresan en paro cardiorrespiratorio (PCR) al servicio de urgencia (SU) es una realidad aún presente. El SU Pediátrico del Hospital Padre Hurtado $(\mathrm{HPH})$ atiende 125.000 menores al año y no se cuenta con evaluación sobre esta situación clínica a la fecha. Objetivo: descripción epidemiológica y clínica de los pacientes menores de 15 años que consultaron en PCR en el SU de Pediatría del HPH entre los años 1999 y 2008. Materiales y Métodos: Revisión de registros clínicos de pacientes con diagnóstico de PCR que consultaron al SU del HPH en el período y en quienes se realizó reanimación cardiopulmonar (RCP) avanzada. Resultados: Se incluyeron un total de 62 pacientes $<15$ años, de los cuales $47 / 62(75 \%)$ fallecieron en el SU y $15 / 62$ $(25 \%)$ ingresaron a UCl. De aquellos que ingresan a UCl, el $7 / 15(47 \%)$ fallece y $8 / 15$ (53\%) logró ser dado vivo de alta, dando una sobrevida global de $8 / 62$ (13\%). De aquellos pacientes dados de alta, la mitad tuvo daño neurológico severo. El promedio de edad de la totalidad de pacientes es de 42 meses ( $9 \mathrm{~d}-15$ a), encontrándose la mayoría en el grupo de lactantes. Sexo masculino $=62 \%$. E $87 \%$ de los PCR ocurrió en el domicilio y el $30 \%$ tenía patología de base. Dentro de los grupos de causas que originaron el paro se distribuyeron de la siguiente manera: indeterminado $58 \%$, trauma $13 \%$, asfixia por ahorcamiento $10 \%$, asfixia por inmersión $6,5 \%$, otras causas $6,5 \%$, electrocución $4,5 \%$ y obstrucción de la vía aérea por cuerpo extraño 1,5\%. De todos los PCR sólo el 17\% fue presenciado y en el $14 \%$ se realizaron maniobras de RCP básica. En cuanto al tratamiento en el SU, el tiempo promedio de duración de la RCP fue de $23 \mathrm{~min}$ (5-80 minutos), el $40 \%$ requirió entre 2 y 4 dosis de adrenalina (1-10 dosis) y en el $25 \%$ se utilizó bicarbonato, un $30 \%$ recibió osteoclisis. Un $15 \%$ tenían livideces al inicio de la reanimación en el SU y recibieron RCP. Si bien hubo una tendencia entre la normalización progresiva del pH sanguíneo y el mejor pronóstico en los pacientes que ingresaron a la UCIP, no hubo una adecuada correlación (R2 = 0,48 ). Tampoco existe correlación entre el pronóstico y la causa del PCR o la edad del paciente. Conclusiones: Se confirma el mal pronóstico del PCR en pediatría: sólo un $14 \%$ sobrevive y de éstos la mitad con daño neurológico severo. Destaca cuán prolongada puede llegar a ser la RCP e incluso a realizarse en pacientes con livideces.

\section{CARACTERIZACIÓN EPIDEMIOLÓGICA, PSIQUIÁTRICA Y SOCIAL EN NIÑOS Y ADOLESCENTES HOSPITALIZADOS POR INTENTO DE SUICIDIO EN UN SERVICIO DE URGENCIA INFANTIL}

Suárez $\mathbf{M A}^{1}$, Cuñado $P P^{1}$, Valenzuela $S A^{2}$.

${ }^{1}$ Pediatras Servicio Urgencia Infantil, Hospital Clínico San Borja Arriarán. ${ }^{2}$ Alumno $3^{\circ}$ medicina Pontificia Universidad Católica de Chile.

Introducción: El servicio de urgencia infantil (SUI) del Hospital Clínico San Borja Arriaran (HCSBA) se ha visto en la necesidad de utilizar sus camas con la hospitalización de pacientes por intento de suicidio (IS), ya que por norma establecimos que todo paciente con dicho diagnóstico se hospitaliza y el servicio pediátrico se encuentra ubicado en el octavo piso con el riesgo que ello implica. Como recibimos constantemente estos pacientes quisimos conocer los factores y motivaciones que estarían llevando a niños y adolescentes a tomar esta decisión. Objetivos: Conocer la prevalencia del IS en la población consultante de SUI HCSBA entre el 1/1/06 al 31/5/08 y conocer características como: medio utilizado, factores de riesgo y desencadenantes. Material y Métodos: Estudio retrospectivo de fichas clínicas de hospitalización con diagnóstico de IS desde e 1/1/06-31/5/07. Se confeccionó base de datos en planilla Excel, se usó programa estadístico SPSS versión 15. Resultados: Encontramos 76 hospitalizados por IS, que corresponde al $0.052 \%$ del total de consultas y al $0,49 \%$ de las hospitalizaciones pediátricas. Rescatamos 67 fichas $(88,2 \%)$. Edad promedio: 13,6 años (10-15), mujeres $94 \%$, predominio primavera $44,8 \%$, ingesta medicamentos principal medio $95,5 \%$ ( $28,1 \%$ benzodiacepinas, $22 \%$ combinación de fármacos, $14,1 \%$ antidepresivos triciclicos), ahorcamiento $3 \%$. Promedio días cama: 3 (1-9), ingreso $\mathrm{UCl} 17,9 \%$. Principal factor desencadenante fue la discusión con padre $\mathrm{y} / \mathrm{0}$ madre $53,7 \%$. La intencionalidad: llamar la atención $52,2 \%$, deseo de morir $22,4 \%$, huir de los problemas $13,4 \%$. En el $22,4 \%$ hay antecedente de IS previo, $23,9 \%$ antecedente de maltrato, $43,8 \%$ depresión materna, $79,7 \%$ disfunción familiar Tuvo evaluación psiquiátrica: $92,5 \%$ y reveló depresión: $51 \%$, trastorno de personalidad: $44,7 \%$, trastorno del animo: $51,1 \%$. Conclusiones: La hospitalización de todo IS es aconsejable ya que permite dimensionar en su totalidad dicho acto, tanto para el médico como para el paciente, evaluar la motivación e identificar aquellos factores que es posible de modificar para que el IS no se vuelva a repetir; además como pediatras nos permite sensibilizarnos e informarnos sobre el tema de modo de prevenir dicha conducta en otros niños y adolescentes. Fundamental es la presencia de la psiquiatra y asistente social al inicio para un trabajo en conjunto familia-paciente, ya que vemos en el 79,7\% disfunción familiar y en el $75,8 \%$ patología psiquiátrica asociada.
ENCEFALOMIELITIS DISEMINADA AGUDA (ADEM): SOSPECHA EN SERVICIO DE URGENCIA INFANTIL (SUI)

Van Capel M, Paredes $M$.

Clínica Santa María (CSM), Universidad de Los Andes.

Introducción: ADEM es una enfermedad desmielinizante del SNC, afecta niños y jóvenes sanos. Prevalencia 0,4-3/100.000/año en $<20$ años. $80 \%$ debuta con síntomas neurológicos: letargia, ataxia, disartria, neuropatía craneana, compromiso de conciencia, cefalea. Objetivo: Caracterización clínica y radiológica de niños con ADEM atendidos en SUI CSM año 2008, destacar tips para sospecha. Pacientes y Métodos: Se diagnostica ADEM en 3 pacientes en un período de 8 meses. Estudio retrospectivo de sus fichas. Resultados: 2, 6, 8 años, sin vacunación cercana. Infección último mes $2 / 3$. Se sospechó el diagnóstico antes de realizar RNM sólo en 1, en 2 fue por evolución tórpida. 3/3 RNM permitió diagnóstico: lesiones multifocales sustancia blanca córtico subcorticales; 1/3 microhemorragias (único TAC alterado). LCR alterado 1/3. Todos recibieron gamaglobulina + metilprednisolona. Un caso herpes 6 recibió antiviral. Al alta todos asintomáticos y examen normal. 2/3 recayeron. Síntomas y Examen físico SUI Infección asociada Paciente 1: 1 semana dificultad en fijación mirada, ptosis, inclinación de cabeza para optimizar visión. Estrabismo y paresia III par izquierdo: durante hospitalización por evolución tórpida se solicita RNM. Herpes 6 LCR y sangre Paciente 2: 5 días corisa, $t^{\circ} 38,5$ y cefalea intermitente. Examen físico normal, LCR: células $759,95 \%$ MN: meningoencefalitis viral. Durante hospitalización, por cefalea persistente e intensa se solicita RNM. Herpes 6 LCR. Paciente 3: 1 semana corisa y tos. 24 horas de cefalea hemicara derecha intensa pese a ibuprofeno y 3 vómitos. Leve paresia braquiocrural izquierda. En SUI por TAC alterado se realiza RNM. IgM mycoplasma. Discusión. Conocer la enfermedad permite diagnóstico precoz. Ante cefalea que no tiene relación en magnitud o duración con cuadros frecuentes, u otras alteraciones neurológicas sin etiología evidente, es fundamental sospecha y realización RNM, TAC no siempre estará alterado. Síntomas revierten, es importante seguimiento por recaídas.

\section{USO DE CORTICOIDES EN LARINGITIS OBSTRUCTIVA EN NUESTRO} MEDIO

Corfio PMJ, Budnik OI, Damm AC, Ojeda WS, Fernández VM. Universidad de Los Andes.

La laringitis obstructiva o croup es la inflamación aguda de la laringe y la gravedad está dada por el grado de obstrucción de la vía aérea. La etiología más común es viral. El manejo debe ser de acuerdo a la gravedad: sólo observar, nebulizar con adrenalina racémica o corriente, corticoides vía oral o parenteral, hospitalizar y dar oxígenoterapia. Existe abundante evidencia, y consenso mundial, que establece dar dexametasona vía oral en dosis única de 0,15 a 0,6 mg/kg para el tratamiento del croup moderado y severo. Esto reduce significativamente las reconsultas y hospitalizaciones por esta patología. En Chile, no existe dexametasona oral, por lo que la norma ministerial propone utilizar corticoides por vía parenteral ya sea dexametasona o su equivalente en betametasona u otros corticoides. Cabe destacar, que la betametasona oral, que si está disponible en Chile, tiene propiedades farmacocinéticas y farmacodinámicas similares a la dexametasona, pero no hay estudios que comparen la eficacia de ambos fármacos por vía oral, no sabiéndose cual es la dosis efectiva por esta vía. El objetivo de nuestro estudio fue describir cuál es el manejo del croup en nuestro medio y saber cuándo y cuáles corticoides se utilizan y su dosis. Se encuestó a un total de 72 pediatras, de los cuales, ante un croup leve el 95,8\% deja en observación en casa y el $31.9 \%$ aplica algún tipo de corticoides, en su mayoría betametasona vía oral con una amplia dispersión de dosis y frecuencia de uso. En el croup moderado, un $52,8 \%$ hospitaliza al niño en sala y el $97,2 \%$ aplica corticoides, siendo la dexametasona intravenosa el corticoide de elección en un $74,3 \%$. En el croup severo, el $100 \%$ hospitaliza al niño en UCl y el $95,8 \%$ le da corticoides, siendo nuevamente la dexametasona intravenosa la principal elección en un $76,8 \%$ de las veces. En nuestro trabajo encontramos que no hubo aplicación de las normas propuestas en la literatura para la utilización de corticoides en el croup, debido seguramente a que la dexametasona oral no se encuentra disponible en Chile y no es conocida la dosis equivalente de betametasona. Además, no hay consenso en cuándo aplicar corticoides y con qué vía de administración. Es por esto, que es necesario hacer un estudio donde se compare el manejo que se propone en la literatura con otro corticoide presente en Chile, como la betametasona oral, por las razones ya mencionadas y así establecer una norma estándar de manejo corticoidal del croup en nuestro país. 